July 1999 • NREL/TP-500-25540

\title{
Variable-Speed Wind Turbine Controller Systematic Design Methodology: A Comparison of Non-Linear and Linear Model- Based Designs
}

M.M. Hand
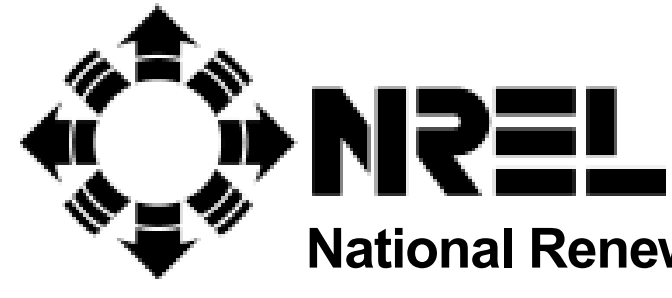

National Renewable Energy Laboratory

1617 Cole Boulevard

Golden, Colorado 80401-3393

NREL is a U.S. Department of Energy Laboratory

Operated by Midwest Research Institute • Battelle • Bechtel

Contract No. DE-AC36-98-G010337 
July $1999 \quad$ NREL/TP-500-25540

\title{
Variable-Speed Wind Turbine Controller Systematic Design Methodology: A Comparison of Non-Linear and Linear Model- Based Designs
}

\author{
M.M. Hand
}

Prepared under Task No. WE901110

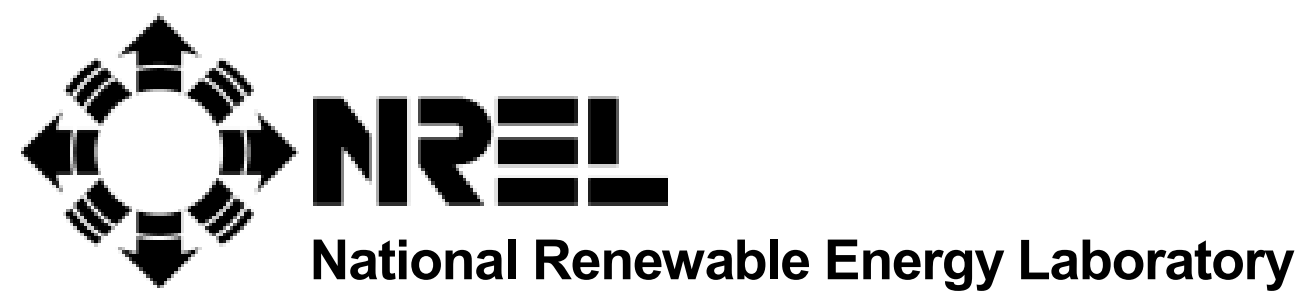

1617 Cole Boulevard

Golden, Colorado 80401-3393

NREL is a U.S. Department of Energy Laboratory

Operated by Midwest Research Institute $\bullet$ Battelle $\bullet$ Bechtel

Contract No. DE-AC36-98-G010337 


\section{NOTICE}

This report was prepared as an account of work sponsored by an agency of the United States government. Neither the United States government nor any agency thereof, nor any of their employees, makes any warranty, express or implied, or assumes any legal liability or responsibility for the accuracy, completeness, or usefulness of any information, apparatus, product, or process disclosed, or represents that its use would not infringe privately owned rights. Reference herein to any specific commercial product, process, or service by trade name, trademark, manufacturer, or otherwise does not necessarily constitute or imply its endorsement, recommendation, or favoring by the United States government or any agency thereof. The views and opinions of authors expressed herein do not necessarily state or reflect those of the United States government or any agency thereof.

Available to DOE and DOE contractors from:

Office of Scientific and Technical Information (OSTI)

P.O. Box 62

Oak Ridge, TN 37831

Prices available by calling 423-576-8401

Available to the public from:

National Technical Information Service (NTIS)

U.S. Department of Commerce

5285 Port Royal Road

Springfield, VA 22161

$703-605-6000$ or $800-553-6847$

or

DOE Information Bridge

http://www.doe.gov/bridge/home.html

Printed on paper containing at least $50 \%$ wastepaper, including $20 \%$ postconsumer waste 


\section{VARIABLE-SPEED WIND TURBINE CONTROLLER SYSTEMATIC DESIGN METHODOLOGY: A COMPARISON OF NON- LINEAR AND LINEAR MODEL-BASED DESIGNS \\ By}

\section{MAUREEN HAND}

B.S., University of Wyoming, 1994

A thesis submitted to the Faculty of the Graduate School of the University of Colorado in partial fulfillment of the requirement for the degree of Master of Science

Department of Mechanical Engineering 1998 
Hand, M. Maureen (M.S., Engineering)

Variable-speed Wind Turbine Controller Systematic Design Methodology: A Comparison of Non-linear and Linear Model-based Designs

Thesis directed by Professor Mark Balas

\begin{abstract}
Variable-speed, horizontal axis wind turbines use blade-pitch control to meet specified objectives for three regions of operation. This paper focuses on controller design for the constant power production regime. A simple, rigid, nonlinear turbine model was used to systematically perform trade-off studies between two performance metrics. Minimization of both the deviation of the rotor speed from the desired speed and the motion of the actuator is desired. The robust nature of the proportional-integral-derivative (PID) controller is illustrated, and optimal operating conditions are determined. Because numerous simulation runs may be completed in a short time, the relationship of the two opposing metrics is easily visualized.

Traditional controller design generally consists of linearizing a model about an operating point. This step was taken for two different operating points, and the systematic design approach was used. A comparison of the optimal regions selected using the non-linear model and the two linear models shows similarities. The linearization point selection does, however, affect the turbine performance slightly.

Exploitation of the simplicity of the model allows surfaces consisting of operation under a wide range of gain values to be created. This methodology provides a means of visually observing turbine performance based upon the two
\end{abstract}


metrics chosen for this study. Design of a PID controller is simplified, and it is possible to ascertain the best possible combination of controller parameters. The wide, flat surfaces indicate that a PID controller is very robust in this variablespeed wind turbine application. 


\section{ACKNOWLEDGMENTS}

The National Renewable Energy Laboratory has supported me throughout this endeavor with facilities, expertise, and encouragement. I am especially grateful to Michael Robinson for providing me with this research opportunity. 


\section{CONTENTS}

CHAPTER

I. INTRODUCTION .................................................................... 1

II. BACKGROUND …................................................................. 3

III. DYNAMIC MODELING ........................................................ 8

IV. TRADITIONAL CONTROLLER DESIGN METHODOLOGY ....... 14

V. SYSTEMATIC CONTROLLER DESIGN METHODOLOGY ......... 18

VI. NON-LINEAR MODEL VS. LINEAR MODEL ............................29

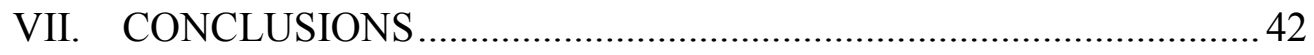

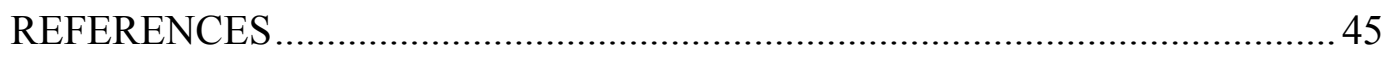

APPENDIX A....................................................47

APPENDIX B.................................................... 53

APPENDIX C...................................................... 80

APPENDIX D................................................... 93 


\section{LIST OF TABLES}

\section{TABLE}

1. Statistics describing wind input files .......................................... 18

2. Comparison of performance metrics for non-linear and linear

model-based controller designs ....................................................... 34 


\section{LIST OF FIGURES}

\section{FIGURE}

1. General schematic of a control system .............................................. 3

2. Torque coefficient surface as a function of tip-speed ratio

and blade-pitch angle. ............................................................ 9

3. Simulation block diagram ...................................................... 11

4. Controller block diagram ....................................................... 12

5. Actuator block diagram ......................................................... 13

6. Power coefficient surface as a function of tip-speed ratio and blade-pitch angle ............................................................... 15

7. Example of $\mathrm{c}_{\mathrm{q}}$ vs. $\lambda$ for 2 blade-pitch angles ..................................... 16

8. Performance metric surfaces generated using the non-linear

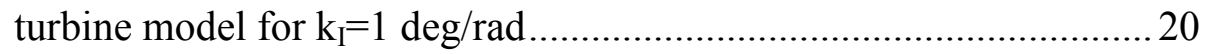

9. Performance metric surfaces generated using the non-linear turbine model for $\mathrm{k}_{\mathrm{l}}=5 \mathrm{deg} / \mathrm{rad}$.

10. Performance metric surfaces generated using the non-linear turbine model for $\mathrm{k}_{\mathrm{I}}=10 \mathrm{deg} / \mathrm{rad}$.

11. Time-series traces of turbine performance ..................................... 24

12. Rotor speed response to step wind input ..................................... 27

13. Pitch rate response to step in wind input .....................................22

14. RMS of pitch rate potential performance metric for $\mathrm{k}_{\mathrm{I}}=5 \mathrm{deg} / \mathrm{rad} \ldots .28$

15. Performance metric surfaces generated using the linear $\operatorname{model}\left(\omega_{\mathrm{T} \text { OP }}=11 \mathrm{rad} / \mathrm{s} ; \mathrm{w}_{\mathrm{OP}}=7.5 \mathrm{~m} / \mathrm{s} ;\right.$ and $\left.\beta_{\mathrm{OP}}=9^{\circ}\right)$ 
for $\mathrm{k}_{\mathrm{I}}=1 \mathrm{deg} / \mathrm{rad}$

16. Performance metric surfaces generated using the linear

$\operatorname{model}\left(\omega_{\mathrm{T} \mathrm{OP}}=11 \mathrm{rad} / \mathrm{s} ; \mathrm{w}_{\mathrm{OP}}=7.5 \mathrm{~m} / \mathrm{s} ;\right.$ and $\left.\beta_{\mathrm{OP}}=9^{\circ}\right)$

for $\mathrm{k}_{\mathrm{I}}=5 \mathrm{deg} / \mathrm{rad}$

17. Performance metric surfaces generated using the linear

$\operatorname{model}\left(\omega_{\mathrm{T} \text { OP }}=11 \mathrm{rad} / \mathrm{s} ; \mathrm{w}_{\mathrm{OP}}=7.5 \mathrm{~m} / \mathrm{s} ;\right.$ and $\left.\beta_{\mathrm{OP}}=9^{\circ}\right)$

for $\mathrm{k}_{\mathrm{I}}=10 \mathrm{deg} / \mathrm{rad}$

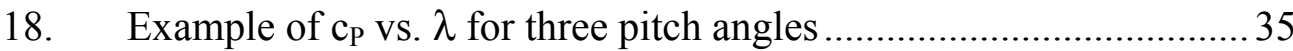

19. Performance metric surfaces generated using the linear

$\operatorname{model}\left(\omega_{\mathrm{T} \text { OP }}=11 \mathrm{rad} / \mathrm{s} ; \mathrm{w}_{\mathrm{OP}}=10 \mathrm{~m} / \mathrm{s} ;\right.$ and $\left.\beta_{\mathrm{OP}}=12^{\circ}\right)$

for $\mathrm{k}_{\mathrm{I}}=1 \mathrm{deg} / \mathrm{rad}$

20. Performance metric surfaces generated using the linear

$\operatorname{model}\left(\omega_{\mathrm{T} \text { OP }}=11 \mathrm{rad} / \mathrm{s} ; \mathrm{w}_{\mathrm{OP}}=10 \mathrm{~m} / \mathrm{s} ;\right.$ and $\left.\beta_{\mathrm{OP}}=12^{\circ}\right)$

for $\mathrm{k}_{\mathrm{I}}=5 \mathrm{deg} / \mathrm{rad}$

21. Performance metric surfaces generated using the linear

$\operatorname{model}\left(\omega_{\mathrm{T} \text { OP }}=11 \mathrm{rad} / \mathrm{s} ; \mathrm{w}_{\mathrm{OP}}=10 \mathrm{~m} / \mathrm{s} ;\right.$ and $\left.\beta_{\mathrm{OP}}=12^{\circ}\right)$

for $\mathrm{k}_{\mathrm{I}}=10 \mathrm{deg} / \mathrm{rad}$

22. Regions of optimal operation

23. Time series traces of turbine performance under the optimal gains as determined using each of the three models 


\section{CHAPTER I}

\section{INTRODUCTION}

Recently, utility-scale wind turbine manufacturers have begun to explore the possibility of operating turbines at variable rotational speeds. Because variable-speed wind turbines have the potential for increased energy capture, controller design has become an area of increasing interest. Blade-pitch regulation provides means for initiating rotation, varying rotational speed to extract power at low wind speeds, and maintaining power production at a maximum level. Controllers must be designed to meet each of these objectives, but this study pertains only to constant power production.

The power regulation regime is entered when the turbine reaches the design rotor speed for maximum power production. Under these conditions, rotational speed is constrained to a specified maximum value through blade-pitch regulation. Fluctuations in wind speed are accommodated to prevent large excursions from the desired rotational speed. Thus the power production is also constrained to a relatively constant level. In addition to maintaining a constant rotational speed, actuator movement must be restrained to prevent fatigue and overheating. The combination of maintaining a constant rotational speed and minimizing actuator motion are the control objectives specified for the power regulation regime.

Controller design has centered mainly on simple, linear, proportionalintegral-derivative (PID) controllers which are easily implemented in the field environment. Gain selection for these controllers has generally been a trial-and- 
error process relying on experience and intuition from the engineers. A systematic approach to gain selection provides visualization of the potential performance capabilities due to control.

This work presents a methodology for selecting gain values for a PID controller that regulates rotor speed of a variable-speed wind turbine by adjusting the blade-pitch angle. The dynamic model used to describe the turbine and its operating environment is discussed. A traditional approach to PID controller gain selection is presented for comparison to the systematic methodology. The traditional approach consists of linearizing a model about an operating point. Response to step input is examined, and the gains are altered until appropriate damping behavior is observed. This approach relies heavily on trial-and-error. Because control design generally begins with a linear model, a comparison of the systematic gain selection methodology using non-linear and linear simulations provides insight on the differences. The performance predictions using the systematic design methodology based on non-linear and linear models are shown. 


\section{CHAPTER II}

\section{BACKGROUND}

Control systems are generally reduced to two components, the plant and the controller. The plant is the object or process being controlled, and the controller uses output from the plant to adjust its input in order to achieve the desired action. Figure 1 illustrates the relationship between these components. As an example, wind turbine control algorithms have focused on maintaining constant power through rotor speed regulation. In the case of maintaining constant rotor speed, the input is generally the blade-pitch angle, $\left(\underline{\mathrm{U}}_{\mathrm{ref}}, \underline{\mathrm{U}}\right)$ in conjunction with a stochastic disturbance due to the wind $\left(\underline{\mathrm{U}}_{\mathrm{D}}\right)$, and the output $(\mathrm{y})$ is rotor speed.

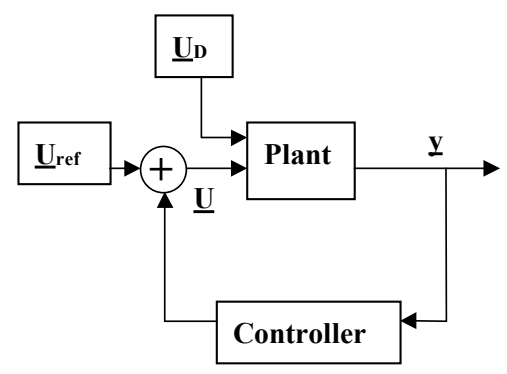

\section{Figure 1: General schematic of a control system.}

A literature review conducted by de la Salle et al., 1990, summarized the status of wind turbine control at that time. They found that PI control acting on a measurement of electrical power was the industry standard for constant-speed machines, but publications dealing with variable-speed turbines were scant at that 
time. Due to a lack of concise statement of objectives in the majority of publications, assessment of controller performance was difficult. Lastly, they concluded that many publications demonstrated performance improvement as a result of control.

In a subsequent publication, Leithead et al., 1990, p. 511, suggest the following control objectives:

- "Alleviate the transient loads throughout the wind turbine.

- Regulate and smooth the power generated.

- Cause the drive-train to have the appropriate dynamic behaviour.

- Maximize the energy capture."

Although these objectives were proposed for control of a three-bladed, constant speed wind turbine, a relevant point is made regarding the specifications required to achieve these objectives: "The different parts of the specification are not complementary but are competing and an appropriate balance must be attained (Leithead et al., 1990, p. 511)." Other than the drive-train behavior, these objectives are appropriate for the different regimes of variable-speed turbine operation. For instance, maximizing energy capture relates to the variable speed operation regime. Power regulation is performed in above-rated wind speed conditions which is the focus of this paper. Competing specifications of maintaining constant rotational speed while minimizing actuator motion, the control objectives of this study, dominate this design as well.

The majority of works dealing with constant speed turbines required simulation of the drive-train dynamics. Generally, the drive-train consists of a low-speed shaft, gearbox, high-speed shaft and generator. Also, the inherent stiffness of the grid frequency added complexity. Variable-speed turbines, 
however, may not include a gearbox in the drive-train, and they are very compliant at the generator end. Thus, drive-train dynamics may be assumed to be negligible to simplify variable-speed turbine models.

Control design revolves around an appropriate model of the plant. Wind turbine design has been aided with the recent development of sophisticated design codes that accommodate numerous degrees of freedom. However, control design does not require complex models of each component. Leithead et al., 1989, p. 336, state "since the overall dynamic response of the complete wind turbine system is required, the models for each component part may be simplified without significant reduction in the accuracy of representation." They use a simple turbine model that consists of an aerodynamic model in the form of a look-up table and a simple wind model.

As variable-speed wind turbines have become more prominent, the PID controller has become the U.S. industry standard for blade-pitch control. This controller regulates the error, or difference between the measured input and the desired input. This error value along with its derivative and integral with respect to time provide a signal to the actuator(s) which affects the controlled process. Knowledge of the plant dynamics is not necessary, and often the three gains are determined based on intuition and experience.

The PID controller is a linear, single-input-single-output controller limited to three gains. These values are determined through a variety of methods. Stuart et al. (1996), Arsudis and Bohnisch (1990), and Leithead et al. (1991) used system identification techniques to estimate a transfer function of the wind turbine 
about a particular operating point (wind speed). The controller is then limited to those operating points specified and is specific to the wind turbine. In other words, the controller is not designed for wind turbine operation at wind speeds other than those specifically chosen for system identification, and the controller is not transportable to other turbines.

Although significantly limited in its operation, favorable results were produced using PID control by both Arsudis and Bohnisch (1990) and Stuart et al. (1996). Arsudis and Bohnisch compared a self-tuning PID controller to one that was "optimized manually based on an operation experience of several years ( $\mathrm{p}$. 565)." The self-tuning controller eliminated the overshoot of the blade angle shown with the original controller, and the time lag to achieve the desired pitch angle was reduced significantly with the self-tuning controller. Stuart et al. showed that a PI controller developed using system identification reduced the response time of the aileron deflection as compared to the previously used controller. Comparison of the PI controller with a controller designed using classical methods was the focus of work by Leithead et al. (1991). They concluded that the classical design marginally outperformed the PI controller.

These studies have shown that simple controllers reduce variation about an operating point, but the ultimate potential for improved performance as a result of controlling rotor speed is not quantified. Also the PI gain selection process may result in adequate operation, but there is no information as to the potential improvement of performance with different gain values. 
Although industry has embraced the PID controller, researchers have begun to investigate the capabilities of more sophisticated control designs such as state estimation designs. State estimation control successfully reduced power and rotor torque excursions above rated levels according to Bossanyi (1989). Constant power production and minimal torque vibrations were achieved with a Linear Quadratic Optimal Output Feedback controller designed by Bongers et al. (1989). Comparisons between PID controllers and state estimation based controllers have been made by Kendall et al. (1997), and Ekelund (1994). A Disturbance Accommodating Control based state estimator was found to be slightly inferior to PI control by Kendall et al, but Ekelund's Linear Quadratic Controller was superior to PI control. In order to fairly make such comparisons, it is necessary to establish the best possible baseline PID controller.

The greatest advantage of state estimation over PID control is the fact that state estimator controllers can incorporate multiple inputs and multiple outputs. Issues such as reducing blade root fatigue and shaft fatigue could be included in the control objectives. However, in order to convince industry to shift toward more complicated controllers, it is necessary to compare the state estimators with PID controllers. Establishing the performance limitations of PID control through systematic design methods will provide a basis for comparison with the sophisticated controllers that potentially will offer greater benefit to the system as a whole. 


\section{CHAPTER III}

\section{DYNAMIC MODELING}

The simple, rigid, non-linear turbine model developed for the purpose of controller design by Kendall et al., 1997 was used for this design study. The geometry and aerodynamic characteristics of the simulated turbine resemble those of a Grumman Windstream-33, 10-m diameter, 20-kW turbine. The National Renewable Energy Laboratory's National Wind Technology Center modified this turbine to operate at variable speeds using blade-pitch regulation. The original drive-train consisting of a low-speed shaft, gearbox, high-speed shaft, and generator was replaced with a single, stiff, shaft and direct-drive generator. Because the drive-train compliance was reduced to that of the stiff shaft only, it has been neglected in this model.

The fundamental dynamics of this variable-speed wind turbine are captured with the following simple mathematical model:

$$
J_{T} \dot{\omega}_{T}=Q_{A}-Q_{E}
$$

The moment of inertia of the turbine rotor, $1270 \mathrm{~kg} \cdot \mathrm{m}^{2}$, is represented by $\mathrm{J}_{\mathrm{T}} ; \omega_{\mathrm{T}}$ is the angular shaft speed; $\mathrm{Q}_{\mathrm{E}}$ is the mechanical torque necessary to turn the generator and was assumed to be a constant value commanded by the generator. Because the generator moment of inertia of a direct-drive turbine is generally several orders of magnitude less than $\mathrm{J}_{\mathrm{T}}$, it has been neglected. The aerodynamic torque, $\mathrm{Q}_{\mathrm{A}}$, is represented by:

$$
Q_{A}=\frac{1}{2} \rho A R c_{q}(\lambda, \beta) w^{2}
$$


The air density, $\rho$, swept area of the rotor, A, and rotor radius, $\mathrm{R}$, are constant.

The radius of this particular turbine is $5 \mathrm{~m}$. The wind speed is given by $\mathrm{w}$.

The torque coefficient, $\mathrm{c}_{\mathrm{q}}$, is a highly non-linear function of tip-speed ratio, $\lambda$, and blade-pitch angle, $\beta$ as illustrated in Figure 2. The tip-speed ratio is defined as the ratio of the blade tip speed to the prevailing wind speed. The surface presented in Figure 2 shows only positive values of $\mathrm{c}_{\mathrm{q}}$ because the turbine operates most often in this region. These non-linear aerodynamic characteristics are implemented as a look-up table which was generated using PROPPC (Tangler, 1987). This aerodynamics code uses blade-element momentum theory and empirical models that predict stalled operation and blade tip losses.

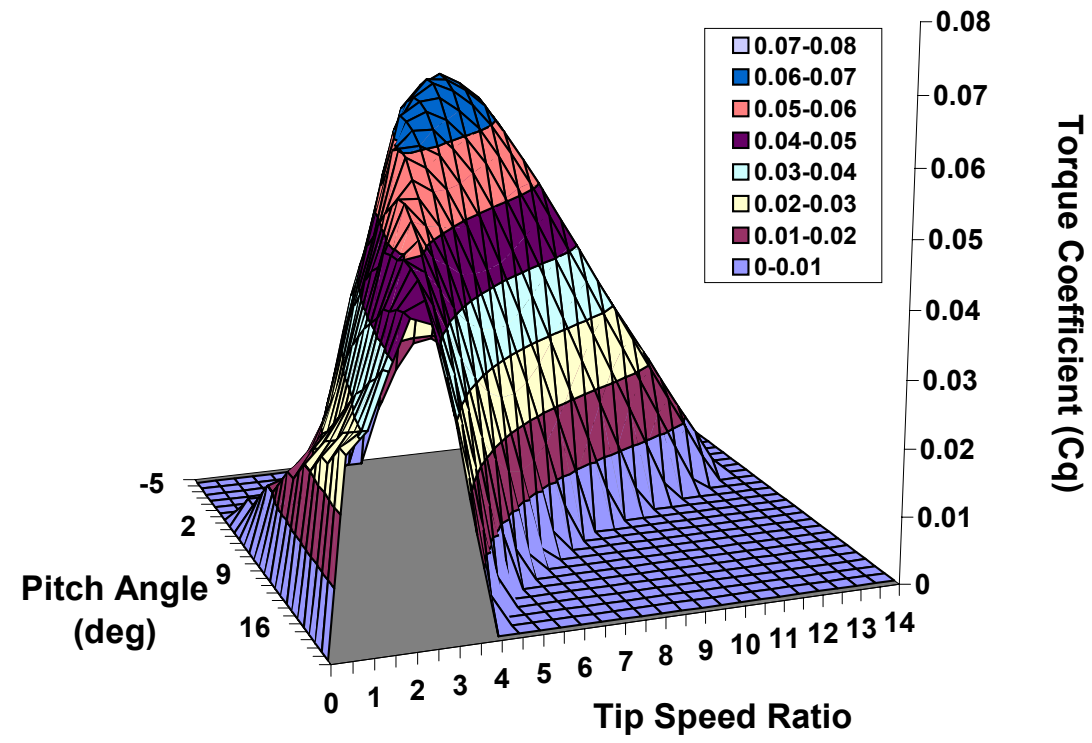

Figure 2: Torque coefficient surface as a function of tip-speed ratio and blade-pitch angle. All negative $c_{q}$ values have been set to zero. 
Because power limitation through speed regulation is the ultimate purpose for the controller, it is important to recognize the relationship between the power coefficient and the torque coefficient. Power extracted from the wind is shown in the following equation:

$$
P=0.5 \rho A c_{P}(\lambda, \beta) w^{3}
$$

Because the torque coefficient is related to the power coefficient, $c_{P}$, through the following relation

$$
c_{P}(\lambda, \beta)=\lambda c_{q}(\lambda, \beta)
$$

manipulation of the torque coefficient using $\lambda$ and $\beta$ will result in manipulation of the power produced by the turbine.

The block diagram in Figure 3 illustrates the simulation logic as implemented with MATLAB $®$ Simulink $®$ software. Actual wind data sampled at $1 \mathrm{~Hz}$ is input to the non-linear plant model. The turbine speed is fed back, and the reference speed, $\omega_{\mathrm{T} \text { ref }}$, is subtracted from it resulting in $\Delta \omega_{\mathrm{T}}$ (noise in the sensor measurements has been neglected). This rotor-speed error is input to the controller which commands a change in blade-pitch angle, $\Delta \beta$, based on $\Delta \omega_{\mathrm{T}}$.

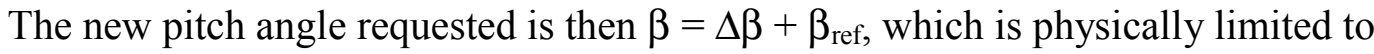
angles between $3^{\circ}$ and $60^{\circ}$ (Selection of the reference speed and reference pitch angle is described in Chapter IV.). The actuator operates on a pitch rate command. The pitch rate is determined from the difference between the commanded pitch angle and the measured blade-pitch angle (noise in the measurements is again neglected). The simulation uses a variable step size with a maximum step of 0.05 seconds. A new wind speed is read from the input file when the simulation time 
step corresponds to the time step of the wind data. A new rotational speed is then determined at the resulting tip-speed ratio and blade-pitch angle.

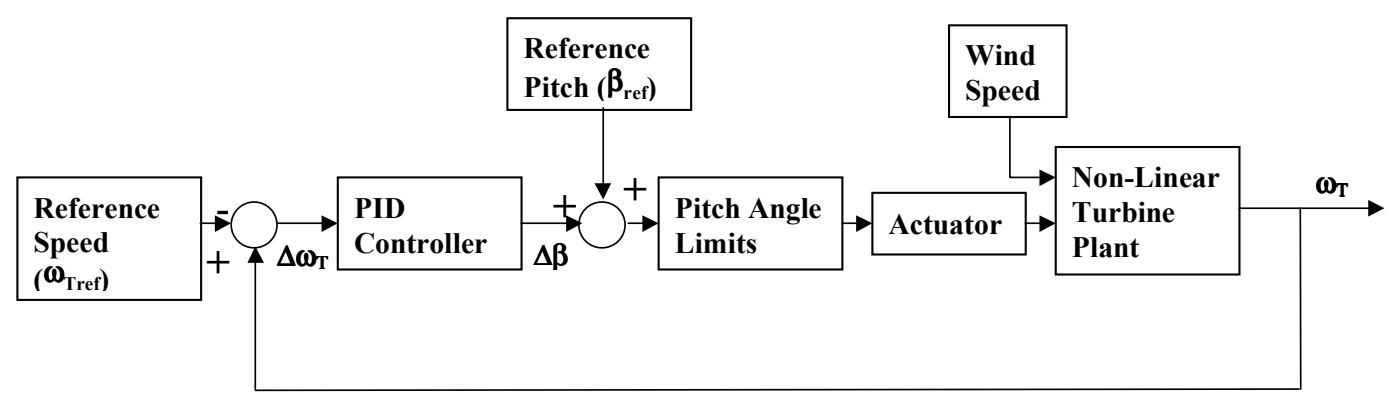

Figure 3: Simulation block diagram.

A block diagram of the Proportional-Integral-Derivative (PID) controller is shown in Figure 4. The difference, or error, between the measured rotor speed and the desired rotor speed is manipulated with three gain values resulting in the pitch angle change necessary to eliminate the error. A proportional value, $\mathrm{k}_{\mathrm{P}}$, multiplies the error signal. The integral with respect to time of the error signal is multiplied by the gain, $\mathrm{k}_{\mathrm{I}}$. The gain $\mathrm{k}_{\mathrm{D}}$ multiplies the derivative of the error signal. The summation of these three terms produces the desired change in bladepitch angle. 


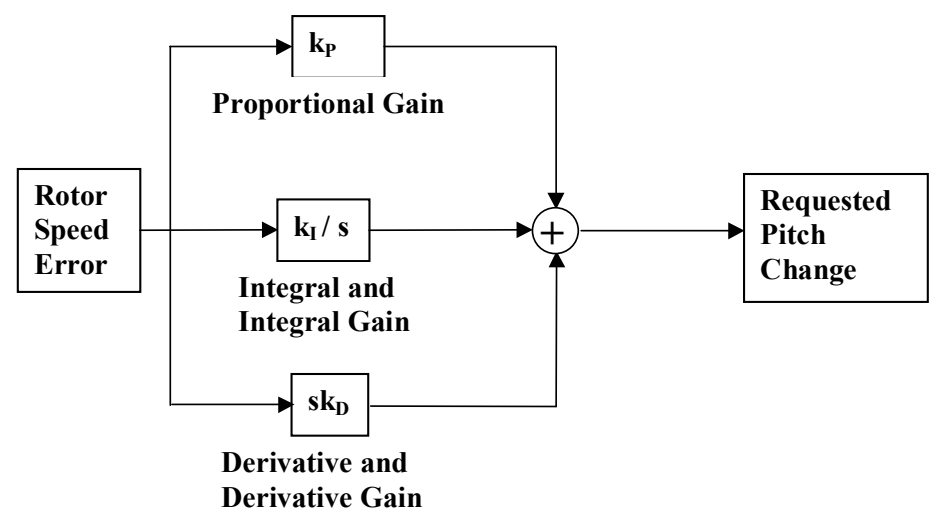

\section{Figure 4: Controller block diagram.}

Hydraulic actuators that adjust the blade-pitch angle are simulated for this study, and the block diagram in Figure 5 illustrates the actuator's operation. Hydraulic fluid tends to overheat with excessive pitch motion requiring judicious use of the actuator. Additionally the linkage between the actuator and the bladepitch mechanism may fatigue with overuse of the actuator. The pitch rate that is commanded by the actuator was physically limited to \pm 10 degrees per second according to manufacturer recommendations. Another measure meant to reduce actuator motion and eliminate noise in the command signal (once it is introduced into the simulation) is the inclusion of a "dead zone" to ignore commanded pitch rates less than $\pm 0.1 \mathrm{deg} / \mathrm{second}$. 


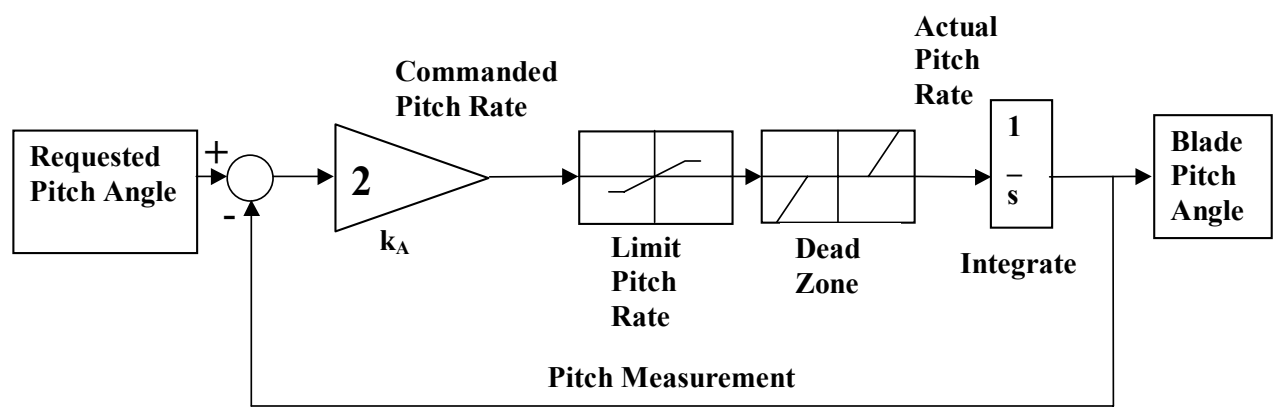

Figure 5: Actuator block diagram.

In order to assess controller performance, two metrics were developed by Kendall et al. (1997). The root mean square (RMS) of the error between the actual rotational speed and the desired rotational speed indicates the capability of the controller to reject the wind speed fluctuations. After the simulation is completed (90 seconds), the RMS of the error is computed. The Actuator Duty Cycle (ADC) was proposed as a measure of actuator motion during a simulation run. It is simply the total number of degrees pitched over the time period of the simulation. In order to prevent over-heating of the hydraulic fluid, this value must remain below $3 \mathrm{deg} / \mathrm{s}$ based on information provided by the manufacturer. For each simulation run, these two metrics were computed, and both must be considered in determining acceptable operating conditions. 


\section{CHAPTER IV}

\section{TRADITIONAL CONTROLLER DESIGN METHODOLOGY}

A traditional approach to design of commonly used linear controllers such as proportional-integral-derivative (PID), requires that the non-linear turbine dynamics be linearized about a specified operating point. Once stability is attained, observation of the system response to step inputs provides direction in choosing gain values. This approach yields gain values which will provide adequate performance.

Linearization of the turbine equation (1) results in the following assuming that $\left.\mathrm{Q}_{\mathrm{A}}\right|_{\mathrm{OP}}=\left.\mathrm{Q}_{\mathrm{E}}\right|_{\mathrm{OP}}$ :

$$
J_{T} \dot{\omega}_{T}=\gamma \Delta \omega_{T}+\alpha \Delta w+\delta \Delta \beta
$$

where the linearization coefficients are given by:

$$
\begin{aligned}
& \gamma=\left.J_{T} \frac{\partial \dot{\omega}_{T}}{\partial \omega_{T}}\right|_{O P}=\left.\frac{1}{2} \rho A R^{2} w_{O P} \frac{\partial c_{q}}{\partial \lambda}\right|_{O P} \\
& \alpha=\left.J_{T} \frac{\partial \dot{\omega}_{T}}{\partial w}\right|_{O P}=\frac{1}{2} \rho A R w_{O P}\left[\left.2 c_{q}\right|_{O P}-\left.\lambda_{O P} \frac{\partial c_{q}}{\partial \lambda}\right|_{O P}\right] \\
& \delta=\left.J_{T} \frac{\partial \dot{\omega}_{T}}{\partial \beta}\right|_{O P}=\left.\frac{1}{2} \rho A R w_{O P}{ }^{2} \frac{\partial c_{q}}{\partial \beta}\right|_{O P}
\end{aligned}
$$

Here, $\Delta \omega_{\mathrm{T}}, \Delta \mathrm{w}$, and $\Delta \beta$ represent deviations from the chosen operating point, $\omega_{\mathrm{TOP}}, \mathrm{w}_{\mathrm{OP}}$, and $\beta_{\mathrm{OP}}$

Selection of the operating point is critical to preserving aerodynamic stability in this system. The rotational speed operating point, $\omega_{\mathrm{T}} \mathrm{OP}$, was selected to be the desired constant speed of the turbine, 105 RPM $(11 \mathrm{rad} / \mathrm{s})$. The blade- 
pitch and wind speed operating points were selected using the power coefficient surface shown in Figure 6 . The maximum $c_{p}$ value over the entire surface occurs at a pitch angle of $3^{\circ}$ and a tip-speed ratio of 7 . Using the constant rotational speed of $11 \mathrm{rad} / \mathrm{s}$, this tip-speed ratio corresponds to a wind speed of $7.5 \mathrm{~m} / \mathrm{s}$. At this point, the turbine would produce maximum power. However, slight deviation from this point toward negative pitch angles could result in stalled blades which dramatically decreases the power produced. By changing the pitch angle to $9^{\circ}$, the magnitude of the power coefficient is reduced, but deviation around a tipspeed ratio of 7 could easily be tolerated. It is important to note that stalled blades can also occur in low tip-speed-ratio conditions.

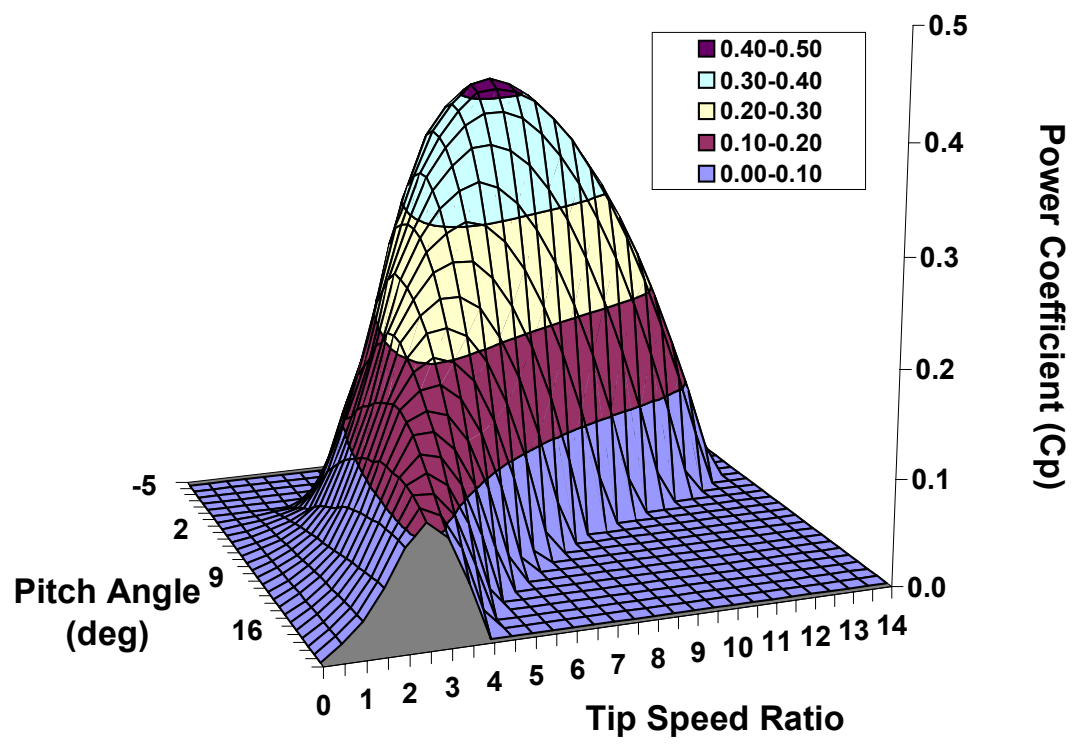

Figure 6: Power coefficient surface as a function of tip-speed ratio and blade-pitch angle. All negative $c_{p}$ values have been set to zero. 
Figure 7 is an example of the torque coefficient, $\mathrm{c}_{\mathrm{q}}$, varying with tip speed ratio, $\lambda$, for pitch angles of $3^{\circ}$ and $9^{\circ}$. The peak $\mathrm{c}_{\mathrm{q}}$ value delineates theoretically stalled and unstalled operating conditions. The region where the slope of the $\mathrm{c}_{\mathrm{q}}$ curve is positive corresponds to stalled operating conditions. The chosen operating point of $\beta=9^{\circ}$ and $\lambda=7$ permits deviation of the tip-speed-ratio without causing blade stall. At this point on the $c_{p}$ surface, the power coefficient may be approximated by a relatively flat plane tangent to the surface which is ideal for linearized models. Thus, the linearization operating point was chosen to be: $\omega_{\mathrm{T}}$ OP $=11 \mathrm{rad} / \mathrm{s} ; \mathrm{w}_{\mathrm{OP}}=7.5 \mathrm{~m} / \mathrm{s} ;$ and $\beta_{\mathrm{OP}}=9^{\circ}$. The peak of the $\mathrm{c}_{\mathrm{p}}$ surface represents the reference values used in the simulation: : $\omega_{\mathrm{T} \text { ref }}=11 \mathrm{rad} / \mathrm{s} ; \mathrm{w}_{\mathrm{ref}}=7.5 \mathrm{~m} / \mathrm{s}$; and $\beta_{\text {ref }}$ $=3^{\circ}$.

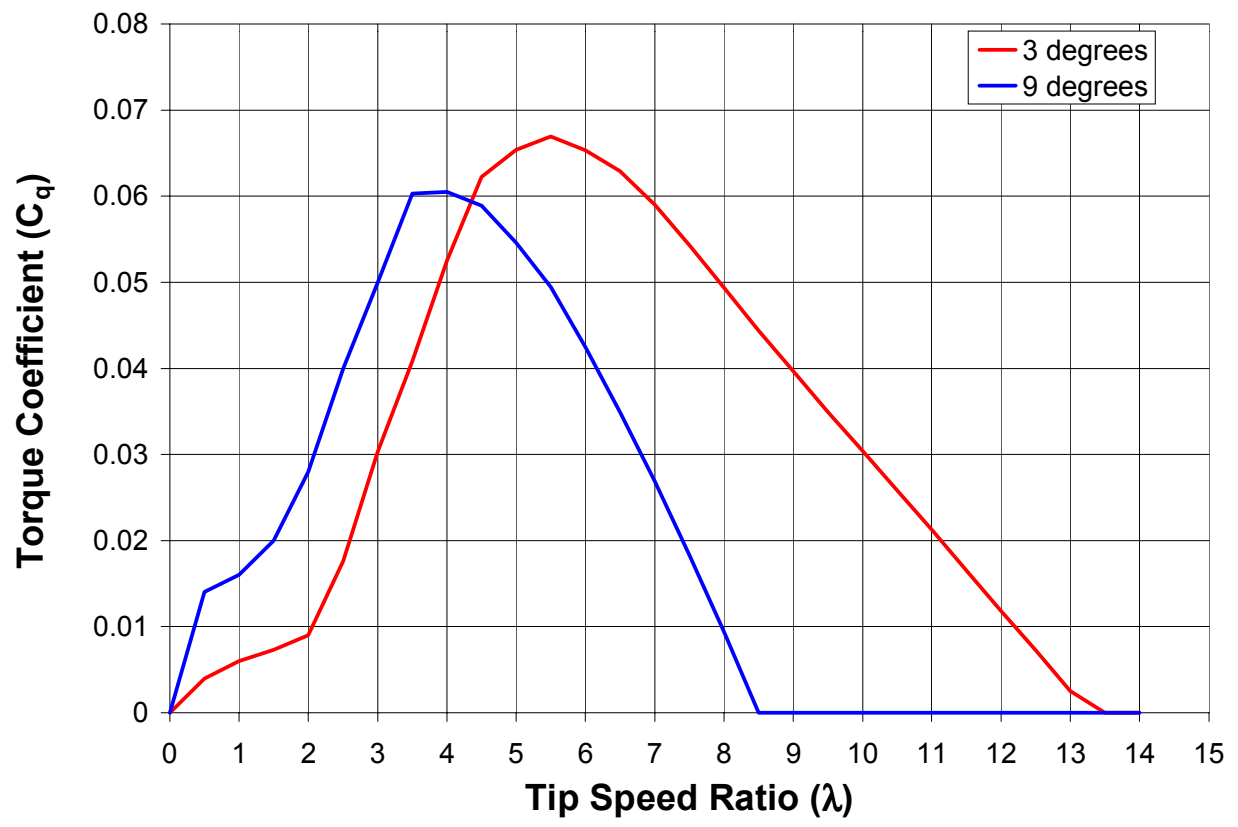

Figure 7: Example of $c_{q}$ vs. $\lambda$ for 2 blade-pitch angles. 
In order to determine regions of stable, controlled operation, the closedloop transfer function between the output rotational speed and the reference speed is determined in the Laplace domain. The denominator of this equation is a thirdorder polynomial. A Routh array analysis requires each of the coefficients of the polynomial to be positive in order for the poles of the system to lie in the left-half plane producing stable, closed-loop operation. The full analysis is found in Appendix A, but the gains must be as follows in order to maintain stability: $\mathrm{k}_{\mathrm{P}}>-1$ $\operatorname{deg} \cdot \mathrm{s} / \mathrm{rad}, \mathrm{k}_{\mathrm{I}}>0 \mathrm{deg} / \mathrm{rad}, \mathrm{k}_{\mathrm{D}}>-8 \mathrm{deg} \cdot \mathrm{s}^{2} / \mathrm{rad}$, and $\left(8+\mathrm{k}_{\mathrm{D}}\right)\left(1+\mathrm{k}_{\mathrm{P}}\right)>\mathrm{k}_{\mathrm{I}}$. For this linear approximation of the system, stability is maintained over a wide region.

At this point the designer may examine the system response to step input in order to select values for each of the gains. A step function approximates an abrupt change in wind speed and was used by Kendall et al. (1997) to tune a PI controller. Visual inspection of the rotor speed response and the pitch rate response may be used to determine the best combination of $\mathrm{k}_{\mathrm{P}}$ and $\mathrm{k}_{\mathrm{I}}$ gains to achieve appropriate damping of the system. However, when the third gain is introduced, this trial and error method becomes much more tedious and complicated. This method does not provide the designer with a feel for the sensitivity of the controller to slight variations in the gain values, and an optimal range of gain values is not identified. 


\section{CHAPTER V}

\section{SYSTEMATIC CONTROLLER DESIGN METHODOLOGY}

In order to systematically determine combinations of three gains that produce acceptable operating conditions, the simulation was used repeatedly. Each of the gains was varied over a wide region, and the two metrics were computed for each run. Additionally, the five different wind input cases shown in Table 1 were used. The average value of the metrics under each combination of gains and each wind input case was computed. Contour plots for both metrics were created while the $\mathrm{k}_{\mathrm{P}}$ and $\mathrm{k}_{\mathrm{D}}$ gains were varied at a specific $\mathrm{k}_{\mathrm{I}}$. This was done for a range of $\mathrm{k}_{\mathrm{I}}$ values from 1 to 20 . Trade-off studies between the series of surfaces were performed to determine the region where optimal operating conditions exist. Lastly, time-series traces of rotational speed, pitch angle, and pitch rate for gain combinations within this region were produced to verify acceptable operation.

Table 1: Statistics describing wind input files.

\begin{tabular}{|l|c|c|c|}
\hline \multicolumn{1}{|c|}{$\begin{array}{c}\text { File } \\
\text { Name }\end{array}$} & $\begin{array}{c}\text { Mean } \\
(\mathbf{m} / \mathbf{s})\end{array}$ & $\begin{array}{c}\text { Standard } \\
\text { Deviation }\end{array}$ & RMS \\
\hline Wind3 & 9.20 & 1.14 & 9.27 \\
\hline Wind4 & 11.43 & 2.28 & 11.66 \\
\hline Wind5 & 10.88 & 1.85 & 11.03 \\
\hline Medwind2 & 10.31 & 1.82 & 10.46 \\
\hline Highwind4 & 14.43 & 2.41 & 14.63 \\
\hline
\end{tabular}

Figures 8-10 depict surfaces for three different values of $\mathrm{k}_{\mathrm{I}}$ for both of the metrics. All of the contour plots indicate wide, flat surfaces for both the actuator 
duty cycle and the RMS of the rotational speed error. These surfaces illustrate that a wide range of gain value combinations may be chosen with similar results. Thus the controller is robust and relatively insensitive to changes in the values of the gains. However, choosing optimal operating setpoints for the gains requires closer examination of the surfaces.

The actuator duty cycle surface for $\mathrm{k}_{\mathrm{I}}=1$, Figure $8 \mathrm{a}$, indicates that the mean value decreases rapidly to zero as $\mathrm{k}_{\mathrm{P}}$ and $\mathrm{k}_{\mathrm{D}}$ approach one. Figure $9 \mathrm{a}$, which represents the surface at $\mathrm{k}_{\mathrm{I}}=5$, portrays the opposite effect near $\mathrm{k}_{\mathrm{P}}=1$ and $\mathrm{k}_{\mathrm{D}}=1$, but a "bucket" with a minimum value of $0.9-1.0 \mathrm{deg} / \mathrm{s}$ appears at moderate gain values of 5-10 for both $\mathrm{k}_{\mathrm{P}}$ and $\mathrm{k}_{\mathrm{D}}$. As the value of $\mathrm{k}_{\mathrm{I}}$ is further increased to 10 in Figure 10a, the "bucket" again appears, but its minimum value of 1.0-1.1 is greater than that of the "bucket" that appears at $\mathrm{k}_{\mathrm{I}}=5$. Therefore, the minimum value of actuator duty cycle over the entire range of the three gain values occurs somewhere between $\mathrm{k}_{\mathrm{I}}=1$ and $\mathrm{k}_{\mathrm{I}}=5$. The trend toward higher actuator duty cycle values as $\mathrm{k}_{\mathrm{I}}$ increases is shown in Appendix B along with tables containing the simulation output values.

A similar comparison of the RMS speed error surfaces was performed to determine the location of its minimum value over the entire range of gain values. Figure $8 \mathrm{~b}$ indicates a sharply increasing slope in the RMS speed error for $\mathrm{k}_{\mathrm{P}}<20$. As the integral gain, $\mathrm{k}_{\mathrm{I}}$, increases from 1 to 5 in Figure $9 \mathrm{~b}$, this sharp slope boundary decreases to $k_{\mathrm{P}}<7$. Increasing the integral gain to 10 , Figure $10 \mathrm{~b}$, moves the slope increase to $\mathrm{k}_{\mathrm{P}}<5$. The RMS speed error slowly decreases as $\mathrm{k}_{\mathrm{P}}$ increases such that the minimum value would occur beyond the range of the plot. However, 

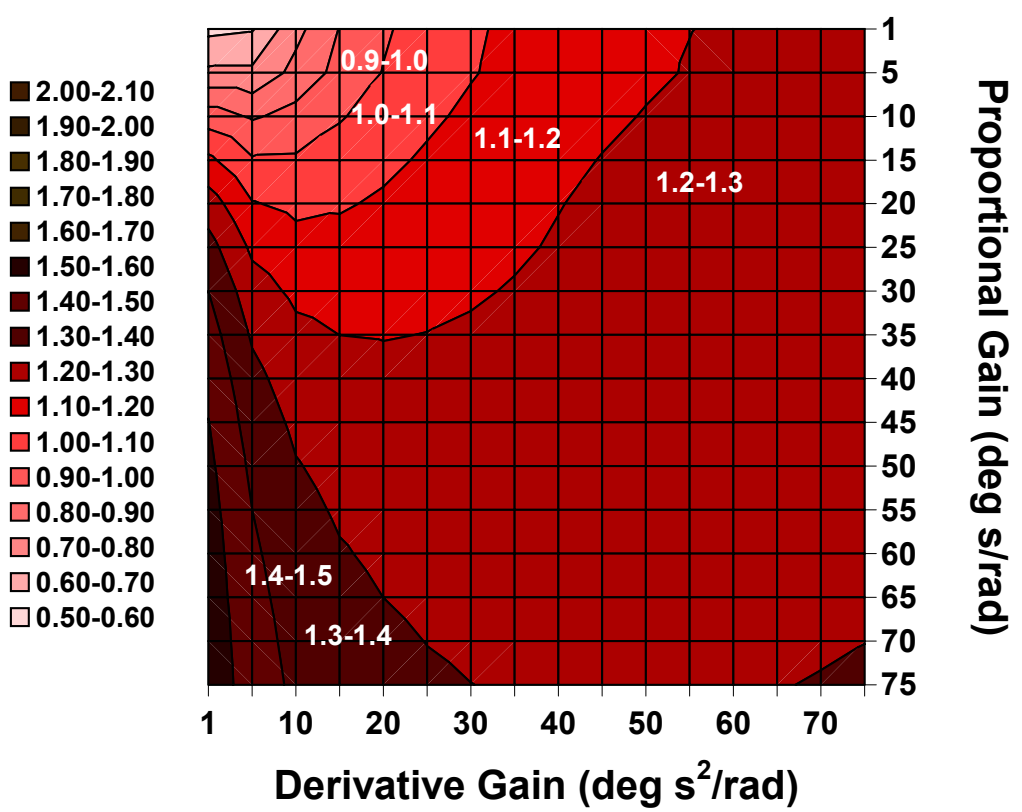

(a) Actuator duty cycle ( $\mathrm{deg} / \mathrm{s})$

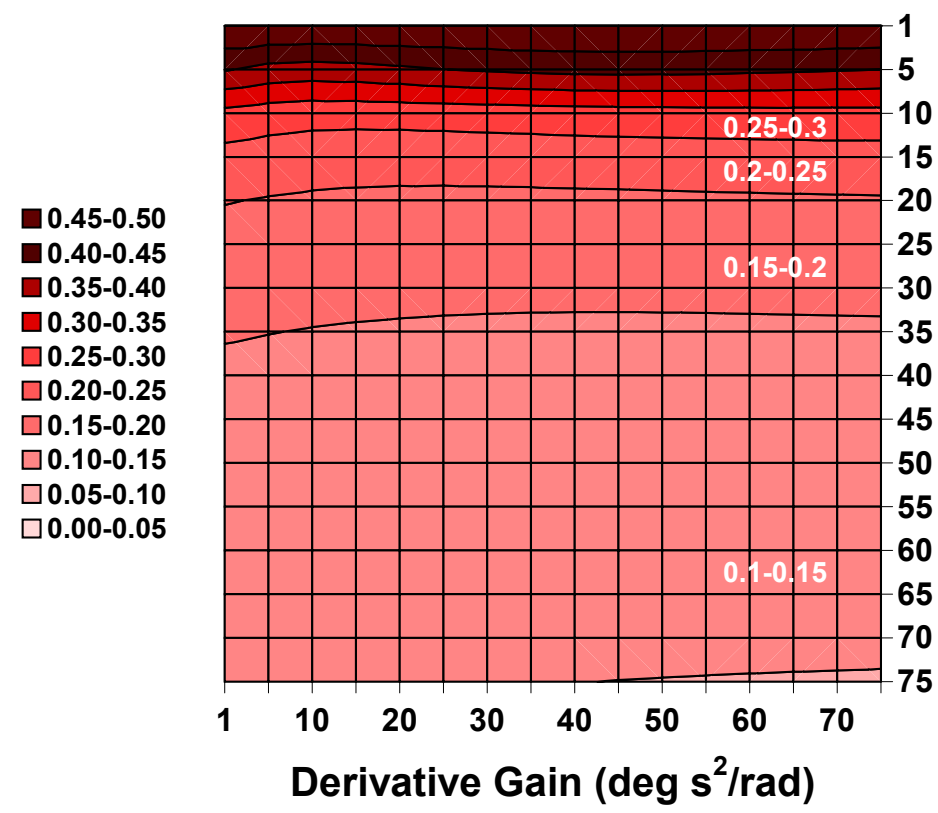

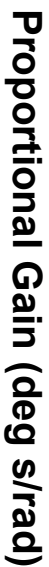

(b) RMS rotor speed error ( $\mathrm{rad} / \mathrm{s})$

Figure 8: Performance metric surfaces generated using the non-linear turbine model for $\mathrm{k}_{\mathrm{I}}=\mathbf{1} \mathrm{deg} / \mathrm{rad}$.

for $\mathrm{k}_{\mathrm{I}}=5$ to 10 , the surface flattens to a mean RMS speed error of $0.05-0.10$. Thus changing the value of $\mathrm{k}_{\mathrm{I}}$ alters the point of sharply increasing slope as the 


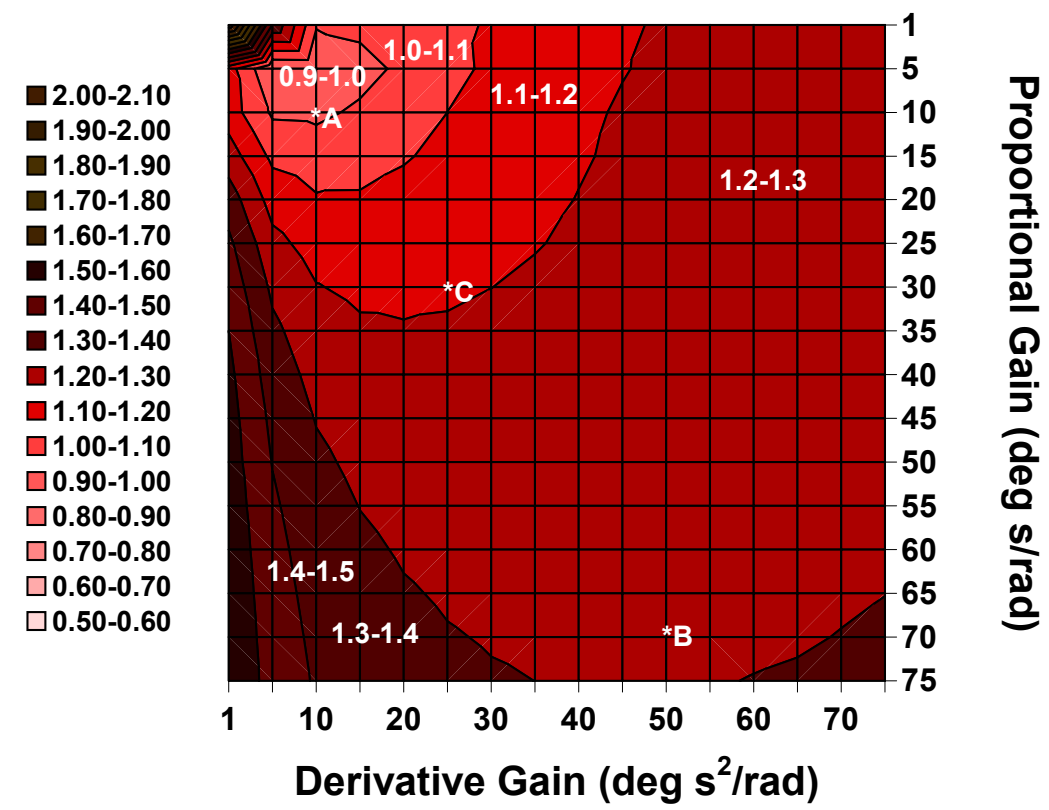

(a) Actuator duty cycle (deg/s)

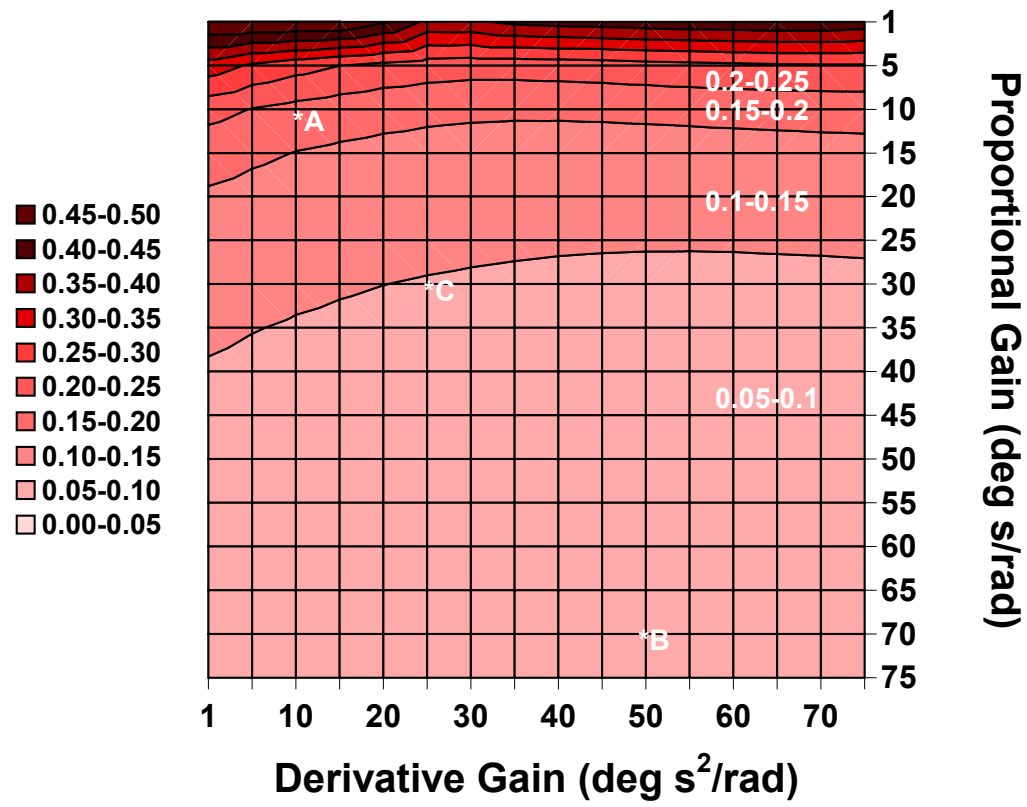

(b) RMS rotor speed error (rad/s)

Figure 9: Performance metric surfaces generated using the non-linear turbine model for $\mathrm{k}_{\mathrm{I}}=\mathbf{5} \mathrm{deg} / \mathrm{rad}$.

proportional gain is reduced, but the flat region from which the sloped area originates is maintained. 


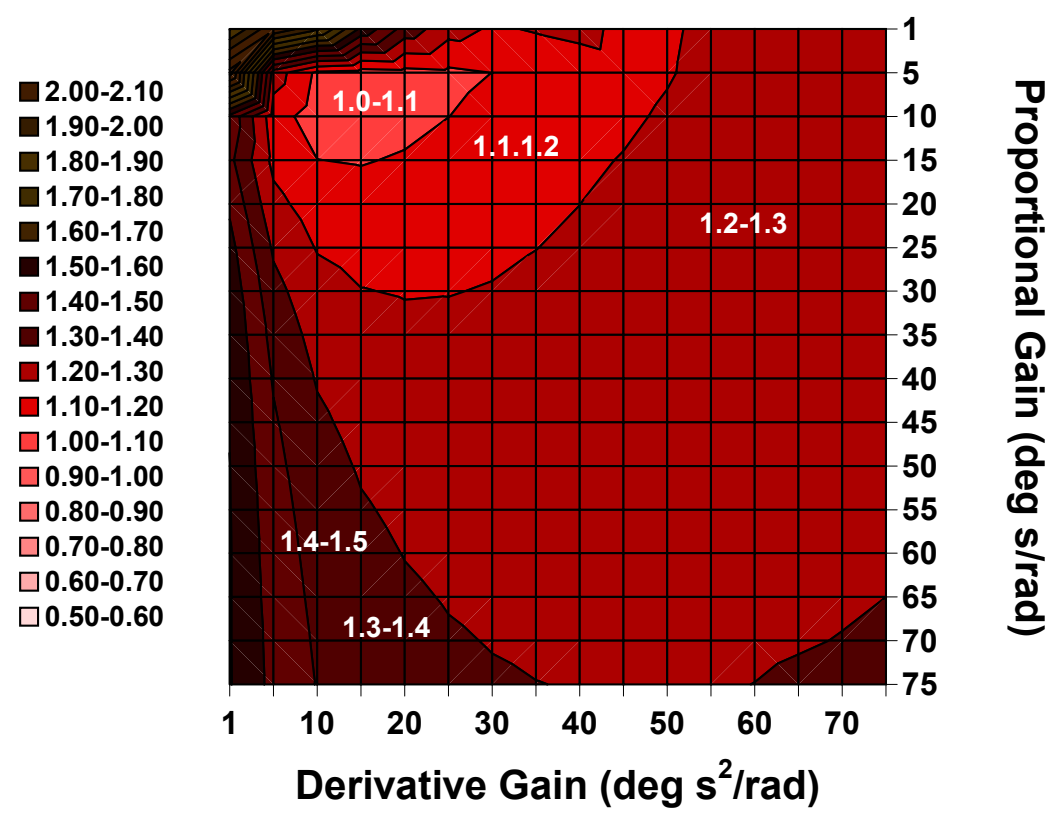

(a) Actuator duty cycle (deg/s)

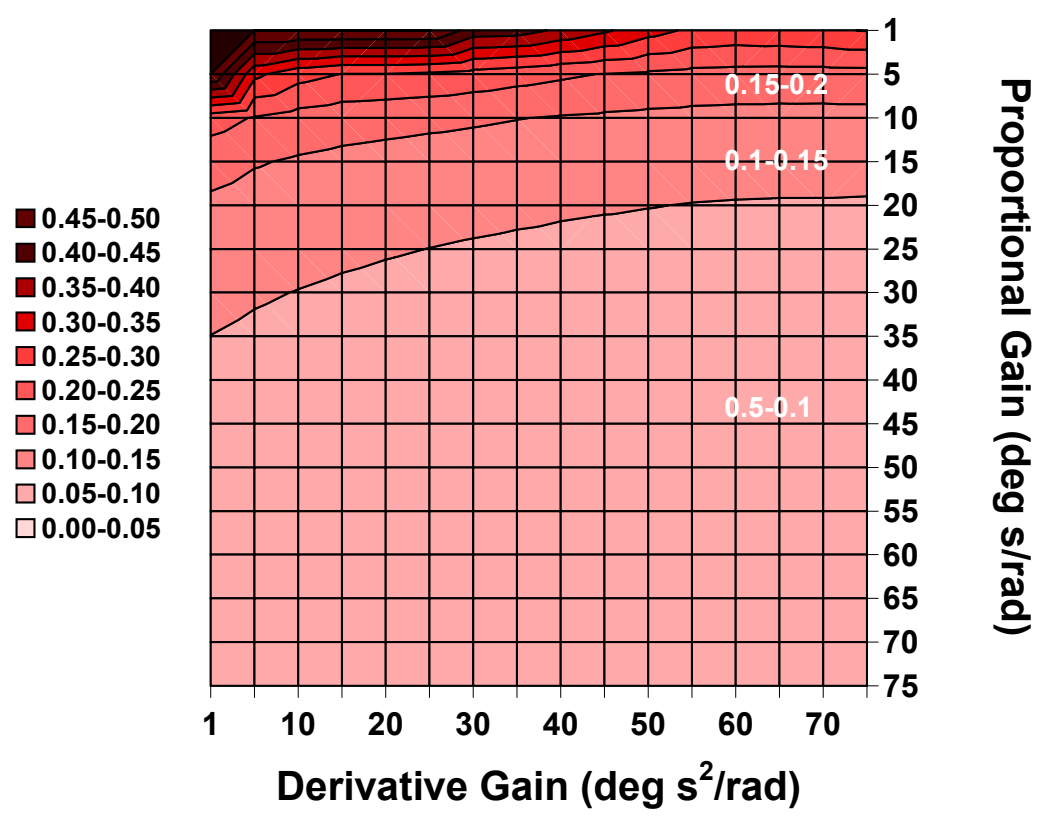

(b) RMS rotor speed error ( $\mathrm{rad} / \mathrm{s})$

Figure 10: Performance metric surfaces generated using the non-linear turbine model for $k_{I}=10 \mathrm{deg} / \mathrm{rad}$.

Both the RMS speed error and the actuator duty cycle must be considered in choosing the optimal operating conditions. If the integral gain were reduced from a value of 5, the RMS speed error surface would retain similar 
characteristics, but the boundary of increasing slope would begin to move from $\mathrm{k}_{\mathrm{P}}=7$ towards $\mathrm{k}_{\mathrm{P}}=20$. The actuator duty cycle surface would also retain similar characteristics, but the sharp rise as $\mathrm{k}_{\mathrm{P}}$ and $\mathrm{k}_{\mathrm{D}}$ approach one would begin to drop toward zero. The "bucket" would remain in approximately the same location. Thus, reducing $\mathrm{k}_{\mathrm{I}}$ from 5 has little effect on the actuator duty cycle in the region of the "bucket," but the corresponding RMS speed error in that region increases. However, if the integral gain were increased, the "bucket" would begin to rise. Therefore, in order to minimize the RMS speed error and the actuator duty cycle simultaneously, the integral gain should be set at 5 .

Using an integral gain of 5, the minimum actuator duty cycle region, 0.9$1.0 \mathrm{deg} / \mathrm{s}$ corresponds to an RMS speed error range of $0.15-0.20 \mathrm{rad} / \mathrm{s}$. The point A on Figure $9 \mathrm{a}$ and $9 \mathrm{~b}$ represents operating conditions where the actuator duty cycle is minimized $\left(\mathrm{k}_{\mathrm{P}}=10, \mathrm{k}_{\mathrm{I}}=5, \mathrm{k}_{\mathrm{D}}=10\right)$. An example of operation in the lowest RMS speed error range uses the operating condition at Point $\mathrm{B}\left(\mathrm{k}_{\mathrm{P}}=70, \mathrm{k}_{\mathrm{I}}=5\right.$, $\mathrm{k}_{\mathrm{D}}=50$ ) shown on Figure 9a and 9b. Because the RMS speed error slowly decreases as the proportional and derivative gains are increased, this point also indicates operation in the low end of the lowest RMS speed error contour.

To determine which metric is more important, time-series traces of rotor speed, blade-pitch angle, and pitch rate are presented in Figure 11. The performance is shown for three different gain combinations based on the surfaces shown in Figure 9. The wind input for each simulation represents the highest average wind speed used in this study which produces the most extreme conditions. Figure 11a includes the time-series of the wind input. 

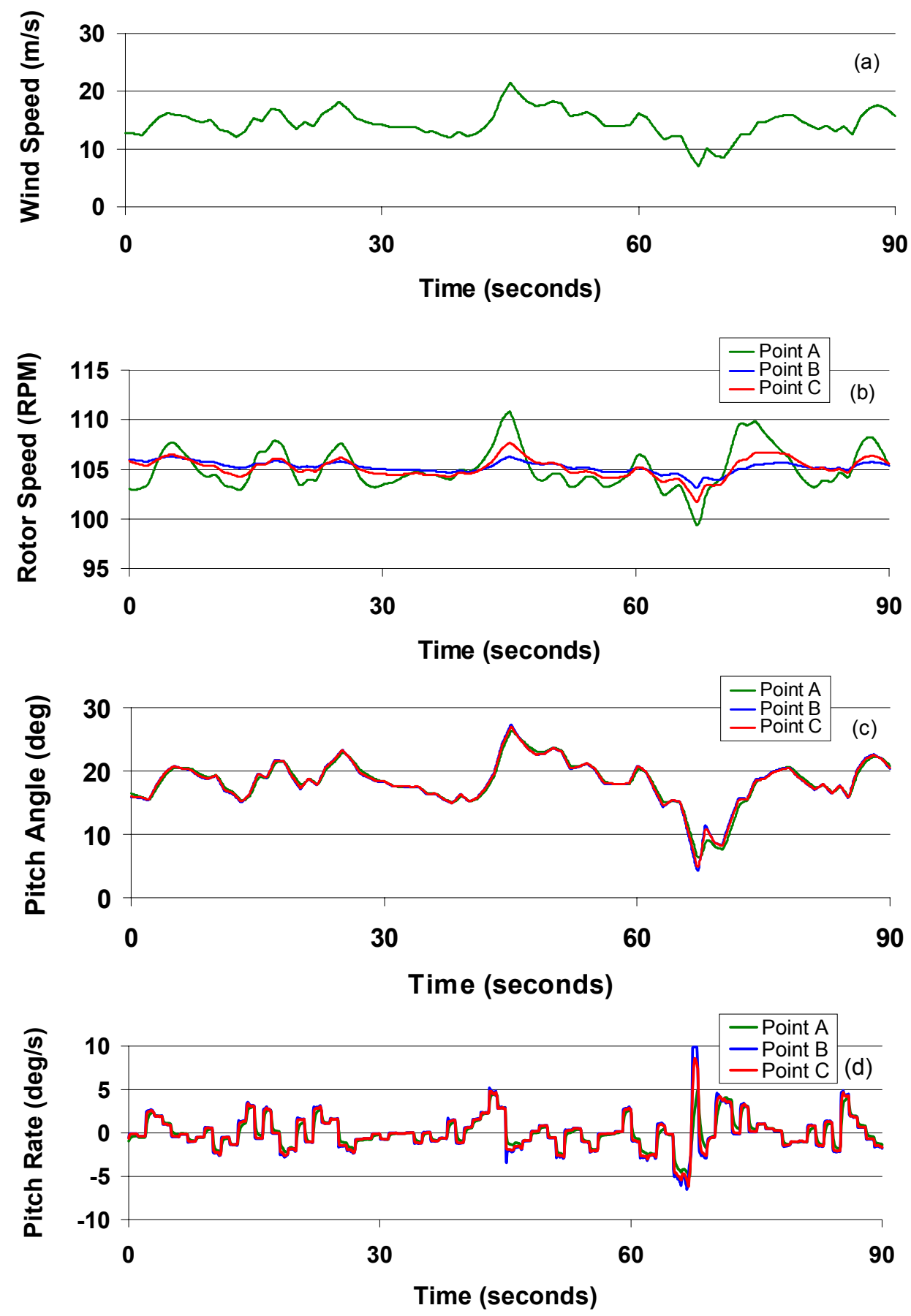

Figure 11: Time-series traces of turbine performance.

Operation at Point A represents the trade-off between minimum actuator duty cycle and a higher level of RMS speed error. The rotational speed deviation 
from the desired 105 RPM, shown in Figure 11b, is slightly greater than \pm 5 RPM. The pitch rate, illustrated in Figure 11d, does not exceed $\pm 5 \mathrm{deg} / \mathrm{s}$. In this case the goal of maintaining constant rotational speed is not met satisfactorily. Operation at Point B depicts the trade-off between minimum RMS speed error and a higher level of actuator duty cycle. In this case the rotational speed deviation from the reference is less than $\pm 2 \mathrm{RPM}$, and the pitch rate reaches the limit of $10 \mathrm{deg} / \mathrm{s}$. The pitch rate also indicates excessive motion at approximately 45 seconds. This type of motion is unacceptable when attempting to reduce fatigue and the potential for overheating.

Point $\mathrm{C}\left(\mathrm{k}_{\mathrm{P}}=30, \mathrm{k}_{\mathrm{I}}=5, \mathrm{k}_{\mathrm{D}}=20\right)$ was chosen at the intersection of the minimum RMS speed error range and the lowest corresponding actuator duty cycle. The rotational speed, pitch angle, and pitch rate obtained at this operating point are included in Figure 11. The rotational speed closely tracks the desired 105 RPM throughout the simulation with peak deviations of less than \pm 3 RPM. The actuator duty cycle does not reach the limit, and the curve is smoother than that produced at the gain combination of Point B. Operation within this region results in the best possible combination of the two performance metrics. Figure $11 \mathrm{c}$ indicates that the pitch angle commanded by the controller is not noticeably affected by the choice of gain values.

When using a traditional design methodology, the engineer would subject the system to step inputs and examine the response in order to adjust the gain values. In this case of the variable-speed turbine, one would presume that the rotor speed response should be overdamped and have a short settling time on the 
order of less than 5 seconds. In other words, the turbine should respond quickly to wind gusts, and the rotor speed should return to the desired speed without dropping below the stated value. The pitch rate response would also be expected to respond in an overdamped manner to reduce unnecessary motion as the speed returned to its constant value. Again, a quick response ( $<5$ seconds) seems appropriate.

The non-linear, turbine model was subjected to wind gusts simulated with step inputs while the gain values reflected those of each of three points selected above. The rotor speed responses are shown in Figure 12 and differ from the above predicted response. The time required to return to a constant speed is lengthy, 25 seconds when the gains were in the optimal region. At Point A, the lowest actuator duty cycle region, the rotor response is under-damped, dropping below the constant speed while the response is over-damped, as suspected, at Points B and C. The pitch rate responses are shown in Figure 13. At Point A, the pitch rate nearly reaches the limit and then slowly drops back to a stationary point. Point $\mathrm{B}$, on the other hand, produces a pitch rate that nearly reaches the limit, then becomes negative before returning to zero. At Point C, the optimal gain combination, the pitch rate jumps almost immediately to just below the rate limit and then drops almost as quickly back to zero.

If one were designing this controller in a traditional manner, it is conceivable that none of these gain combinations would be selected. The long settling time evident in the rotor speed response seems contradictory, and the extreme amplitude of the pitch rate is surprising. However, because the wind 


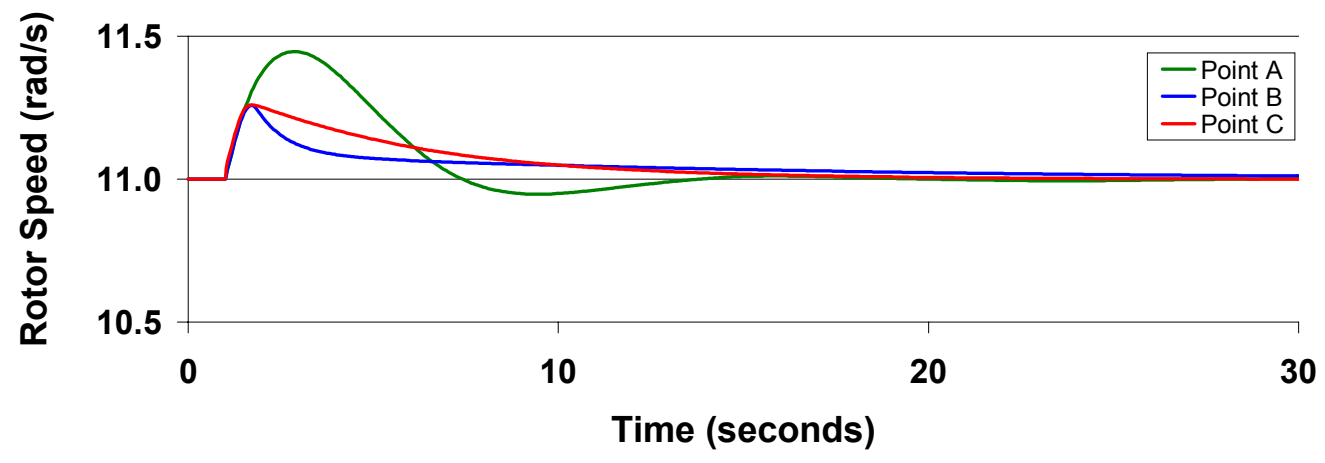

Figure 12: Rotor speed response to step in wind input.

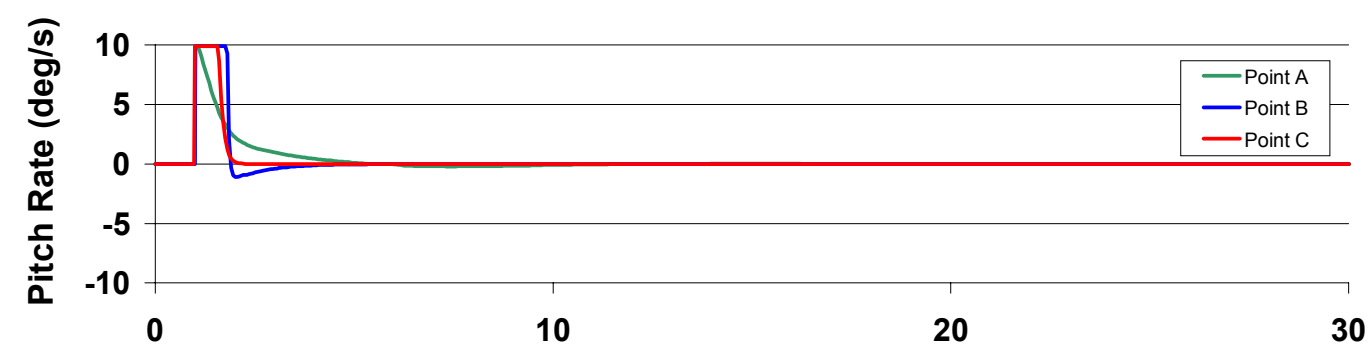

Figure 13: Pitch rate response to step in wind input.

actually behaves as a persistent disturbance, instead of a single step, the traditional view of PID controller performance is questionable.

The systematic approach presented herein relies heavily on the two specific metrics that were selected for this particular application. The hydraulic actuators that were simulated for this study could easily be replaced by servomechanical actuators. In this case, the actuator duty cycle metric would not apply. However, servo motors are also susceptible to over-heating. Constant acceleration of the motor draws current which could lead to heat build-up if the blade-pitch rate is not regulated. 
Substituting the RMS of the pitch rate signal for the actuator duty cycle yields the surface shown in Figure 14. This surface represents $k_{P}$ and $k_{D}$ gain variations while the integral gain is 5 and corresponds to actuator duty cycle surface shown in Figure 9a. The RMS pitch rate surface is very similar to the corresponding actuator duty cycle surface. A trade-off study could be performed between the corresponding RMS speed error surface shown in Figure $9 \mathrm{~b}$ and the RMS pitch rate surface to determine which gain combination will provide the best overall performance of the turbine. Due to the similar gain sensitivity illustrated by the actuator duty cycle and the RMS pitch rate, the optimal gain combinations will also be similar.

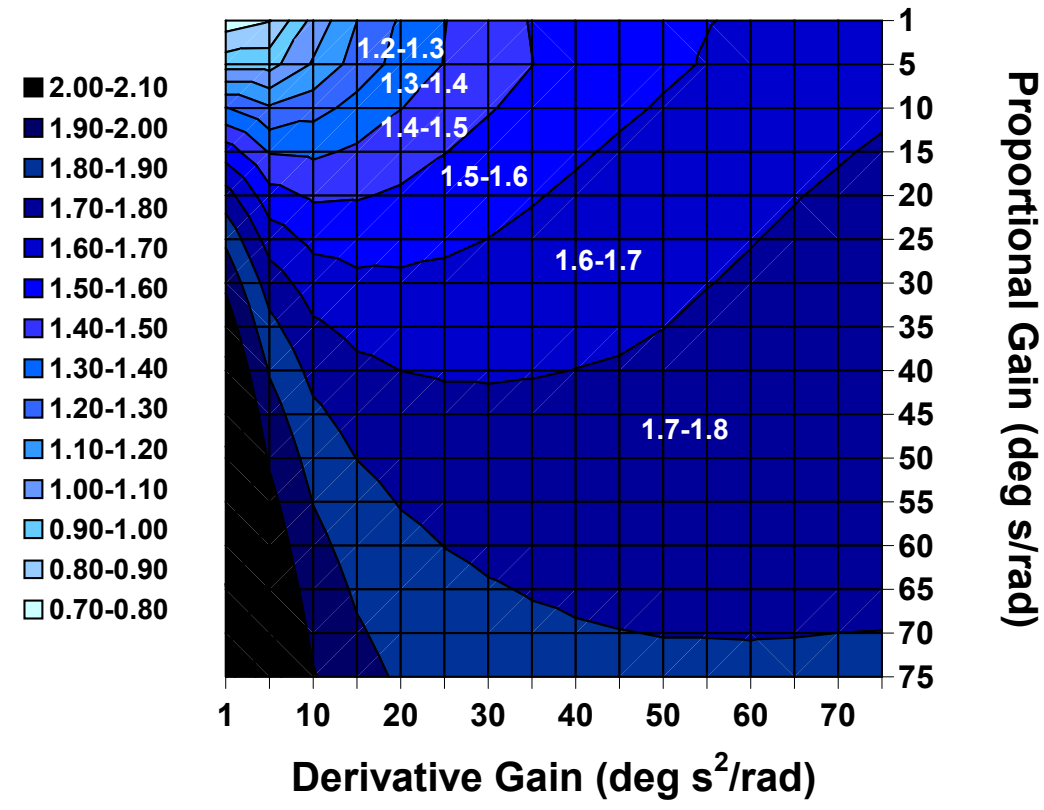

Figure 14: RMS of pitch rate potential performance metric for $k_{\mathrm{I}}=5 \mathrm{deg} / \mathrm{rad}$. 


\section{CHAPTER VI}

\section{NON-LINEAR MODEL VS. LINEAR MODEL}

Controller design theory is based almost exclusively on the assumption that a linear model of a system will closely approximate the non-linear behavior observed in reality. Because the initial action a control engineer takes is to linearize the system about a chosen operating point, it is useful to explore the consequences of such action through comparison with a non-linear model. The systematic design approach described in Chapter V was applied to surfaces created using a linear turbine model for comparison with those generated by the non-linear model. The linearized turbine described in Chapter IV was inserted into the Simulink ${ }^{\circledR}$ model, and the gains were varied as described in Chapter V. Surfaces depicting the actuator duty cycle and RMS speed error were created.

Figures 15-17 contain the surfaces generated using the linear model of the turbine $\left(\omega_{\mathrm{T}} \mathrm{OP}=11 \mathrm{rad} / \mathrm{s} ; \mathrm{w}_{\mathrm{OP}}=7.5 \mathrm{~m} / \mathrm{s} ;\right.$ and $\left.\beta_{\mathrm{OP}}=9^{\circ}\right)$. Again, the average performance over five wind input cases was computed for both RMS speed error and actuator duty cycle over the entire range of gain values. These surfaces portray similar characteristics to those generated using the non-linear model of the turbine. The actuator duty cycle surface for $\mathrm{k}_{\mathrm{l}}=1$ drops sharply toward zero for low values of $k_{\mathrm{P}}$ and $\mathrm{k}_{\mathrm{D}}$, while the "bucket" is evident on the surface corresponding to $\mathrm{k}_{\mathrm{l}}=5$. The RMS speed error surfaces all show a flat plane that slopes up sharply for low values of $\mathrm{k}_{\mathrm{P}}$ as was seen on the non-linear model surfaces. This linear model produces an additional contour representing 

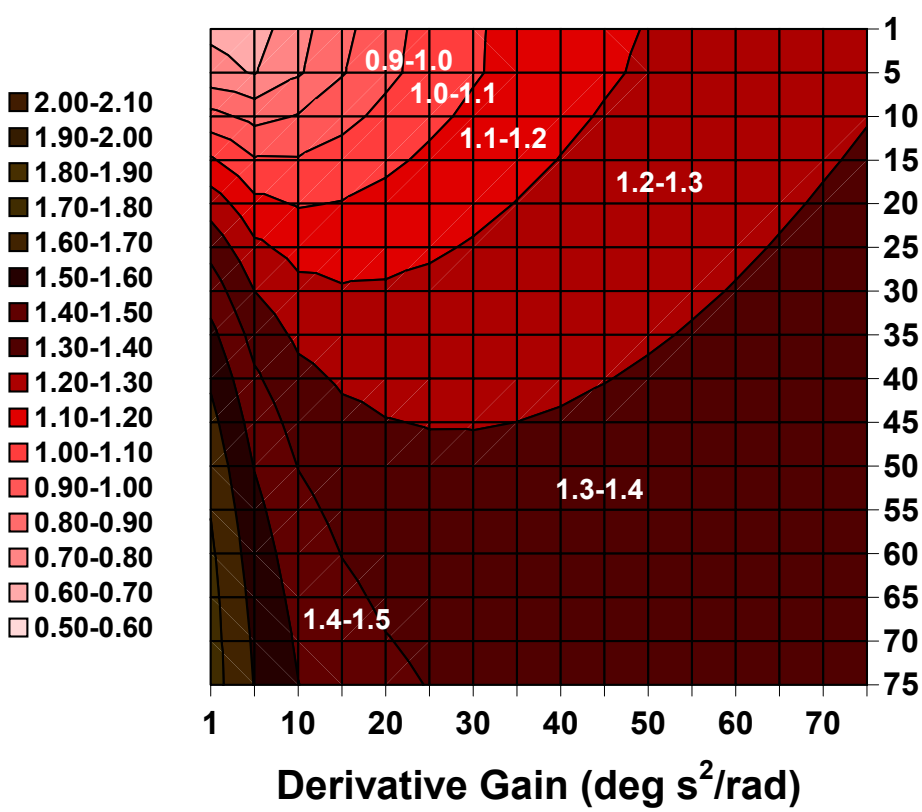

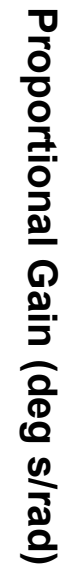

(a) Actuator duty cycle (deg/s)
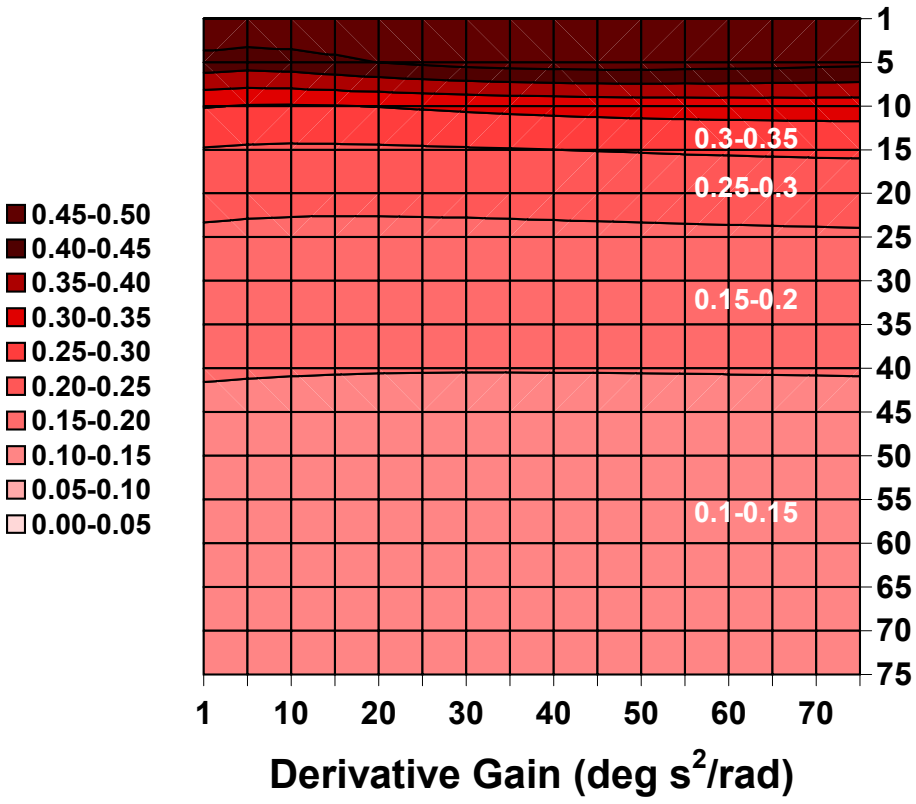

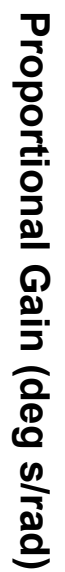

(b) RMS Speed Error ( $\mathrm{rad} / \mathrm{s})$

Figure 15: Performance metric surfaces generated using the first linear $\operatorname{model}\left(\omega_{\mathrm{T}} \mathrm{OP}=11 \mathrm{rad} / \mathrm{s} ; \omega_{O P}=7.5 \mathrm{~m} / \mathrm{s} ;\right.$ and $\left.\beta_{O P}=9^{\circ}\right)$ for $k_{\mathrm{I}}=1 \mathrm{deg} / \mathrm{rad}$. 0.0-0.05 RMS speed error for integral gains of 5 and higher. This contour does not appear in Figures 9 and 10 which were generated by the non-linear model. The gentle slope toward the high $k_{P}$ values of the surfaces appears slightly 


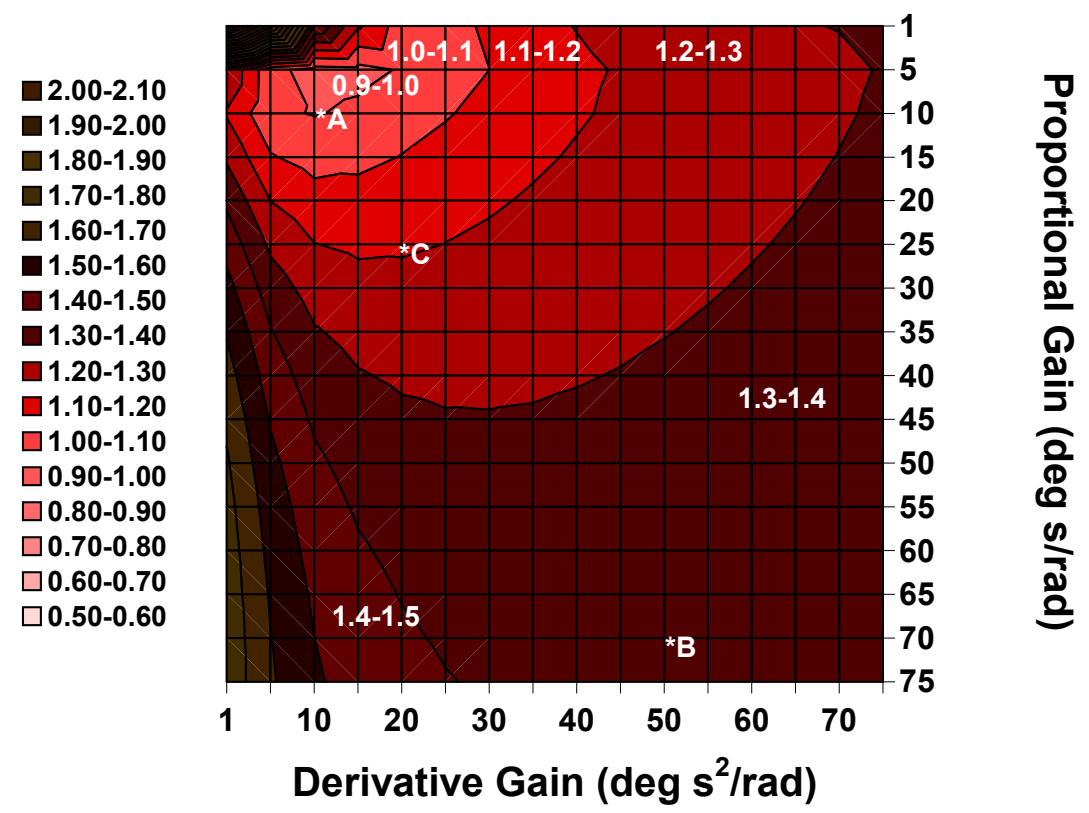

(a) Actuator duty cycle (deg/s)

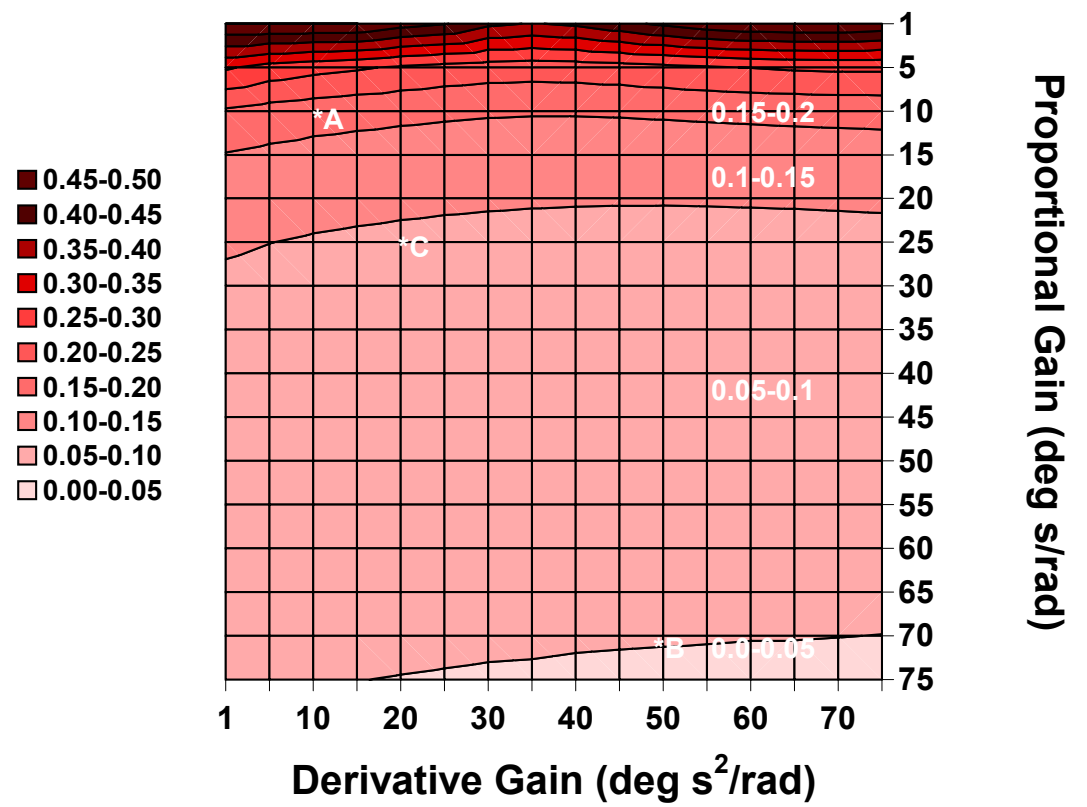

(b) RMS speed error $(\mathrm{rad} / \mathrm{s})$

Figure 16: Performance metric surfaces generated using the first linear $\operatorname{model}\left(\omega_{\mathrm{T}} \mathrm{OP}=11 \mathrm{rad} / \mathrm{s} ; \mathrm{w}_{\mathrm{OP}}=7.5 \mathrm{~m} / \mathrm{s} ;\right.$ and $\left.\beta_{\mathrm{OP}}=9^{\circ}\right)$ for $\mathrm{k}_{\mathrm{I}}=5 \mathrm{deg} / \mathrm{rad}$. sharper than that of the surfaces generated using the non-linear model.

A similar trade-off study was performed to select the region of optimal operation. For reasons described in Chapter V, the integral gain was determined 

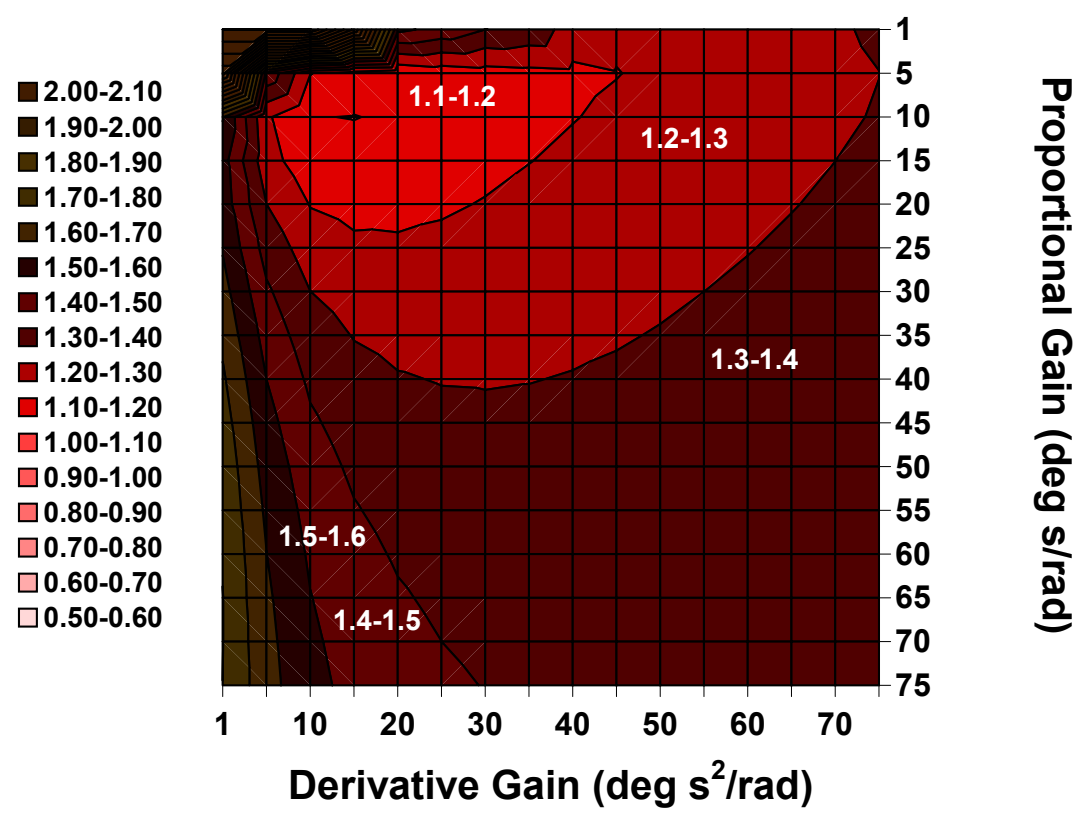

(a) Actuator duty cycle (deg/s)
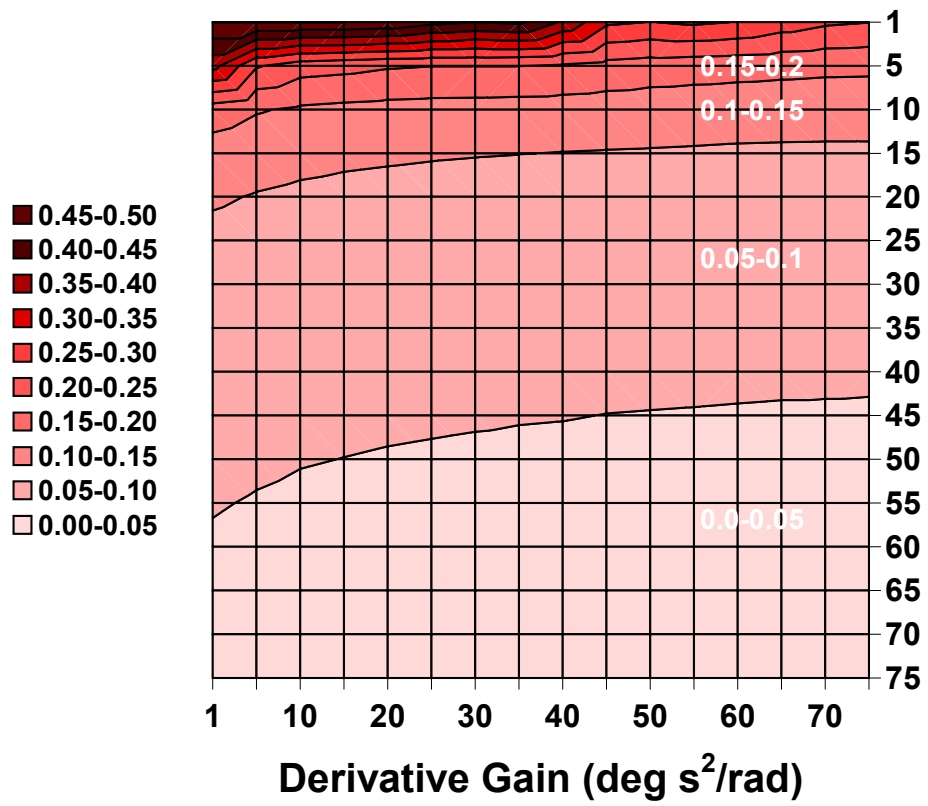

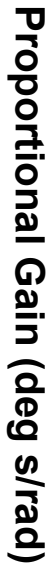

(b) RMS speed error ( $\mathrm{rad} / \mathrm{s})$

Figure 17: Performance metric surfaces generated using the first linear $\operatorname{model}\left(\omega_{\mathrm{T}} \mathrm{OP}=11 \mathrm{rad} / \mathrm{s} ; \omega_{O P}=7.5 \mathrm{~m} / \mathrm{s} ;\right.$ and $\left.\beta_{\mathrm{OP}}=9^{\circ}\right)$ for $k_{\mathrm{I}}=10 \mathrm{deg} / \mathrm{rad}$. 
to be 5 for the best accommodation of the two metrics. Again, Point A represents operation in the lowest actuator duty cycle region which corresponds to somewhat higher RMS speed error. Point B was selected to represent operation in the lowest RMS speed error contour with a slightly elevated actuator duty cycle. Lastly, Point $\mathrm{C}$ corresponds to the best trade-off between the two: the intersection between one of the lowest RMS speed error contours and the corresponding minimum region of actuator duty cycle.

The magnitudes of the metrics as well as the gain values are identical between the two models for Point A as shown in Table 2. The additional contour that appears in the RMS speed error surface generated by the linear model, Figure 16b, would alter the selection of Point B slightly. A proportional gain greater than 70 would place the point in the lowest RMS speed error contour. Also, the compromise point, C, must be based on the second lowest RMS speed error contour due to the additional contour that results from use of the linear model. The intersection of the second lowest RMS speed error contour and the corresponding actuator duty cycle contour are in a slightly different location than the corresponding point on the non-linear model generated surface. This leads to slightly different gain values in this region of optimal operation.

The design approach was repeated using the linear model in order to assess the dependence on operating point selection. Using the $c_{P}$ surface shown in Figure 6, the first operating point was selected a distance away from the peak and on the sloped side that prevents blade stall. Simply increasing the pitch angle from $9^{\circ}$ to $12^{\circ}$ and maintaining the tip-speed-ratio of 7 places the point in the 
negative power coefficient region. By shifting the linearization point in both pitch angle and tip-speed-ratio, the tangent area around the point is maintained near the top of the curve as shown in Figure 18. This tip-speed-ratio of 5 corresponds to a wind speed of $10 \mathrm{~m} / \mathrm{s}$ when maintaining the rotor speed at 11

Table 2: Comparison of performance metrics for non-linear and linear model-based controller designs.

\begin{tabular}{|c|c|c|}
\hline Non-Linear Model Design & $\begin{array}{l}\text { Actuator Duty } \\
\text { Cycle (deg/s) }\end{array}$ & $\begin{array}{l}\text { RMS Speed } \\
\text { Error }(\mathrm{rad} / \mathrm{s})\end{array}$ \\
\hline $\begin{array}{c}\text { Point A } \\
\mathrm{k}_{\mathrm{P}}=10, \mathrm{k}_{\mathrm{l}}=5, \mathrm{k}_{\mathrm{D}}=10\end{array}$ & $0.9-1.0$ & $0.10-0.15$ \\
\hline $\begin{array}{c}\text { Point B } \\
\mathrm{k}_{\mathrm{P}}=70, \mathrm{k}_{\mathrm{I}}=5, \mathrm{k}_{\mathrm{D}}=50\end{array}$ & $1.2-1.3$ & $0.05-0.10$ \\
\hline $\begin{array}{c}\text { Point C } \\
k_{P}=30, k_{I}=5, k_{D}=25\end{array}$ & $1.1-1.2$ & $0.05-0.10$ \\
\hline \multicolumn{3}{|l|}{$\begin{array}{l}\text { Linear I: } \omega_{\mathrm{T} O P}=11 \mathrm{rad} / \mathrm{s} ; \\
\mathrm{w}_{\mathrm{OP}}=7.5 \mathrm{~m} / \mathrm{s} ; \text { and } \beta_{\mathrm{OP}}=9^{\circ}\end{array}$} \\
\hline $\begin{array}{c}\text { Point A } \\
\mathrm{k}_{\mathrm{P}}=10, \mathrm{k}_{\mathrm{l}}=5, \mathrm{k}_{\mathrm{D}}=10\end{array}$ & $0.9-1.0$ & $0.15-0.20$ \\
\hline $\begin{array}{c}\text { Point B } \\
\mathrm{k}_{\mathrm{P}}=75, \mathrm{k}_{\mathrm{I}}=5, \mathrm{k}_{\mathrm{D}}=50\end{array}$ & $1.3-1.4$ & $0.00-0.05$ \\
\hline $\begin{array}{c}\text { Point C } \\
k_{P}=25, k_{I}=5, k_{D}=20\end{array}$ & $1.1-1.2$ & $0.05-0.10$ \\
\hline \multicolumn{3}{|l|}{$\begin{array}{l}\text { Linear II: } \omega_{\mathrm{T}} \mathrm{OP}=11 \mathrm{rad} / \mathrm{s} \\
\mathrm{w}_{\mathrm{OP}}=10 \mathrm{~m} / \mathrm{s} ; \text { and } \beta_{\mathrm{OP}}=12^{\circ}\end{array}$} \\
\hline $\begin{array}{c}\text { Point } \mathrm{A} \\
\mathrm{k}_{\mathrm{P}}=10, \mathrm{k}_{\mathrm{I}}=5, \mathrm{k}_{\mathrm{D}}=10\end{array}$ & $0.9-1.0$ & $0.15-0.20$ \\
\hline $\begin{array}{c}\text { Point B } \\
\mathrm{k}_{\mathrm{P}}=75, \mathrm{k}_{\mathrm{l}}=5, \mathrm{k}_{\mathrm{D}}=50\end{array}$ & $1.2-1.3$ & $0.00-0.05$ \\
\hline $\begin{array}{c}\text { Point } C \\
k_{P}=20, k_{I}=5, k_{D}=15\end{array}$ & $1.0-1.1$ & $0.05-0.10$ \\
\hline
\end{tabular}




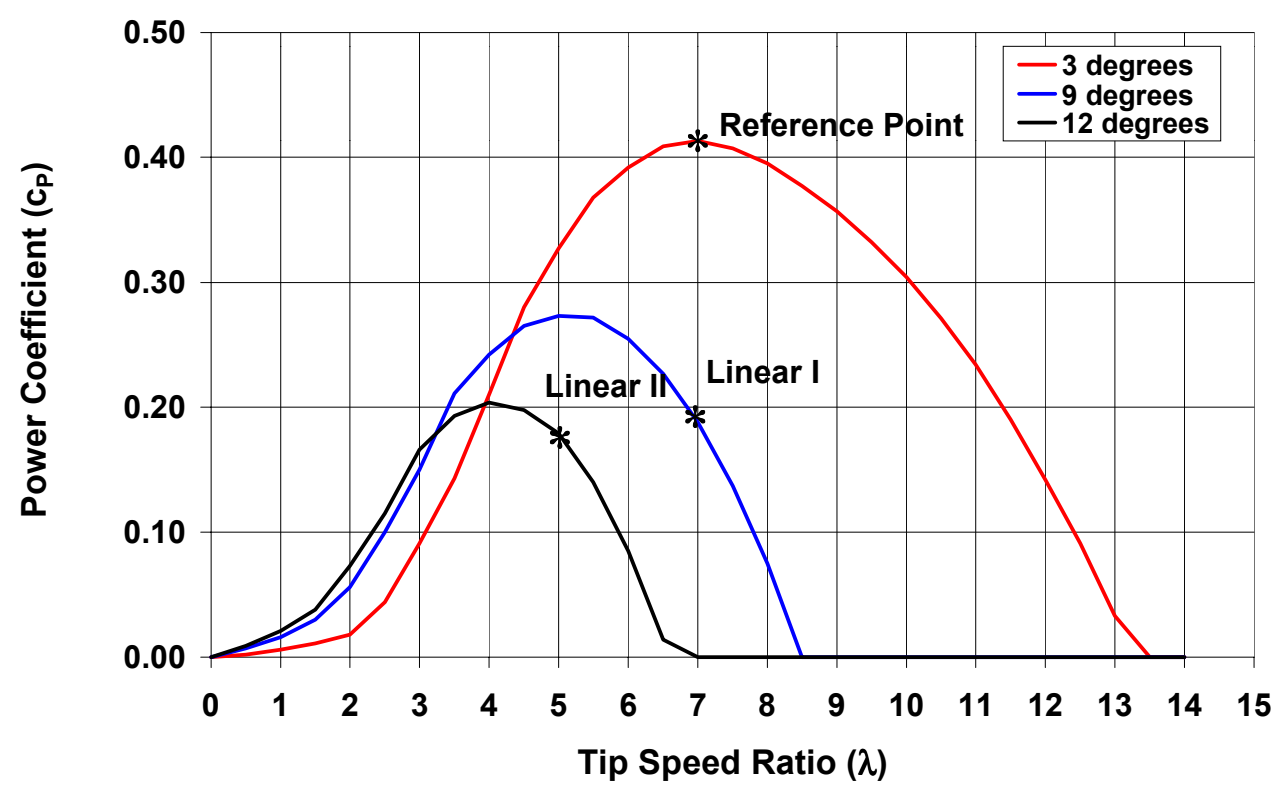

Figure 18: Example of $c_{P} v s . \lambda$ for three pitch angles.

$\mathrm{rad} / \mathrm{s}$. Thus the second linearization point was selected to be as follows: $\omega_{\mathrm{T} \mathrm{OP}}=$ $11 \mathrm{rad} / \mathrm{s} ; \mathrm{w}_{\mathrm{OP}}=10 \mathrm{~m} / \mathrm{s} ;$ and $\beta_{\mathrm{OP}}=12^{\circ}$.

Again, the surfaces were generated over a range of gain values, and a trade-off study was performed to select an optimal operating region. The surfaces shown in Figures 19-21 illustrate similar characteristics to those generated using the non-linear model (Figures 8-10), and Points A, B, and C represent operation in the various regions as described above. Table 2 includes the performance metric magnitudes as well as the selected gain values for the linear model design based on this second operating point.

In general, the surfaces created by all three models are similar. The second linear model $\left(\omega_{\mathrm{T} O P}=11 \mathrm{rad} / \mathrm{s} ; \mathrm{w}_{\mathrm{OP}}=10 \mathrm{~m} / \mathrm{s}\right.$; and $\left.\beta_{\mathrm{OP}}=12^{\circ}\right)$ surfaces more closely represent those generated by the non-linear model. The actuator duty cycle increases toward the perimeters of the surface most rapidly when the 


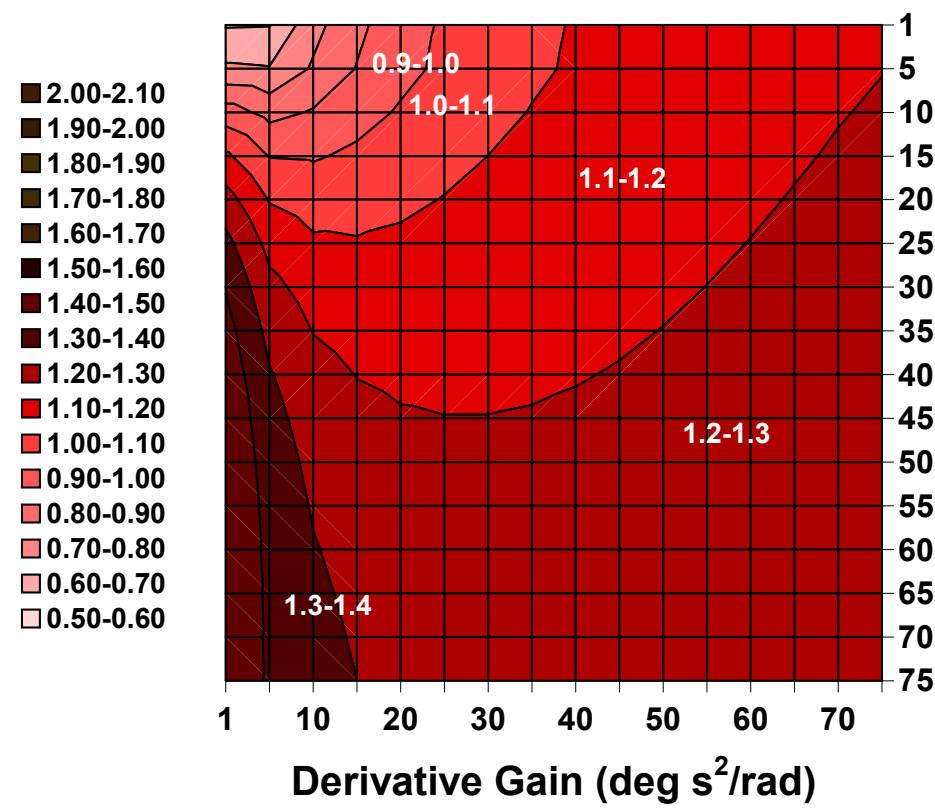

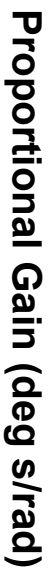

(a) Actuator duty cycle (deg/s)
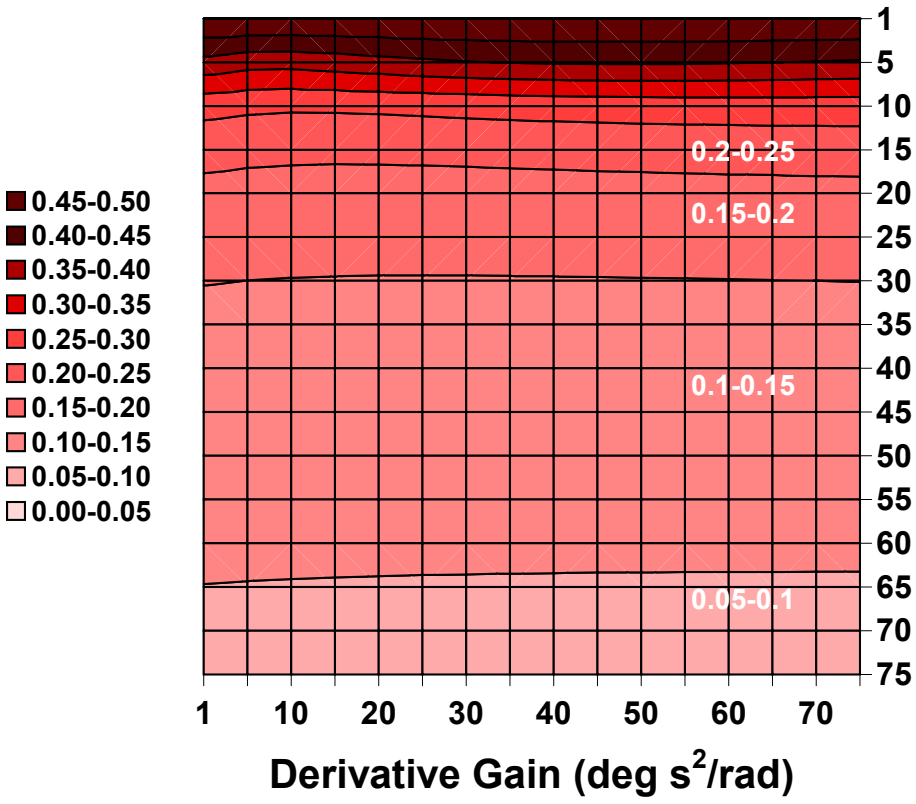

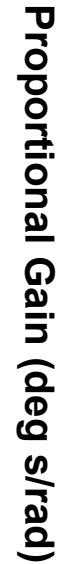

(b) RMS speed error $(\mathrm{rad} / \mathrm{s})$

Figure 19: Performance metric surfaces generated using the second linear $\operatorname{model}\left(\omega_{\mathrm{T}} \mathrm{OP}=11 \mathrm{rad} / \mathrm{s} ; \omega_{\mathrm{OP}}=10 \mathrm{~m} / \mathrm{s} ;\right.$ and $\left.\beta_{\mathrm{OP}}=12^{\circ}\right)$ for $\mathrm{k}_{\mathrm{I}}=1 \mathrm{deg} / \mathrm{rad}$. first linear model $\left(\omega_{\mathrm{T} \text { OP }}=11 \mathrm{rad} / \mathrm{s} ; \mathrm{w}_{\mathrm{OP}}=7.5 \mathrm{~m} / \mathrm{s}\right.$; and $\left.\beta_{\mathrm{OP}}=9^{\circ}\right)$ is used, and the corresponding non-linear model based surface is the flattest. Comparison of the RMS speed error surfaces for $\mathrm{k}_{\mathrm{I}}=5 \mathrm{deg} / \mathrm{rad}$ (Figures $9 \mathrm{~b}, 16 \mathrm{~b}$, and 20b) indicates 


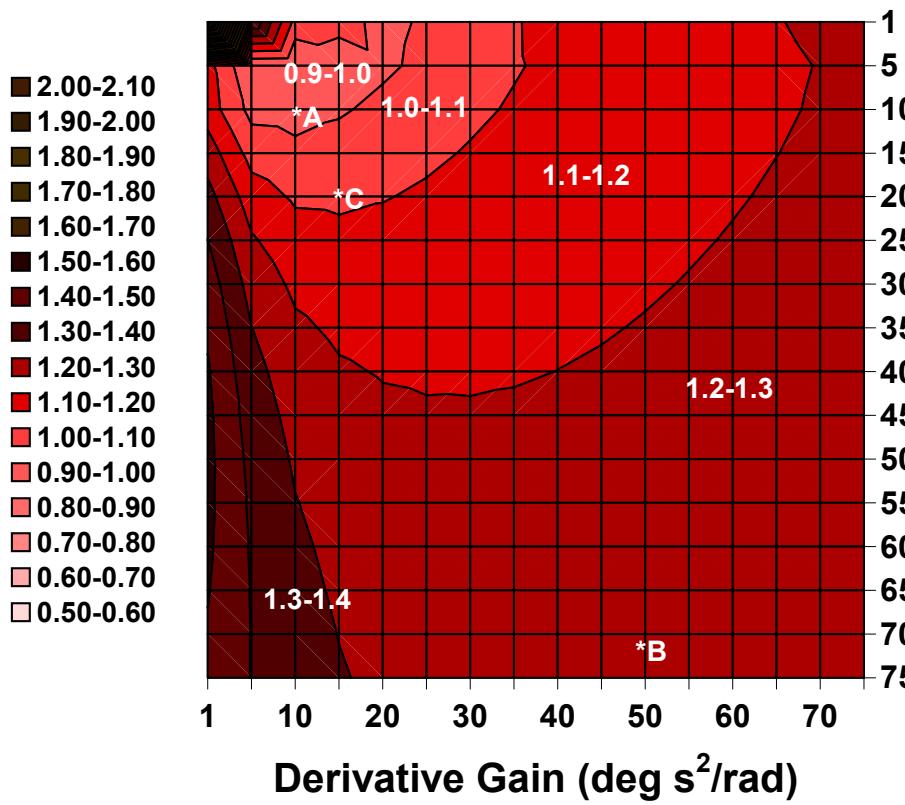

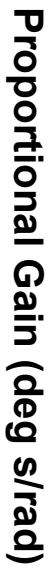

(a) Actuator duty cycle (deg/s)
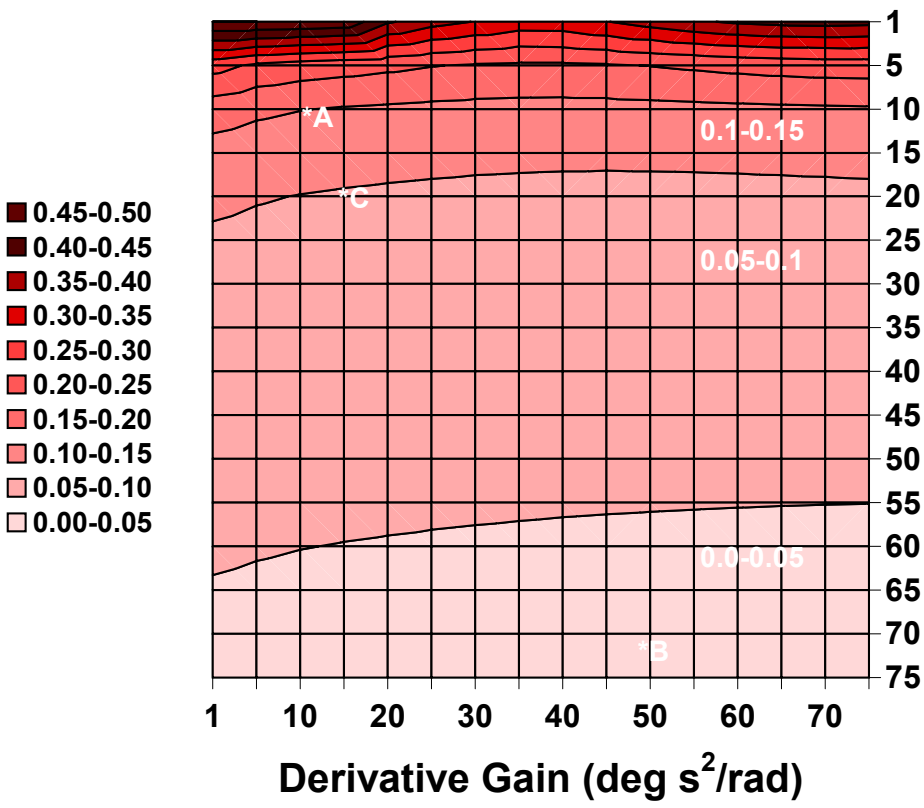

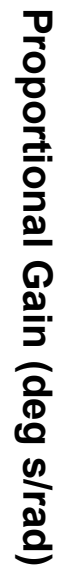

(b) RMS speed error ( $\mathrm{rad} / \mathrm{s})$

Figure 20: Performance metric surfaces generated using the second linear $\operatorname{model}\left(\omega_{\mathrm{T}} \mathrm{OP}=11 \mathrm{rad} / \mathrm{s} ; \omega_{O P}=10 \mathrm{~m} / \mathrm{s} ;\right.$ and $\left.\beta_{\mathrm{OP}}=12^{\circ}\right)$ for $\mathrm{k}_{\mathrm{I}}=5$.

that the non-linear model generated surface is the flattest, and the second linear model surfaces are the steepest. Thus, in the area surrounding Point $\mathrm{C}$, the 

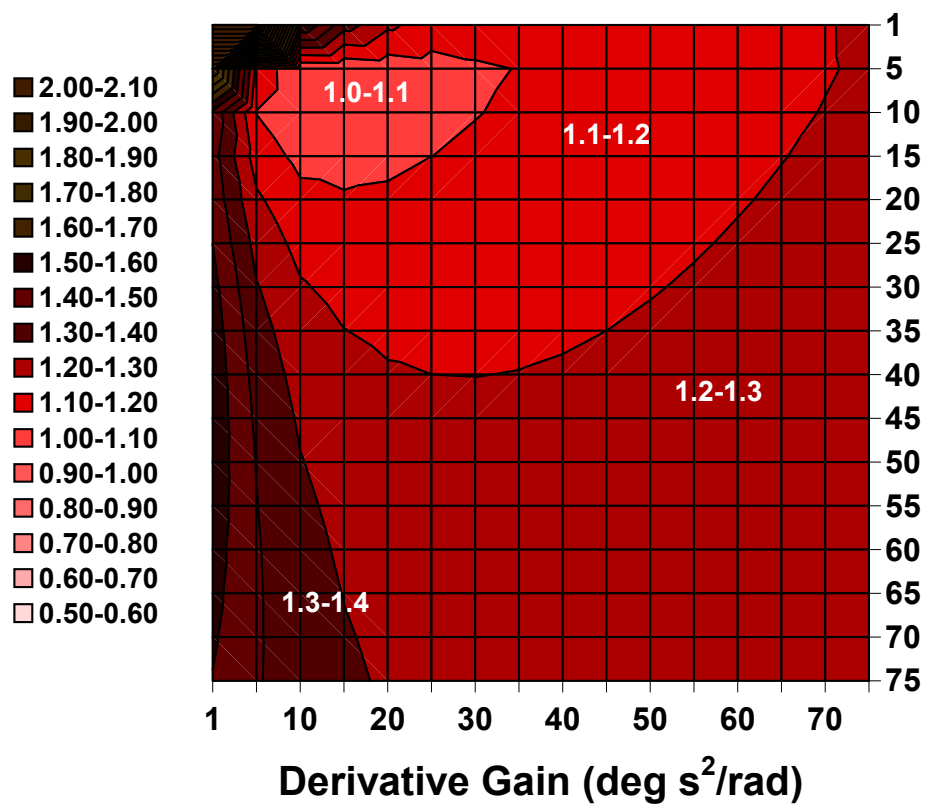

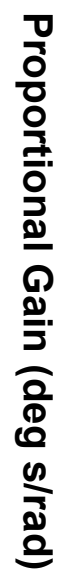

(a) Actuator duty cycle (deg/s)
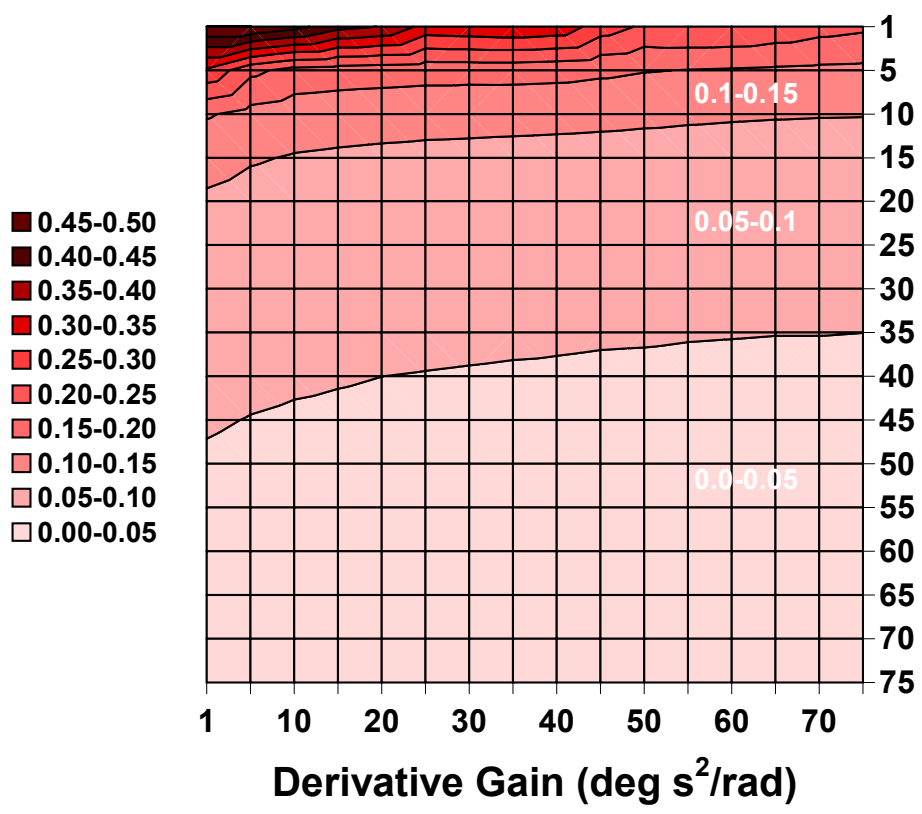

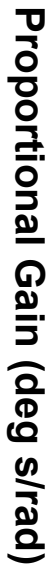

(b) RMS speed error $(\mathrm{rad} / \mathrm{s})$

Figure 21: Performance metric surfaces generated using the second linear $\operatorname{model}\left(\omega_{\mathrm{T}} \mathrm{OP}=11 \mathrm{rad} / \mathrm{s} ; \omega_{O P}=10 \mathrm{~m} / \mathrm{s} ;\right.$ and $\left.\beta_{O P}=12^{\circ}\right)$ for $k_{I}=10 \mathrm{deg} / \mathrm{rad}$. models all behave similarly. The greatest differences appear toward the edges of the surfaces. 
Comparison of the regions of optimal operation selected using the nonlinear model, the first linear model, $\omega_{\mathrm{T}} \mathrm{OP}=11 \mathrm{rad} / \mathrm{s} ; \mathrm{w}_{\mathrm{OP}}=7.5 \mathrm{~m} / \mathrm{s} ;$ and $\beta_{\mathrm{OP}}=9^{\circ}$, and the second linear model, $\omega_{\mathrm{T}} \mathrm{OP}=11 \mathrm{rad} / \mathrm{s} ; \mathrm{w}_{\mathrm{OP}}=10 \mathrm{~m} / \mathrm{s}$; and $\beta_{\mathrm{OP}}=12$ is shown in Figure 22. The optimal region selected using the second linear model deviates the most from that obtained using the non-linear model. Assuming that the non-linear model provides the best representation of actual turbine operation, time series traces were created using the optimal gain combination obtained from both linear models. Figure 23 illustrates the time series turbine behavior when subjected to the highest wind speed case. Included in Figure 23 are the time traces produced by the non-linear plant simulation when the gains are chosen using the non-linear model design approach as well as the two linear models.

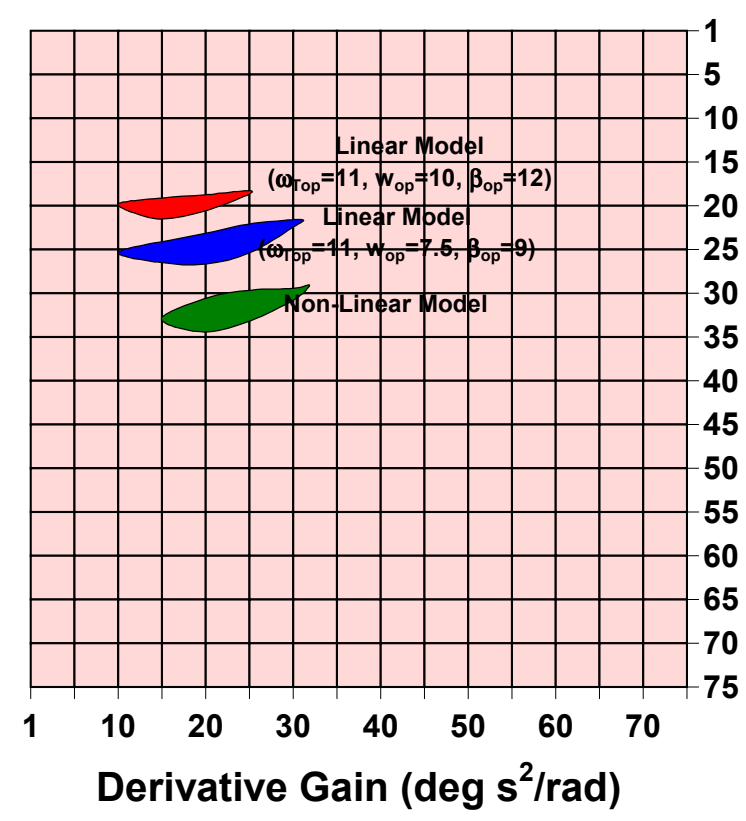

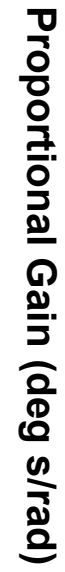

Figure 22: Regions of optimal operation. 

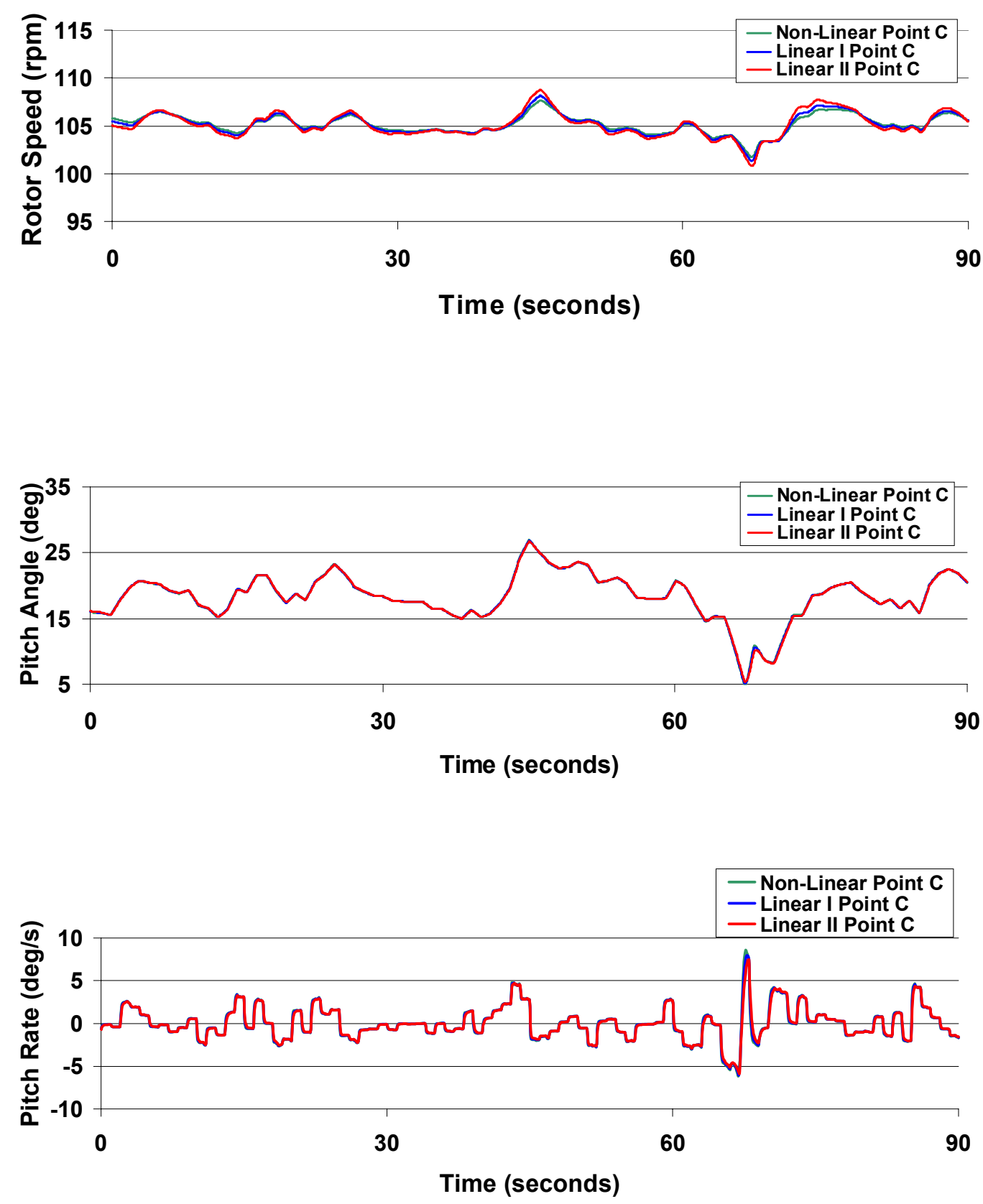

Figure 23: Time series traces of turbine performance under the optimal gains as determined using each of the three models.

Using the gains selected based on the first linear model, the rotor speed nearly duplicates that of the non-linear model optimal gain combination. The pitch rate traces are very similar for all three gain combinations, but the second linear 
model-based optimal gains slightly out-perform those from the first linear model design. Again, the blade pitch angles commanded by the controller are nearly identical. 


\section{CHAPTER VII}

\section{CONCLUSIONS}

This systematic approach to PID-controller design provides a means of visually observing the effect of gain changes on both RMS speed error and actuator duty cycle. While these metrics are in opposition by nature, the surfaces permit selection of gain values that produce favorable results for both of the metrics. The simplicity of the model requires minimal computation time such that hundreds of simulations can be completed within a few hours. The resolution of the contour plots may easily be improved by increasing the number of simulations. This visualization of the effect of gain permits selection of the best possible combination of controller parameters without requiring a lengthy trialand-error process.

A valuable aspect of this design approach is the ability to observe the robust nature of the PID controller in this variable-speed wind turbine application. Generation of the surfaces over such varied gain values illustrates the controller sensitivity. The wide, flat surfaces indicate robust behavior. This is valuable information for comparison with other types of controllers.

The non-linear dynamics simulated with this simple model are easily linearized, but several considerations must be made in order to design a PID controller using a linear model. First, the step response that one would expect is drastically different from that observed with the gain combination determined to produce optimum performance. Also, the optimal region based on the balanced performance of the two metrics shifts with the linearization point selection. The 
surfaces generated by the linear models tend to slope less gradually toward the perimeters. These differing slopes yield different areas on the surface that provide the desired combination of the two performance metrics. Operating point selection for a linear model is critical to obtaining the best possible performance from this highly non-linear system.

Although the surfaces are relatively flat, performance does vary when gain combinations from different areas of the surface are compared. These small variations may be exacerbated by more complicated dynamics and sensor noise when these gains are implemented in the field. Thus it is assumed that the nonlinear model-based design will be superior to the designs that relied upon the linear model. It is hoped that the choice of controller parameters using the simulation will also be satisfactory for the field turbine.

Lastly, this systematic approach still requires judgement on the part of the designer. A mathematical relationship between the two metrics could eliminate this requirement if such can be found. The systematic design methodology could be automated once weighting functions are determined.

Several opportunities for use of control exist within the wind turbine industry. In addition to speed regulation with mitigated actuator motion, control may be used to extend the fatigue life of blades and rotor shafts. Adding control objectives introduces the need for multiple-input-multiple-output controllers. Also the interaction between control objectives increases the complexity. For instance, blade loads could be affected by the blade-pitch control implemented in this study. To incorporate a blade load objective into a controller, the interaction 
between the blade pitch motion that regulates the speed and the induced loads must be accommodated within the controller. Fuzzy logic and neural network controllers, as well as state-estimation based controllers, could be employed to incorporate the interaction between the various control objectives. 


\section{REFERENCES}

Arsudis, D., and Bohnisch, H, 1990, "Self-tuning linear controller for the blade pitch control of a $100 \mathrm{~kW}$ WEC," European Community Wind Energy Conference, H.S. Stephens, Bedford, United Kingdom, Vol. xvi+771, pp. 564568.

Bongers, P., van Engelen, T., Dijkstra, S., Kock, Z.-J., 1989, “Optimal control of a wind turbine in full load-a case study," Proceedings, European Wind Energy Conference and Exhibition, Peter Peregrinus, London, United Kingdom, Vol. $\mathrm{xxx}+1063$, pp. 345-349.

Bossanyi, E.A., 1989, "Practical results with adaptive control of the MS2 wind turbine," European Wind Energy Conference and Exhibition, Peter Peregrinus, London, United Kingdom, Vol. xxx+1063, pp. 331-335.

De la Salle, S.A., Reardon, D., Leithead, W.E., 1990, "Review of wind turbine control," International Journal of Control, vol. 52, no. 6, pp. 1295-1310.

Ekelund, T., 1994, "Speed control of wind turbines in the stall region." Proceedings, IEEE International Conference on Control and Applications, IEEE; New York, NY, USA, Vol. xlii+1952, pp. 227-32.

Leithead, W.E., Anderson, C.G., 1989, "Simulation of wind turbines by simple models," European Wind Energy Conference and Exhibition, Peter Peregrinus, London, United Kingdom, Vol. xxx+1063, pp. 336-340.

Leithead, W.E., de la Salle, S., Reardon, D., 1990, "Wind turbine control objectives and design," European Community Wind Energy Conference, H.S. Stephens, Bedford, United Kingdom, Vol. xvi+771, pp. 510-515.

Leithead, W.E., de la Salle, S., Reardon, D., Grimble, M.J., 1991, "Wind turbine modelling and control," International Conference on Control, IEE, London, United Kingdom, Conference Publication No. 332.

Kendall, L., Balas, M.J., Lee, Y.J., and Fingersh, L.J., 1997, “Application of Proportional-Integral and Disturbance Accommodating Control to Variable-speed Variable Pitch Horizontal Axis Wind Turbines," Wind Engineering (12:1); pp. 21-38.

Stuart, J.G., Wright, A.D., and Butterfield, C. P., 1996, "Considerations for an Integrated Wind Turbine Controls Capability at the National Wind Technology Center: An Aileron Control Case Study for Power Regulation and Load Mitigation," TP-440-21335, National Renewable Energy Laboratory, Golden, CO, USA. 
Tangler, J.L., 1987, “User's Guide. A Horizontal Axis Wind Turbine Performance Prediction Code for Personal Computers," Solar Energy Research Institute, Golden, CO, USA. 
APPENDIX A

STABILITY ANALYSIS IN LAPLACE DOMAIN 


\section{Laplace Transformation of System Components}

\section{Linear Turbine Plant (Eq. 2)}

$$
J_{T} \dot{\omega}_{T}=\alpha \Delta w(t)+\gamma \Delta \omega_{T}+\delta \Delta \beta
$$

After Laplace Transformation the equation becomes:

$$
J_{T} s \Delta \Omega_{T}=\alpha \Delta W(s)+\gamma \Delta \Omega_{T}+\delta \Delta U(s)
$$

Let $\lambda=\frac{\gamma}{J_{T}}$.

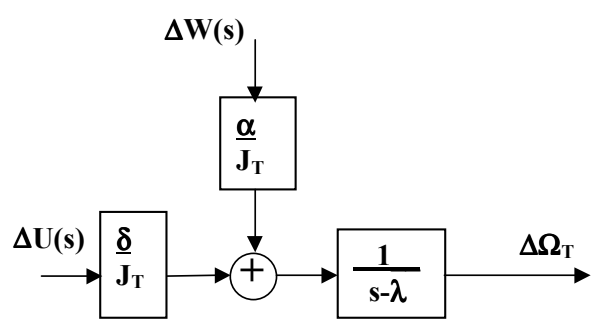

Figure A-1: Block diagram of the linear turbine plant model.

The rotor speed ouput from the plant may be represented as:

$$
\Delta \Omega_{T}=\left[\frac{\alpha}{J_{T}} \Delta W(s)+\frac{\delta}{J_{T}} \Delta U(s)\right] \frac{1}{s-\lambda}
$$

\section{Actuator}

The actuator may be represented by the following diagram after the Laplace transformation where $\mathrm{U}_{\mathrm{a}}(\mathrm{s})$ is the Laplace transform of the pitch angle input and $\mathrm{U}_{\mathrm{o}}(\mathrm{s})$ is the Laplace transform of the pitch angle output. 


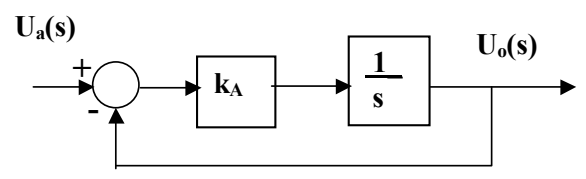

\section{Figure A-2: Block diagram of the actuator.}

The transfer function between the input pitch angle and the commanded pitch angle is:

$$
\frac{U_{o}(s)}{U_{a}(s)}=\frac{\frac{k_{A}}{s}}{1+\frac{k_{A}}{s}}=\frac{k_{A}}{s+k_{A}}
$$

\section{Controller}

The PID controller is illustrated in Figure A-3 where $\Delta \Omega_{\mathrm{T}}(\mathrm{s})$ represents the input rotor speed, and $\Delta \mathrm{U}_{\mathrm{c}}(\mathrm{s})$ represents the output pitch angle change.

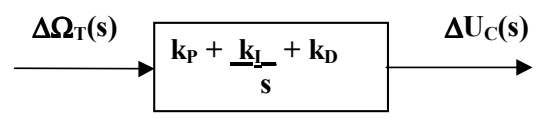

\section{Figure A-3: Block diagram of controller.}

The transfer function between the input rotor speed and the output pitch angle change is as follows:

$$
C(s)=\frac{\Delta U_{c}}{\Delta \Omega_{T}}=\frac{s^{2} k_{D}+s k_{P}+k_{I}}{s} .
$$




\section{System Transfer Function}

Substituting the actuator transfer function and the controller transfer function into the system diagram shown in Figure A-4, simplifies the determination of the output rotor speed equation.

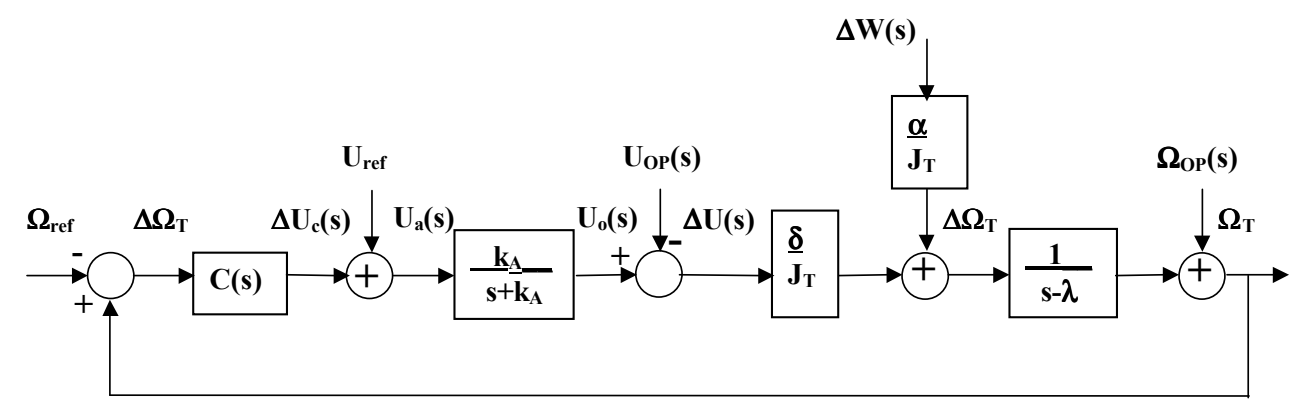

Figure A-4: System block diagram in Laplace Domain.

The output rotor speed may be represented by:

$$
\begin{aligned}
& \Omega_{T}=\frac{\Delta W(s)\left(\frac{\alpha}{J_{T}}\right)\left(\frac{1}{s-\lambda}\right)}{1-C(s)\left(\frac{k_{A}}{s+k_{A}}\right)\left(\frac{\delta}{J_{T}}\right)\left(\frac{1}{s-\lambda}\right)}+\frac{U_{r e f}\left(\frac{k_{A}}{s+k_{A}}\right)\left(\frac{\delta}{J_{T}}\right)\left(\frac{1}{s-\lambda}\right)}{1-C(s)\left(\frac{k_{A}}{s+k_{A}}\right)\left(\frac{\delta}{J_{T}}\right)\left(\frac{1}{s-\lambda}\right)} \\
& -\frac{U_{O P}(s)\left(\frac{\delta}{J_{T}}\right)\left(\frac{1}{s-\lambda}\right)}{1-C(s)\left(\frac{k_{A}}{s+k_{A}}\right)\left(\frac{\delta}{J_{T}}\right)\left(\frac{1}{s-\lambda}\right)}+\frac{\Omega_{O P}(s)}{1-C(s)\left(\frac{k_{A}}{s+k_{A}}\right)\left(\frac{\delta}{J_{T}}\right)\left(\frac{1}{s-\lambda}\right)} \\
& -\frac{\Omega_{r e f} C(s)\left(\frac{k_{A}}{s+k_{A}}\right)\left(\frac{\delta}{J_{T}}\right)\left(\frac{1}{s-\lambda}\right)}{1-C(s)\left(\frac{k_{A}}{s+k_{A}}\right)\left(\frac{\delta}{J_{T}}\right)\left(\frac{1}{s-\lambda}\right)}
\end{aligned}
$$

Simplifying the denominator and substituting for $\mathrm{C}(\mathrm{s})$, 


$$
\begin{aligned}
& 1-\left(k_{P}+\frac{k_{I}}{s}+s k_{D}\right)\left(\frac{k_{A}}{s+k_{A}}\right)\left(\frac{\delta}{J_{T}}\right)\left(\frac{1}{s-\lambda}\right) \\
& =\frac{s\left(s+k_{A}\right)(s-\lambda)-\left(s k_{P}+k_{I}+s^{2} k_{D}\right)\left(k_{A} \frac{\delta}{J_{T}}\right)}{s\left(s+k_{A}\right)(s-\lambda)}
\end{aligned}
$$

\section{Stability Analysis}

Applying the Routh array to the denominator of the system equation, the system stability may be ascertained.

Table A-1: Routh Array.

\begin{tabular}{|l|c|c|}
\hline $\mathrm{s}^{3}$ & 1 & $-\lambda k_{A}-k_{P} k_{A} \frac{\delta}{J_{T}}$ \\
\hline $\mathrm{s}^{2}$ & $-k_{A}-\lambda-k_{D} k_{A} \frac{\delta}{J_{T}}$ & $-k_{I} k_{A} \frac{\delta}{J_{T}}$ \\
\hline $\mathrm{s}^{1}$ & $\left(k_{A}-\lambda-k_{D} k_{A} \frac{\delta}{J_{T}}\right)\left(-\lambda k_{A}-k_{P} k_{A} \frac{\delta}{J_{T}}\right)+k_{I} k_{A} \frac{\delta}{J_{T}}$ & 0 \\
\hline $\mathrm{s}^{0}$ & $k_{A}-\lambda-k_{D} k_{A} \frac{\delta}{J_{T}}$ & \\
\hline
\end{tabular}

For stability, the coefficients of the terms in the denominator of the transfer function must be positive, and each term in the first column of Table 1 must also be positive. At the operating point, $\omega_{\mathrm{T}} \mathrm{OP}=11 \mathrm{rad} / \mathrm{s} ; \mathrm{w}_{\mathrm{OP}}=7.5 \mathrm{~m} / \mathrm{s}$; and $\beta_{\mathrm{OP}}=9^{\circ}$, $\gamma=-150, \delta=-150, \mathrm{~J}_{\mathrm{T}}=1270$, and $\mathrm{k}_{\mathrm{A}}=2$. Note: $\lambda<0$ and $\delta<0$.

Thus, 
- $k_{A}-\lambda-k_{D} k_{A} \frac{\delta}{J_{T}}>0 \Rightarrow k_{A}+|\lambda|-k_{D} k_{A} \frac{-|\delta|}{J_{T}}>0 \Rightarrow k_{D}>-8$

$-\lambda k_{A}-k_{P} k_{A} \frac{\delta}{J_{T}}>0 \Rightarrow|\lambda| k_{A}-k_{P} k_{A} \frac{-|\delta|}{J_{T}}>0 \Rightarrow k_{P}>-1$

$-k_{I} k_{A} \frac{\delta}{J_{T}}>0 \Rightarrow-k_{I} k_{A} \frac{-|\delta|}{J_{T}}>0 \Rightarrow k_{I}>0$

$\left(k_{A}-\lambda-k_{D} k_{A} \frac{\delta}{J_{T}}\right)\left(-\lambda k_{A}-k_{P} k_{A} \frac{\delta}{J_{T}}\right)>-k_{I} k_{A} \frac{\delta}{J_{T}}$

- $\Rightarrow\left(k_{A}-|\lambda|-k_{D} k_{A} \frac{|\delta|}{J_{T}}\right)\left(-|\lambda| k_{A}-k_{P} k_{A} \frac{|\delta|}{J_{T}}\right)>-k_{I} k_{A} \frac{|\delta|}{J_{T}}$

$\Rightarrow\left(8+k_{D}\right)\left(1+k_{P}\right)>k_{I}$ 
APPENDIX B

APPLICATION OF THE SYSTEMATIC METHODOLOGY

USING THE NON-LINEAR MODEL 
Table B-1: RMS speed error obtained using the non-linear model and medwind 2 as wind input file.

\begin{tabular}{|c|c|c|c|c|c|c|c|c|c|c|c|c|c|c|c|c|}
\hline \multirow{3}{*}{$\begin{array}{l}\text { Proportional } \\
\text { Gain }\end{array}$} & \multicolumn{16}{|c|}{ Derivative Gain } \\
\hline & & & & & & & & & & & & & & & & \\
\hline & 1 & 5 & 10 & 15 & 20 & 25 & 30 & 35 & 40 & 45 & 50 & 55 & 60 & 65 & 70 & 75 \\
\hline Integral Gain=1 & 0.75 & 0.81 & 0.96 & 1.01 & 1.08 & 1.22 & 1.34 & 1.38 & 51.37 & 1.32 & 1.25 & 1.18 & 31.11 & 1.05 & 0.99 & 0.94 \\
\hline & 0.47 & 0.45 & 0.46 & 0.48 & 0.50 & 0.52 & 0.55 & 0.56 & 0.57 & 0.58 & 0.58 & 0.57 & 0.56 & 0.55 & 0.54 & 0.52 \\
\hline 10 & 0.32 & 0.31 & 0.30 & 0.30 & 0.31 & 0.31 & 0.32 & 0.33 & 0.33 & 0.33 & 0.34 & 0.34 & 0.34 & 0.34 & 0.34 & 0.34 \\
\hline 15 & 0.25 & 0.25 & 0.24 & 0.24 & 0.23 & 0.24 & 0.24 & 0.24 & 0.24 & 0.24 & 0.25 & 0.25 & 50.25 & 0.25 & 0.25 & 0.25 \\
\hline 20 & 0.21 & 0.21 & 0.20 & 0.20 & 0.20 & 0.20 & 0.20 & 0.20 & 0.20 & 0.20 & 0.20 & 0.20 & 0.20 & 0.20 & 0.20 & 0.21 \\
\hline 25 & 0.19 & 0.18 & 0.18 & 0.18 & 0.18 & 0.17 & 0.17 & 0.17 & 0.17 & 0.17 & 0.17 & 0.18 & 30.18 & 0.18 & 0.18 & 0.18 \\
\hline 30 & 0.17 & 0.17 & 0.17 & & & 0.16 & 0.16 & 0.16 & 0.16 & 0.16 & 16 & 0.16 & 0.16 & 0.16 & 0.16 & 0.16 \\
\hline 35 & 0.16 & 0.16 & 0.15 & & 0.15 & 0.15 & 0.15 & 0.15 & 0.15 & 0.15 & & 0.15 & 50.15 & 0.15 & 0 & 0.15 \\
\hline 40 & 0.15 & 0.15 & 0.15 & 0.1 & 0.14 & 0.14 & 0.14 & 0.14 & 0.14 & 0.14 & 0.14 & 0.14 & 0.14 & 0.14 & 0.14 & 0.14 \\
\hline 45 & 0.14 & 0.14 & 0.14 & 0.14 & 0.14 & 0.13 & 0.13 & 0.13 & 0.13 & 0.13 & 0.13 & 0.13 & 0.13 & 0.13 & 0.13 & 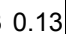 \\
\hline 50 & 0.13 & 0.13 & 0.13 & & 0.13 & 0.13 & 0.13 & 0.13 & 0.13 & 30.13 & & 0.13 & 30.13 & 0.12 & 0.12 & 0.12 \\
\hline 55 & 0.13 & 0.13 & 0.13 & 0.13 & 0.12 & 0.12 & 0.12 & 0.12 & 0.12 & 0.12 & 0.12 & 0.12 & 0.12 & 0.12 & 0.12 & 0.12 \\
\hline 60 & 0.12 & 0.12 & 0.12 & 0.12 & 0.12 & 0.12 & 0.12 & 0.12 & 0.12 & 0.12 & & 0.12 & 0.12 & 0.12 & 0.12 & 0.12 \\
\hline 65 & 0.12 & 0.12 & 0.12 & 0.12 & 0.12 & 0.12 & 0.12 & 0.12 & 0.11 & 0.11 & & 0.11 & 0.11 & 0.11 & 0.11 & 0.11 \\
\hline 70 & 0.12 & 0.12 & 0.12 & & 0.11 & 0.11 & 0.11 & 0.11 & 0.11 & 0.11 & & 0.11 & & 0.11 & 0.11 & 0.11 \\
\hline & 0.11 & 0.11 & 0.11 & 0.11 & 0.11 & 0.11 & 0.11 & 0.11 & 0.11 & 0.11 & 0 & 0.11 & 10 & 0.11 & 0.11 & 0.11 \\
\hline egral Gain $=5 \quad 1$ & 2.81 & 0.95 & 0.81 & 0.63 & 30.42 & 0.33 & 0.39 & 0.45 & 0.51 & $\Gamma 0.55$ & 50.58 & 50.59 & 90.59 & 0.57 & 0.53 & 0.49 \\
\hline & 0.48 & 0.44 & 0.39 & 0.32 & 0.27 & 0.24 & 0.24 & 0.25 & 0.26 & 0.28 & 0.29 & 0.30 & 0.30 & 0.30 & 0.29 & 0.29 \\
\hline 10 & 0.30 & 0.28 & 0.26 & 0. & 0.21 & 0.19 & 0.19 & 0.19 & 0.19 & 0.19 & 0.19 & 0.20 & 0.20 & 0.20 & 0 & 0.20 \\
\hline 15 & 0.23 & 0.22 & 0.21 & 0. & 0.18 & 0.17 & 0.17 & 0.16 & 0.16 & 0.16 & 0.16 & 0.16 & 0.17 & 0.17 & 0.17 & 0.17 \\
\hline 20 & 0.20 & 0.19 & 0.18 & 0. & 0.17 & 0.16 & 0.15 & 0.15 & 0.15 & 0.15 & 0.15 & 0.15 & 0.15 & 0.15 & 0.15 & .1 \\
\hline 25 & 0.18 & 0.17 & 0.16 & 0. & 0.15 & 0.15 & 0.15 & 0.14 & 0.14 & 0.14 & 0. & 0.14 & 0.14 & 0.14 & 0. & 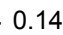 \\
\hline 30 & 0.16 & 0.16 & & 0.15 & 0.14 & 0.14 & 0.14 & 0.14 & 0.13 & 0.13 & & 0.13 & 0.13 & 0.13 & 0. & 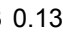 \\
\hline 35 & 0.15 & 0.15 & 0.14 & 0. & 0.14 & 0.13 & 0.13 & 0.13 & 0.13 & 0.13 & 30.13 & 0.12 & 0.12 & 0.12 & 0.12 & 0.12 \\
\hline 40 & 0.14 & 0.14 & 0.13 & & 50.13 & 0.13 & 0. & 0.12 & 0.12 & 0.12 & & 0.12 & & 0. & 0.12 & 0.12 \\
\hline 45 & 0.13 & 0.13 & 0.13 & & 0.12 & 0.12 & 0. & 0.12 & 0.12 & 0.12 & & 0.12 & & 0 & 0 & ( \\
\hline 50 & 0.13 & 0.12 & 0.12 & & 0.12 & 0.12 & 0.12 & 0.12 & 0.12 & 0.11 & & 0.11 & 10 & 0 & 0.11 & 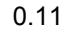 \\
\hline 55 & 0.12 & 0.12 & 0.12 & 0. & 0. & 0.11 & 0. & 0 & 0.11 & 0. & & 0 & & & & 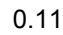 \\
\hline 60 & 0.12 & 0.12 & 0. & 0 & 0. & 0.11 & 0 & 0 & 0.11 & 0. & 0 & 0.11 & 10.11 & 0. & 0 & ( \\
\hline 65 & 0.11 & 0.11 & 0.11 & 0 & 0.11 & 0.11 & 0. & 0.11 & 0.11 & 0.11 & 0.11 & 0.10 & 0.10 & 0.10 & 0.10 & 1 \\
\hline 70 & 0.11 & 0.11 & 0.11 & 0. & 0.11 & 0.11 & 0.11 & 0.10 & 0.10 & 0.10 & 0.10 & 0.10 & 0.10 & 0.10 & 0.10 & ( \\
\hline 15 & 0.11 & 0.11 & 0.11 & 0.11 & 0.10 & 0.10 & 0.10 & 0.10 & 0.10 & 0.10 & 0.10 & 0.10 & 0.10 & 0.10 & 0.10 & 0.1 \\
\hline tegral Gain=10 1 & 19.40 & 4.02 & 1.62 & 0.91 & 1.01 & 0.88 & 0.73 & 0.61 & 0.45 & 50.31 & 0.24 & 0.22 & 20.28 & 0.33 & 0.33 & 0.31 \\
\hline 5 & 1.81 & 0.53 & 0.47 & 0. & 0.42 & 0.43 & 0.39 & 0.32 & 0.26 & 0.21 & 0.19 & 0.19 & 90.19 & 0.20 & 0.20 & 0.21 \\
\hline 10 & 0.29 & 0.30 & 0.30 & 0. & 0.28 & 0.27 & 0.25 & 0.23 & 0.20 & 0.18 & 0.17 & 0.16 & 0.16 & 0.16 & 0.16 & 0.16 \\
\hline 15 & 0.24 & 0.24 & 0.23 & 0. & 0.22 & 0.21 & 0.20 & 0.19 & 0.17 & 0.16 & 0. & 0.15 & 50.14 & 0.14 & 0.14 & 0.14 \\
\hline 20 & 0.21 & 0.20 & 0.20 & 0 & 0.19 & 0.18 & 0.17 & 0.16 & 0.16 & 0.15 & & 0.14 & 40 & 0.13 & 0.13 & 3 \\
\hline 25 & 0.1 & 0.18 & 0.17 & 0. & 0. & 0.16 & 0. & 0.15 & 0.14 & 0 & 0 & 0.13 & 30 & 0. & 0. & \\
\hline 30 & 0.1 & 0.16 & 0.16 & 0. & 0.15 & 0.15 & 0.14 & 0.14 & 0.14 & 0.13 & 0 & 0.13 & 30.12 & 0.12 & 0.12 & 0. \\
\hline 35 & 0.1 & 0.15 & 0.15 & 0. & 0.14 & 0.14 & 0.13 & 0.13 & 0.13 & 0.13 & 0.12 & 0.12 & 0.12 & 0.12 & 0.12 & \\
\hline 40 & 0.1 & 0.14 & 0. & 0. & 0.13 & 0.13 & 0.13 & 0.13 & 0.12 & 0.12 & 0.12 & 0.12 & 0.12 & 0.11 & 0.11 & \\
\hline 45 & 0.14 & 0.13 & 0.13 & 0. & 0.13 & 0.12 & 0.12 & 0.12 & 0.12 & 0.12 & 0.12 & 0.11 & 0.11 & 0.11 & 0.11 & \\
\hline 50 & 0.13 & 0.13 & 0.13 & 0.12 & 0.12 & 0.12 & 0.12 & 0.12 & 0.12 & 0.11 & 0.11 & 0.11 & 0.11 & 0.11 & 0.11 & 0.11 \\
\hline 55 & 0.13 & 0.12 & 0.12 & 0.12 & 0.12 & 0.12 & 0.12 & 0.11 & 0.11 & 0.11 & 0.11 & 0.11 & 10.11 & 0.11 & 0.11 & 0.11 \\
\hline 60 & 0.12 & 0.12 & 0.12 & 0.12 & 0.11 & 0.11 & 0.11 & 0.11 & 0.11 & 0.11 & 0.11 & 0.11 & 0.11 & 0.11 & 0.11 & \\
\hline 65 & 0.12 & 0.12 & 0.11 & 0.11 & 0.11 & 0.11 & 0.11 & 0.11 & 0.11 & 0.11 & 0.11 & 0.11 & 10.10 & 0.10 & 0.10 & \\
\hline 70 & 0.11 & 0.11 & 0.11 & 0.1 & 0.11 & 0.11 & 0.11 & 0.11 & 0.11 & 0.11 & 0.10 & 0.10 & 0.10 & 0.10 & 0.10 & 0.1 \\
\hline 15 & 0.11 & 0.11 & 0.11 & U. & 0.11 & 0.11 & 0.11 & 0.10 & 0.10 & 0.10 & 0.10 & 0.10 & 0.10 & 0.10 & 0.10 & \\
\hline
\end{tabular}


Table B-1: RMS speed error obtained using the non-linear model and medwind 2 as wind input file.

\begin{tabular}{|c|c|c|c|c|c|c|c|c|c|c|c|c|c|c|c|c|}
\hline \multirow{3}{*}{$\begin{array}{c}\text { Proportional } \\
\text { Gain }\end{array}$} & \multicolumn{16}{|c|}{ Derivative Gain } \\
\hline & & & & & & & & & & & & & & & & \\
\hline & 1 & 5 & 10 & 15 & 20 & 25 & 30 & 35 & 40 & 45 & 50 & 55 & 60 & 65 & 70 & 75 \\
\hline Integral Gain=15 1 & 20.56 & 9.52 & 7.98 & 2.96 & 1.71 & 0.98 & 0.73 & 1.01 & 0.92 & 0.78 & 0.68 & 50.60 & 0.45 & 0.32 & 0.25 & 0.22 \\
\hline & 16.07 & 7.28 & 0.57 & 0.50 & 0.48 & 0.41 & 0.40 & 0.45 & 0.47 & 0.45 & 0.40 & 0.34 & 0.28 & 0.23 & 0.19 & 0.18 \\
\hline 10 & 0.28 & 0.29 & 0.31 & 0.31 & 0.31 & 0.30 & 0.30 & 0.30 & 0.30 & 0.29 & 0.26 & 0.24 & 0.21 & 0.19 & 0.17 & 0.16 \\
\hline 15 & 0.26 & 0.24 & 0.24 & 0.24 & 0.25 & 0.24 & 0.24 & 0.24 & 0.23 & 0.22 & 0.21 & 0.19 & 0.18 & 0.17 & 0.16 & 0.15 \\
\hline 20 & 0.22 & 0.21 & 0.21 & 0.21 & 0.21 & 0.20 & 0.20 & 0.20 & 0.19 & 0.18 & 0.18 & 0.17 & 0.16 & 0.15 & 0.15 & 0.14 \\
\hline 25 & 0.20 & 0.19 & 0.19 & 0.18 & 0.18 & 0.18 & 0.18 & 0.17 & 0.17 & 0.16 & 0.16 & 0 & 0. & 0.14 & 0 & 0.13 \\
\hline 30 & 0.18 & 0.17 & 0.17 & 0.17 & 0.16 & 0.16 & 0.16 & 0.16 & 0.15 & 0. & 0.15 & 50. & 0.14 & 0.13 & 0.13 & 0.13 \\
\hline 35 & 0.17 & 0.16 & 0.16 & 0.15 & 0.15 & 0.15 & 0.15 & 0.14 & 0.14 & 0.14 & 0.14 & 0.13 & 0.13 & 0.13 & 0.13 & 0.12 \\
\hline 40 & 0.15 & 0.15 & 0.15 & 0.14 & 0.14 & 0.14 & 0.14 & 0.14 & 0.13 & 0.13 & 0.13 & 0.13 & 0.12 & 0.12 & 0.12 & 0.12 \\
\hline 45 & 0.15 & 0.14 & 0.14 & 0.14 & 0.13 & 0.13 & 0.13 & 0.13 & 0.13 & 0.13 & 0.12 & 0.12 & 0.12 & 0.12 & 0.12 & 0.11 \\
\hline 50 & 0.14 & 0.14 & 0.13 & 0.13 & 0.13 & 0.13 & 0.13 & 0.12 & 0.12 & 0.12 & 0.12 & 0.12 & 0.12 & 0.11 & 0.11 & 0.11 \\
\hline 55 & 0.13 & 0.13 & 0.13 & 0.13 & 0.12 & 0.12 & 0.1 & 0.12 & 0.12 & 0.12 & & 0.11 & 0.11 & 0.11 & 0.11 & 0.11 \\
\hline 60 & 0.13 & 0.12 & 0.12 & & & 0.12 & & & 0.11 & & & & & 0. & & 0.11 \\
\hline 65 & 0.12 & 0.12 & 0.12 & & 0.12 & 0.12 & & 0.11 & 0.11 & 0 & & & & 0 & & 0.11 \\
\hline 70 & 0.12 & 0.12 & 0.12 & 0. & 0. & 0.11 & 0. & & 0.11 & 0. & & & 0.11 & 0.11 & 0.10 & 0.10 \\
\hline 15 & 0.12 & 0.11 & 0.11 & 0.11 & 0.11 & 0.11 & 0.11 & 0.11 & 0.11 & 0.11 & 0.11 & 0.11 & 0.10 & 0.10 & 0.10 & 0.10 \\
\hline ain=20 1 & 423.68 & .98 & 8.42 & 5.31 & 2.86 & 2.07 & 1.37 & 0.98 & 0.74 & 0.82 & 1.00 & 0.93 & 0.83 & 0.73 & 0.66 & 0.60 \\
\hline 5 & 175.44 & 11.26 & 2. & 0.66 & 0.48 & 0.56 & 0.48 & 0.42 & 0.40 & 0.44 & 0. & 0. & 0 & 0.46 & 0. & 0.36 \\
\hline 10 & 7.33 & 0.25 & 0.29 & 0.31 & 0.32 & 0.33 & 0.32 & 0.31 & 0.31 & 0.32 & 0.33 & 0.33 & 0.32 & 0.30 & 0.28 & 0.25 \\
\hline 15 & 1.79 & 0.24 & 0.23 & 0.24 & 0.25 & 0.25 & 0.26 & 0.26 & 0.25 & 0.25 & 0.25 & 0.25 & 0.24 & 0.23 & 0.22 & 0.21 \\
\hline 20 & 0.24 & 22 & 0.21 & 0.21 & 0.21 & 0.22 & 0.22 & 0.22 & 0.22 & 0.21 & 0.21 & 0.21 & 0.20 & 0.19 & 0.19 & 0.18 \\
\hline 25 & 0.21 & 20 & 0. & 0.19 & 0.19 & 0.19 & 0. & 0.19 & 0.19 & 0. & 0.18 & 0. & 0.18 & 0.17 & 0.17 & 0.16 \\
\hline 30 & 0.19 & 0.18 & 0.18 & 0.18 & 0.17 & 0.17 & 0.17 & 0.17 & 0.17 & 0.17 & 0.17 & 0.16 & 0.16 & 0.16 & 0.15 & 0.15 \\
\hline 35 & 0.18 & 0.17 & 0.17 & 0. & 0.16 & 0.16 & 0.16 & 0.16 & 0.16 & 0.15 & 0.15 & 0.15 & 0.15 & 0.14 & 0.14 & 0.14 \\
\hline 40 & 0.17 & 0.16 & 0.16 & 0. & 0.1 & 0.15 & 0.1 & 0.15 & 0.15 & 0.14 & & 0. & 0.14 & 0.14 & 0.13 & 0.13 \\
\hline 45 & 0.1 & 0.15 & 0.15 & 0 & 0.1 & 0.14 & 0.14 & 0.14 & 0.14 & 0 & 0. & 0. & 0. & 0. & & 0.13 \\
\hline 50 & 0.1 & 0.14 & 0.14 & 0 & 0.14 & 0.13 & 0.13 & 0.13 & 0.13 & 0 & 0. & 0. & 0. & 0.12 & 0.12 & 0.12 \\
\hline 55 & 0. & 0.14 & 0.13 & 0 & 0.13 & 0.13 & 0.13 & 0.13 & 0.13 & 0.12 & 0. & 0.12 & 0.12 & 0.12 & 0.12 & 0.12 \\
\hline 00 & 0. & 0.13 & 0.13 & 0 & 0.13 & 0.12 & 0.1 & 0.12 & 0.12 & 0.12 & 0.12 & 0.12 & 0.12 & 0.12 & 0.12 & 0.11 \\
\hline 65 & 0. & 0.13 & 0.12 & 0.1 & 0.12 & 0.12 & 0.12 & 0.12 & 0.12 & 0.12 & 0.12 & 0.1 & 0.11 & 0.11 & 0.11 & 0.11 \\
\hline 70 & 0.13 & 0.12 & 0.12 & 0.1 & 0.12 & 0.12 & 0.12 & 0.12 & 0.11 & 0.11 & 0.11 & 0.11 & 0.11 & 0.11 & 0.11 & 0.11 \\
\hline 15 & 0.12 & 0.12 & 0.12 & 0.12 & 0.12 & 0.11 & 0.11 & 0.11 & 0.11 & 0.11 & 0.11 & 0.11 & 0.11 & 0.11 & 0.11 & 0.11 \\
\hline
\end{tabular}


Table B-2: RMS speed error obtained using the non-linear model and wind 3 as wind input file.

Derivative Gain

\begin{tabular}{|c|c|c|c|c|c|c|c|c|c|c|c|c|c|c|c|c|}
\hline roportional & & & & & & & & & & & & & & & & \\
\hline Gain & 1 & 5 & 10 & 15 & 20 & 25 & 30 & 35 & 40 & 45 & 50 & 55 & 60 & 65 & 70 & 75 \\
\hline Integral Gain=1 1 & 0.52 & 0.52 & 0.54 & 0.55 & 0.59 & 0.65 & 0.69 & 0.70 & 0.70 & 0.69 & 0.67 & 0.65 & 0.63 & 0.61 & 0.59 & 0.57 \\
\hline & 0.33 & 0.32 & 0.32 & 0.33 & 0.34 & 0.35 & 0.36 & 0.37 & 0.37 & 0.37 & 0.37 & 0.37 & 0.37 & 0.37 & 0.37 & 0.37 \\
\hline 10 & 0.26 & 0.25 & 0.24 & 0.24 & 0.25 & 0.25 & 0.25 & 0.26 & 0.26 & 0.26 & 0.26 & 0.27 & 0.27 & 0.27 & 0.27 & 0.27 \\
\hline 15 & 0.22 & 0.21 & 0.20 & 0.20 & 0.20 & 0.20 & 0.21 & 0.21 & 0.21 & 0.21 & 0.21 & 0.22 & 0.22 & 0.22 & 0.22 & 0.22 \\
\hline 20 & 0.20 & 0.19 & 0.18 & 0.18 & 0.18 & 0.18 & 0.18 & 0.18 & 0.18 & 0.18 & 0.18 & 0.18 & 0.19 & 0.19 & 0.19 & 0.19 \\
\hline 25 & 0.18 & 0.17 & 0.17 & 0.16 & 0.16 & 0.16 & 0.16 & 0.16 & 0.16 & & 0.16 & & & 0.17 & & 0.17 \\
\hline 30 & 0.16 & 0.16 & .15 & 0.15 & 0.15 & 0.15 & 0.15 & 0.15 & 0.15 & & 0.15 & 0.15 & 0.15 & 0.15 & & 0.15 \\
\hline 35 & 0.15 & 0.15 & 0.14 & 0.14 & 0.14 & 0.14 & 0.14 & 0.14 & 0.14 & 0.14 & 0.14 & 0. & 0.14 & 0.14 & 0. & 0.14 \\
\hline 40 & 0.14 & 0.14 & 0.14 & 0.13 & 0.13 & 0.13 & 0.13 & 0.13 & 0.13 & 0.13 & 0.13 & 0.13 & 0.13 & 0.13 & 0.13 & 0.13 \\
\hline 45 & 0.13 & 0.13 & 0.13 & 0.13 & 0.13 & 0.12 & 0.12 & 0.12 & 0.12 & 0.12 & 0.12 & 0.12 & 0.12 & 0.12 & 0.12 & 0.12 \\
\hline 50 & 0.13 & 0.12 & 0.12 & 0.12 & 0.12 & 0.12 & 0.12 & 0.12 & 0.12 & 0.12 & 0.12 & 0.12 & 0.12 & 0.12 & 0.12 & 0.12 \\
\hline 55 & 0.12 & 0.12 & 0.12 & 0.12 & 0.11 & 0.11 & 0.11 & 0.11 & 0.11 & 0.11 & 0.11 & 0.11 & 0.11 & 0.1 & 0.11 & 0.11 \\
\hline 60 & 0.12 & 0.11 & 0.11 & 0.11 & 0.11 & 0.11 & 0.11 & 0.11 & 0.11 & 0.11 & 0 & 0.11 & 0 & 0.1 & 0.11 & 0.11 \\
\hline 65 & 0.11 & 0.11 & 0.11 & 0.11 & 0.11 & 0.11 & 0.11 & 0.10 & 0.10 & 0.10 & 0 & 0. & 0 & 0. & 0 & 0.10 \\
\hline 70 & 0.1 & 0.11 & 0.11 & 0.11 & 0.10 & 0.10 & 0.10 & 0.10 & 0.10 & 0. & 0 . & 0 . & 0 & 0. & 0 & 0.10 \\
\hline 15 & 0.11 & 0.10 & 0.10 & 0.10 & 0.10 & 0.10 & 0.10 & 0.10 & 0.10 & 0.10 & 0.10 & 0.10 & 0.10 & 0.10 & u. & 0.10 \\
\hline & 0.92 & 0.65 & 0.46 & 0.34 & 0.41 & 0.37 & 0.29 & 0.32 & 0.35 & 0.39 & 0.41 & 0.39 & 0.37 & 0.38 & 0.38 & 0.37 \\
\hline 5 & 0.35 & 0.28 & 0.23 & 0.20 & 0.19 & 0.19 & 0.19 & 0.19 & 0.20 & 0 . & 0.2 & 0 & 0 . & 0. & 0. & 0.23 \\
\hline 10 & 0.24 & 0.20 & 0.17 & 0.16 & 0.15 & 0.14 & 0.14 & 0.15 & 0.15 & 0.15 & 0.16 & 0.16 & 0.16 & 0.1 & 0.1 & 0.17 \\
\hline 15 & 0.19 & 0.17 & 0.15 & 0.14 & 0.13 & 0.13 & 0.13 & 0.13 & 0.13 & 0.13 & 0.14 & 0.1 & 0.1 & 0.1 & 0.15 & 0.15 \\
\hline 20 & 0.17 & 0.15 & 0.14 & 0.13 & 0.13 & 0.12 & 0.12 & 0.12 & 0.12 & 0.12 & 0.12 & 0.1 & 0.1 & 0.1 & 0.13 & 0.13 \\
\hline 25 & 0.15 & 0.14 & 0.13 & 0.13 & 0.12 & 0.12 & 0.12 & 0.12 & 0.12 & 0.12 & 0.12 & 0. & & 0.1 & 0. & 0.12 \\
\hline 30 & 0.14 & 0.13 & 0.13 & 0. & 0.12 & & 0. & 0.11 & 0.1 & & & & & 0.1 & 0.12 & 0.12 \\
\hline 35 & 0.13 & 0.13 & 0.12 & 0.12 & 0.11 & 0.11 & 0.11 & 0.11 & 0.11 & & & & & 0. & 0.11 & 0.11 \\
\hline 40 & 0.13 & 0.12 & 0.12 & 0. & 0.11 & 0.11 & 0. & 0 & 0.11 & & ) & & 0 & 0 & 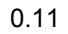 & 0.11 \\
\hline 45 & 0.1 & 0.12 & 0 & 0 . & 0 . & 0 . & 0 . & & 0. & & 0 & & & 0 & & 0.1 \\
\hline 50 & 0.12 & 0.11 & 0. & 0. & 0. & 0.10 & 0. & 0 & 0.10 & 0 & 0. & 0 & 0 & 0.10 & 0 & 0.1 \\
\hline 55 & 0.1 & 0.11 & 0. & 0. & 0.10 & 0.10 & 0. & 0.10 & 0.10 & 0. & 0. & 0. & 0 & 0.10 & 0 & 0.10 \\
\hline 60 & 0.1 & 0.11 & 0 & 0. & 0.10 & 0.10 & 0.10 & 0.10 & 0.10 & 0. & 0.10 & 0. & 0 & 0.10 & 0 & 0.10 \\
\hline 65 & 0.1 & 0.10 & ) & 0. & 0.10 & 0.10 & 0.10 & 0.10 & 0.10 & 0. & 0.09 & 0. & 0. & 0.0 & 0.09 & 0.09 \\
\hline 70 & 0.10 & 0.10 & 0.10 & 0.10 & 0.10 & 0.10 & 0.10 & 0.09 & 0.09 & 0.09 & 0.09 & 0.09 & 0.09 & 0.09 & 0.09 & 0.09 \\
\hline & 0.10 & 0.10 & 0.10 & 0.10 & 0.10 & 0.09 & 0.09 & 0.09 & 0.09 & 0.09 & 0.09 & 0.09 & 0.09 & 0.09 & 0.09 & 0.09 \\
\hline tegral Gain=10 1 & 175.80 & 1.29 & 0.84 & 0.70 & 0.58 & 0.53 & 0.39 & 0.36 & 0.30 & 0.44 & 0.47 & 0.40 & 0.32 & 0.2 & 0.29 & 0.34 \\
\hline & 0.58 & 0.41 & 0.32 & 0. & 0.27 & 0.24 & 0.21 & 0.20 & 0.20 & 0. & 0.22 & 0.21 & 0 & 0.2 & 0.20 & 0.20 \\
\hline 10 & 0. & 0.26 & 0.22 & 0 & 0.18 & 0. & 0. & 0 & 0. & 0 & & & & 0 & & 0.15 \\
\hline 15 & 0.2 & 0.20 & 0.17 & 0. & 0. & 0. & 0. & 0. & 0. & & 0. & & & 0 . & & 0. \\
\hline 20 & 0. & 0.17 & 0.15 & 0.1 & 0.13 & 0.13 & 0.12 & 0.12 & 0.12 & 0.12 & 0.12 & 0.12 & 0. & 0. & 0.12 & 0.1 \\
\hline 25 & 0.1 & 0.15 & 0.14 & 0.13 & 0.12 & 0.12 & 0.12 & 0.11 & 0.11 & 0. & 0.1 & 0 & 0 & 0. & 0.11 & 0.1 \\
\hline 30 & 0.1 & 0.14 & 0.13 & 0.12 & 0.12 & 0.11 & 0.11 & 0.11 & 0.11 & 0.11 & 0.10 & 0.10 & 0. & 0.10 & 0.11 & 01 \\
\hline 35 & 0.1 & 0.13 & 0. & 0. & 0.11 & 0.11 & 0.11 & 0 & 0.10 & 0.10 & 0.10 & 0.10 & 0. & 0.10 & 0. & 0.10 \\
\hline 40 & 0.13 & 0.12 & 0.12 & 0.11 & 0.11 & 0.11 & 0.11 & 0.10 & 0.10 & 0.10 & 0.10 & 0.10 & 0.10 & 0.10 & 0.10 & 0.10 \\
\hline 45 & 0.12 & 0.12 & 0.11 & 0.11 & 0.11 & 0.11 & 0.10 & 0.10 & 0.10 & 0.10 & 0.10 & 0.10 & 0.10 & 0.10 & 0.10 & 0.10 \\
\hline 50 & 0.12 & 0.11 & 0.11 & 0.11 & 0.11 & 0.10 & 0.10 & 0.10 & 0.10 & 0.10 & 0.10 & 0.10 & 0.10 & 0.10 & 0.10 & 0.10 \\
\hline 55 & 0.11 & 0.11 & 0.11 & 0.11 & 0.10 & 0.10 & 0.10 & 0.10 & 0.10 & 0.10 & 0.10 & 0.09 & 0.09 & 0.09 & 0.09 & \\
\hline 60 & 0.11 & 0.11 & 0.10 & 0.10 & 0.10 & 0.10 & 0.10 & 0.10 & 0.10 & 0.09 & 0.09 & 0.09 & 0.09 & 0.09 & 0.09 & 0.0 \\
\hline 65 & 0.1 & 0.10 & 0.10 & 0.10 & 0.10 & 0.10 & 0.10 & 0.10 & 0.09 & 0.09 & 0.09 & 0.09 & 0. & 0.09 & 0. & 0. \\
\hline 10 & & 0.10 & 0.10 & 0.10 & 0.10 & 0.10 & 0.10 & 0.09 & 0.09 & 0.09 & 0.09 & 0.09 & 0.09 & 0.09 & 0.09 & 0.09 \\
\hline & 0.10 & 0.10 & 0.10 & 0.10 & 0.10 & 0.09 & 0.09 & 0.09 & 0.09 & 0.09 & 0.09 & 0.09 & 0.09 & 0.09 & $0.0 y$ & \\
\hline
\end{tabular}


Table B-2: RMS speed error obtained using the non-linear model and wind 3 as wind input file.

Derivative Gain

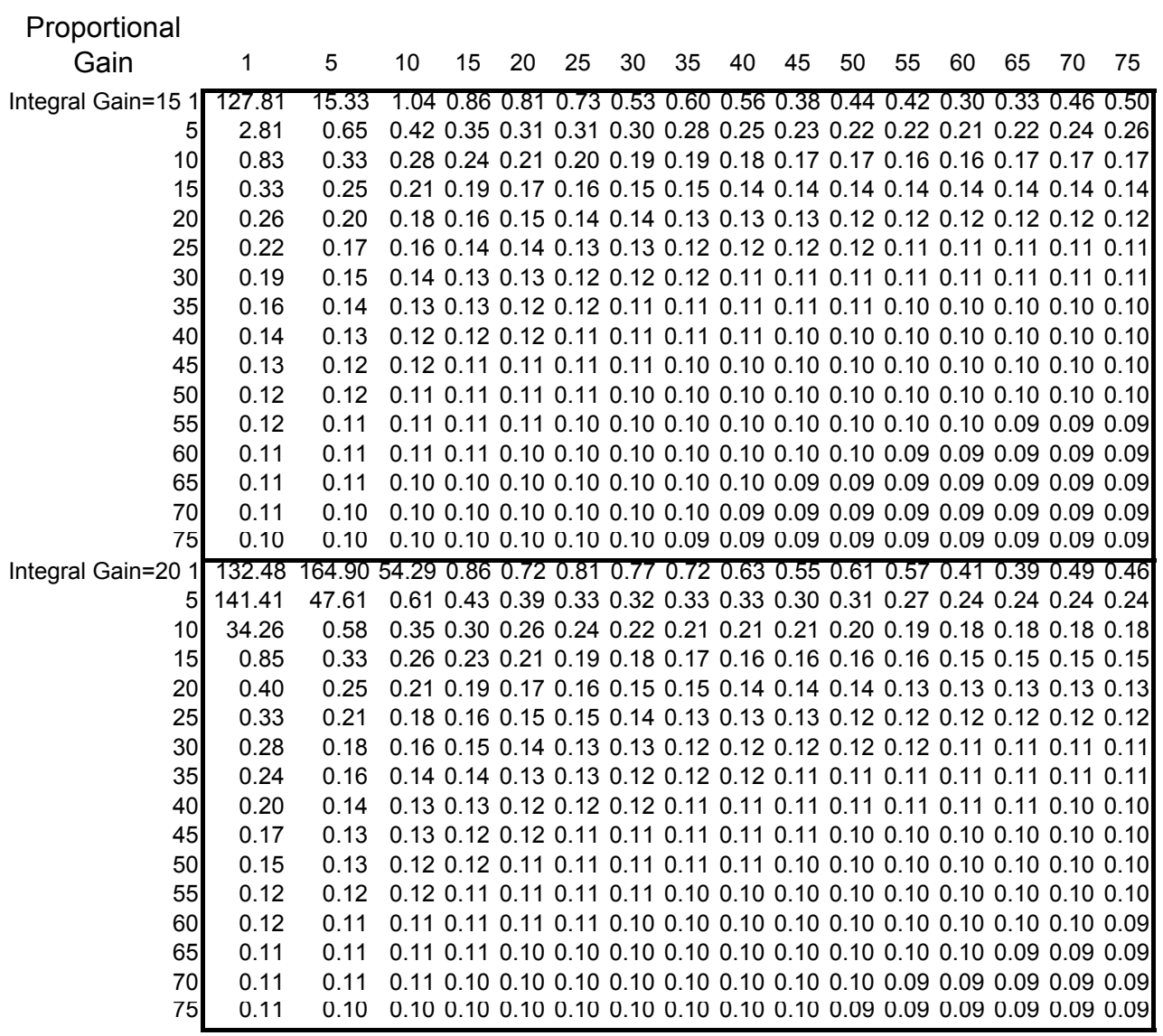


Table B-3: RMS speed error obtained using the non-linear model and wind4 as wind input file.

Derivative Gain

\begin{tabular}{|c|c|c|c|c|c|c|c|c|c|c|c|c|c|c|c|c|}
\hline roportional & & & & & & & & & & & & & & & & \\
\hline Gain & 1 & 5 & 10 & 15 & 20 & 25 & 30 & 35 & 40 & 45 & 50 & 55 & 60 & 65 & 70 & 75 \\
\hline Integral Gain=1 & 1.11 & 1.03 & 0.85 & 0.72 & 0.65 & 0.62 & 0.61 & 0.60 & 0.59 & 0.58 & 0.57 & 0.56 & 0.54 & 0.53 & 0.51 & 0.49 \\
\hline & 0.45 & 0.43 & 0.41 & 0.39 & 0.37 & 0.35 & 0.34 & 0.33 & 0.32 & 0.32 & 0.31 & 0.31 & 0.30 & 0.30 & 0.29 & 0.29 \\
\hline 10 & 0.29 & 0.28 & 0.27 & 0.26 & 0.26 & 0.25 & 0.24 & 0.24 & 0.23 & 0.23 & 0.22 & 0.22 & 0.22 & 0.22 & 0 & 0.21 \\
\hline 15 & 0.23 & 0.22 & 0.21 & 0.21 & 0.21 & 0.20 & 0.20 & 0.20 & 0.19 & 0.19 & 0.19 & 0.19 & & 0.18 & & 0.18 \\
\hline 20 & 0.19 & 0.19 & 0.18 & 0.18 & 0.18 & 0.18 & 0.18 & 0.17 & 0.17 & 0.17 & 0.17 & 0.17 & 0.16 & 0.16 & 0.16 & 0.16 \\
\hline 25 & 0.17 & 0.17 & 0.17 & 0.16 & 0.16 & 0.16 & 0.16 & 0.16 & 0.16 & 0.15 & 0.15 & 0.15 & 0.15 & 0.15 & 0.15 & 0.15 \\
\hline 30 & 0.16 & 0.15 & 0.15 & 0.15 & 0.15 & 0.15 & 0.15 & 0.15 & 0.14 & 0.14 & 0.14 & 0.14 & 0.14 & 0.14 & 0.14 & 0.14 \\
\hline 35 & 0.14 & 0.14 & 0.14 & 0.14 & 0.14 & 0.14 & 0.14 & 0.14 & 0.13 & 0.13 & 0.13 & 0.13 & 0.13 & 0.13 & 0.13 & 0.13 \\
\hline 40 & 0.13 & 0.13 & 0.13 & 0.13 & 0.13 & 0.13 & 0.13 & 0.13 & 0.13 & 0.13 & 0.13 & 0.13 & 0.12 & 0.12 & 0.12 & 0.12 \\
\hline 45 & 0.13 & 0.13 & 0.12 & 0.12 & 0.12 & 0.12 & 0.12 & 0.12 & 0.12 & 0.12 & 0.12 & 0.12 & 0.12 & 0.12 & 0.12 & 0.12 \\
\hline 50 & 0.12 & 0.12 & 0.12 & 0.12 & 0.12 & 0.12 & 0.12 & 0.11 & 0.11 & 0.11 & 0.11 & 0.11 & 0 & 0.1 & 0.11 & 0. \\
\hline 55 & 0.11 & 0.11 & 0.11 & 0.11 & 0.11 & 0.11 & 0.11 & 0.11 & 0.11 & 0.11 & 0.11 & 0.11 & 0 & 0.1 & 0.1 & 0.11 \\
\hline 60 & 0.11 & 0.11 & & & 0. & & 0.10 & 0.10 & 0.10 & 0. & 0.10 & 0.10 & 0 & 0.10 & 0 & 0.10 \\
\hline 65 & 0.10 & 0.10 & & 0.10 & 0 . & 0.10 & 0.10 & 0.10 & 0.10 & 0 & 0.10 & 0.10 & 0 & 0.10 & 0 & 0.10 \\
\hline 70 & 0.10 & 0.10 & 0 & 0.10 & 0.10 & 0.10 & 0.10 & 0.10 & 0.10 & 0.10 & 0.09 & 0.09 & 0.09 & 0.09 & 0.09 & 0.09 \\
\hline 15 & $0.0 y$ & 0.09 & $0.0 y$ & 0.uy & U.UY & U.Uy & U.UY & 0.09 & U.UY & 0.09 & 0.09 & $0.0 y$ & U.0y & u.uy & U.0y & 0.09 \\
\hline the & 1.13 & 0.76 & 50 & 0.47 & 0.43 & 0.41 & 0.50 & 0.63 & 0.67 & 0.64 & 0.60 & 0.58 & 0.56 & 0.55 & 0.53 & 0.49 \\
\hline & 0.30 & 0.26 & 0.24 & 0.24 & 0.24 & 0.25 & 0.26 & 0.28 & 0.29 & 0.30 & 0.30 & 0.30 & 0.30 & 0.2 & 0.29 & 0.28 \\
\hline 10 & 0.20 & 0.18 & 0.17 & 0.17 & 0.17 & 0.17 & 0.18 & 0.18 & 0.19 & 0.19 & 0.19 & 0.19 & 0.19 & 0.1 & 0.1 & 0.18 \\
\hline 15 & 0.16 & 0.15 & 0.14 & 0. & 0.14 & & 0. & 0.14 & 0.14 & & 0.14 & & & 0.1 & 0. & 0.14 \\
\hline 20 & 0.13 & 0.12 & 0.12 & 0. & 0.11 & & 0.11 & 0.11 & 0.11 & 0.11 & 0 & 0.11 & & 0.1 & 0.11 & 0.11 \\
\hline 25 & 0.11 & 0.10 & 0.10 & 0.10 & 0.10 & 0.10 & 0.10 & 0.10 & 0.10 & 0.10 & 0. & 0.10 & 0 & 0.10 & 0. & 0.10 \\
\hline 30 & 0.10 & 0.09 & 0.09 & & 0.09 & & 0.09 & 0.09 & 0.09 & 0. & 0 & 0.08 & c & 0.08 & . & 0.08 \\
\hline 35 & 0.09 & 0.08 & 0 & 0. & 0.08 & 0.08 & 0.08 & 0. & 0.08 & 0. & 0.08 & 0. & 0 & 0.08 & 0 & 0.07 \\
\hline 40 & 0.08 & 0.08 & 0. & 0.07 & 0.07 & 0.07 & 0.07 & 0.07 & 0.07 & 0. & 0.07 & 0.07 & 0 & 0.07 & 0 & 0.07 \\
\hline 45 & 0.07 & 0.07 & 0. & 0.07 & 0.07 & 0.07 & 0.06 & 0.06 & 0.06 & 0. & 0.06 & 0.06 & 0. & 0.06 & 0. & 0.06 \\
\hline 50 & 0.07 & 0.06 & 0.06 & 0.06 & 0.06 & 0.06 & 0.06 & 0.06 & 0.06 & 0.06 & 0.06 & 0.06 & 0.06 & 0.06 & 0.06 & 0.06 \\
\hline 55 & 0.06 & 0.06 & 0. & 0.06 & 0.06 & 0.06 & 0.06 & 0.06 & 0.06 & 0.06 & 0.06 & 0.06 & 0.05 & 0.0 & 0.05 & 0.05 \\
\hline 60 & 0.06 & 0.06 & 6 & 0.06 & 0.05 & 0.05 & 0.05 & 0.05 & 0.05 & 0.05 & 0.05 & 0.05 & 0. & 0.0 & 0. & 0.05 \\
\hline 65 & 0.06 & 0.05 & 0.05 & 0. & 0.05 & 0.05 & 0.05 & 0. & 0.05 & 0.05 & 0.05 & 0.05 & 0. & 0.0 & 0.05 & 0.05 \\
\hline 70 & 0.05 & 0.05 & 0.05 & $0 . C$ & 0.05 & 0.05 & 0.05 & 0.05 & 0.05 & 0.05 & 0.0 & 0.0 & $0 . C$ & 0.0 & 0.0 & 0.05 \\
\hline & U.US & U.Ub & U.US & 0 & 0. & 0 & 0. & 0.05 & 0 & 0.05 & ( & 0.05 & 0.05 & 0.04 & 0.04 & 0.04 \\
\hline 101 & 24.92 & 20.47 & 0.86 & 0.55 & 0.50 & 0.49 & 0.37 & 0.36 & 0.35 & 0.33 & 0.33 & 0.31 & 0.28 & 0.28 & 0. & 0.43 \\
\hline & 0.36 & 0.26 & 0.21 & & 0. & & 0. & & 0. & 0. & 0. & & & & & 0.23 \\
\hline 10 & 0.21 & 0.16 & 0.14 & 0.13 & 0.12 & 0.12 & 0.12 & 0.12 & 0.12 & 0.12 & 0.13 & 0.13 & 0. & 0.14 & 0. & 0.16 \\
\hline 15 & 0.14 & 0.12 & 0.11 & 0. & 0.10 & 0.10 & 0.10 & 0.10 & 0.10 & 0.10 & 0.10 & 0.11 & 0. & 0.11 & 0.12 & 0.12 \\
\hline 20 & 0.1 & 0.10 & 0. & 0.09 & 0.09 & 0.09 & 0.09 & 0.09 & 0.09 & 0.09 & 0.09 & 0.09 & 0. & 0.10 & 0. & \\
\hline 25 & 0.0 & 0.09 & 0. & 0.08 & 0.08 & 0.08 & 0.08 & 0.08 & 0.08 & 0.08 & 0.08 & 0.08 & 0.08 & 0.08 & 0.08 & \\
\hline 30 & 0.0 & 0.08 & 0.07 & 0.07 & 0.07 & 0.07 & 0.07 & 0.07 & 0.07 & 0.07 & 0.07 & 0.07 & 0.07 & 0.07 & 0.07 & 0.07 \\
\hline 35 & 0.07 & 0.07 & 0.07 & 0.07 & 0.07 & 0.06 & 0.06 & 0.06 & 0.06 & 0.06 & 0.06 & 0.06 & 0.06 & 0.07 & 0.07 & 0.07 \\
\hline 40 & 0.07 & 0.06 & 0.06 & 0.06 & 0.06 & 0.06 & 0.06 & 0.06 & 0.06 & 0.06 & 0.06 & 0.06 & 0.06 & 0.06 & 0.06 & 0.06 \\
\hline 45 & 0.06 & 0.06 & 0.06 & 0.06 & 0.06 & 0.06 & 0.05 & 0.05 & 0.05 & 0.05 & 0.05 & 0.05 & 0.05 & 0.05 & 0.05 & 0.06 \\
\hline 50 & 0.06 & 0.06 & 0.05 & 0.05 & 0.05 & 0.05 & 0.05 & 0.05 & 0.05 & 0. & 0.05 & 0.05 & $0 . C$ & 0.05 & 0 & 0.05 \\
\hline 55 & 0.0 & 0.05 & 0.05 & 0.05 & 0.05 & 0.05 & 0.05 & 0.05 & 0.05 & 0.05 & 0.05 & 0.05 & 0.05 & 0.05 & 0. & 0.05 \\
\hline 60 & 0.0 & 0.0 & 0.05 & 0.05 & 0.05 & 0.05 & 0.05 & 0.05 & 0.05 & 0.04 & 0.04 & 0. & 0. & 0.04 & 0. & 0.04 \\
\hline 65 & 0. & $0 . C$ & 0.04 & 0.04 & 0. & 0.04 & 0.0 & 0.04 & 0.0 & 0.04 & 0.0 & 0. & 0. & 0.04 & 0. & .04 \\
\hline 75 & 0 & & 0. & 0.0 & 0. & 0.04 & 0. & 0. & 0.04 & 0.04 & 0.04 & 0.04 & 0.04 & 0.0 & 0.04 & 0.04 \\
\hline & 0.04 & 0.04 & 0.04 & 0.04 & 0.04 & 0.04 & 0.04 & 0.04 & 0.04 & 0.04 & 0.04 & 0.04 & 0.04 & 0.04 & 0.04 & .04 \\
\hline
\end{tabular}


Table B-3: RMS speed error obtained using the non-linear model and wind4 as wind input file.

Derivative Gain

\begin{tabular}{|c|c|c|c|c|c|c|c|c|c|c|c|c|c|c|c|c|}
\hline \multicolumn{17}{|l|}{ Proportional } \\
\hline Gain & 1 & 5 & 10 & 15 & 20 & 25 & 30 & 35 & 40 & 45 & 50 & 55 & 60 & 65 & 70 & 75 \\
\hline egral Gain $=151$ & 558.15 & 179.12 & 1.37 & 0.42 & 0.27 & 0.30 & 0.28 & 0.36 & 0.45 & 0.42 & 0.34 & 0.33 & 0.33 & 0.31 & 0.30 & 0.30 \\
\hline & 0.67 & 0.29 & 0.26 & 0.21 & 0.16 & 0.14 & 0.13 & 0.14 & 0.15 & 0.15 & 0.15 & 0.15 & 0.16 & 0.16 & 0.16 & 0.1 \\
\hline 10 & 0.23 & 0.18 & 15 & 0.13 & 0.11 & 0.10 & 0.10 & 0.09 & 0.09 & 0.10 & 0 & 0.10 & U & U & c & 0.7 \\
\hline 15 & 0.14 & 0.12 & 11 & 0.10 & 0.09 & 0.09 & 0.08 & 0.08 & 0.08 & 0.08 & 0.08 & 0.08 & 0.08 & 0. & 0 & 0.09 \\
\hline 20 & 0.10 & 0.09 & .09 & 0.08 & 0.08 & 0.08 & 0.07 & 0.07 & 0.07 & 0.07 & 0.07 & 0.07 & 0.07 & & 0.07 & 0.08 \\
\hline 25 & 0.08 & 0.08 & 0.08 & 0.07 & 0.07 & 0.07 & 0.07 & 0.06 & 0.06 & 0.06 & 0.06 & 0.06 & 0.06 & 0.0 & 0.07 & 0.07 \\
\hline 30 & 0.07 & 0.07 & 0.07 & 0.06 & 0.06 & 0.06 & 0.06 & 0.06 & 0.06 & 0.06 & 0.06 & 0.06 & 0.06 & 0.06 & 0.06 & 0.06 \\
\hline 35 & 0.07 & 0.06 & 0.06 & 0.06 & 0.06 & 0.06 & 0.06 & 0.06 & 0.05 & 0.05 & 0.05 & 0.05 & 0.05 & 0.06 & 0.06 & 0.06 \\
\hline 40 & 0.06 & 0.06 & 0.06 & 0.05 & 0.05 & 0.05 & 0.05 & 0.05 & 0.05 & 0.05 & 0.05 & 0.05 & 0.05 & 0.0 & 0.05 & 0.05 \\
\hline 45 & 0.06 & 0.05 & 0 & 0.05 & 0.05 & 0.05 & 0.05 & 0.05 & 0.05 & $0 .($ & 0.05 & 0.05 & 0.0 & 0. & 0 & 0.05 \\
\hline 50 & 0.05 & 0.05 & 0.05 & 0.0 & & & 0.05 & 0.05 & 0.05 & 0.05 & 0. & 0.04 & & & 0. & 0.0 \\
\hline 5 & 0.05 & 0.05 & & & 0. & & 0.04 & 0.04 & 0.04 & 0.04 & & 0. & & & 0.04 & 0.0 \\
\hline 60 & 0.05 & .04 & 0.04 & & 0. & & 0.04 & 0.04 & 0.04 & 0.04 & 0.6 & 0. & & 0. & . & 0.04 \\
\hline 65 & 0. & 0.04 & 4 & 0.04 & 0. & 0.04 & 0.04 & 0.04 & 0.04 & 0.04 & 0.04 & 0. & 4 & & 0 & 0.04 \\
\hline 70 & .04 & 0.04 & 0. & 0.04 & 0.04 & 0.04 & 0.04 & 0.04 & 0.04 & 0.04 & 0.04 & 0.04 & 0.04 & 0. & 0.04 & 0.04 \\
\hline 15 & 0.04 & 0.04 & 0.04 & 0.04 & 0.04 & 0.04 & 0.04 & 0.04 & 0.04 & 0.04 & 0.04 & 0.04 & 0.03 & 0.03 & 0.03 & 0.03 \\
\hline 201 & 730.92 & 415.88 & 0.76 & 0.65 & 0.33 & 0.20 & 0.18 & 0.20 & 0.19 & 0.21 & 0.27 & 0.39 & 0.42 & 0.38 & 0.33 & 0.32 \\
\hline 5 & 19.91 & 24.75 & 0.27 & 0.28 & 0.24 & 0.18 & 0.14 & 0.1 & 0.11 & 0.11 & 0.12 & 0. & 0.15 & 0. & 0 & 0.16 \\
\hline 10 & 22.87 & 20 & 7 & 0.14 & 0.12 & 0.11 & 0.10 & 0. & 0.08 & 0.0 & 0.08 & 0.08 & 0.09 & 0. & 0. & 0.10 \\
\hline 15 & 0 & 12 & 1 & 0.10 & 0. & 0.08 & 0.08 & 0.07 & 0.07 & 0.07 & 0.07 & 0.07 & 0.07 & 0. & 0.07 & 0.07 \\
\hline 20 & 0.10 & 09 & 0. & 0.08 & 0. & 0.07 & 0.07 & 0.06 & 0.06 & 0.06 & 0. & 0.06 & 0.06 & 0. & 0.06 & 0.06 \\
\hline 25 & 0.08 & 07 & & 0 & 0. & 0. & 0. & 0. & 0. & 0 & & & & & 0 & $0 . C$ \\
\hline 3 & & 6 & 0. & 0 & 0. & 0. & 0. & & 0. & 0 & 0. & & & & 0 & 0.05 \\
\hline 35 & & 0.06 & 0. & 0. & 0. & 0. & 0. & & 0. & & & & & & & 0.05 \\
\hline 40 & 0.06 & 0.05 & 0.0 & 0.05 & $0 . C$ & 0.05 & 0.05 & 0.05 & 0.05 & 0. & 0. & 0. & 0. & 0. & 0. & 0.04 \\
\hline 45 & 0.0 & 0.05 & 0.05 & 0.05 & 0.0 & 0.04 & 0.04 & 0.04 & 0.04 & 0.04 & 0.04 & 0.04 & 0. & 0. & 0.04 & 0.04 \\
\hline 50 & 0.05 & 0.05 & 0.04 & 0.04 & 0.04 & 0.04 & 0.04 & 0.04 & 0.04 & 0.04 & 0.04 & 0.04 & 0.04 & 0.0 & 0.04 & 0.04 \\
\hline 55 & 0.0 & 0.04 & 0.04 & 0.04 & 0. & 0.04 & 0.04 & 0.04 & 0.04 & 0.04 & 0.0 & 0.04 & 0.04 & 0.04 & 0.04 & 0.04 \\
\hline 6 & & 0 & 0. & 0.04 & 0. & 0.04 & $0 .($ & 0. & 0.04 & 0.0 & 0.0 & 0.04 & 0.0 & 0. & 0. & 0.04 \\
\hline 65 & 0.04 & 4 & 0. & 0.04 & 0. & 0.04 & 0. & 0. & 0.04 & 0.04 & 0. & 0.04 & 0.03 & 0. & 0.03 & 0.03 \\
\hline 701 & 0.04 & 04 & 0.04 & 0.04 & 0.04 & 0.03 & 0.03 & 0.03 & 0.03 & 0.03 & 0.03 & 0.03 & 0.03 & 0.03 & 0.03 & 0.03 \\
\hline & .04 & .04 & 0 & 0.03 & 0.03 & 0.03 & 0.03 & 0.03 & 0.03 & 0.03 & 0. & 0.03 & 0.05 & 11 & 0.03 & 0.0 \\
\hline
\end{tabular}


Table B-4: RMS speed error obtained using the non-linear model and wind5 as wind input file.

Derivative Gain

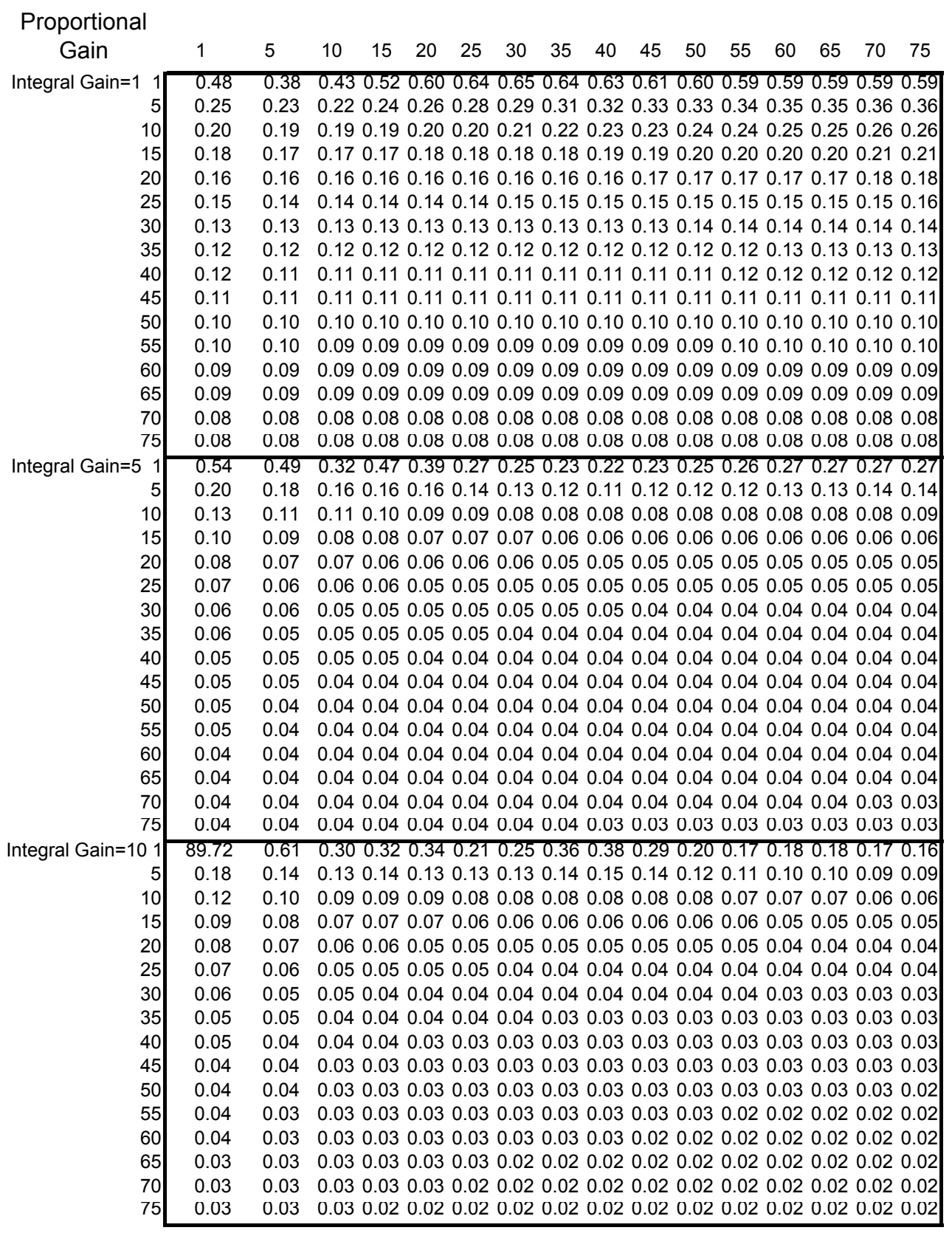


Table B-4: RMS speed error obtained using the non-linear model and wind5 as wind input file.

Derivative Gain

\begin{tabular}{|c|c|c|c|c|c|c|c|c|c|c|c|c|c|c|c|c|}
\hline \multicolumn{17}{|l|}{ Proportional } \\
\hline Gain & 1 & 5 & 10 & 15 & 20 & 25 & 30 & 35 & 40 & 45 & 50 & 55 & 60 & 65 & 70 & 75 \\
\hline$=151$ & 126.42 & 1.45 & .45 & 0.17 & 0.23 & 0.22 & 0.33 & 0.21 & 0.16 & 0.17 & 0.22 & 0.29 & 0.31 & 0.29 & .2 & 0.1 \\
\hline 5 & 30.96 & 0.14 & 11 & 0.09 & 0.10 & 0.12 & 0.12 & 0.11 & 0.10 & 0.11 & 0.12 & 0.13 & 0.14 & 0.14 & 0.15 & \\
\hline 10 & 0.12 & 0.09 & 08 & 0.07 & 0.07 & 0.07 & 0.07 & 0.07 & 0.07 & 0.07 & 0.08 & 0.08 & 0.08 & 0.08 & 0.08 & 0.07 \\
\hline 15 & 0.09 & 0.07 & 0.06 & 0.06 & 0.06 & 0.06 & 0.06 & 0.06 & 0.06 & 0.06 & 0.06 & 0.06 & 0.06 & 0.06 & 0.06 & 0.05 \\
\hline 20 & 0.08 & 0.06 & .06 & 0.05 & 0.05 & 0.05 & 0.05 & 0.05 & 0.05 & 0.05 & 0.05 & 0.05 & 0.05 & 0.04 & 0.04 & 0.04 \\
\hline 25 & 0.07 & 0.05 & 0.05 & 0.05 & 0.04 & 0.04 & 0.04 & 0.04 & 0.04 & 0.04 & 0.04 & 0.04 & 0.04 & 0.04 & 0.04 & 0.04 \\
\hline 30 & 0.06 & 0.05 & 0.04 & 0.04 & 0.04 & 0.04 & 0.04 & 0.04 & 0.04 & 0.03 & 0.03 & 0.03 & 0.03 & 0.03 & 0.03 & 0.03 \\
\hline 35 & 0.05 & 0.04 & 04 & 0.04 & 0.04 & 0.03 & 0.03 & 0.03 & 0.03 & 0.03 & 0.03 & 0.03 & 0.03 & 0.03 & 0.03 & 0.03 \\
\hline 40 & 0.05 & 0.04 & 0.04 & 0.03 & 0.03 & 0.03 & 0.03 & 0.03 & 0.03 & 0.03 & 0.03 & 0.03 & 0.03 & 0.03 & 0.03 & $0 . C$ \\
\hline 45 & 0.04 & 0.04 & & 0.03 & 0.03 & 0.03 & 0.03 & 0.03 & 0.03 & 0.03 & 0.03 & 0.03 & 0.03 & 0.02 & 0.02 & 0.02 \\
\hline 50 & 0.04 & 0.03 & 0.03 & 0.03 & 0.03 & 0.03 & 0.03 & 0.03 & 0.03 & 0. & 0.02 & 0. & 0.02 & 0.02 & 0.4 & 0.02 \\
\hline 55 & 0.04 & 0.03 & & 0.03 & 0.03 & 0.03 & 0.02 & 0.02 & 0.02 & & 0.02 & 0. & 0 & . & 0 & 0.6 \\
\hline 60 & 0.03 & 0.03 & 0.03 & 0.03 & 0.02 & 0.02 & 0.02 & 0.02 & 0.02 & 0 & 0.02 & 0. & 0 & 0.02 & 0.02 & 0.02 \\
\hline 65 & 0.03 & 0.03 & 0. & 0.02 & 0.02 & 0.02 & 0.02 & 0.02 & 0.02 & 0.02 & 0.02 & 0.02 & 0.02 & 0.02 & 0.02 & 0.02 \\
\hline 70 & 0.03 & 0.03 & 0.02 & 0.02 & 0.02 & 0.02 & 0.02 & 0.02 & 0.02 & 0.02 & 0.02 & 0.02 & 0.02 & 0.02 & 0.02 & 0.02 \\
\hline 15 & 0.03 & 0.03 & 0.02 & 0.02 & 0.02 & 0.02 & 0.02 & 0.02 & 0.02 & 0.02 & 0.02 & 0.02 & 0.02 & 0.02 & 0.02 & 0.02 \\
\hline 01 & 10.58 & 75.02 & 14.05 & 0.36 & 0.16 & 0.21 & 0.20 & 0.16 & 0.27 & 0.25 & 0.15 & 0.12 & 0.14 & 0.1 & 0.1 & 0.24 \\
\hline & 84.37 & 0.20 & 0 & 0 & 0. & 0. & 0.0 & 0 & 0. & 0 & 0 & 0 & 0 & 10 & 0.11 & 0.12 \\
\hline 10 & 15 & 0.10 & 0 & 0 & 0. & 0. & $0 . C$ & 0.07 & 0. & 0. & 0 & 0. & 0. & 0.0 & 0.0 & ( \\
\hline 15 & 10 & 0.07 & & 0 & 0. & 0 & 0.05 & 0. & 0 & 0 & 0 & 0. & 0 & 10 & 0.0 & ( \\
\hline 20 & 0.08 & 0.06 & & & 0. & 0 & 0. & 0 & 0 & 0 & 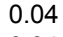 & 0 & 0 & 0.0 & ( & 0.04 \\
\hline 25 & 0.07 & 0.05 & 0. & 0. & 0. & 0 & 0. & 0. & 0. & 0 & 0. & & 0 & 0. & 0 & 0. \\
\hline 30 & 0.06 & 0.05 & 0.04 & 0.0 & 0.04 & 0.04 & 0.03 & 0.03 & 0.03 & 0. & 0.03 & 0. & 0.03 & 0.03 & 0.03 & $0 . C$ \\
\hline 35 & 0.05 & 0.04 & 0. & 0.03 & 0.03 & 0.03 & 0.03 & 0.03 & 0.03 & 0. & 0.03 & 0.03 & 0.03 & 0.03 & 0.03 & 0.03 \\
\hline 40 & 0.05 & 0.04 & 0. & 0.03 & 0.03 & 0.03 & 0.03 & 0.03 & 0.03 & 0.03 & 0.03 & 0.03 & 0.03 & 0.03 & 0.03 & 0.03 \\
\hline 45 & 0.04 & 0.03 & 0. & 0.03 & 0.03 & 0.03 & 0.03 & 0.03 & 0.03 & 0.03 & 0.02 & 0.02 & 0.02 & 0.02 & 0.02 & \\
\hline 50 & 0.0 & 0.03 & 0.03 & 0.03 & 0.03 & 0.03 & 0.03 & 0.02 & 0.02 & 0.02 & 0.02 & 0.02 & 0.02 & 0.02 & 0.02 & $0 . C$ \\
\hline 55 & 0.04 & 0.03 & 0.03 & 0.03 & 0.02 & 0.02 & 0.02 & 0.02 & 0.02 & 0.02 & 0.02 & 0.02 & 0.02 & 0.02 & 0.02 & 0.02 \\
\hline 60 & 0.03 & 0.03 & 0. & 0.02 & 0.02 & 0.02 & 0.02 & 0.02 & 0.02 & 0.02 & 0.02 & 0.02 & 0.02 & 0.02 & 0.02 & 0.02 \\
\hline 65 & 0.03 & 0.03 & 0.02 & 0.02 & 0.02 & 0.02 & 0.02 & 0.02 & 0.02 & 0.02 & 0.02 & 0.02 & 0.02 & 0.02 & 0.02 & 0.02 \\
\hline 70 & 0.03 & 0.03 & 0.02 & 0.02 & 0.02 & 0.02 & 0.02 & 0.02 & 0.02 & 0.02 & 0.02 & 0.02 & 0.02 & 0.02 & 0.02 & 0.02 \\
\hline 15 & 0.03 & 0.02 & 0.02 & 0 & 0.02 & 0.02 & 0.0 & 0.02 & 0.02 & 0.02 & 0.02 & 0.02 & 0.02 & 0.0 & 0.02 & \\
\hline
\end{tabular}


Table B-5: RMS speed error obtained using the non-linear model and highwind4 as wind input file.

Derivative Gain

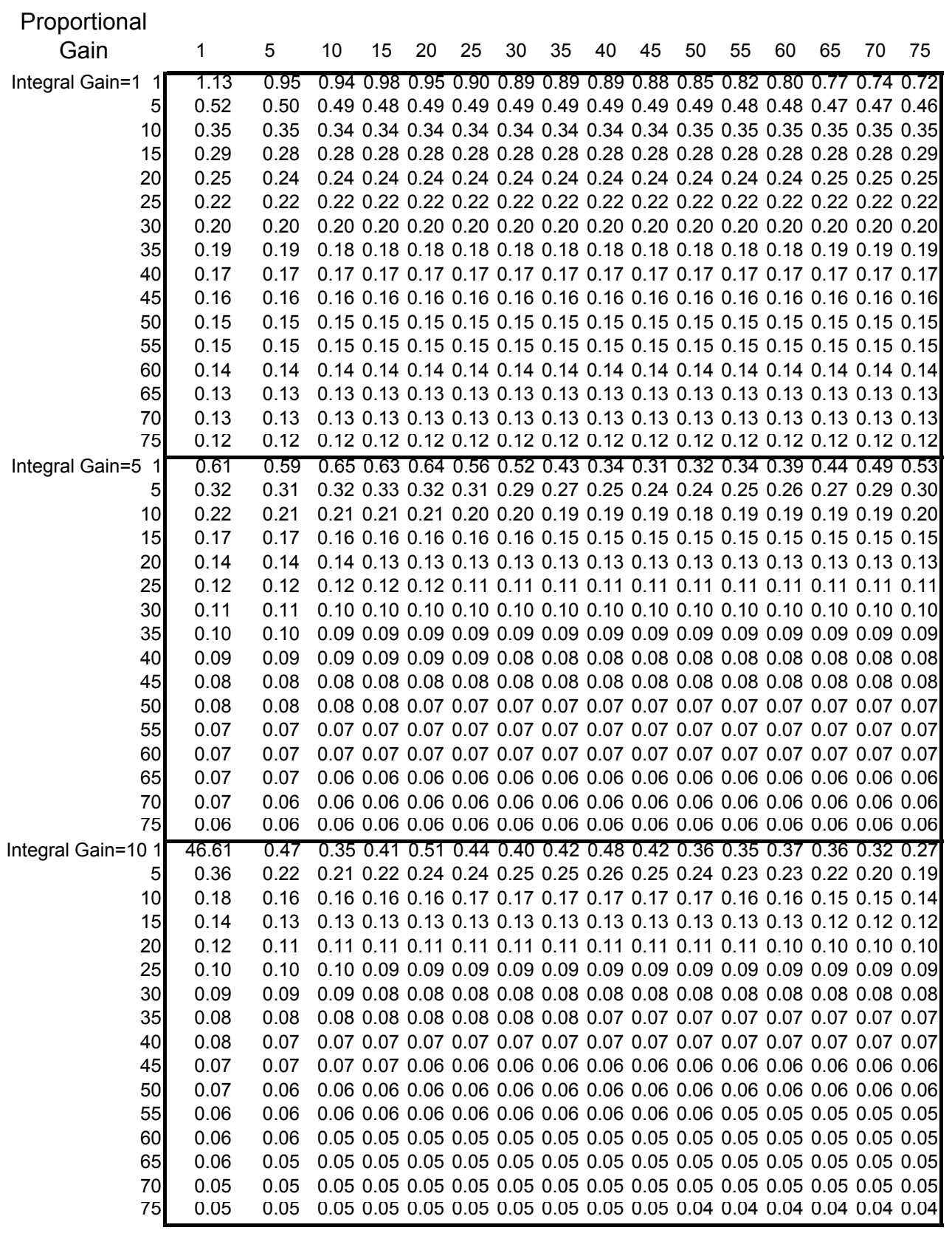


Table B-5: RMS speed error obtained using the non-linear model and highwind4 as wind input file.

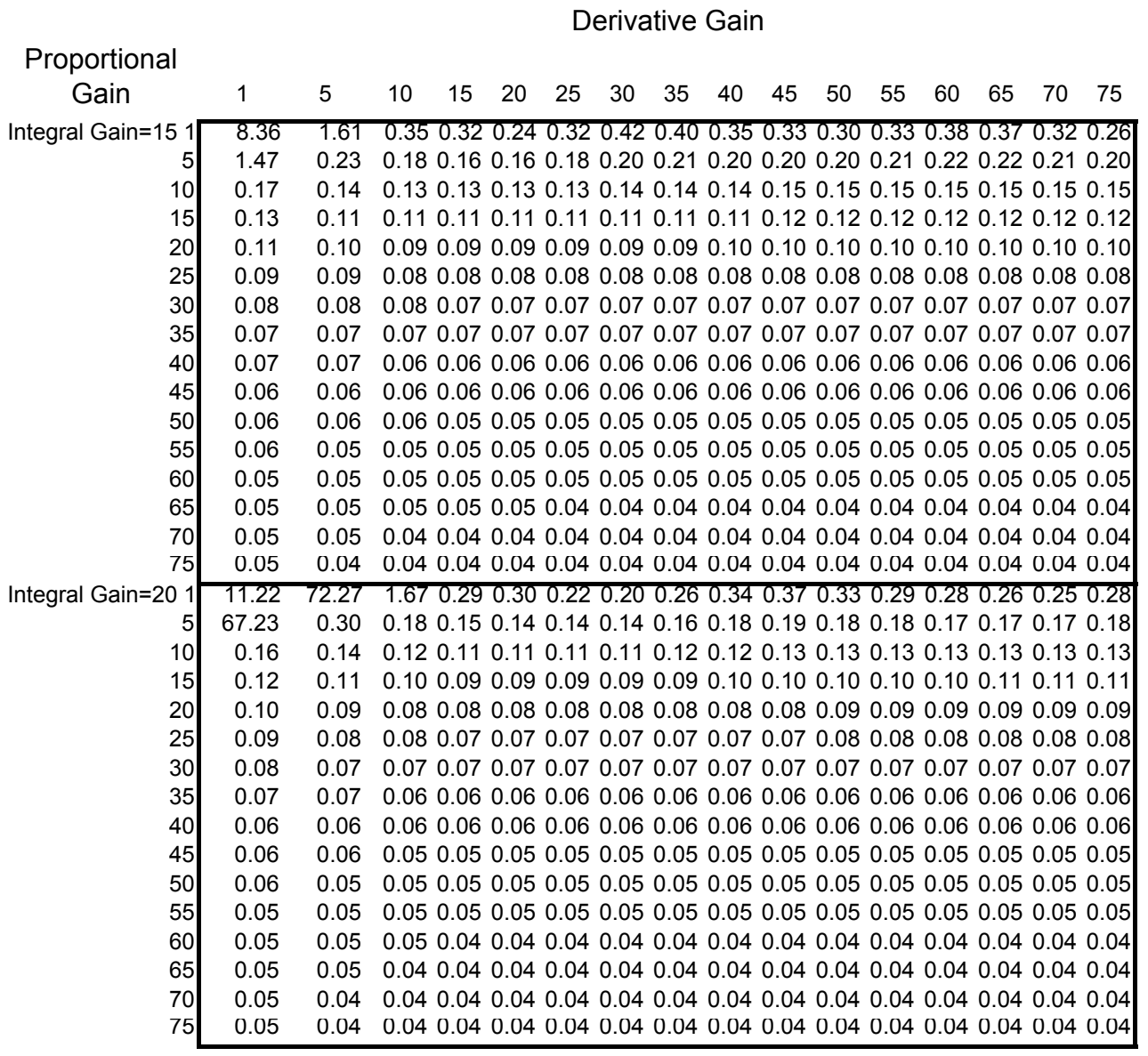


Table B-6: RMS speed error obtained using the non-linear model averaged with all five wind input cases.

Derivative Gain

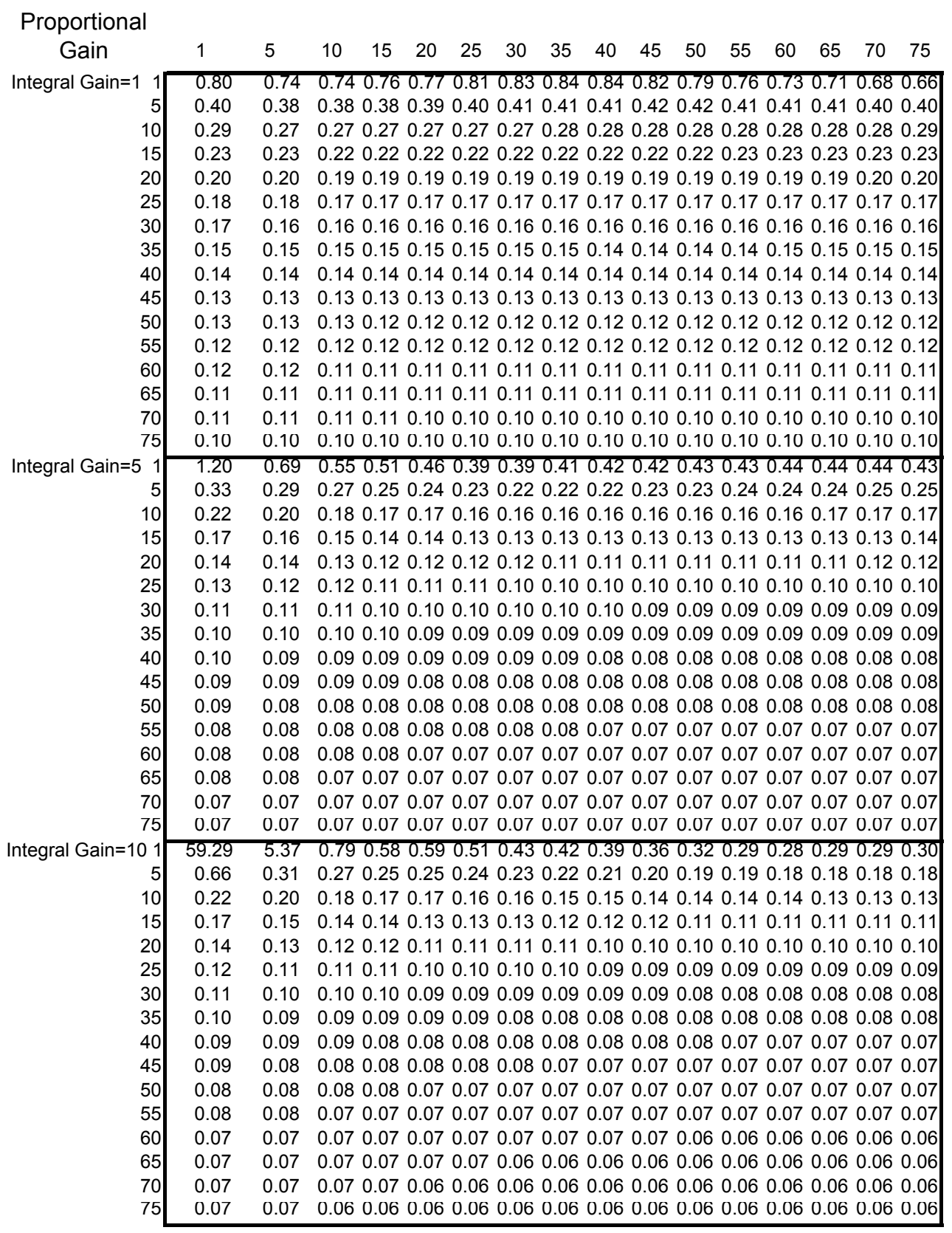


Table B-6: RMS speed error obtained using the non-linear model averaged with all five wind input cases.

Derivative Gain

\begin{tabular}{|c|c|c|c|c|c|c|c|c|c|c|c|c|c|c|c|c|}
\hline \multicolumn{17}{|l|}{ Proportional } \\
\hline Gain & 1 & 5 & 10 & 15 & 20 & 25 & 30 & 35 & 40 & 45 & 50 & 55 & 60 & 65 & 70 & 75 \\
\hline$n=151$ & 168.26 & 49.40 & 2.24 & 0.95 & 0.65 & 0.51 & 0.46 & 0.52 & 0.49 & 0.42 & 0.40 & 0.39 & 0.35 & 0.33 & 0.31 & 0.29 \\
\hline 5 & 10.40 & 1.72 & 31 & 0.27 & 0.24 & 0.23 & 0.23 & 0.24 & 0.24 & 0.23 & 0.22 & 0.21 & 0.20 & & & 0. \\
\hline 10 & 0.33 & 0.21 & 19 & 0.18 & 0.17 & 0.16 & 0.16 & 0.16 & 0.16 & 0.15 & 0.15 & 0.15 & 0.14 & & 0.14 & 0.13 \\
\hline 15 & 0.19 & 0.16 & 15 & 0.14 & 0.13 & 0.13 & 0.13 & 0.13 & 0.12 & 0.12 & 0.12 & 0. & 0.12 & 0. & 0 & 0.1 \\
\hline 20 & 0.15 & 0.13 & 0.12 & 0.12 & 0.12 & 0.11 & 0.11 & 0.11 & 0.11 & 0.10 & 0.10 & 0.10 & 0.10 & 0.10 & 0.10 & 0.10 \\
\hline 25 & 0.13 & 0.12 & 0.11 & 0.11 & 0.10 & 0.10 & 0.10 & 0.10 & 0.09 & 0.09 & 0.09 & 0.09 & 0.09 & 0.09 & 0.09 & 0.09 \\
\hline 30 & 0.12 & 0.10 & 0.10 & 0.10 & 0.09 & 0.09 & 0.09 & 0.09 & 0.09 & 0.09 & 0.08 & 0.08 & 0.08 & 0.08 & 0.08 & 0.08 \\
\hline 35 & 0.10 & 0.10 & 09 & 0.09 & 0.09 & 0.08 & 0.08 & 0.08 & 0.08 & 0.08 & 0.08 & 0.08 & 0.08 & 0.08 & 0.08 & 0.08 \\
\hline 40 & 0.09 & 0.09 & 09 & 0.08 & 0.08 & 0.08 & 0.08 & 0.08 & 0.08 & 0.08 & 0.07 & 0.07 & 0.07 & 0.0 & 0.07 & 0.07 \\
\hline 45 & 0.09 & 0.08 & 08 & 0.08 & 0.08 & 0.08 & 0.07 & 0.07 & 0.07 & 0.07 & 0.07 & 0.07 & 0.07 & 0. & 0.07 & 0.07 \\
\hline 50 & 0.08 & 0.08 & 68 & 0.07 & 0.07 & 0.07 & 0.07 & 0.07 & 0.07 & 0.07 & 0.07 & 0.07 & 0.07 & 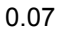 & 0.07 & 0.07 \\
\hline 55 & 0. & 07 & 7 & 0.07 & 0.07 & 0.07 & 0.07 & 0.07 & 0.07 & 0.07 & 0.07 & 0. & 0.06 & 0 & 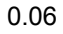 & 0.06 \\
\hline 60 & 0.07 & 0.07 & 07 & 0.07 & 0.07 & 0.07 & 0.07 & 0.07 & 0.06 & 0.06 & 0.06 & 0.06 & 0.06 & 0. & 0.06 & 0.06 \\
\hline 65 & 0.07 & 0.07 & 0.07 & 0.07 & 0.07 & 0.06 & 0.06 & 0.06 & 0.06 & 0.06 & 0.06 & 0.06 & 0.06 & 0.06 & 0.06 & 0.06 \\
\hline 10 & 0.07 & 0.07 & 0.07 & 0.06 & 0.06 & 0.06 & 0.06 & 0.06 & 0.06 & 0.06 & 0.06 & 0.06 & 0.06 & 0.06 & 0.06 & 0.06 \\
\hline 15 & $0.0 /$ & 0.06 & 0.06 & 0.06 & 0.06 & 0.06 & 0.06 & 0.06 & 0.06 & 0.066 & 0.06 & 0.06 & 0.06 & 0.06 & 0.06 & 0.06 \\
\hline $\begin{array}{ll}0 & 1\end{array}$ & 1.78 & 46.81 & 17.84 & 1.49 & 0.87 & 0.70 & 0.54 & 0.46 & 0.43 & 0.44 & 0.47 & 0.46 & 0.42 & 0.38 & 0.38 & 0.38 \\
\hline 5 & 97.67 & 16.82 & 0.75 & 0.32 & 0.27 & 0.26 & 0.23 & 0.22 & 0.22 & 0. & 0.24 & 0.24 & 0. & 0.2 & 0.2 & 0.21 \\
\hline 10 & 12.95 & 0.25 & 0.20 & 0. & 0. & 0. & 0. & 0. & 0.1 & 0.16 & 0.1 & 0. & 0. & 0. & 0.1 & 0.15 \\
\hline 15 & 0 & 0.17 & 0 & 0 & 0. & 0 & 0. & 3 & 0. & 0. & 0.1 & 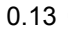 & 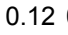 & 0.1 & 0 & 0.12 \\
\hline 20 & 8 & 0.14 & 0.13 & 0 & 0. & & 0. & 0 & 0 & & U. & 0.11 & 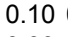 & & 0.10 & 0.1 \\
\hline 25 & 0 & 2 & 1 & 0.1 & 0. & 0. & 0. & 0.10 & 0. & & 0. & & $0 .($ & & 0 & 0.09 \\
\hline 30 & 0 & 1 & 0.10 & 0.10 & 0.09 & 0.09 & 0.09 & 0.09 & 0.09 & 0.09 & 0.09 & 0.09 & 0.08 & 0.08 & 0.08 & 0.08 \\
\hline 35 & 0. & .10 & 0.09 & 0.09 & 0.09 & 0.09 & 0.08 & 0.08 & 0.08 & 0.08 & 0.08 & 0.08 & 0.08 & 0.08 & 0.08 & 0.08 \\
\hline 40 & 0.11 & 0.09 & 0.09 & 0.08 & 0.08 & 0.08 & 0.08 & 0.08 & 0.08 & 0.08 & 0.08 & 0.07 & 0.07 & 0.07 & 0.07 & 0.07 \\
\hline 45 & 0. & 0.08 & 0.08 & 0.08 & 0.08 & 0.08 & 0.07 & 0.07 & 0.07 & 0.07 & 0.07 & 0.07 & 0.07 & 0.07 & 0.07 & 0.07 \\
\hline 50 & 0.09 & .08 & 0.08 & 0.08 & 0.07 & 0.07 & 0.07 & 0.07 & 0.07 & 0.07 & 0.07 & 0.07 & 0.07 & 0.07 & 0.07 & 0.07 \\
\hline 55 & 0.08 & 0.08 & 0.07 & 0.07 & 0.07 & 0.07 & 0.07 & 0.07 & 0.07 & 0.07 & 0.07 & 0.07 & 0.06 & 0.06 & 0.06 & 0.06 \\
\hline 60 & 0.08 & 0.07 & 0.07 & 0.07 & 0.07 & 0.07 & 0.07 & 0.07 & 0.06 & 0.06 & 0.06 & 0.06 & 0.06 & 0.06 & 0.06 & 0.06 \\
\hline 65 & 0.07 & 0.07 & 0.07 & 0.07 & 0.07 & 0.06 & 0.06 & 0.06 & 0.06 & 0.06 & 0.06 & 0.06 & 0.06 & 0.06 & 0.06 & 0.06 \\
\hline 70 & 0.0 & 0.07 & 0.07 & 0.06 & 0.06 & 0.06 & 0.06 & 0.06 & 0.06 & 0.06 & 0.06 & 0.06 & 0.06 & 0.06 & 0.06 & 0.06 \\
\hline 15 & $0.0 /$ & U.U/ & 0.06 & 0.06 & 0.06 & 0.06 & 0.06 & 0.06 & 0.06 & 0.06 & 0.06 & 0.06 & 0.06 & 0.06 & 0.06 & 0.06 \\
\hline
\end{tabular}


Table B-7: Actuator duty cycle obtained using the non-linear model and medwind 2 as wind input file.

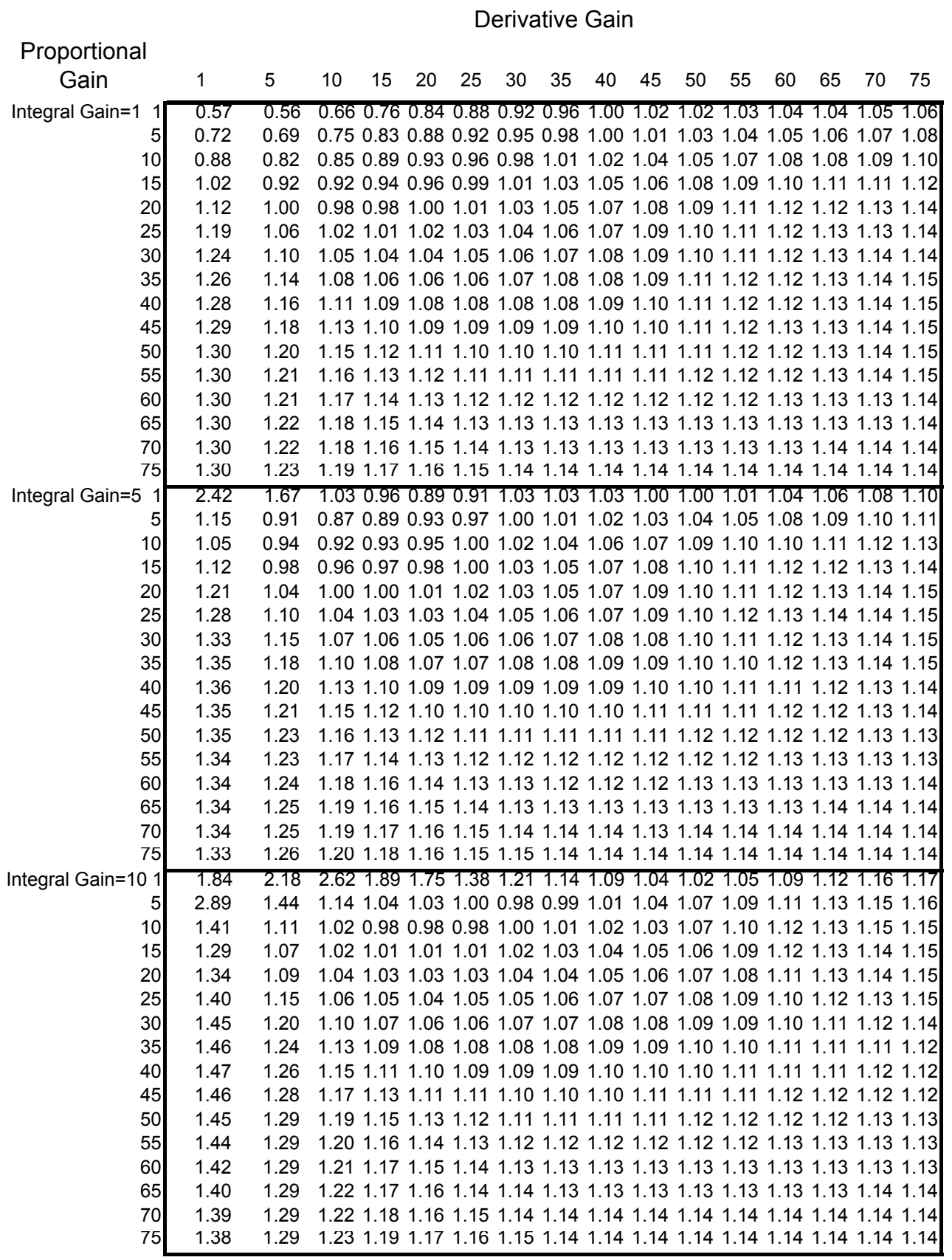


Table B-7: Actuator duty cycle obtained using the non-linear model and medwind 2 as wind input file.

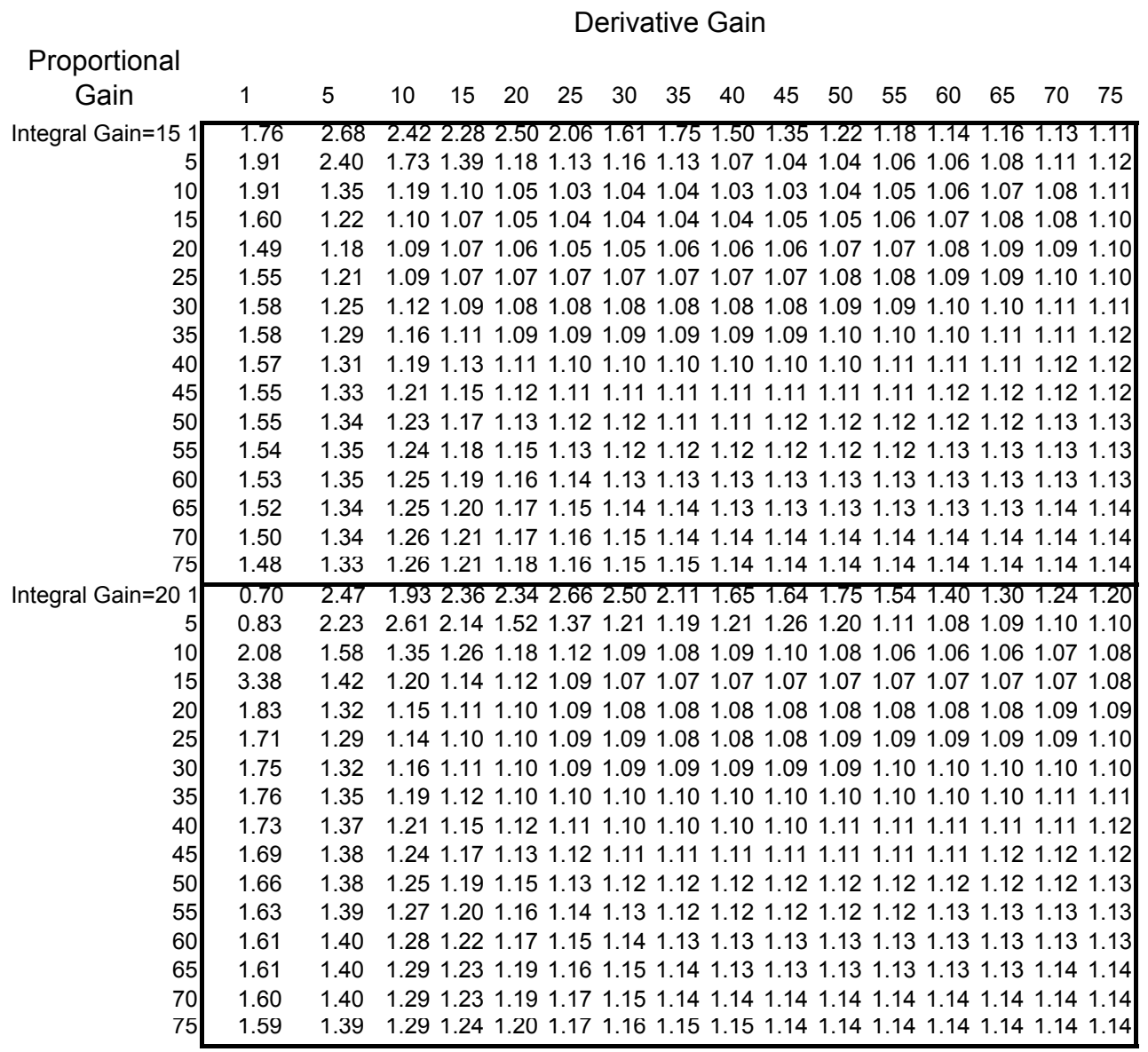


Table B-8: Actuator duty cycle obtained using the non-linear model and wind 3 as wind input file.

Derivative Gain

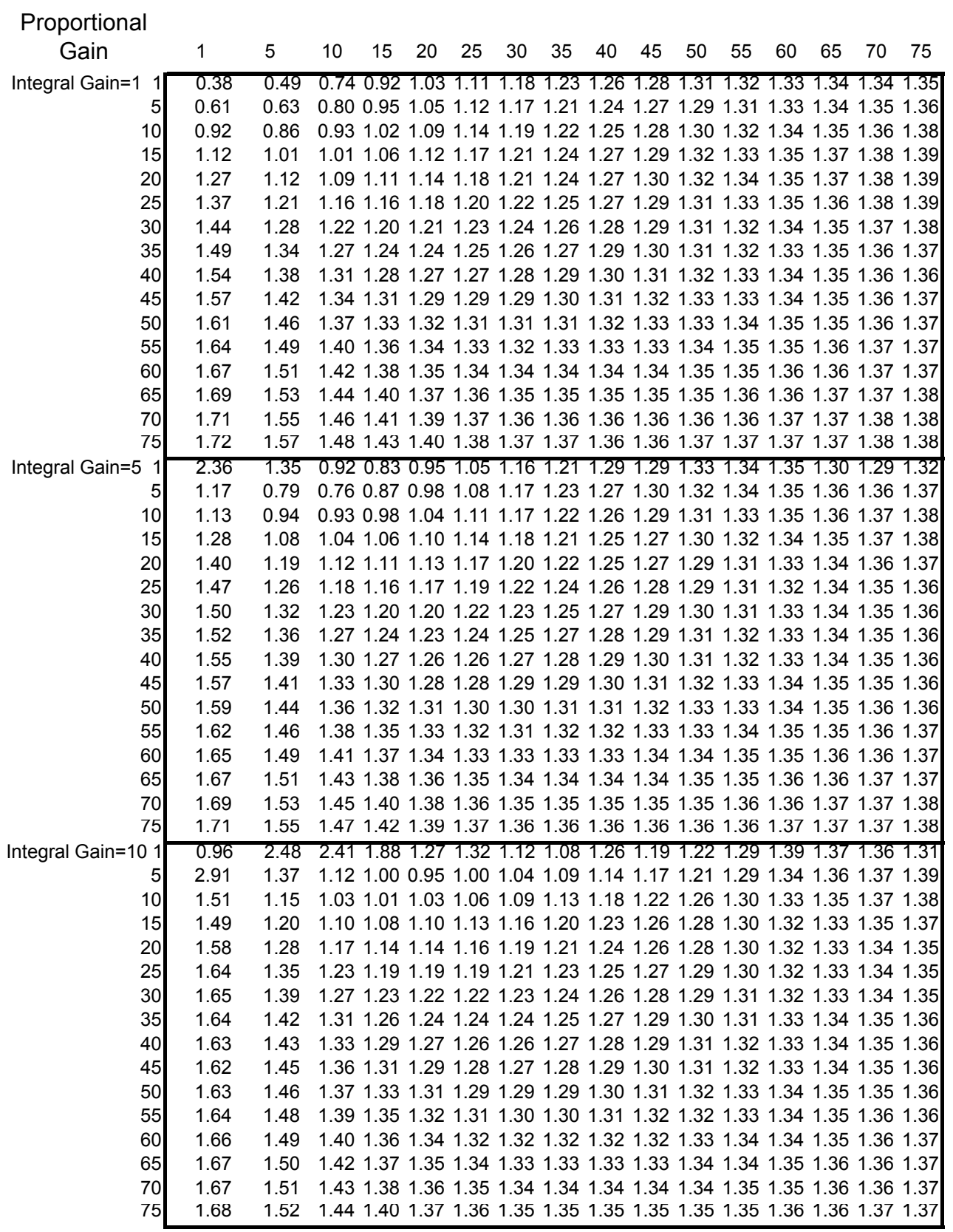


Table B-8: Actuator duty cycle obtained using the non-linear model and wind 3 as wind input file.

Derivative Gain

\begin{tabular}{|c|c|c|c|c|c|c|c|c|c|c|c|c|c|c|c|c|}
\hline \multicolumn{17}{|l|}{ Proportional } \\
\hline Gain & 1 & 5 & 10 & 15 & 20 & 25 & 30 & 35 & 40 & 45 & 50 & 55 & 60 & 65 & 70 & 75 \\
\hline tegral Gain $=151$ & 1.11 & 1.63 & 2.68 & 2.55 & 2.36 & 2.07 & 7.66 & 1.39 & 1.49 & 1.37 & 1.24 & 1.20 & 1.40 & 1.33 & 1.28 & 1.27 \\
\hline & 1.58 & 3.13 & 51 & 1.27 & 1.26 & 1.17 & 1.09 & 1.11 & 1.13 & 1.16 & 1.16 & 1.19 & 1.26 & 1.28 & 1.26 & 1.27 \\
\hline 10 & 3.93 & .46 & 18 & & 1.11 & 1.12 & 1.11 & 1.12 & 1.14 & 1.16 & 1.19 & 1.22 & 1.25 & 1.28 & 30 & 1.32 \\
\hline 15 & 1.98 & 1.38 & 9 & 1.14 & 1.13 & 1.14 & 1.16 & 1.18 & 1.20 & 1.21 & 1.23 & 1.25 & 1.28 & 1. & 1 & \\
\hline 20 & 1.89 & 1.40 & 23 & 1.18 & 1.17 & 1.17 & 1.19 & 1.21 & 1.22 & 1.24 & 1.26 & 1.28 & 1.31 & 1.32 & 1 & 1.35 \\
\hline 25 & 1.75 & 1.45 & .28 & 1.22 & 1.21 & 1.20 & 1.21 & 1.22 & 1.24 & 1.25 & 1.27 & 1.29 & 1.31 & 1.33 & 1 & 1.35 \\
\hline 30 & 1.73 & 1.49 & 1.32 & 1.26 & 1.24 & 1.23 & 1.23 & 1.24 & 1.25 & 1.27 & 1.28 & 1.30 & 1.32 & 1.33 & 1.34 & 1.35 \\
\hline 35 & 1.81 & 1.51 & 1.35 & 1.29 & 1.26 & 1.25 & 1.25 & 1.26 & 1.26 & 1.27 & 1.29 & 1.30 & 1.32 & 1.33 & 1.34 & 1.35 \\
\hline 40 & 1.78 & 1.52 & 1.37 & 1.31 & 1.29 & 1.27 & 1.27 & 1.27 & 1.27 & 1.28 & 1.29 & 1.31 & 1.32 & 1.33 & 1.34 & 1.35 \\
\hline 45 & 1.76 & 1.52 & 1.39 & 1.33 & 1.30 & 1.29 & 1.28 & 1.28 & 1.28 & 1.29 & 1.30 & 1.31 & 1.32 & 1.33 & 1.34 & 1.3 \\
\hline 50 & 1.75 & 1.51 & 1.40 & 1.35 & 1.32 & 1.30 & 1.30 & 1.29 & 1.29 & 1.30 & & 1.32 & & 1.3 & 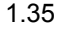 & \\
\hline 5 & 1.74 & 1.51 & 1.41 & 1.36 & 1. & 1.32 & 1.31 & 1.30 & 1.30 & 1.31 & & 1.32 & & 1.3 & . & \\
\hline 0 & 1.72 & 1.51 & 1.42 & & 1. & & 1.32 & 1.31 & 1.31 & 1.31 & 2 & 1.33 & & 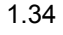 & 35 & 1. \\
\hline 65 & 1. & 1.52 & 3 & 1.38 & 1.36 & 1.34 & 1.33 & 1.32 & 1.32 & 1.32 & 1.33 & 1.33 & 1.34 & 1.35 & 1 & 1. \\
\hline 70 & 1.71 & 1.53 & 1. & 1.39 & 1.37 & 1.35 & 1.34 & 1.33 & 1.33 & 1.33 & 1.33 & 1.34 & 1.34 & 1.35 & 1.36 & 1.36 \\
\hline 15 & 1.10 & 1.54 & 1.45 & 1.40 & 1.38 & 1.36 & 1.35 & 1.34 & 1.34 & 1.34 & 1.34 & 1.34 & 1.35 & 1.35 & 1.36 & 1.31 \\
\hline 201 & 1.20 & 1.07 & 1.51 & 2.87 & 2.33 & 2.43 & 2.25 & 2.09 & 1.83 & 1.43 & 1.49 & 1.59 & 1.46 & 1.42 & 1.34 & 1.29 \\
\hline 5 & 1.03 & 1.55 & 2.95 & 1.63 & 1.42 & 1.32 & 1.41 & 1.29 & 1.19 & 1.18 & 1.21 & 1.21 & 1.26 & 1.25 & 1.22 & 1.24 \\
\hline 10 & 1.49 & 62 & 1. & 1.23 & 1.18 & 1.18 & 1.20 & 1.21 & 1.17 & 1.17 & 1.18 & 1.20 & 1.21 & 1.23 & 1.25 & .27 \\
\hline 15 & 3.24 & 1.66 & 3 & 1.21 & 1.17 & 1.17 & 1.18 & 1.20 & 1.21 & 1.22 & 1.22 & 1.23 & 1.24 & 1.25 & 1.27 & 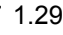 \\
\hline 20 & 2. & 1.64 & 1. & 1.24 & 1.21 & 1.20 & 1.20 & 1.21 & 1.22 & 1.24 & 1. & 1.27 & 1.28 & 1.2 & 1.30 & 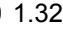 \\
\hline 25 & 2. & 1. & 5 & 1.2 & 1. & 1.2 & 1.22 & 1. & 1.24 & 1.25 & 1. & 1.28 & 1.29 & 1.30 & 1.31 & 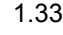 \\
\hline 30 & 2.1 & 1.57 & 1.38 & 1. & 1. & 1. & 1.24 & 1. & 1.25 & 1.26 & 1.2 & 1.29 & 1.30 & 1.3 & 1.32 & 1. \\
\hline 35 & 2. & 1.60 & 1.42 & 1.32 & 1.2 & 1.27 & 1.26 & 1.26 & 1.26 & 1.27 & 1.2 & 1.29 & 1.30 & 1. & 1.33 & 3 \\
\hline 40 & 1.8 & 1.61 & 1.44 & 1.35 & 1.3 & 1.29 & 1.28 & 1.28 & 1.28 & 1.28 & 1.29 & 1.30 & 1.31 & 1.32 & 1.33 & 31. \\
\hline 45 & $1 . \varepsilon$ & 1.60 & 1.45 & 1.36 & 1.32 & 1.30 & 1.29 & 1.29 & 1.29 & 1.29 & 1.30 & 1.30 & 1.31 & 1.32 & 1.33 & 31.3 \\
\hline 50 & 1. & 1.60 & 1.45 & 1.37 & 1.34 & 1.32 & 1.31 & 1.30 & 1.30 & 1.30 & 1.30 & 1.31 & 1.32 & 1.32 & 1.34 & 1.35 \\
\hline 55 & 1. & 1.59 & 1.45 & 1.38 & 1.3 & 1.33 & 1.32 & 1.31 & 1.31 & 1.31 & 1.31 & 1.31 & 1.32 & 1.33 & 1.34 & 1.35 \\
\hline 60 & 1. & 1.58 & 1.45 & 1.39 & 1. & 1.34 & 1.33 & 1.32 & 1.32 & 1.32 & 1.32 & 1.32 & 1.32 & 1.33 & 1.34 & \\
\hline 65 & 1. & 1.58 & 1. & 1.40 & 1.37 & 1.35 & 1.34 & 1.33 & 1.33 & 1.32 & 1.32 & 1.33 & 1.33 & 1.34 & 1.34 & \\
\hline 70 & $1 . \varepsilon$ & 1.57 & 1. & 1.41 & 1. & 1.36 & 1.35 & 1.34 & 1.33 & 1.33 & 1.33 & 1.33 & 1.33 & 1.34 & 1.35 & \\
\hline & $1.8 /$ & $.5 /$ & $1 .-7$ & & 1.0 & 31 & 1.35 & 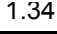 & 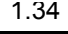 & .34 & 1.33 & 1.34 & 1.34 & 1.3 & 3 & \\
\hline
\end{tabular}


Table B-9: Actuator duty cycle obtained using the non-linear model and wind4 as wind input file.

Derivative Gain

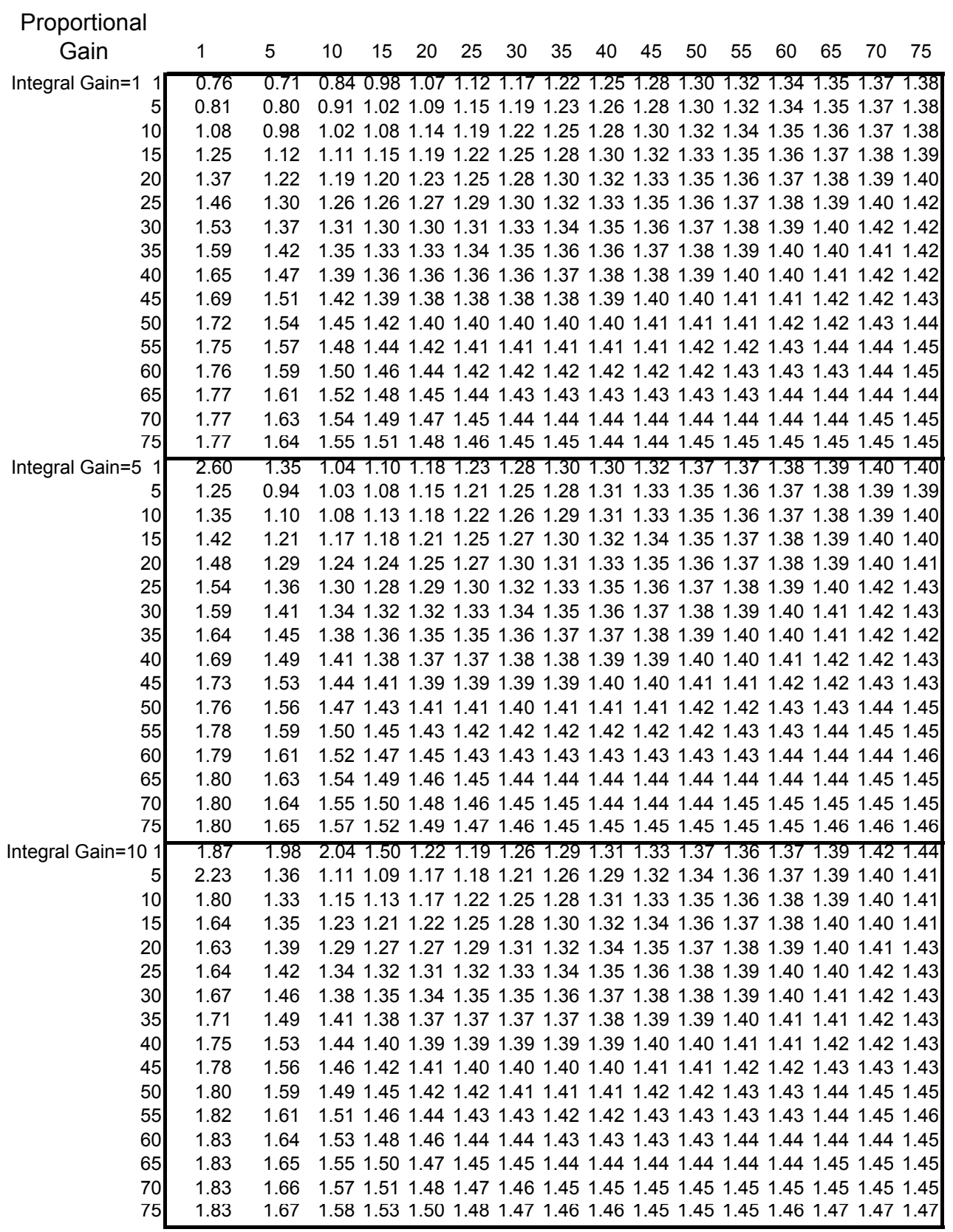


Table B-9: Actuator duty cycle obtained using the non-linear model and wind4 as wind input file.

Derivative Gain

\begin{tabular}{|c|c|c|c|c|c|c|c|c|c|c|c|c|c|c|c|c|}
\hline roportional & & & & & & & & & & & & & & & & \\
\hline Gain & 1 & 5 & 10 & 15 & 20 & 25 & 30 & 35 & 40 & 45 & 50 & 55 & 60 & 65 & 70 & 75 \\
\hline tegral Gain $=151$ & 0.82 & 1.11 & 4.12 & 1.64 & 1.38 & 1.34 & 1.32 & 29 & 1.28 & 1.29 & 1.36 & 1.39 & 1.38 & 1.39 & 1.40 & 1.42 \\
\hline & 3.42 & 1.90 & 49 & 1.31 & 1.15 & 1.18 & 1.23 & 1.27 & 1.26 & 1.28 & 1.31 & 1.34 & 1.35 & 1.37 & $1.3 \varepsilon$ & 1.4 \\
\hline 10 & 2.36 & 60 & 35 & 1.22 & 1.18 & & 1.24 & 1.28 & 1.30 & 1 & 1.33 & 1.34 & 1.36 & 1.38 & 1.39 & 1.40 \\
\hline 15 & 1.85 & 49 & 34 & 1.27 & 1.24 & 1.24 & 1.27 & 1.29 & 1.32 & 1.33 & 1.35 & 1.36 & 1.37 & 1.38 & & \\
\hline 20 & 1.78 & 1.48 & 36 & 1.32 & 1.30 & 1.30 & 1.31 & $1.3^{2}-x+5$ & 1.33 & 1.35 & 1.36 & 1.37 & 1.38 & 1.39 & & 1.42 \\
\hline 25 & 1.75 & 1.48 & 1.39 & 1.35 & 1.34 & 1.33 & 1.34 & 1.34 & 1.35 & 1.36 & 1.37 & 1.38 & 1.39 & 1.40 & 1 & 1.43 \\
\hline 30 & 1.75 & 1.50 & 1.41 & 1.38 & 1.36 & 1.36 & 1.36 & 1.36 & 1.37 & 1.38 & 1.39 & 1.39 & 1.40 & 1.41 & 1.41 & 1.42 \\
\hline 35 & 1.78 & 1.53 & 1.44 & 1.40 & 1.39 & 1.38 & 1.38 & 1.38 & 1.39 & 1.39 & 1.40 & 1.40 & 1.41 & 1.41 & 1.42 & 1.43 \\
\hline 40 & 1.81 & 1.56 & 1.46 & 1.42 & 1.40 & 1.40 & 1.40 & 1.40 & 1.40 & 1.40 & 1.41 & 1.41 & 1.42 & 1.42 & 1.42 & 1.43 \\
\hline 45 & 1.83 & 1.59 & 1.48 & 1.44 & 1.42 & 1.41 & 1.41 & 1.41 & 1.41 & 1.41 & 1.42 & 1. & 1.42 & 1.43 & 1.44 & 1.45 \\
\hline 50 & 1.85 & 1.61 & 1.51 & 1.46 & 1.44 & 1.43 & 1.42 & 1.42 & 1.42 & 1.42 & 1. & 1. & & 1.4 & 1.45 & 1. \\
\hline 5 & 1.86 & 1.64 & 1.53 & 1.48 & 1.45 & 1.44 & 1.43 & 1.43 & 1.43 & 1.43 & & 1. & & 1.4 & 1.45 & 1. \\
\hline 0 & 1.86 & 1.66 & & 1.49 & 1.47 & & 1.44 & 4 & 1.44 & 1.44 & & 1. & & 1.44 & 1.45 & 1.45 \\
\hline 65 & 1. & 1.67 & & 1.51 & 1. & 1.46 & 1.45 & 1.45 & 1.45 & 1.45 & 1.45 & & & 1.45 & T & 1.6 \\
\hline 70 & 1.86 & 1.68 & 1. & 1.52 & 1.49 & 1.47 & 1.46 & 1.46 & 1.45 & 1.45 & 1.45 & 1.45 & 1.45 & 1.46 & 1.46 & 1.46 \\
\hline 15 & 1.85 & 1.69 & 1.59 & 1.54 & 1.50 & 1.48 & 1.41 & $1.46^{\circ}$ & $1.46^{\circ}$ & 1.46 & 1.46 & 1.46 & 1.46 & 1.41 & 1.41 & $1.4 /$ \\
\hline 201 & 0.93 & 1.21 & 3.19 & 2.54 & 1.48 & 1.23 & 1.25 & 1.33 & 1.31 & 1.33 & 1.32 & 1.33 & 1.31 & 1.35 & 1.42 & 1.45 \\
\hline 5 & 2.26 & 2.36 & 1.69 & 1.65 & 1.49 & 1.29 & 1.19 & 1.23 & 1.28 & 1.32 & 1.32 & 1.31 & 1.31 & 1.34 & 1.37 & 1.39 \\
\hline 10 & 2.32 & .91 & 1. & 1.38 & 1.30 & 1.24 & 1.23 & 1.25 & 1.28 & 1.31 & 1.34 & 1.35 & 1.34 & 1.35 & 1.36 & 1.38 \\
\hline 15 & 2.08 & 62 & 1. & 1.36 & 1.31 & 1.28 & 1.27 & 1.28 & 1.30 & 1.32 & 1. & 1.36 & 1.37 & 1.38 & 1.3 & 1.40 \\
\hline 20 & 1. & 6 & 1. & 1.3 & 1. & 1.32 & 1.31 & 1. & 1.33 & 1.34 & 1. & 1. & 1. & 1.39 & 1.41 & 1.41 \\
\hline 25 & 1. & 1.54 & 3 & 1.3 & 1. & 1. & 1.35 & 1. & 1.3 & 1. & 1 & 1. & & 1. & 1 & 1.42 \\
\hline 30 & 1.84 & 1. & 1.44 & 1.4 & 1. & 1. & 1.3 & 1. & 1.3 & 1 & 1 & 1. & 1 & 1. & 1.41 & 1.42 \\
\hline 35 & 1. & 1. & 1.46 & 1.42 & 1.4 & 1.40 & 1.39 & 1.39 & 1.39 & 1.39 & 1. & 1. & & 1. & & 1.42 \\
\hline 40 & 1.8 & 1.5 & 1.48 & 1.44 & 1.42 & 1.41 & 1.41 & 1.40 & 1.40 & 1.41 & 1.4 & 1. & 1.42 & 1.42 & 1. & 1. \\
\hline 45 & 1.8 & 1.62 & 1.51 & 1.46 & 1.43 & 1.42 & 1.42 & 1.4 & 1.42 & 1.42 & 1.42 & 1.42 & 1.43 & 1.44 & 1. & 1. \\
\hline 50 & 1.89 & 1. & 1.53 & 1.47 & 1.45 & 1.44 & 1.43 & 1.43 & 1.43 & 1.43 & 1.43 & 1.43 & 1.43 & 1.44 & 1.45 & 1.45 \\
\hline 55 & 1. & 1.6 & 1. & 1.49 & 1.46 & 1.45 & 1.44 & 1.44 & 1.43 & 1.43 & 1.44 & 1.44 & 1.44 & 1.44 & 1.44 & 1.45 \\
\hline 60 & 1. & 1.68 & 1. & 1.51 & 1.48 & 1.46 & 1.45 & 1.45 & 1.44 & 1.44 & 1.44 & 1.44 & 1.44 & 1.45 & 1.45 & 1.45 \\
\hline 65 & 1.89 & 1.69 & 1. & 1.52 & 1. & 1.47 & 1.46 & 1.45 & 1.45 & 1.45 & 1.45 & 1. & 1.45 & 1.45 & 1. & \\
\hline 70 & 1 & 1. & 1. & 1.53 & 1.5 & 1.48 & 1.47 & 1.46 & 1.46 & 1.45 & 1.45 & 1.46 & 1.46 & 1.46 & 1.47 & \\
\hline & 1.88 & .11 & 1. & 1.54 & $\cdots$ & & 1.48 & $1.4 /$ & $1.46^{\circ}$ & $1.46^{\circ}$ & 1.7 & 1.4 & $\because$ & 1.4 & $1.4 \pi$ & \\
\hline
\end{tabular}


Table B-10: Actuator duty cycle obtained using the non-linear model and wind5 as wind input file.

Derivative Gain

\begin{tabular}{|c|c|c|c|c|c|c|c|c|c|c|c|c|c|c|c|c|}
\hline roportional & & & & & & & & & & & & & & & & \\
\hline Gain & 1 & 5 & 10 & 15 & 20 & 25 & 30 & 35 & 40 & 45 & 50 & 55 & 60 & 65 & 70 & 75 \\
\hline Integral Gain=1 & 0.37 & 0.40 & 0.61 & 0.73 & 0.81 & 0.85 & 0.88 & 0.90 & 0.92 & 0.94 & 0.95 & 0.96 & 0.97 & 0.98 & 0.98 & 0.99 \\
\hline & 0.53 & 0.54 & 0.65 & 0.74 & 0.80 & 0.85 & 0.88 & 0.91 & 0.93 & 0.94 & 0.96 & 0.97 & 0.98 & 0.99 & 1.00 & 1.00 \\
\hline 10 & 0.72 & 0.68 & 0.72 & 0.78 & 0.83 & & 0.89 & 0.92 & 0.94 & 0.95 & 0.97 & 0.98 & 0.99 & 1.00 & 1.00 & \\
\hline 15 & 0.89 & 0.78 & 0.79 & 0.82 & 0.85 & 0.88 & 0.91 & 0.93 & 0.95 & 0.96 & 0.97 & 0.98 & 0.99 & 1.00 & 1.01 & 1.01 \\
\hline 20 & 1.04 & 0.88 & 0.85 & 0.86 & 0.88 & 0.90 & 0.92 & 0.94 & 0.95 & 0.97 & 0.98 & 0.99 & 1.00 & 1.00 & 1.01 & 1.02 \\
\hline 25 & 1.14 & 0.96 & 0.90 & 0.90 & 0.91 & 0.92 & 0.94 & 0.95 & 0.96 & 0.98 & 0.99 & 0.99 & 1.00 & 1.01 & 1.0 & 1.02 \\
\hline 30 & 1.21 & 1.02 & 0.95 & 0.93 & 0.93 & 0.94 & 0.95 & 0.96 & 0.97 & 0.98 & 0.99 & 1.00 & 1.01 & 1.01 & 1.02 & 1.02 \\
\hline 35 & 1.26 & 1.07 & 0.99 & 0.96 & 0.96 & 0.96 & 0.97 & 0.98 & 0.98 & 0.99 & 1.00 & 1.01 & 1.01 & 1.02 & 1.02 & 1.0 \\
\hline 40 & 1.29 & 1.10 & 1.02 & 0.99 & 0.98 & 0.98 & 0.98 & 0.99 & 0.99 & 1.00 & 1.01 & 1.01 & 1.02 & 1.02 & 1.03 & 1.03 \\
\hline 45 & 1.30 & 1.13 & 1.05 & 1.01 & 1.00 & 0.99 & 0.99 & 1.00 & 1.00 & 1.01 & 1.01 & 1.02 & 1.02 & 1.03 & 1.03 & 1.03 \\
\hline 50 & 1.32 & 1.15 & 1.07 & 1.03 & 1.01 & 1.01 & 1.01 & 1.01 & 1.01 & 1.01 & 1.02 & 1.02 & 1 & 1.03 & 1. & $1 .{ }^{1}$ \\
\hline 55 & 1.32 & 1.17 & 1.09 & 1.05 & 1.03 & 1.02 & 1.02 & 1.02 & 1.02 & 1.02 & & 1.03 & 1.03 & 1.04 & 1.04 & 1.0 \\
\hline 60 & 1.33 & 1.18 & 1.10 & 1.06 & 1.04 & & 1.03 & 1.03 & 1.03 & 1.03 & & 1.03 & & 1. & 04 & 1.05 \\
\hline 65 & 1. & 1.19 & 1.12 & 1.08 & 1.06 & 1.04 & 1.04 & 1.03 & 1.03 & 1.04 & 1.04 & 1.04 & 1.04 & 1.04 & 1 & 1.0 \\
\hline 70 & 1.34 & 1.20 & 1.13 & 1.09 & 1.07 & 1.05 & 1.05 & 1.04 & 1.04 & 1.04 & 1.04 & 1.04 & 1.05 & 1.05 & 1. & 1.6 \\
\hline 15 & 1.34 & 1.21 & 1.14 & 1.10 & 1.08 & 1.06 & 1.05 & 1.05 & 1.05 & 1.05 & 1.05 & 1.05 & 1.05 & 1.05 & 1.05 & 1.0 \\
\hline nte & 1.66 & 1.14 & 0.79 & 0.95 & 0.80 & 0.82 & 0.85 & 0.88 & 0.91 & 0.94 & 0.96 & 0.99 & 1.00 & 1.01 & 7.02 & 1.02 \\
\hline & 0.82 & 0.72 & 0.71 & 0.76 & 0.80 & 0.83 & 0.87 & 0.90 & 0.92 & 0.94 & 0.9 & 0.98 & 0.99 & 1.00 & 1. & 1.18 \\
\hline 10 & 0.87 & 0.75 & 0.76 & 0.79 & 0.83 & 0.86 & 0.89 & 0.91 & 0.94 & 0.95 & 0.97 & 0.98 & 0.99 & 1.00 & 1.01 & 1.0 \\
\hline 15 & 1.00 & 0.83 & 0.81 & 0.83 & 0.86 & 0.89 & 0.91 & 0.93 & 0.95 & 0.96 & 0.98 & 0.99 & 1.00 & 1.0 & 1.01 & 1.02 \\
\hline 20 & 1.12 & 0.92 & 0.87 & 0.87 & 0.89 & 0.91 & 0.93 & 0.94 & 0.96 & 0.97 & $0 . s$ & 0.99 & 1. & 1.0 & 1 & 1.02 \\
\hline 25 & 1.22 & 0.99 & 0.92 & 0.91 & 0.92 & 0.93 & 0.94 & 0.96 & 0.97 & 0.98 & 0.99 & 1.00 & 1.01 & 1.01 & 2 & $1 .($ \\
\hline 30 & 1.28 & 1.05 & 0.97 & 0. & 0.94 & & 0.9 & 0.97 & 0.98 & 0.99 & 0 & 1.01 & 1 & 1.02 & 1 & \\
\hline 35 & 1. & 1.10 & 1. & 0.97 & 0.97 & 0.97 & 0.97 & 0. & 0.99 & 1.00 & 1.00 & 1. & 1 & 1.02 & 1 & 1.0 \\
\hline 40 & 1. & 1.13 & 1.04 & 1.00 & 0.99 & 0.99 & 0. & 0.99 & 1.00 & 1.01 & 1.01 & 1.02 & 1.02 & 1.03 & 1 & 1.0 \\
\hline 45 & 1.3 & 1.16 & 1.06 & 1.02 & 1.01 & 1.00 & 1.00 & 1.00 & 1.01 & 1.01 & 1.02 & 1.02 & 1.03 & 1.03 & 1. & 1.0 \\
\hline 50 & 1.3 & 1.18 & 1.08 & 1.04 & 1.02 & 1.02 & 1.01 & 1.01 & 1.02 & 1.02 & 1.02 & 1.03 & 1.03 & 1.04 & 1.04 & 1.0 \\
\hline 55 & 1.3 & 1.19 & 1. & 1.06 & 1.04 & 1.03 & 1.02 & 1.02 & 1.02 & 1.03 & 1.03 & 1.03 & 1.04 & 1.0 & 1 & 1.05 \\
\hline 60 & 1.36 & 1.20 & 1.12 & 1.07 & 1.05 & 1.04 & 1.03 & 1.03 & 1.03 & 1.03 & 1.04 & 1.04 & 1.04 & 1.04 & 1.05 & 1.05 \\
\hline 65 & 1. & 1.21 & 1.13 & 1.09 & 1.06 & 1.05 & 1.04 & 1.04 & 1.04 & 1.04 & 1.04 & 1.04 & 1.05 & 1.05 & 1. & 1.05 \\
\hline 70 & 1.36 & 1.22 & 1.14 & 1.10 & 1.07 & 1.06 & 1.05 & 1.05 & 1.05 & 1.05 & 1.05 & 1.05 & 1.05 & 1.05 & 1.0 & 1.06 \\
\hline & 1.36 & 1.22 & 1.15 & 1. & 1.08 & $1.0 /$ & 1.06 & 1.06 & 1 & 1.05 & 1.05 & 1.05 & b & $1.06^{\circ}$ & 16 & \\
\hline in $=101$ & 1.86 & 1.97 & 1.13 & 1.1 & 7.09 & 0.91 & 0.96 & 1.09 & 1.01 & 0.94 & 0. & 0.96 & 0.9 & 0.9 & 0.99 & 1.00 \\
\hline & 1.2 & 0.79 & 0.80 & & 0.8 & 0. & 0.9 & 0. & 0. & 0. & 0. & 0.5 & 0 & 0. & & 1. \\
\hline 10 & 1.12 & 0.82 & 0.80 & 0.83 & 0.86 & 0.89 & 0.91 & 0.92 & 0.94 & 0.95 & 0.96 & 0.97 & 0.98 & 0.99 & 1.00 & 1.0 \\
\hline 15 & 1.1 & 0.89 & 0.84 & 0.85 & 0.88 & 0.90 & 0.92 & 0.93 & 0.95 & 0.96 & 0.97 & 0.98 & 0.99 & 1.00 & 1. & 1. \\
\hline 20 & 1.2 & 0.97 & 0.89 & 0.89 & 0.90 & 0.92 & 0.93 & 0.95 & 0.96 & 0.97 & 0.98 & 0.99 & 1.00 & 1.01 & 1. & 1. \\
\hline 25 & 1. & 1.04 & 0.94 & 0.92 & 0.93 & 0.94 & 0.95 & 0.96 & 0.97 & 0.98 & 0.99 & 1.00 & 1.01 & 1.01 & 1. & 1.03 \\
\hline 30 & 1.3 & 1.09 & 0.99 & 0.96 & 0.95 & 0.96 & 0.96 & 0.97 & 0.98 & 0.99 & 1.00 & 1.01 & 1.01 & 1.02 & 1.0 & 1.03 \\
\hline 35 & 1.4 & 1.13 & 1.02 & 0.98 & 0.97 & 0.97 & 0.98 & 0.98 & 0.99 & 1.00 & 1.01 & 1.01 & 1.02 & 1.02 & 1.03 & 1.0 \\
\hline 40 & 1.40 & 1.17 & 1.05 & 1.01 & 0.99 & 0.99 & 0.99 & 1.00 & 1.00 & 1.01 & 1.01 & 1.02 & 1.02 & 1.03 & 1.03 & 1.04 \\
\hline 45 & 1.40 & 1.19 & 1.08 & 1.03 & 1.01 & 1.01 & 1.00 & 1.01 & 1.01 & 1.01 & 1.02 & 1.02 & 1.03 & 1.03 & 1.04 & 1.04 \\
\hline 50 & 1.40 & 1.20 & 1.10 & 1.05 & 1.03 & 1.02 & 1.02 & 1.02 & 1.02 & 1.02 & 1.03 & 1.03 & 1.03 & 1.04 & 1.04 & $1 . C$ \\
\hline 55 & 1. & 1.21 & 1.12 & 1.07 & 1.05 & 1.03 & 1.03 & 1.03 & 1.03 & 1.03 & 1.03 & 1.03 & 1.04 & 1.04 & 1. & 1. \\
\hline 60 & 1. & 1.2 & 1.13 & 1.08 & 1.06 & 1.05 & 1.04 & 1.04 & 1.03 & 1.04 & 1.04 & 1.04 & 1.04 & 1.04 & 1.05 & 1. \\
\hline 65 & 1. & 1.2 & 1.14 & 1.10 & 1.07 & 1.06 & 1.05 & 1.04 & 1.0 & 1.04 & 1.04 & 1.04 & 1.05 & 1.05 & 1. & 1.0 \\
\hline 10 & 1. & 1.23 & 1.15 & 1.11 & 1.08 & 1.07 & 1.06 & 1.0 & 1.05 & 1.05 & 1.05 & 1.05 & 1.05 & 1.05 & 1.06 & \\
\hline 15 & 1.39 & 1.24 & 1.16 & 1.11 & 1.09 & $1.0 /$ & 1.06 & 1.06 & 1.06 & 1.05 & 1.05 & 1.05 & $1.06^{\circ}$ & 1.06 & 1.06 & \\
\hline
\end{tabular}


Table B-10: Actuator duty cycle obtained using the non-linear model and wind5 as wind input file.

Derivative Gain

\begin{tabular}{|c|c|c|c|c|c|c|c|c|c|c|c|c|c|c|c|c|}
\hline \multicolumn{17}{|l|}{ Proportional } \\
\hline Gain & 1 & 5 & 10 & 15 & 20 & 25 & 30 & 35 & 40 & 45 & 50 & 55 & 60 & 65 & 70 & 75 \\
\hline tegral Gain $=151$ & 1.44 & 2.25 & 1.87 & 0.91 & 1.06 & 1.09 & 1.23 & 1.00 & 0.97 & 0.97 & 1.04 & 1.12 & 1.10 & 1.02 & 0.99 & 0.98 \\
\hline & 2.68 & 1.03 & 0.80 & 0.81 & 0.88 & 0.94 & 0.96 & 0.96 & 0.96 & 0.97 & 0.98 & 0.99 & 0.99 & 0.99 & 0.99 & 1.0 \\
\hline 10 & 1.47 & 0.94 & 82 & 0 & 0.87 & & 0.93 & 0.95 & 0.96 & 0.97 & 0.97 & 0.98 & 0.99 & 0.99 & 00 & 1.07 \\
\hline 15 & 1.35 & 98 & 0.87 & 0.87 & 0.89 & 0.91 & 0.93 & 0.95 & 0.96 & 0.97 & 0.98 & 0.99 & 1.00 & 1.00 & & 1.02 \\
\hline 20 & 1.40 & .03 & 0.92 & 0.90 & 0.91 & 0.92 & 0.94 & 0.96 & 0.97 & 0.98 & 0.99 & 0.99 & 1.00 & 1.01 & 1. & 1.02 \\
\hline 25 & 1.46 & 1.09 & 0.97 & 0.94 & 0.93 & 0.94 & 0.95 & 0.97 & 0.98 & 0.99 & 0.99 & 1.00 & 1.01 & 1.01 & 1. & 1.03 \\
\hline 30 & 1.48 & 1.14 & 1.01 & 0.97 & 0.96 & 0.96 & 0.97 & 0.98 & 0.99 & 0.99 & 1.00 & 1.01 & 1.01 & 1.02 & 1.03 & 1.03 \\
\hline 35 & 1.48 & 1.17 & 1.04 & 1.00 & 0.98 & 0.98 & 0.98 & 0.99 & 0.99 & 1.00 & 1.01 & 1.01 & 1.02 & 1.02 & 1.03 & 1.03 \\
\hline 40 & 1.47 & 1.20 & 1.07 & 1.02 & 1.00 & 1.00 & 1.00 & 1.00 & 1.00 & 1.01 & 1.01 & 1.02 & 1.02 & 1.03 & 1.03 & 1.04 \\
\hline 45 & 1.46 & 1.22 & 1.10 & 1.04 & 1.02 & 1.01 & 1.01 & 1.01 & 1.01 & 1.02 & 1. & 1.02 & 1.03 & 1.03 & 1.04 & 1.0 \\
\hline 50 & 1.45 & 1.23 & 1.12 & $1 .($ & 1.04 & 1.03 & 1.0 & 1.02 & 1.02 & 1.02 & & 1.03 & & 1. & 1.04 & 1. \\
\hline 5 & 1.44 & 1.24 & 1.13 & 1. & 1. & & 1. & 1.03 & 1.03 & 1. & & 1.04 & & 1. & 1.04 & $1 .(\mathrm{g}$ \\
\hline 0 & 1.43 & 1.24 & 1 . & & 1.07 & & 1. & 1. & 1.04 & 1.04 & 1.04 & 1.04 & 4 & 1 & 1 & 1.18 \\
\hline 65 & 1. & 1. & 1 & 1.10 & 1.08 & 1.06 & 1. & 1. & 1.04 & 1. & 1.04 & 1. & 1. & 1. & 1 & 1.06 \\
\hline 70 & 1.42 & 1.25 & 1. & 1.11 & 1.09 & 1.07 & 1.06 & 1.05 & 1.05 & 1.05 & 1.05 & 1.05 & 1.05 & 1.05 & 1.06 & 1.06 \\
\hline 15 & 1.42 & $1.2 b$ & $1.1 /$ & 1.12 & 1.10 & 1.08 & $1.0 /$ & 1.06 & 1.06 & 1.06 & 1.06 & 1.06 & 1.06 & 1.06 & 1.06 & 1.06 \\
\hline 201 & 1.70 & 2.27 & 2.94 & 1.78 & 1.03 & 1.11 & 1.10 & 1.03 & 1.28 & 1.14 & 1.00 & 1.01 & 1.01 & 1.01 & 1.07 & 1.13 \\
\hline 5 & 0.94 & 1.75 & 0.97 & 0.8 & 0.83 & 0.88 & 0.9 & 0.98 & 1.01 & 1.01 & 1.00 & 1.00 & 1.00 & 1.01 & 1.02 & .03 \\
\hline 10 & 2.03 & .16 & 0.86 & 0.84 & 0.86 & 0.89 & 0.9 & 0. & 0.97 & 0.98 & 0.99 & 1.00 & 1.00 & 1.01 & 1.01 & 1.02 \\
\hline 15 & 1.6 & 1.0 & 0.91 & 0.88 & 0.89 & 0.91 & 0.93 & 0.95 & 0.97 & 0.98 & 0.99 & 1.00 & 1.00 & 1.01 & 1.01 & 1.02 \\
\hline 20 & 1. & 1.1 & 0.95 & 0.92 & 0.91 & 0.93 & 0.94 & 0.96 & 0.97 & 0.98 & 0.99 & 1.00 & 1.01 & 1.0 & 1.02 & 1.02 \\
\hline 25 & 1. & 1.15 & 1. & 0. & 0. & 0. & 0. & 0. & 0.5 & 0. & 1. & 1. & 1 & 1. & 1. & 1.0 \\
\hline 30 & 1.6 & 1.19 & 1. & 0. & 0. & 0. & 0. & 0 & 0.99 & 1. & 1. & 1. & 1 & 1. & 1.03 & 1.03 \\
\hline 35 & 1. & 1.2 & 1.0 & 1. & 0. & 0.98 & 0. & 0. & 1.00 & 1. & 1. & 1.02 & 1 & 1. & 1. & \\
\hline 40 & 1. & 1.2 & 1.09 & 1.04 & 1.01 & 1.00 & 1.0 & 1.00 & 1.01 & 1.01 & 1.02 & 1.02 & 1.03 & 1.03 & 1.03 & 1. \\
\hline 45 & 1.5 & 1.2 & 1.11 & 1.06 & 1.03 & 1.02 & 1.0 & 1.01 & 1.02 & 1.02 & 1.02 & 1.03 & 1.03 & 1.03 & 1.0 & 1. \\
\hline 50 & 1.4 & 1.25 & 1.13 & 1.07 & 1.05 & 1.03 & 1.0 & 1.02 & 1.02 & 1.03 & 1.03 & 1.03 & 1.04 & 1.04 & 1.04 & 1.04 \\
\hline 55 & 1. & 1.2 & 1.15 & 1.09 & 1.06 & 1.04 & 1.0 & 1.03 & 1.03 & 1.03 & 1.03 & 1.04 & 1.04 & 1.04 & 1.05 & 1.05 \\
\hline 60 & 1. & 1 & 1.16 & 1.10 & 1.07 & 1.06 & 1.05 & 1.04 & 1.04 & 1.04 & 1.04 & 1.04 & 1.04 & 1.05 & 1.05 & \\
\hline 65 & 1. & 1.26 & 1. & 1.11 & 1.08 & 1.07 & 1.06 & 1.05 & 1.05 & 1.05 & 1.05 & 1.05 & 1.05 & 1.05 & 1.05 & \\
\hline 70 & 1. & 1.26 & 1.17 & 1.12 & 1.09 & 1.07 & 1.06 & 1.06 & 1.05 & 1.05 & 1.05 & 1.05 & 1.05 & 1.06 & 1.06 & \\
\hline & 1.44 & . 26 & 1.18 & & 1.10 & 1.08 & $1.0 /$ & 1.06 & 1.06 & 1.06 & . & $1.0 t$ & 1.06 & 1.06 & 1.06 & \\
\hline
\end{tabular}


Table B-11: Actuator duty cycle obtained using the non-linear model and highwind4 as wind input file.

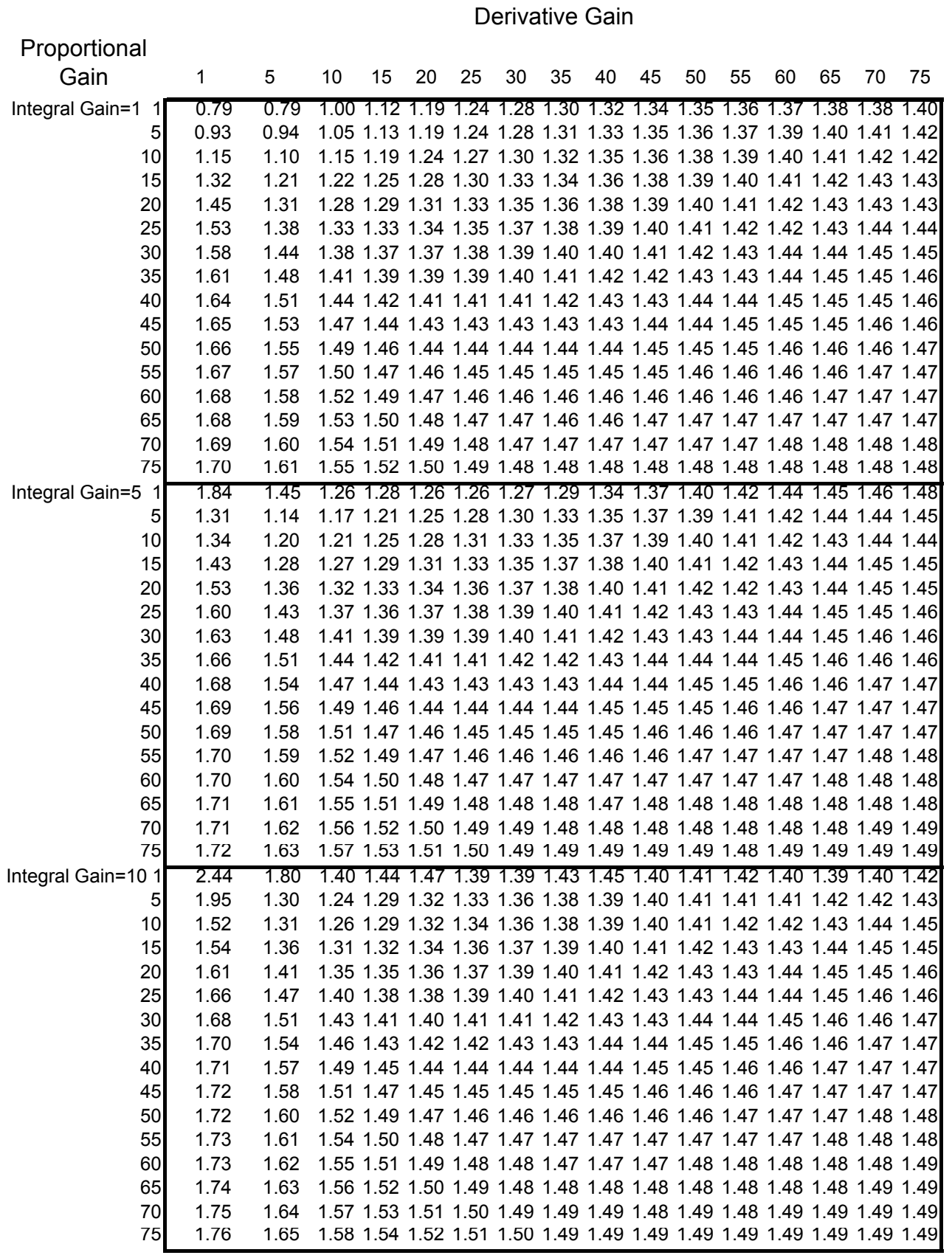


Table B-11: Actuator duty cycle obtained using the non-linear model and highwind4 as wind input file.

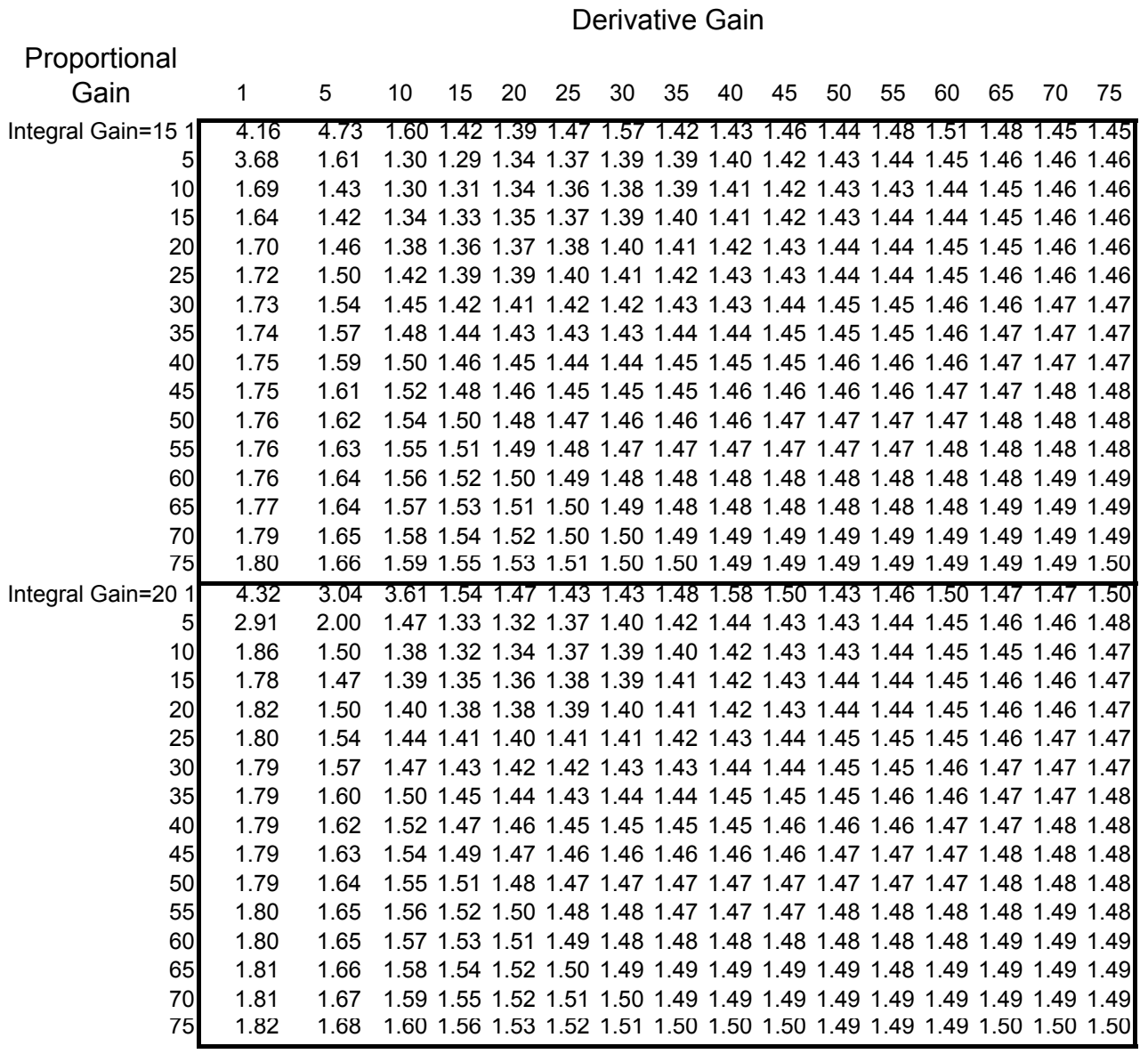


Table B-12: Actuator duty cycle obtained using the non-linear model averaged over five wind input cases.

Derivative Gain

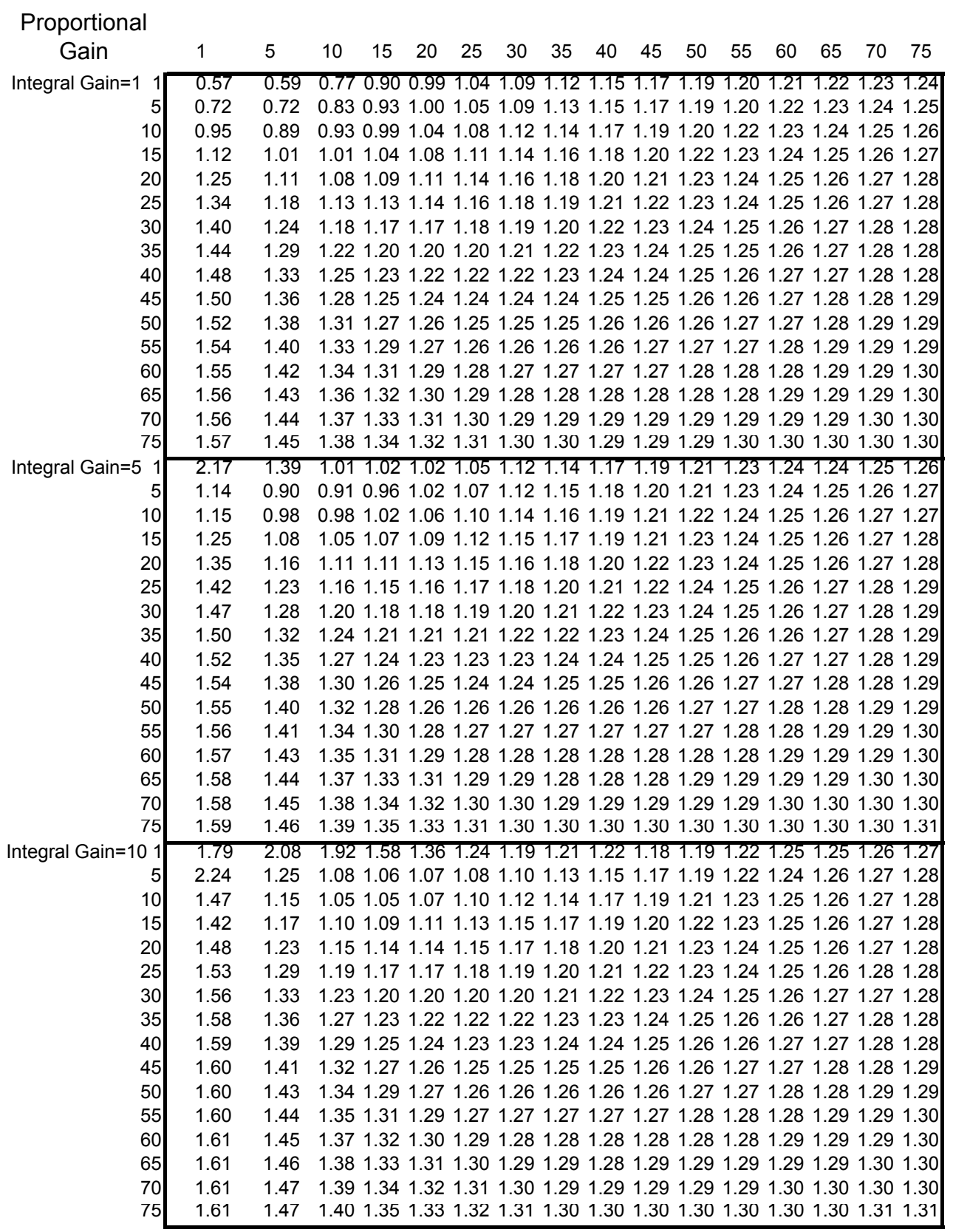


Table B-12: Actuator duty cycle obtained using the non-linear model averaged over five wind input cases.

\section{Derivative Gain}

\begin{tabular}{|c|c|c|c|c|c|c|c|c|c|c|c|c|c|c|c|c|}
\hline \multicolumn{17}{|l|}{ Proportional } \\
\hline Gain & 1 & 5 & 10 & 15 & 20 & 25 & 30 & 35 & 40 & 45 & 50 & 55 & 60 & 65 & 70 & 75 \\
\hline egral Gain=15 1 & 1.86 & 2.48 & 2.54 & 1.76 & 1.74 & 1.60 & 1.48 & 1.37 & 1.34 & 1.29 & 1.26 & 1.28 & 1.31 & 1.27 & 1.25 & 1.25 \\
\hline 5 & 2.65 & 2.01 & 37 & 1.21 & 1.16 & 1.16 & 1.17 & 1.17 & 1.16 & 1.17 & 1.18 & 1.20 & 1.22 & 1.24 & 21 & 1.2 \\
\hline 10 & 2.27 & 35 & 17 & 1.12 & 1.11 & 1.12 & 1.14 & 1.15 & 1.17 & 1.18 & 1.19 & 1.20 & 1.22 & 1.23 & 1. & 1.26 \\
\hline 15 & 1.69 & .30 & 17 & 1.14 & 1.13 & 1.14 & 1.16 & 1.17 & 1.19 & 1.20 & 1.21 & 1.22 & 1.23 & 1.24 & 1.26 & 1.27 \\
\hline 20 & 1.65 & 1.31 & 20 & 1.17 & 1.16 & 1.17 & 1.18 & 1.19 & 1.20 & 1.21 & 1.22 & 1.23 & 1.24 & 1.25 & 1.26 & 1.27 \\
\hline 25 & 1.65 & 1.35 & 1.23 & 1.20 & 1.19 & 1.19 & 1.20 & 1.20 & 1.21 & 1.22 & 1.23 & 1.24 & 1.25 & 1.26 & 1.27 & 1.27 \\
\hline 30 & 1.66 & 1.39 & 26 & 1.22 & 1.21 & 1.21 & 1.21 & 1.22 & 1.22 & 1.23 & 1.24 & 1.25 & 1.26 & 1.26 & 1.27 & 1.28 \\
\hline 35 & 1.68 & 1.42 & 29 & 1.25 & 1.23 & 1.23 & 1.23 & 1.23 & 1.23 & 1.24 & 1.25 & 1.25 & 1.26 & 1.27 & 1.27 & 1.28 \\
\hline 40 & 1.68 & 1.44 & 32 & 1.27 & 1.25 & 1.24 & 1.24 & 1.24 & 1.24 & 1.2 & 1.25 & 1.26 & 1.27 & 1.27 & I & 1.28 \\
\hline 45 & 1.67 & 1.45 & 34 & 1.29 & 1.27 & 1.26 & 1.25 & 1.25 & 1.25 & 1.2 & 1.26 & 1.27 & 1.27 & 1.28 & 1.28 & 1.29 \\
\hline 50 & 1. & 1.46 & 6 & 1.31 & 1.28 & 1.27 & 1.26 & 1.26 & 1.26 & 1.2 & 1.27 & 1.27 & 1.28 & 1.28 & 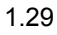 & 1.29 \\
\hline 55 & 1.67 & 1.47 & 1.37 & 1.32 & 1.29 & 1.28 & 1.27 & 1.27 & 1.27 & 1.27 & 1.27 & 1.28 & 1.28 & 1.29 & 1.29 & 1.29 \\
\hline 60 & 1.66 & 1.48 & 38 & 1.33 & 1.31 & 1.29 & 1.28 & 1.28 & 1.28 & 1.28 & 1.28 & 1.28 & 1.29 & 1.29 & 1.29 & 1.30 \\
\hline 65 & 1.66 & 1.48 & 39 & 1.35 & 1.32 & 1.30 & 1.29 & 1.29 & 1.29 & 1.29 & 1.29 & 1.29 & 1.29 & 1.29 & 1.30 & 1.30 \\
\hline 70 & 1.66 & 49 & 1.40 & 1.36 & 1.33 & 1.31 & 1.30 & 1.29 & 1.29 & 1.29 & 1.29 & 1.29 & 1.30 & 1.30 & 1.30 & 1.30 \\
\hline 15 & 1.65 & 1.50 & 1.41 & 1.36 & 1.34 & 1.32 & 1.31 & 1.30 & 1.30 & 1.30 & 1.30 & 1.30 & 1.30 & 1.30 & 1.31 & 1.31 \\
\hline egral Gain=20 1 & 1.77 & 2.01 & 2.64 & 2.22 & 1.73 & 1.77 & 1.71 & 1.61 & 1.53 & 1.41 & 1.40 & 1.38 & 1.34 & 1.31 & 1.31 & 1.31 \\
\hline 5 & 1.60 & 1.98 & 4 & 1.5 & 1.3 & 1.25 & 1.23 & 1 & 1.23 & 1. & 1. & 1.2 & 1 & 1.2 & 1.24 & 1.25 \\
\hline 10 & 1.96 & 1. & 30 & 1.2 & 1.17 & 6 & 1.17 & 3 & 1.19 & 1. & 1.2 & 1.21 & 1.2 & 1.22 & 1.23 & 1.24 \\
\hline 15 & 2.42 & 1.45 & 5 & 1.19 & 1.17 & 1.17 & 1.17 & 1.18 & 1.19 & 1.20 & 1.21 & 1.22 & 1.23 & 1.23 & 1.24 & 1.25 \\
\hline 20 & 1.87 & 1.43 & 1.25 & 1.20 & 1.19 & 1.18 & 1.19 & 1.19 & 1.21 & 1.22 & 1.22 & 1.23 & 1.24 & 1.25 & 1.26 & 1.26 \\
\hline 25 & 1.85 & 1.42 & 1.27 & 1.22 & 1.21 & 1.20 & 1.21 & 1.21 & 1.22 & 1.23 & 1.23 & 1.24 & 1.25 & 1.25 & 1.26 & 1.27 \\
\hline 30 & 1.82 & 1.44 & 30 & 1.24 & 1.23 & 1.22 & 1.22 & 1.22 & 1.23 & 1.24 & 1.24 & 1.25 & 1.25 & 1.26 & 1.27 & 1.27 \\
\hline 35 & 1.79 & 1.47 & 33 & 1.27 & 1.24 & 1.24 & 1.23 & 1.24 & 1.24 & 1.24 & 1.25 & 1.25 & 1.26 & 1.27 & 1.27 & 1.28 \\
\hline 40 & 1.75 & 1.48 & 1.35 & 1.29 & 1.26 & 1.25 & 1.25 & 1.25 & 1.25 & 1.25 & 1.26 & 1.26 & 1.26 & 1.27 & 1.28 & 1.28 \\
\hline 45 & 1.75 & 1.50 & 7 & 1.31 & 1.28 & 1.26 & 1.26 & 1.26 & 1.26 & 1.26 & 1.26 & 1.27 & 1.27 & 1.28 & 1.28 & 1.29 \\
\hline 50 & 1.76 & 1.50 & 8 & 1.32 & 1.29 & 1.28 & 1.27 & 1.27 & 1.27 & 1.27 & 1.27 & 1.27 & 1.28 & 1.28 & 1.29 & 1.29 \\
\hline 55 & 1.73 & 1.51 & 1.39 & 1.34 & 1.31 & 1.29 & 1.28 & 1.28 & 1.27 & 1.27 & 1.28 & 1.28 & 1.28 & 1.28 & 1.29 & 1.29 \\
\hline 60 & 1.73 & 1.51 & 1.40 & 1.35 & 1.32 & 1.30 & 1.29 & 1.28 & 1.28 & 1.28 & 1.28 & 1.28 & 1.29 & 1.29 & 1.29 & 1.29 \\
\hline 65 & 1.73 & 1.5 & 1.41 & 1.36 & 1.33 & 1.31 & 1.30 & 1.29 & 1.29 & 1.2 & 1.29 & 1.29 & 1.29 & 1.29 & 1.30 & 1.30 \\
\hline 10 & 1. & 1.52 & 1.42 & 1.37 & 1.34 & 1.32 & 1.31 & 1.30 & 1.29 & 1.29 & 1.29 & 1.29 & 1.29 & 1.30 & 1.30 & 1.30 \\
\hline 15 & 1.12 & 1.52 & 1.43 & 1.38 & 1.35 & 1.33 & 1.31 & 1.31 & 1.30 & 1.30 & 1.30 & 1.30 & 1.30 & 1.30 & 1.30 & 1.31 \\
\hline
\end{tabular}




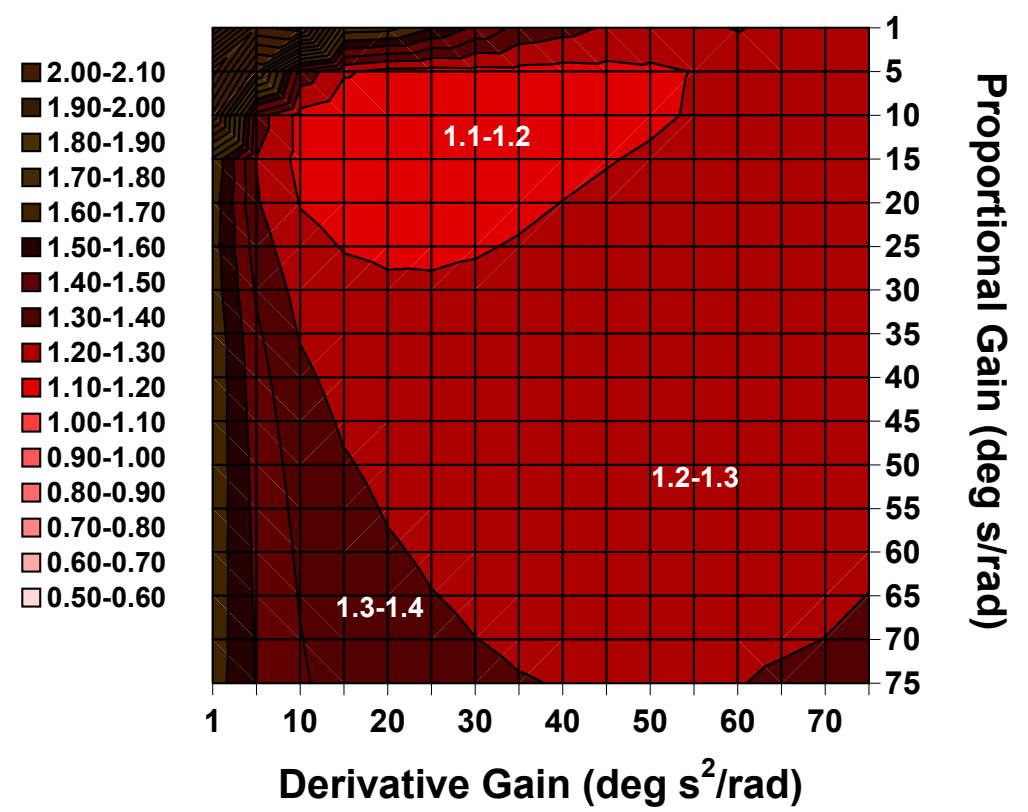

(a) Actuator duty cycle (deg/s)

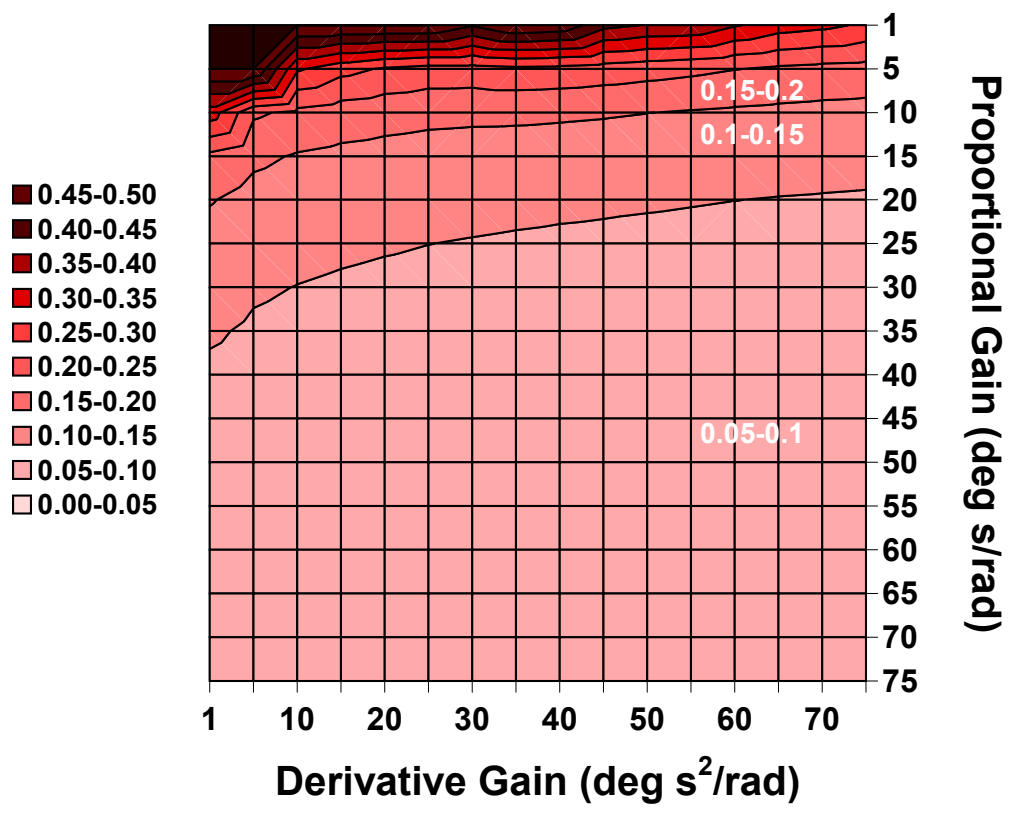

(b) RMS speed error $(\mathrm{rad} / \mathrm{s})$

Figure B-1: Performance metric surfaces generated using the non-linear model for $\mathrm{k}_{\mathrm{I}}=15 \mathrm{deg} / \mathrm{rad}$. 

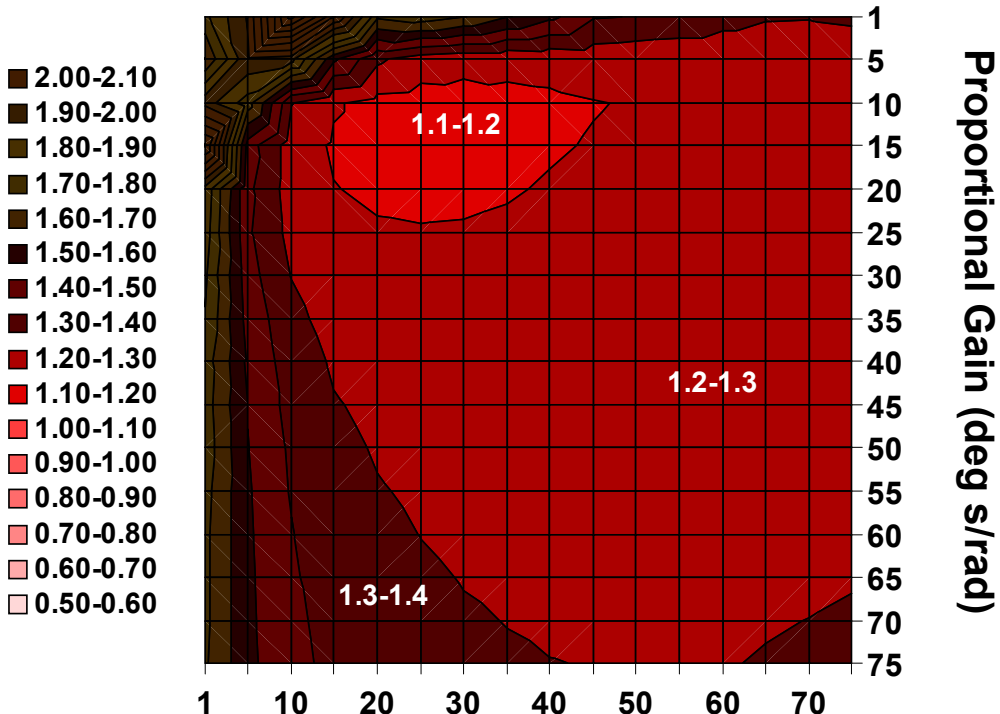

Derivative Gain (deg s $\mathbf{s}^{2} / \mathrm{rad}$ )

(a) Actuator duty cycle (deg/s)

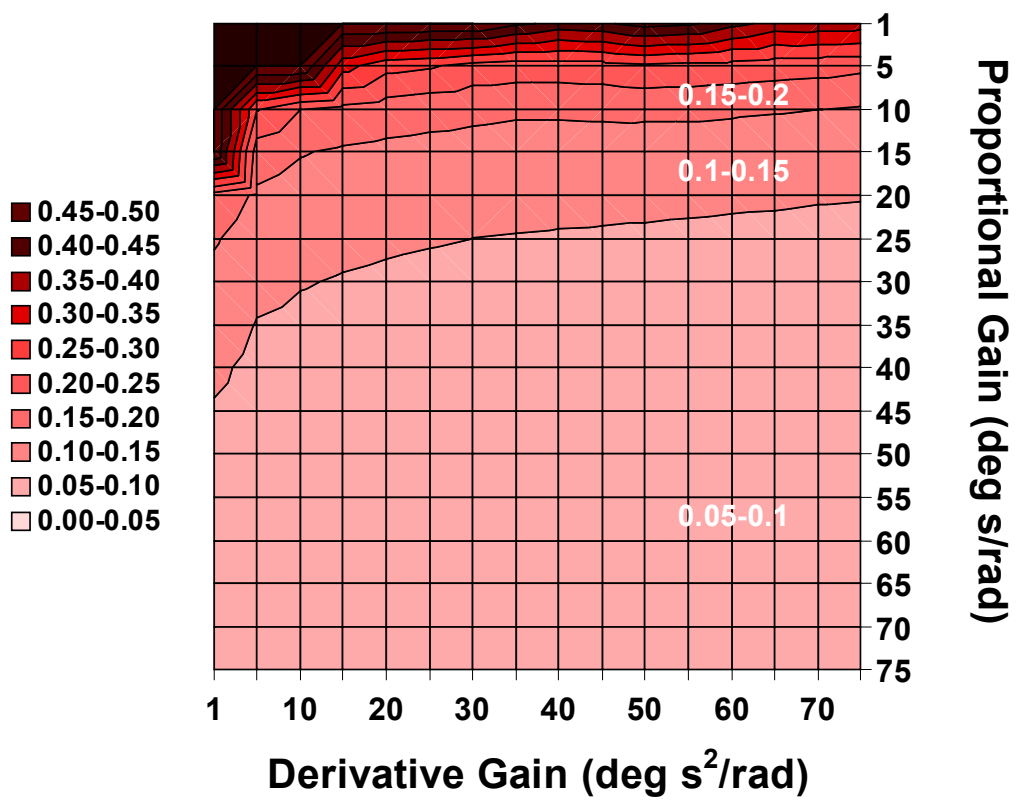

(b) RMS speed error ( $\mathrm{rad} / \mathrm{s})$

Figure B-2: Performance metric surfaces generated using the non-linear model for $\mathrm{k}_{\mathrm{l}}=\mathbf{2 0} \mathrm{deg} / \mathrm{rad}$. 
APPENDIX C

APPLICATION OF THE SYSTEMATIC METHODOLOGY

USING THE LINEAR MODEL I 
Table C-1: RMS speed error obtained using the non-linear model and medwind 2 as wind input file.

\begin{tabular}{|c|c|c|c|c|c|c|c|c|c|c|c|c|c|c|c|c|}
\hline \multirow{3}{*}{$\begin{array}{l}\text { Proportional } \\
\text { Gain }\end{array}$} & \multicolumn{16}{|c|}{ Derivative Gain } \\
\hline & & & & & & & & & & & & & & & & \\
\hline & 1 & 5 & 10 & 15 & 20 & 25 & 30 & 35 & 40 & 45 & 50 & 55 & 60 & 65 & 70 & 75 \\
\hline Integral Gain=1 & 0.98 & 1.08 & 1.08 & 1.06 & 1.10 & 1.20 & 1.30 & 1.36 & 1.37 & 1.34 & 1.29 & 1.23 & 1.17 & 1.12 & 1.06 & 1.00 \\
\hline & 0.44 & 0.46 & 0.48 & 0.51 & 0.53 & 0.55 & 0.57 & 0.58 & 0.58 & 0.58 & 0.58 & 0.58 & 0.57 & 0.55 & 0.54 & 0.53 \\
\hline 10 & 0.28 & 0.28 & 0.29 & 0.30 & 0.31 & 0.32 & 0.32 & 0.33 & 0.33 & 0.33 & 0.34 & 0.34 & 0.34 & 0.33 & 0.33 & 0.33 \\
\hline 15 & 0.21 & 0.21 & 0.22 & 0.22 & 0.22 & 0.23 & 0.23 & 0.23 & 0.24 & 0.24 & 0.24 & 0.24 & 0.24 & 0.24 & 0.24 & 0.24 \\
\hline 20 & 0.18 & 0.18 & 0.18 & 0.18 & 0.18 & 0.18 & 0.19 & 0.19 & 0.19 & 0.19 & 0.19 & 0.19 & 0.19 & 0.20 & 0.20 & 0.20 \\
\hline 25 & 0.16 & 0.16 & 0.16 & 0.16 & 0.16 & 0.16 & 0.16 & 0.16 & 0.16 & 0.16 & 0.16 & 0.17 & 0.17 & 0.17 & 0.17 & 0.17 \\
\hline 30 & 0.14 & 0.14 & 0.14 & & 0.14 & 0.14 & 0.14 & 0.14 & 0.14 & 0.15 & & 0.15 & 0.15 & 0.15 & 0.15 & 0.15 \\
\hline 35 & 0.13 & 0.13 & 0.13 & 0.13 & 0.13 & 0.13 & 0.13 & 0.13 & 0.13 & 0.13 & 0.13 & 0.13 & 0 & 0.14 & 0.14 & 0.14 \\
\hline 40 & 0.12 & 0.12 & 0.12 & 0.12 & 0.12 & 0.12 & 0.12 & 0.12 & 0.12 & 0.12 & 0.12 & 0.12 & 0.13 & 0.13 & 0.13 & 0.13 \\
\hline 45 & 0.12 & 0.12 & 0.11 & 0.12 & 0.12 & 0.12 & 0.12 & 0.12 & 0.12 & 0.12 & 0.12 & 0.12 & 0.12 & 0.12 & 0.12 & 011 \\
\hline 50 & 0.11 & 0.11 & 0.11 & & 0.11 & 0.11 & 0.11 & 0.11 & 0.11 & 0.11 & 0 & 0.11 & 0.1 & 0.11 & 0.11 & 0.11 \\
\hline 55 & 0.10 & 0.10 & 0.10 & 0.10 & 0.10 & 0.10 & 0.10 & 0.10 & 0.10 & 0.10 & 0.11 & 0.11 & 0.11 & 0.11 & 0.11 & 0.11 \\
\hline 60 & 0.10 & 0.10 & 0.10 & & 0.10 & 0.10 & 0.10 & 0.10 & 0.10 & 0.10 & 0.10 & 0.10 & 0.10 & 0.10 & 0.10 & 0.10 \\
\hline 65 & 0.10 & 0.10 & 0.10 & & 0.10 & 0.10 & 0.10 & 0.10 & 0.10 & 0.10 & 0.10 & 0.10 & 0.10 & 0.10 & 0.10 & 0.10 \\
\hline 70 & 0.09 & 0.09 & 0.09 & & 0.09 & 0.09 & 0.09 & 0.09 & 0.09 & 0.09 & & 0.09 & 0.09 & 0.09 & 0.09 & 0.09 \\
\hline & $0.0 y$ & $0.0 y$ & $0.0 y$ & 0.0y & 0.0y & 0.0y & U.Uy & 0.09 & $0.0 y$ & 0.0y & 0.0y & $0.0 y$ & $0.0 y$ & 0.09 & 0.05 & $0.0 y$ \\
\hline egral Gain $=5 \quad 1$ & 4.77 & 0.79 & 0.68 & 0.50 & 0.40 & 0.32 & 0.34 & 0.43 & 0.51 & 0.57 & 0.59 & 0.60 & 0.59 & 0.58 & 0.56 & 0.54 \\
\hline & 0.24 & 0.23 & 0.22 & 0.21 & 0.20 & 0.20 & 0.21 & 0.23 & 0.25 & 0.27 & 0.28 & 0.29 & 0.29 & 0.29 & 0 . & 0.29 \\
\hline 10 & 0.16 & 0.15 & 0.15 & 0.15 & 0.15 & 0.15 & 0.15 & 0.16 & 0.16 & 0.17 & 0.17 & 0.18 & 0.18 & 0.19 & 0 & 0.19 \\
\hline 15 & 0.13 & 0.12 & 0.12 & 0.12 & 0.12 & 0.12 & 0.12 & 0.13 & 0.13 & 0.13 & 0.13 & 0. & 0. & 0.14 & 0. & 0.15 \\
\hline 20 & 0.11 & 0.11 & 0.10 & 0.10 & 0.10 & 0.10 & 0.11 & 0.11 & 0.11 & 0.11 & 0.11 & 0.11 & 0.11 & 0.12 & 0.1 & 0.12 \\
\hline 25 & 0.09 & 0.09 & 0.09 & 0.09 & 0.09 & 0.09 & 0.09 & 0.09 & 0.09 & 0.10 & 0.10 & 0.10 & 0.10 & 0.10 & 0.1 & 0.10 \\
\hline 30 & 0.08 & 0.08 & 0.08 & 0.08 & 0.08 & 0.08 & 0.08 & 0.08 & 0.08 & 0.08 & 0.09 & 0.09 & 0.09 & 0.09 & 0.09 & 0.09 \\
\hline 35 & 0.08 & 0.08 & 0.07 & 0.0 & 0.07 & 0.07 & 0.07 & 0.08 & 0.08 & 0.08 & 0.08 & 0.08 & 0.08 & 0.0 & 0.08 & 0.08 \\
\hline 40 & 0.07 & 0.07 & 0.07 & & 0.07 & 0.07 & 0.07 & 0.07 & 0.07 & 0.07 & 0 & 0. & 0. & 0.0 & 0. & 0.07 \\
\hline 45 & 0.06 & 0.06 & 0.06 & & 0.06 & 0.06 & 0.06 & 0.06 & 0.06 & 0. & & 0. & 0 & 0.0 & 0 & 0.07 \\
\hline 50 & 0.06 & 0.06 & 0.06 & & 0.06 & 0.06 & 0.06 & 0.06 & 0.06 & 0. & & 0.06 & 0 & 0.06 & 0 & 0.06 \\
\hline 55 & 0.06 & 0.05 & 0. & & 0.05 & 0.05 & 0. & 0. & 0.05 & & 0. & 0. & & 0.06 & & 0.06 \\
\hline 60 & 0.05 & 0.05 & 0.0 & 0.05 & 0.05 & 0.05 & 0.05 & 0.05 & 0.05 & 0. & 0.05 & 0.05 & 0 & 0.05 & 0 & 0.05 \\
\hline 65 & 0.05 & 0.05 & 0.05 & 0.05 & 0.05 & 0.05 & 0.05 & 0.05 & 0.05 & 0.05 & 0.05 & 0.05 & 0.05 & 0.05 & 0.05 & 0.05 \\
\hline 70 & 0.05 & 0.05 & 0.05 & 0.05 & 0.05 & 0.05 & 0.05 & 0.05 & 0.05 & 0.05 & 0.05 & 0.05 & 0.05 & 0.05 & 0.05 & 0.05 \\
\hline 15 & 0.04 & 0.04 & 0.04 & 0.04 & 0.04 & 0.04 & 0.04 & 0.04 & 0.04 & 0.04 & 0.04 & 0.04 & 0.04 & 0.04 & 0.04 & 0.04 \\
\hline tegral Gain=10 1 & 6.86 & 5.61 & 0.53 & 0.52 & 0.42 & 0.38 & 0.47 & 0.40 & 0.32 & 0.28 & 0.25 & 0.21 & 0.18 & 0.18 & 0.20 & 0.24 \\
\hline 5 & 0.31 & 0.18 & 0.18 & 0. & 0.17 & 0.17 & 0.17 & 0.17 & 0.15 & 0.14 & 0. & 0.1 & 0. & 0.1 & 0.14 & 0.16 \\
\hline 10 & 0.13 & 0.12 & 0.11 & 0. & 0.11 & 0.11 & 0.11 & 0.11 & 0.11 & 0.10 & 0.10 & 0.1 & 0.10 & 0.1 & 0.11 & 0.11 \\
\hline 15 & 0.10 & 0.09 & 0.09 & 0. & 0.09 & 0.09 & 0.09 & 0.09 & 0.09 & 0.09 & 0. & 0.0 & 0.09 & 0.09 & 0.09 & 0.09 \\
\hline 20 & 0.08 & 0.08 & 0.08 & 0. & 0.08 & 0.08 & $0 .($ & 0.07 & 0.07 & 0.07 & 0 & 0. & 0 & 0. & 0 & 0.08 \\
\hline 25 & 0.07 & 0.07 & 0.07 & 0. & 0.07 & 0.07 & 0. & 0.07 & 0.07 & 0.07 & 0. & 0. & 0 & 0.07 & 0. & 0.07 \\
\hline 30 & 0.07 & 0.06 & 0.06 & 0.06 & 0.06 & 0.06 & 0.06 & 0.06 & 0.06 & 0.06 & 0.06 & 0.06 & 0.06 & 0.06 & 0.06 & 0.06 \\
\hline 35 & 0.06 & 0.06 & 0.06 & 0.06 & 0.06 & 0.06 & 0.06 & 0.06 & 0.06 & 0.06 & 0.06 & 0.06 & 0.06 & 0.06 & 0.06 & 0.06 \\
\hline 40 & 0.06 & 0.05 & 0.05 & $0 .($ & 0.05 & 0.05 & 0.05 & 0.05 & 0.05 & 0.05 & 0.05 & 0.05 & 0.05 & 0.05 & 0.05 & \\
\hline 45 & 0.05 & 0.05 & 0.05 & 0. & 0.05 & 0.05 & 0.05 & 0.05 & 0.05 & 0.05 & 0.05 & 0.05 & 0.05 & 0.05 & 0.05 & \\
\hline 50 & 0.05 & 0.05 & 0.05 & 0.05 & 0.05 & 0.05 & 0.05 & 0.05 & 0.05 & 0.05 & 0.05 & 0.05 & 0.05 & 0.05 & 0.05 & 0.05 \\
\hline 55 & 0.05 & 0.04 & 0.04 & 0.04 & 0.04 & 0.04 & 0.04 & 0.04 & 0.04 & 0.04 & 0.04 & 0.04 & 0.04 & 0.04 & 0.04 & 0.04 \\
\hline 60 & 0.04 & 0.04 & 0.04 & 0.04 & 0.04 & 0.04 & 0.04 & 0.04 & 0.04 & 0.04 & 0.04 & 0.04 & 0.04 & 0.04 & 0.04 & 0.04 \\
\hline 65 & 0.04 & 0.04 & 0.04 & 0.04 & 0.04 & 0.04 & 0.04 & 0.04 & 0.04 & 0.04 & 0.04 & 0.04 & 0.04 & 0.04 & 0.04 & \\
\hline 70 & 0.04 & 0.04 & 0.04 & 0.04 & 0.04 & 0.04 & 0.04 & 0.04 & 0.04 & 0.04 & 0.04 & 0.04 & 0.04 & 0.04 & 0.04 & 0.04 \\
\hline 15 & 0.04 & 0.04 & 0.04 & 0.04 & 0.04 & 0.04 & 0.04 & 0.04 & 0.04 & 0.04 & 0.04 & 0.04 & 0.04 & 0.04 & 0.04 & \\
\hline
\end{tabular}


Table C-2: RMS speed error obtained using the non-linear model and wind 3 as wind input file.

Derivative Gain

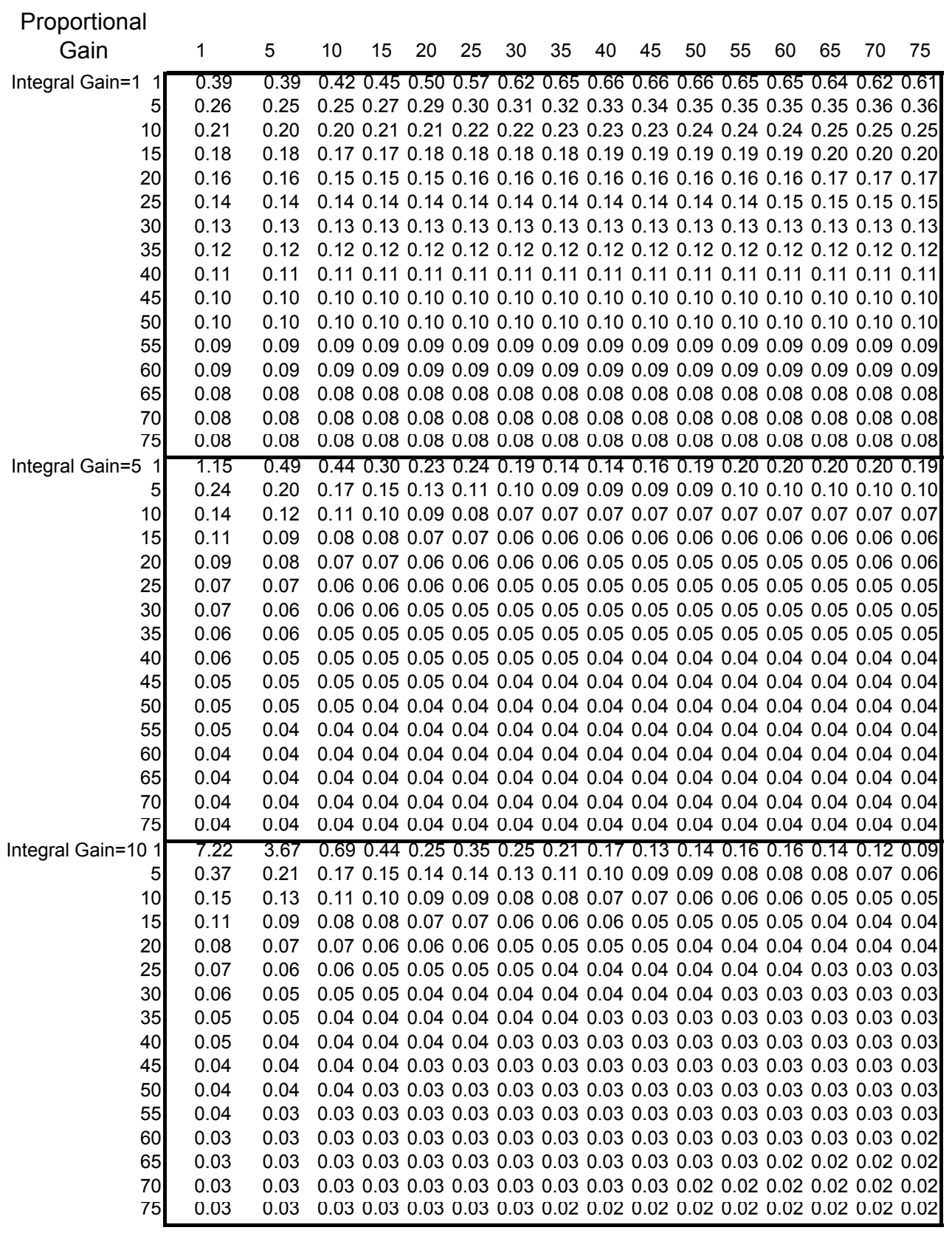


Table C-3: RMS speed error obtained using the non-linear model and wind4 as wind input file.

Derivative Gain

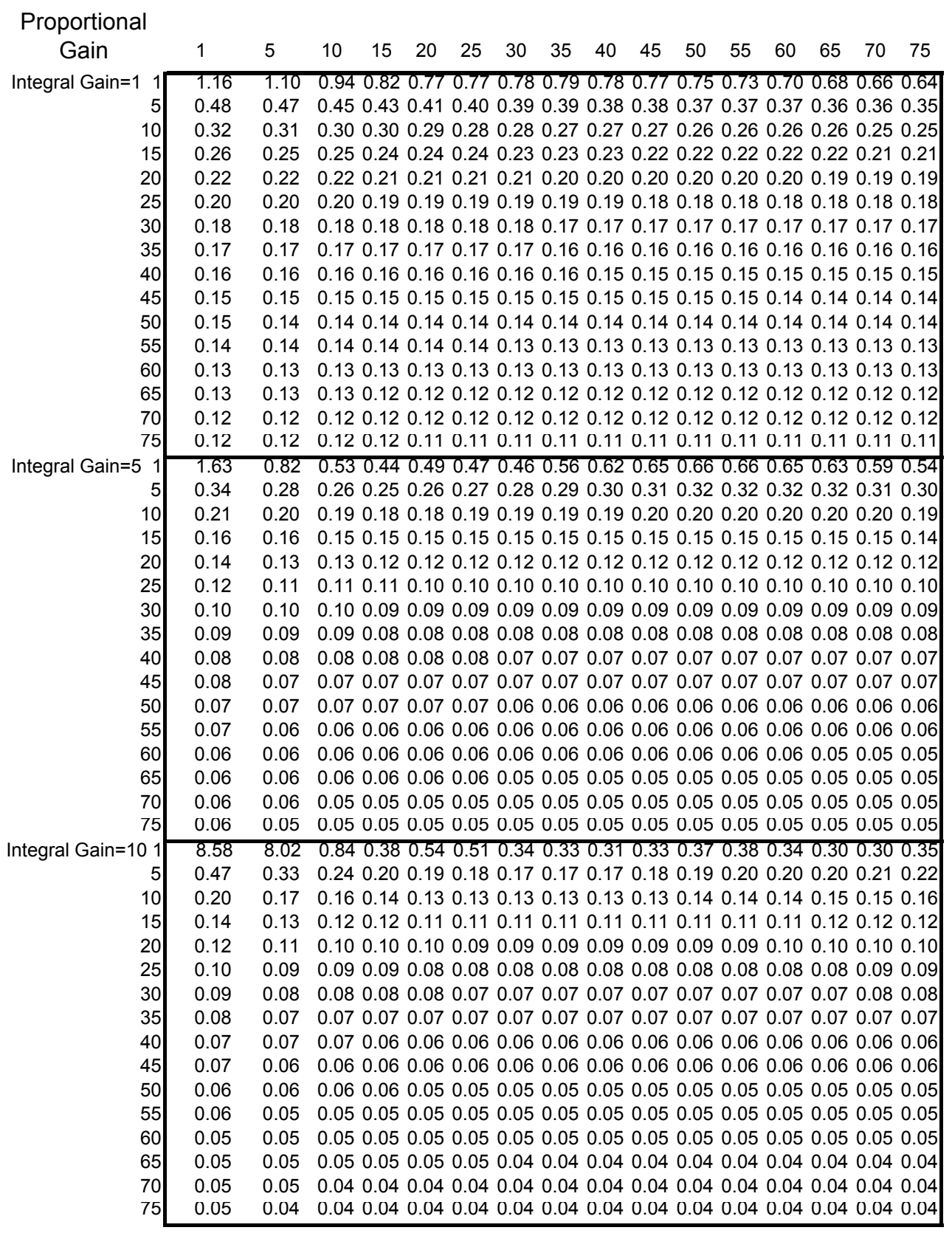


Table C-4: RMS speed error obtained using the non-linear model and wind5 as wind input file.

Derivative Gain

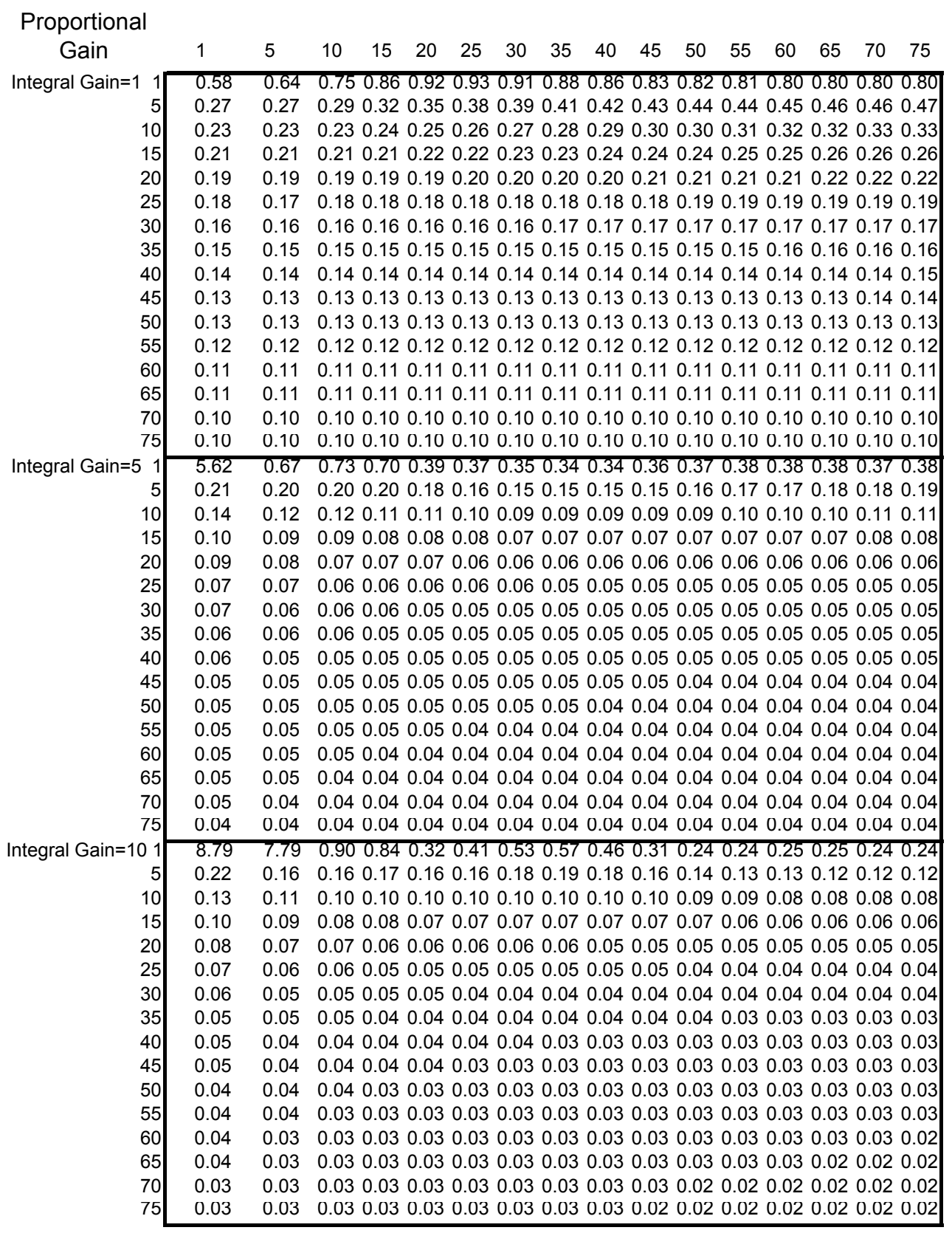


Table C-5: RMS speed error obtained using the non-linear model and highwind4 as wind input file.

\begin{tabular}{|c|c|c|c|c|c|c|c|c|c|c|c|c|c|c|c|c|}
\hline \multirow{3}{*}{$\begin{array}{l}\text { Proportional } \\
\text { Gain }\end{array}$} & \multicolumn{16}{|c|}{ Derivative Gain } \\
\hline & & & & & & & & & & & & & & & & \\
\hline & 1 & 5 & 10 & 15 & 20 & 25 & 30 & 35 & 40 & 45 & 50 & 55 & 60 & 65 & 70 & 75 \\
\hline Integral Gain $=11$ & 1.48 & 1.48 & 1.56 & 1.43 & 1.30 & 1.26 & 1.29 & 1.30 & 1.28 & 1.24 & 1.20 & 1.15 & 1.10 & 1.05 & 1.01 & 0.97 \\
\hline & 0.71 & 0.68 & 0.67 & 0.67 & 0.67 & 0.67 & 0.67 & 0.67 & 0.66 & 0.65 & 0.65 & 0.64 & 0.63 & 0.62 & 0.61 & 0.61 \\
\hline 10 & 0.47 & 0.46 & 0.45 & 0.45 & 0.45 & 0.45 & 0.45 & 0.45 & 0.45 & 0.45 & 0.45 & 0.45 & 0.45 & 0.45 & 0.45 & 0.45 \\
\hline 15 & 0.38 & 0.37 & 0.37 & 0.36 & 0.36 & 0.36 & 0.36 & 0.36 & 0.37 & 0.37 & 0.37 & 0.37 & 0.37 & 0.37 & 0.37 & 0.37 \\
\hline 20 & 0.32 & 0.32 & 0.32 & 0.32 & 0.32 & 0.31 & 0.31 & 0.32 & 0.32 & 0.32 & 0.32 & 0.32 & 0.32 & 0.32 & 0.32 & 0.32 \\
\hline 25 & 0.29 & 0.29 & 0.28 & 0.28 & 0.28 & 0.28 & 0.28 & 0.28 & 0.28 & 0.28 & 0.28 & 0.28 & 0.28 & 0.28 & 0.29 & 0.29 \\
\hline 30 & 0.26 & 0.26 & 0.26 & & 0.26 & 0.26 & 0.26 & 0.26 & 0.26 & 0.26 & 0.26 & 0.26 & 0.26 & 0.26 & 0.26 & 0.26 \\
\hline 35 & 0.24 & 0.24 & 0.24 & & 0.24 & 0.24 & 0.24 & 0.24 & 0.24 & 0.24 & 0.24 & 0.24 & 0.24 & 0.24 & 0.24 & 0.24 \\
\hline 40 & 0.23 & 0.23 & 0.23 & 0.22 & 0.22 & 0.22 & 0.22 & 0.22 & 0.22 & 0.22 & 0.22 & 0.22 & 0.22 & 0.22 & 0 & 0.22 \\
\hline 45 & 0.21 & 0.21 & 0.21 & 0.21 & 0.21 & 0.21 & 0.21 & 0.21 & 0.21 & 0.21 & 0.21 & 0.21 & 0.21 & 0.21 & 0. & 0.21 \\
\hline 50 & 0.20 & 0.20 & 0.20 & 0.20 & 0.20 & 0.20 & 0.20 & 0.20 & 0.20 & 0.20 & 0.20 & 0.20 & 0.20 & 0.20 & 0. & 0.20 \\
\hline 55 & 0.19 & 0.19 & 0.19 & 0.19 & 0.19 & 0.19 & 0.19 & 0.19 & 0.19 & 0.19 & 0.19 & 0.19 & 0.19 & 0.19 & 0.19 & 0.19 \\
\hline 60 & 0.18 & 0.18 & 0.18 & 0.18 & 0.18 & 0.18 & 0.18 & 0.18 & 0.18 & 0.18 & 0.18 & 0.18 & 0.18 & 0.18 & 0.18 & 0.18 \\
\hline 65 & 0.17 & 0.17 & 0.17 & 0.17 & 0.17 & 0.17 & 0.17 & 0.17 & 0.17 & 0.17 & 0.17 & 0.17 & 0.17 & 0.17 & 0.17 & 0.17 \\
\hline 70 & 0.17 & 0.17 & 0.17 & 0.17 & 0.17 & 0.17 & 0.17 & 0.17 & 0.17 & 0.17 & 0.17 & 0.17 & 0.17 & 0.17 & 0.1 & 0.17 \\
\hline & 0.16 & $0.16^{\circ}$ & 0.16 & 0.16 & 0.16 & 0.16 & 0.16 & 0.16 & 0.16 & 0.16 & 0.16 & $0.16^{\circ}$ & 0.16 & 0.16 & 0.1 & 0.16 \\
\hline Integral Gain=5 1 & 6.29 & 1.69 & 7.04 & 1.14 & 0.85 & 0.87 & 0.72 & 0.51 & 0.43 & 0.43 & 0.49 & 0.57 & 0.65 & 0.73 & 0.77 & 0.79 \\
\hline & 0.50 & 0.49 & 0.48 & 0.47 & 0.45 & 0.42 & 0.38 & 0.35 & 0.34 & 0.33 & 0.34 & 0.36 & 0.38 & 0.40 & 0.4 & 0.42 \\
\hline 10 & 0.32 & 0.31 & 0.30 & 0.29 & 0.29 & 0.28 & 0.27 & 0.26 & 0.25 & 0.25 & 0.25 & 0.25 & 0.26 & 0.26 & 0 & 0.27 \\
\hline 15 & 0.24 & 0.23 & 0.23 & 0.22 & 0.22 & 0.21 & 0.21 & 0.21 & 0.20 & 0.20 & 0.20 & 0.20 & 0.20 & 0.20 & 0 & 0.20 \\
\hline 20 & 0.19 & 0.19 & 0.18 & 0.18 & 0.18 & 0.18 & 0.17 & 0.17 & 0.17 & 0.17 & 0.17 & 0.17 & 0.17 & 0.17 & 0.17 & 0.17 \\
\hline 25 & 0.16 & 0.16 & 0.16 & 0.16 & 0.15 & 0.15 & 0.15 & 0.15 & 0.15 & 0.15 & 0.15 & 0. & 0 & 0.14 & 0. & 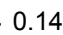 \\
\hline 30 & 0.14 & 0.14 & 0.14 & 0.14 & 0.14 & 0.13 & 0.13 & 0.13 & 0.13 & 0.13 & 0.13 & 0.13 & 0.13 & 0.13 & 0.13 & 0 \\
\hline 35 & 0.13 & 0.13 & 0.12 & 0.12 & 0.12 & 0.12 & 0.12 & 0.12 & 0.12 & 0.12 & 0.12 & 0.12 & 0.12 & 0.12 & 0. & ? \\
\hline 40 & 0.12 & 0.12 & 0.11 & 0. & 0.11 & 0.11 & 0.11 & 0.11 & 0.11 & 0.11 & 0.1 & 0.11 & 0. & 0.1 & 0.11 & 0.11 \\
\hline 45 & 0.11 & 0.11 & 0.11 & 0. & 0.10 & 0.10 & 0.10 & 0.10 & 0.10 & 0.10 & 0 & 0.10 & 0.10 & 0.10 & 0.10 & 0.10 \\
\hline 50 & 0.10 & 0.10 & 0.10 & & 0.10 & 0.10 & 0. & 0.10 & 0.10 & 0. & 0 & 0. & 0 & 0 & 0 & 0.09 \\
\hline 55 & 0.09 & 0.09 & 0.09 & 0. & 0.09 & 0.09 & 0. & 0 & 0.09 & 0 & 0 & 0. & 0.09 & 0 & 0 & 0.0 \\
\hline 60 & 0.09 & 0.09 & 0.09 & & 0.09 & 0.09 & 0. & 0 & 0.09 & 0. & 0.09 & 0. & 0 & 0.08 & 0 & $0 . C$ \\
\hline 65 & 0.08 & 0.08 & 0.08 & 0.08 & 0.08 & 0.08 & 0.08 & 0.08 & 0.08 & 0.08 & 0.08 & 0.08 & 0.08 & 0.08 & 0. & 0.0 \\
\hline 70 & 0.08 & 0.08 & 0.08 & 0.08 & 0.08 & 0.08 & 0.08 & 0.08 & 0.08 & 0.08 & 0.08 & 0.08 & 0.08 & 0.08 & 0.08 & 0.08 \\
\hline 15 & 0.08 & 0.08 & 0.08 & 0.08 & 0.08 & 0.08 & 0.08 & 0.08 & 0.08 & 0.08 & 0.08 & 0.08 & 0.08 & 0.01 & $0.0 /$ & $0.0 /$ \\
\hline 101 & 11.29 & 6.59 & 1.24 & 2.37 & 0.92 & 0.68 & 0.67 & 0.80 & 0.69 & 0.50 & 0.49 & 0.55 & 0.56 & 0.51 & 0.42 & \\
\hline & 0.48 & 0.39 & 0 & 0.38 & 0.36 & 0.35 & 0.35 & 0. & 0.36 & 0.34 & 0.33 & 0.32 & 0.31 & 0.29 & 0. & 0.24 \\
\hline 10 & 0.26 & 0.24 & 0.24 & 0.24 & 0.24 & 0.24 & 0.24 & 0.24 & 0.23 & 0.23 & 0.22 & 0.22 & 0.21 & 0.20 & 0.19 & 0.19 \\
\hline 15 & 0.20 & 0.19 & 0.18 & 0. & 0.18 & 0.18 & 0.18 & 0.18 & 0.18 & 0.18 & 0.17 & 0.17 & 0.17 & 0.1 & 0.16 & 0.15 \\
\hline 20 & 0.16 & 0.15 & 0.15 & 0 & 0.15 & 0.15 & 0. & 0. & 0.15 & 0.14 & 0.1 & 0.1 & 0.14 & 0.1 & 0.13 & 0.13 \\
\hline 25 & 0.14 & 0.13 & 0.13 & 0. & 0.13 & 0.13 & 0. & 0.13 & 0.13 & 0. & 0 & 0. & 0.12 & 0.1 & 0.12 & 0. \\
\hline 30 & 0.12 & 0.12 & 0.12 & 0. & 0. & 0.11 & 0. & 0. & 0.11 & 0. & 0. & 0. & 0 & 0. & 0. & 0. \\
\hline 35 & 0.1 & 0.10 & 0.10 & 0. & 0.10 & 0.10 & 0.10 & 0.10 & 0.10 & 0.10 & 0.10 & 0.10 & 0.10 & 0.10 & 0. & 0.0 \\
\hline 40 & 0.10 & 0.10 & 0.09 & 0.09 & 0.09 & 0.09 & 0.09 & 0.09 & 0.09 & 0.09 & 0.09 & 0.09 & 0.09 & 0.09 & 0.09 & 0.09 \\
\hline 45 & 0.09 & 0.09 & 0.09 & 0.09 & 0.09 & 0.08 & 0.08 & 0.08 & 0.08 & 0.08 & 0.08 & 0.08 & 0.08 & 0.08 & 0.08 & \\
\hline 50 & 0.08 & 0.08 & 0.08 & 0.08 & 0.08 & 0.08 & 0.08 & 0.08 & 0.08 & 0.08 & 0.08 & 0.08 & 0.08 & 0.08 & 0.08 & \\
\hline 55 & 0.08 & 0.08 & 0.07 & 0.07 & 0.07 & 0.07 & 0.07 & 0.07 & 0.07 & 0.07 & 0.07 & 0.07 & 0.07 & 0.07 & 0.07 & 0.07 \\
\hline 60 & 0.07 & 0.07 & 0.07 & 0.07 & 0.07 & 0.07 & 0.07 & 0.07 & 0.07 & 0.07 & 0.07 & 0.07 & 0.07 & 0.07 & 0.07 & 0.07 \\
\hline 65 & 0.07 & 0.07 & 0.07 & 0.07 & 0.07 & 0.07 & 0.07 & 0.07 & 0.06 & 0.06 & 0.06 & 0.06 & 0.06 & 0.06 & 0.06 & \\
\hline 70 & 0.06 & 0.06 & 0.06 & 0.06 & 0.06 & 0.06 & 0.06 & 0.06 & 0.06 & 0.06 & 0.06 & 0.06 & 0.06 & 0.06 & 0.06 & 0.06 \\
\hline 15 & 0.06 & 0.06 & 0.06 & 0.06 & 0.06 & 0.06 & 0.06 & 0.06 & 0.06 & 0.06 & 0.06 & 0.06 & 0.06 & 0.06 & 0.06 & ; 0.06 \\
\hline
\end{tabular}


Table C-6: RMS speed error obtained using the non-linear model averaged with all five wind input cases.

Derivative Gain

\begin{tabular}{|c|c|c|c|c|c|c|c|c|c|c|c|c|c|c|c|c|}
\hline Proportional & & & & & & & & & & & & & & & & \\
\hline Gain & 1 & 5 & 10 & 15 & 20 & 25 & 30 & 35 & 40 & 45 & 50 & 55 & 60 & 65 & 70 & 75 \\
\hline tegral Gain=1 & 0.92 & 0.94 & 0.95 & 0.92 & 0.92 & 0.94 & 0.98 & 0.99 & 0.99 & 0.97 & 0.94 & 0.91 & 0.89 & 0.86 & 0.83 & 0.80 \\
\hline & 0.43 & 0.42 & 0.43 & 0.44 & 0.45 & 0.46 & 0.47 & 0.47 & 0.48 & 0.48 & 0.48 & 0.48 & 0.47 & 0.47 & 0.47 & 0.46 \\
\hline 10 & 0.30 & 0.30 & 0.30 & 0.30 & 0.30 & 0.31 & 0.31 & 0.31 & 0.31 & 0.32 & 0.32 & 0.32 & 0.32 & 0.32 & 0.32 & 0.32 \\
\hline 15 & 0.25 & 0.24 & 0.24 & 0.24 & 0.24 & 0.24 & 0.25 & 0.25 & 0.25 & 0.25 & 0.25 & 0.25 & 0.26 & 0.26 & 0.26 & 0.26 \\
\hline 20 & 0.21 & 0.21 & 0.21 & 0.21 & 0.21 & 0.21 & 0.21 & 0.21 & 0.21 & 0.22 & 0.22 & 0.22 & 0.22 & 0.22 & 0.22 & 0.22 \\
\hline 25 & 0.19 & 0.19 & 0.19 & 0.19 & 0.19 & 0.19 & 0.19 & 0.19 & 0.19 & 0.19 & 0.19 & 0.19 & 0.19 & 0.19 & 0.19 & 0.19 \\
\hline 30 & 0.18 & 0.18 & 0.17 & 0.17 & 0.17 & 0.17 & 0.17 & 0.17 & 0.17 & 0.17 & 0.17 & 0.18 & 0.18 & 0.18 & 0.18 & 0.18 \\
\hline 35 & 0.16 & 16 & 0.16 & 0.16 & 0.16 & 0.16 & 0.16 & 0.16 & 0.16 & 0.16 & 0.16 & 0.16 & 0.16 & 0.1 & 0.16 & 0.1 \\
\hline 40 & 0.15 & 0.15 & 0.15 & 0.15 & 0.15 & 0.15 & 0.15 & 0.15 & 0.15 & 0.15 & 0.15 & 0.1 & 0.15 & 0. & 0. & 0.15 \\
\hline 45 & 0.14 & 14 & 0.14 & 0.14 & 0.14 & 0.14 & 0.14 & 0.14 & 0.14 & 0.14 & 0.14 & 0.14 & 0.14 & 0.1 & 0.14 & 0.14 \\
\hline 50 & 0.14 & 14 & 4 & 0.14 & 0.13 & 0.13 & 0.13 & 0.13 & 0.13 & 0.13 & 0.13 & 0.13 & 0.13 & 0.13 & 0. & 0.13 \\
\hline 55 & 0.13 & 0.13 & 0.13 & 0.13 & 0.13 & 0.13 & 0.13 & 0.13 & 0.13 & 0.13 & 0.13 & 0.13 & 0.13 & 0.13 & 0. & 0. \\
\hline 60 & 0.12 & 0.12 & 0.12 & 0.12 & 0.12 & 0.12 & 0.12 & 0.12 & 0.12 & 0.12 & 0.12 & 0.12 & 0.12 & 0.12 & 0.12 & 0.12 \\
\hline 65 & 0.12 & 0.12 & 0.12 & 0.12 & 0.12 & 0.12 & 0.12 & 0.12 & 0.12 & 0.12 & 0.12 & 0.12 & 0.12 & 0.12 & 0.12 & 0.12 \\
\hline 70 & 0.11 & 0.11 & 0.11 & 0.11 & 0.11 & 0.11 & 0.11 & 0.11 & 0.11 & 0.11 & 0.11 & 0.11 & 0.11 & 0.11 & 0.11 & 0.11 \\
\hline 15 & 0.11 & 0.11 & 0.11 & 0.11 & 0.11 & 0.11 & 0.11 & 0.11 & 0.11 & 0.11 & 0.11 & 0.11 & 0.11 & 0.11 & 0.1 & 0.11 \\
\hline Integral Gain $=5 \quad 1$ & 3.89 & 0.89 & 0.68 & 0.62 & 0.47 & 0.45 & 0.41 & 0.40 & 0.41 & 0.43 & 0.46 & 0.48 & 0.50 & 0.50 & 0.50 & 0.2 \\
\hline & 0.31 & 0.28 & 0.27 & 0.26 & 0.24 & 0.23 & 0.23 & 0.22 & 0.22 & 0.23 & & 0.25 & 0 & 0.2 & 0.2 & 0. \\
\hline 10 & 0.19 & 0.18 & 7 & & 0.16 & 6 & 0.16 & & 0.15 & 0.16 & & 0. & & 0.16 & 0.17 & 0 \\
\hline 15 & 0.15 & 4 & & & 0.13 & 0.12 & 0.12 & 2 & 0.12 & 0.12 & 0 & 0. & 0.12 & 0.12 & 0 & 0.1 \\
\hline 20 & 0.12 & 0.12 & 0. & 0.11 & 0.11 & 0.10 & 0.10 & 0.10 & 0.10 & 0.10 & 0.10 & 0.10 & 0.10 & 0.10 & 0 & 0.1 \\
\hline 25 & 0.10 & 0.10 & 0.10 & 0.09 & 0.09 & 0.09 & 0.09 & 0.09 & 0.09 & 0.09 & 0.09 & 0.09 & 0.09 & 0.09 & 0.0 & 0.09 \\
\hline 30 & 0.09 & 0.09 & 0.09 & 0.09 & 0.08 & 0.08 & 0.08 & 0.08 & 0.08 & 0.08 & 0.08 & 0.08 & 0.08 & 0.08 & 0.0 & 0.0 \\
\hline 35 & 0.08 & 0.08 & 0.08 & 0.08 & 0.08 & 0.08 & 0.08 & 0.07 & 0.07 & 0.07 & 0.07 & 0.07 & 0.07 & 0.07 & 0.0 & $0 . c$ \\
\hline 40 & 0.08 & 0.07 & 0.07 & 0.07 & 0.07 & 0.07 & 0.07 & 0.07 & 0.07 & 0.07 & 0.07 & 0.07 & 0.07 & 0.0 & 0 & ( \\
\hline 45 & 0.0 & 0 & 0. & 0.07 & 0.07 & 0.07 & 0.07 & 0.06 & 0.06 & 0.06 & 0 & 0. & 0.06 & 0.0 & 0 & ( \\
\hline 50 & 0. & 0 & 0 & 0 & $0 .($ & 0.06 & 0. & 6 & 0. & 0. & & 0. & 6 & 0.0 & 0. & ( \\
\hline 55 & 0. & 6 & & 0 & 0. & 0. & 0. & 0. & 0. & 0. & & & & 0. & & ( \\
\hline 60 & 0.06 & 6 & 0. & 0 & $0 .($ & 0 & 0. & 6 & 0. & 0 & & 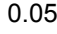 & 4 & 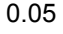 & & 0.0 \\
\hline 65 & 0.06 & 0.06 & 0. & $0 . c$ & 0.05 & 0.05 & 0.05 & 0.05 & 0.0 & 0. & & 0 & 0. & 0.05 & 0 & $0 . c$ \\
\hline 70 & 0.05 & 0.05 & 0.05 & 0.05 & 0.05 & 0.05 & 0.05 & 0.05 & 0.05 & 0.05 & 0.05 & 0.05 & 0.05 & 0.05 & 0.05 & 0.05 \\
\hline 15 & 0.05 & 0.05 & 0.05 & 0.05 & 0.05 & 0.05 & 0.05 & 0.05 & 0.05 & 0.05 & 0.Ub & 0.05 & 0.0b & 0.05 & 0.05 & 0.05 \\
\hline tegral Gain $=101$ & 8.55 & 6.34 & 0.84 & 0.91 & 0.49 & 0.47 & 0.45 & 0.46 & 0.39 & 0.31 & 0.30 & 0.31 & 0.30 & 0.28 & 0.26 & \\
\hline 5 & 0.37 & 0.25 & 0.22 & 0.22 & 0.20 & 0.20 & 0.20 & 0.20 & 0.19 & 0.18 & 0. & 0.17 & 0.17 & 0.17 & 0. & \\
\hline 10 & 0.17 & 0.15 & 0 & 0.14 & 0.13 & 0.13 & 0.13 & 0.13 & 0.13 & 0.13 & 0.12 & 0.12 & 0.12 & 0.12 & 0.12 & .12 \\
\hline 15 & 0.1 & 0.12 & 0.11 & 0.11 & 0.11 & 0.10 & 0.10 & 0.10 & 0.10 & 0.10 & 0.10 & 0.10 & 0.09 & 0.09 & 0.09 & ( \\
\hline 20 & 0.10 & 0.10 & 0.09 & 0.09 & 0.09 & 0.09 & 0.09 & 0.08 & 0.08 & 0.08 & 0. & 0.08 & 0.08 & 0.08 & 0.08 & 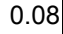 \\
\hline 25 & 0. & 0 & 0 & 0 & 0. & 0. & $0 . C$ & 0. & 0. & 0. & & 0. & 0 & 0.0 & 0 & 0.07 \\
\hline 3 & 0. & 0.07 & 0.07 & $0 . C$ & 0.07 & 0.07 & 0.07 & 0.07 & 0.06 & 0.06 & 0. & 0. & 0. & 0.0 & 0 & 0.06 \\
\hline 35 & 0. & & 0. & 0. & $0 .($ & 0.06 & $0 . C$ & 0. & 0.0 & 0. & 0. & 0. & 0. & 0. & & 0. \\
\hline 40 & 0. & 0. & 0.06 & 0.06 & 0.06 & 0.06 & 0.06 & 0.05 & 0.05 & 0.05 & 0. & 0. & 0.05 & 0.05 & 0. & 0. \\
\hline 45 & $0 . C$ & 0.06 & 0.05 & 0.05 & 0.05 & 0.05 & 0.05 & 0.05 & 0.05 & 0.05 & 0. & 0.0 & 0.05 & 0.05 & 0.05 & 0.05 \\
\hline 50 & 0.05 & 0.05 & 0.05 & 0.05 & 0.05 & 0.05 & 0.05 & 0.05 & 0.05 & 0.05 & 0.0 & 0.05 & 0.05 & 0.05 & 0.05 & 0.05 \\
\hline 55 & 0. & 0.05 & 0.05 & 0.05 & 0.05 & 0.05 & 0.05 & 0.04 & 0.04 & 0.04 & 0. & 0.0 & 0.04 & 0.04 & 0.04 & 0.0 \\
\hline 60 & 0.0 & 0.05 & 0.04 & 0.04 & 0.04 & 0.04 & 0.04 & 0.04 & 0.04 & 0.04 & 0. & 0.0 & 0.04 & 0.04 & 0.04 & 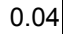 \\
\hline 65 & 0.05 & 0.04 & 0.04 & 0.04 & 0.04 & 0.04 & 0.04 & 0.04 & 0.04 & 0.04 & 0.04 & 0.04 & 0.04 & 0.04 & 0.04 & 0 \\
\hline 70 & 0.04 & 0.04 & 0.04 & 0.04 & 0.04 & 0.04 & 0.04 & 0.04 & 0.04 & 0.04 & 0.04 & 0.04 & 0.04 & 0.04 & 0.04 & .04 \\
\hline 10 & 0.04 & 0.04 & 0.0 & & 0.04 & 0.04 & 0.04 & 0.04 & U & 0.0 & 0.04 & 0.0 & 0.04 & 0.04 & 0.0 & \\
\hline
\end{tabular}


Table C-7: Actuator duty cycle obtained using the non-linear model and medwind 2 as wind input file.

Derivative Gain

\begin{tabular}{|c|c|c|c|c|c|c|c|c|c|c|c|c|c|c|c|c|}
\hline roportional & & & & & & & & & & & & & & & & \\
\hline Gain & 1 & 5 & 10 & 15 & 20 & 25 & 30 & 35 & 40 & 45 & 50 & 55 & 60 & 65 & 70 & 75 \\
\hline Integral Gain=1 & 0.75 & 0.66 & 0.68 & 0.74 & 0.80 & 0.85 & 0.88 & 0.90 & 0.91 & 0.92 & 0.92 & 0.94 & 0.95 & 0.96 & 0.98 & 0.99 \\
\hline & 0.66 & 0.62 & 0.67 & 0.73 & 0.78 & 0.83 & 0.86 & 0.89 & 0.91 & 0.93 & 0.94 & 0.96 & 0.97 & 0.98 & 0.99 & 1.00 \\
\hline 10 & 0.75 & 0.72 & 0.74 & 0.78 & 0.82 & 0.86 & 0.89 & 0.91 & 0.93 & 0.95 & 0.96 & 0.98 & 0.99 & 1.00 & 1 & 1.02 \\
\hline 15 & 0.87 & 0.80 & 0.81 & 0.83 & 0.86 & 0.89 & 0.91 & 0.93 & 0.95 & 0.96 & 0.98 & 0.99 & 1.00 & 1.01 & & 1.03 \\
\hline 20 & 0.97 & 0.88 & 0.87 & 0.88 & 0.90 & 0.92 & 0.93 & 0.95 & 0.97 & 0.98 & 0.99 & 1.00 & 1.01 & 1.02 & 1.03 & 1.03 \\
\hline 25 & 1.05 & 0.95 & 0.92 & 0.92 & 0.93 & 0.94 & 0.95 & 0.97 & 0.98 & 0.99 & 1.00 & 1.01 & 1.02 & 1.03 & 1. & 1.04 \\
\hline 30 & 1.12 & 1.01 & 0.96 & 0.95 & 0.96 & 0.96 & 0.97 & 0.98 & 0.99 & 1.00 & 1.01 & 1.02 & 1.03 & 1.03 & 1.04 & 1.05 \\
\hline 35 & 1.18 & 1.06 & 1.00 & 0.98 & 0.98 & 0.98 & 0.99 & 1.00 & 1.01 & 1.01 & 1.02 & 1.03 & 1.03 & 1.04 & 1.05 & 1.0 \\
\hline 40 & 1.22 & 1.10 & 1.04 & 1.01 & 1.00 & 1.00 & 1.01 & 1.01 & 1.02 & 1.02 & 1.03 & 1.04 & 1.04 & 1.05 & 1.05 & 1. \\
\hline 45 & 1.26 & 1.14 & 1.07 & 1.04 & 1.02 & 1.02 & 1.02 & 1.02 & 1.03 & 1.03 & 1.04 & 1.04 & 1.05 & 1.05 & 1.06 & 1.0 \\
\hline 50 & 1.29 & 1.16 & 1.09 & 1.06 & 1.04 & 1.04 & 1.03 & 1.04 & 1.04 & 1.04 & 1.05 & 1.05 & 1.05 & 1.06 & 1. & $1 .{ }^{1}$ \\
\hline 55 & 1.31 & 1.19 & 1.11 & 1.08 & 1.06 & 1.05 & 1.05 & 1.05 & 1.05 & 1.05 & 1.05 & 1.06 & 1.06 & 1.06 & 1 & 1.0 \\
\hline 60 & 1.33 & 1.21 & 1.13 & 1.09 & 1.07 & 1.06 & 1.06 & 1.06 & 1.06 & 1.06 & 1.06 & 1.06 & 1.07 & 1.07 & 1 & 1.07 \\
\hline 65 & 1.34 & 1.22 & 1. & 1.11 & 1.09 & 1.08 & 1.07 & 1.07 & 1.07 & 1.07 & 1.07 & 1.07 & 1.07 & 1.07 & 1 & 1.08 \\
\hline 70 & 1.35 & 1.24 & 1.16 & 1.12 & 1.10 & 1.09 & 1.08 & 1.07 & 1.07 & 1.07 & 1.07 & 1.07 & 1.08 & 1.08 & 1. & 1.0 \\
\hline 15 & 1.35 & $1.2 b$ & $1.1 /$ & 1.13 & 1.11 & 1.10 & 1.09 & 1.08 & 1.08 & 1.08 & 1.08 & 1.08 & 1.08 & 1.08 & 1.08 & 1.0 \\
\hline tee & 4.23 & 2.11 & 1.44 & 0.91 & 0.83 & 0.85 & 0.93 & 1.02 & 1.07 & 7.08 & 1.07 & 7.05 & 1.04 & 1.02 & 7.01 & 1.02 \\
\hline & 1.01 & 0.84 & 0.81 & 0.80 & 0.81 & 0.85 & 0.90 & 0.94 & 0.96 & 0.98 & 0.99 & 1.00 & 1.01 & 1.0 & 1. & 1.18 \\
\hline 10 & 0.93 & 0.84 & 0.82 & 0.83 & 0.86 & 0.88 & 0.91 & 0.93 & 0.95 & 0.97 & 0.98 & 1.00 & 1.01 & 1.0 & 1.02 & 1.03 \\
\hline 15 & 0.99 & 0.88 & 0.86 & 0.87 & 0.89 & 0.91 & 0.93 & 0.95 & 0.96 & 0.98 & 0.99 & 1.00 & 1.01 & 1.02 & 1. & 1.04 \\
\hline 20 & 1.06 & 0.94 & 0.91 & 0.91 & 0.92 & 0.93 & 0.95 & 0.96 & 0.98 & 0.99 & 1.00 & 1.01 & 1.02 & 1.03 & 1 & 1.04 \\
\hline 25 & 1.12 & 1.00 & 0.95 & 0.94 & 0.95 & 0.95 & 0.97 & 0.98 & 0.99 & 1.00 & 1. & 1.02 & 1.02 & 1.03 & 1 & 1.05 \\
\hline 30 & 1.18 & 1.05 & 0.99 & 0. & 0.97 & & 0.98 & 0.99 & 1.00 & 1.01 & 1 & 1. & 3 & 1.04 & 1 & $1 .{ }^{1}$ \\
\hline 35 & 1.23 & 1.09 & 1. & 1.00 & 0. & 0.99 & 1.00 & 1. & 1.01 & 1. & 1. & 1. & 4 & 1. & 1 & $1 .(8$ \\
\hline 40 & 1.27 & 1.13 & 1. & 1.03 & 1.01 & 1.01 & 1.01 & 1.02 & 1.02 & 1.03 & 1.03 & 1. & 1.04 & 1.05 & 1 & 1.0 \\
\hline 45 & 1.3 & 1.16 & 1.08 & 1.05 & 1.03 & 1.03 & 1.03 & 1.03 & 1.03 & 1.04 & 1.04 & 1.05 & 1.05 & 1.05 & 1. & 1.0 \\
\hline 50 & 1.32 & 1.19 & 1.11 & 1.07 & 1.05 & 1.04 & 1.04 & 1.04 & 1.04 & 1.05 & 1.05 & 1.05 & 1.06 & 1.06 & 1. & 1.07 \\
\hline 55 & 1.34 & 1.21 & 1 & 1.09 & 1.07 & 1.06 & 1.0 & 1. & 1.05 & 1. & 1.06 & 1. & 1.06 & 1.07 & 1. & 1.07 \\
\hline 60 & 1.35 & 1.22 & 1.14 & 1.10 & 1.08 & 1.07 & 1.06 & 1.06 & 1.06 & 1.06 & 1.06 & 1.07 & 1.07 & 1.07 & 1.07 & 1.0 \\
\hline 65 & 1.36 & 1.24 & 1.16 & 1.12 & 1.09 & 1.08 & 1.07 & 1.07 & 1.07 & 1.07 & 1.07 & 1.07 & 1.07 & 1.08 & 1. & $1 .(\mathrm{g}$ \\
\hline 70 & 1.36 & 1.25 & 1.17 & 1. & 1.11 & 1. & 1.08 & 1.08 & 1.08 & 1.08 & 1.08 & 1.0 & 1.08 & 1.08 & 1. & 1.08 \\
\hline & 1.31 & 1.26 & 1.18 & 1.14 & 1.12 & 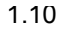 & 1. & 1.09 & 1 & 1.08 & 1.08 & 1.08 & נ8 & 1.08 & jy & \\
\hline $\mathrm{ain}=101$ & 3.98 & 4.42 & 2.26 & 1.6 & 1.26 & 1.23 & 1.22 & 1.04 & 0.9 & 0.96 & 0.95 & 0.96 & 0.99 & 1.02 & 7.05 & 1.07 \\
\hline & 2.30 & 1.09 & 0.98 & 0. & 0.92 & & 0.9 & 0. & 0. & 0. & 0. & 0. & 0 & 1. & & 1.0 \\
\hline 10 & 1.19 & 0.96 & 0.90 & 0.90 & 0.90 & 0.91 & 0.93 & 0.94 & 0.95 & 0.96 & 0.97 & 0.98 & 1.00 & 1.01 & 1 & 1. \\
\hline 15 & 1.16 & 0.97 & 0.92 & 0.91 & 0.92 & 0.93 & 0.94 & 0.95 & 0.97 & 0.98 & 0.99 & 1.00 & 1.01 & 1.02 & 1. & $1 . C$ \\
\hline 20 & 1.1 & 1.01 & 0.95 & 0.94 & 0.94 & 0.95 & 0.96 & 0.97 & 0.98 & 0.99 & 1.00 & 1.01 & 1.02 & 1.03 & 1. & \\
\hline 25 & 1.2 & 1.05 & 0.98 & 0.96 & 0.96 & 0.97 & 0.98 & 0.99 & 1.00 & 1.00 & 1.01 & 1.02 & 1.03 & 1.03 & 1. & 1.05 \\
\hline 30 & 1.26 & 1.09 & 1.02 & 0.99 & 0.99 & 0.99 & 0.99 & 1.00 & 1.01 & 1.01 & 1.02 & 1.03 & 1.03 & 1.04 & 1.05 & 1.0 \\
\hline 35 & 1.29 & 1.13 & 1.05 & 1.02 & 1.01 & 1.01 & 1.01 & 1.01 & 1.02 & 1.02 & 1.03 & 1.04 & 1.04 & 1.05 & 1.05 & 1.06 \\
\hline 40 & 1.32 & 1.16 & 1.08 & 1.04 & 1.03 & 1.02 & 1.02 & 1.03 & 1.03 & 1.03 & 1.04 & 1.04 & 1.05 & 1.05 & 1.06 & 1.06 \\
\hline 45 & 1.34 & 1.19 & 1.10 & 1.06 & 1.05 & 1.04 & 1.04 & 1.04 & 1.04 & 1.04 & 1.05 & 1.05 & 1.05 & 1.06 & 1.06 & 1.07 \\
\hline 50 & 1.36 & 1.21 & 1.12 & 1.08 & 1.06 & 1.05 & 1.05 & 1.05 & 1.05 & 1.05 & 1.05 & 1.06 & 1.06 & 1.06 & 1.07 & 1.07 \\
\hline 55 & 1. & 1.2 & 1.14 & 1.10 & 1.08 & 1.07 & 1.06 & 1.06 & 1.06 & 1.06 & 1.06 & 1.06 & 1.07 & 1.07 & 1.07 & 1.0 \\
\hline 60 & 1. & 1.2 & 1.16 & 1.12 & 1.09 & 1.08 & 1.07 & 1.07 & 1.07 & 1.07 & 1.07 & 1.07 & 1.07 & 1.07 & 1.08 & 1. \\
\hline 65 & 1. & 1.2 & 1.17 & 1.1 & 1. & 1.09 & 1.08 & 1.08 & 1.07 & 1.07 & 1.07 & 1.07 & 1.08 & 1.08 & & 1.08 \\
\hline 10 & 1. & 1.27 & 1.19 & 1.1 & 1.11 & 1.10 & 1.09 & 1.08 & 1.08 & 1.08 & 1.08 & 1.08 & 1.08 & 1.08 & 1.08 & 1.09 \\
\hline 15 & 1.39 & 1.21 & 1.19 & 1.15 & 1.12 & 1.11 & 1.10 & 1.09 & 1.09 & 1.09 & 1.09 & 1.09 & 1.09 & 1.09 & 1.09 & \\
\hline
\end{tabular}


Table C-8: Actuator duty cycle obtained using the non-linear model and wind 3 as wind input file.

Derivative Gain

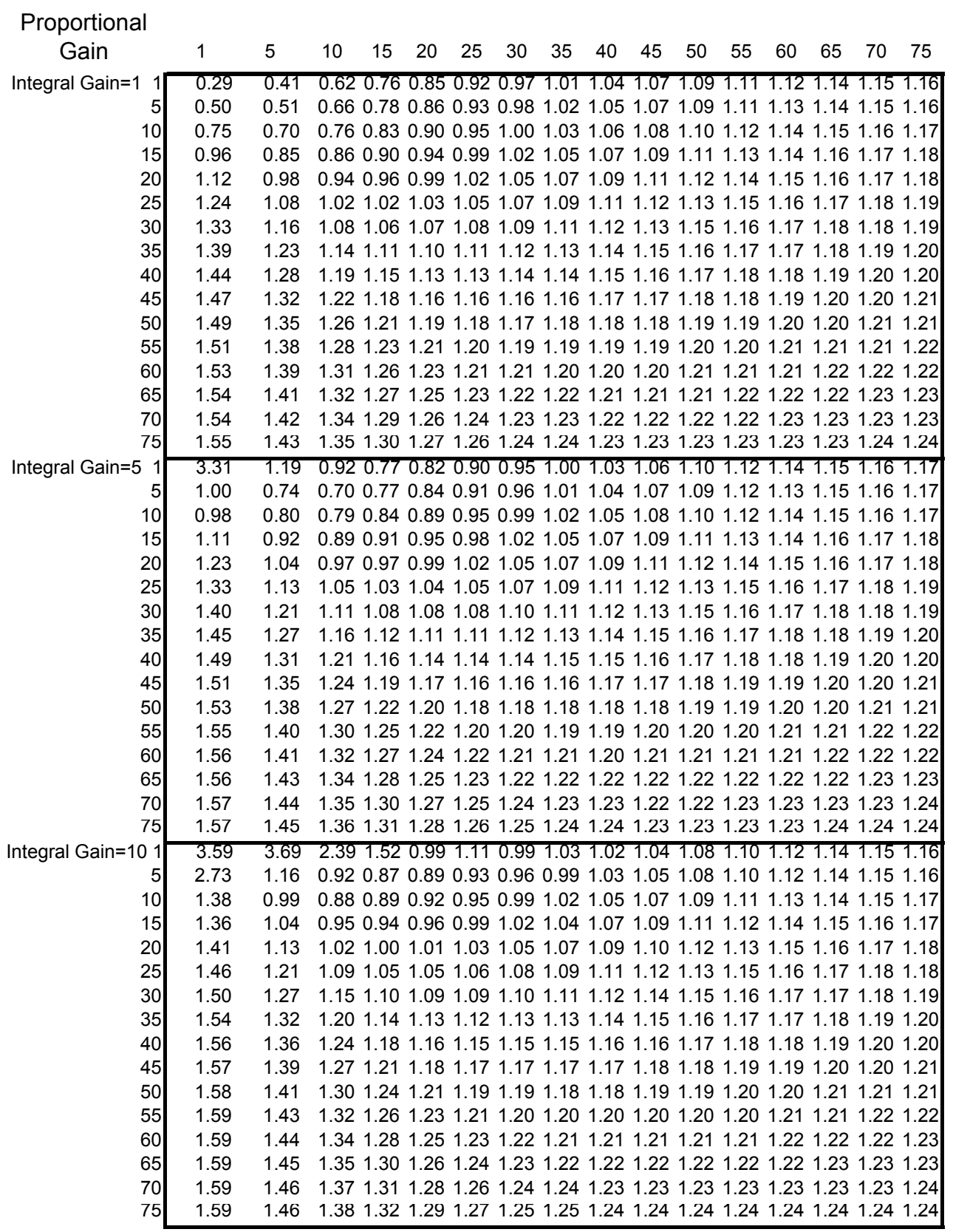


Table C-9: Actuator duty cycle obtained using the non-linear model and wind4 as wind input file.

Derivative Gain

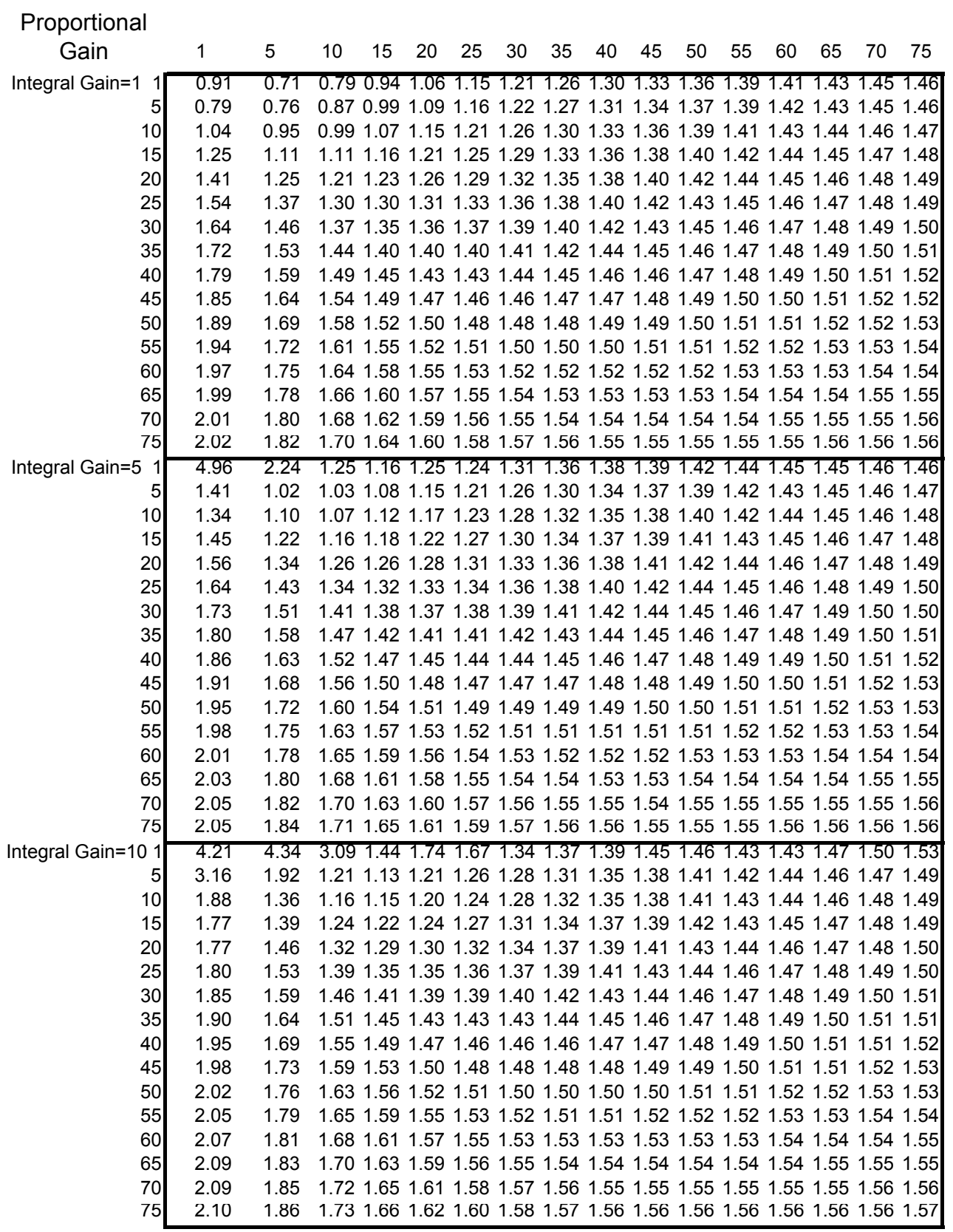


Table C-10: Actuator duty cycle obtained using the non-linear model and wind5 as wind input file.

Derivative Gain

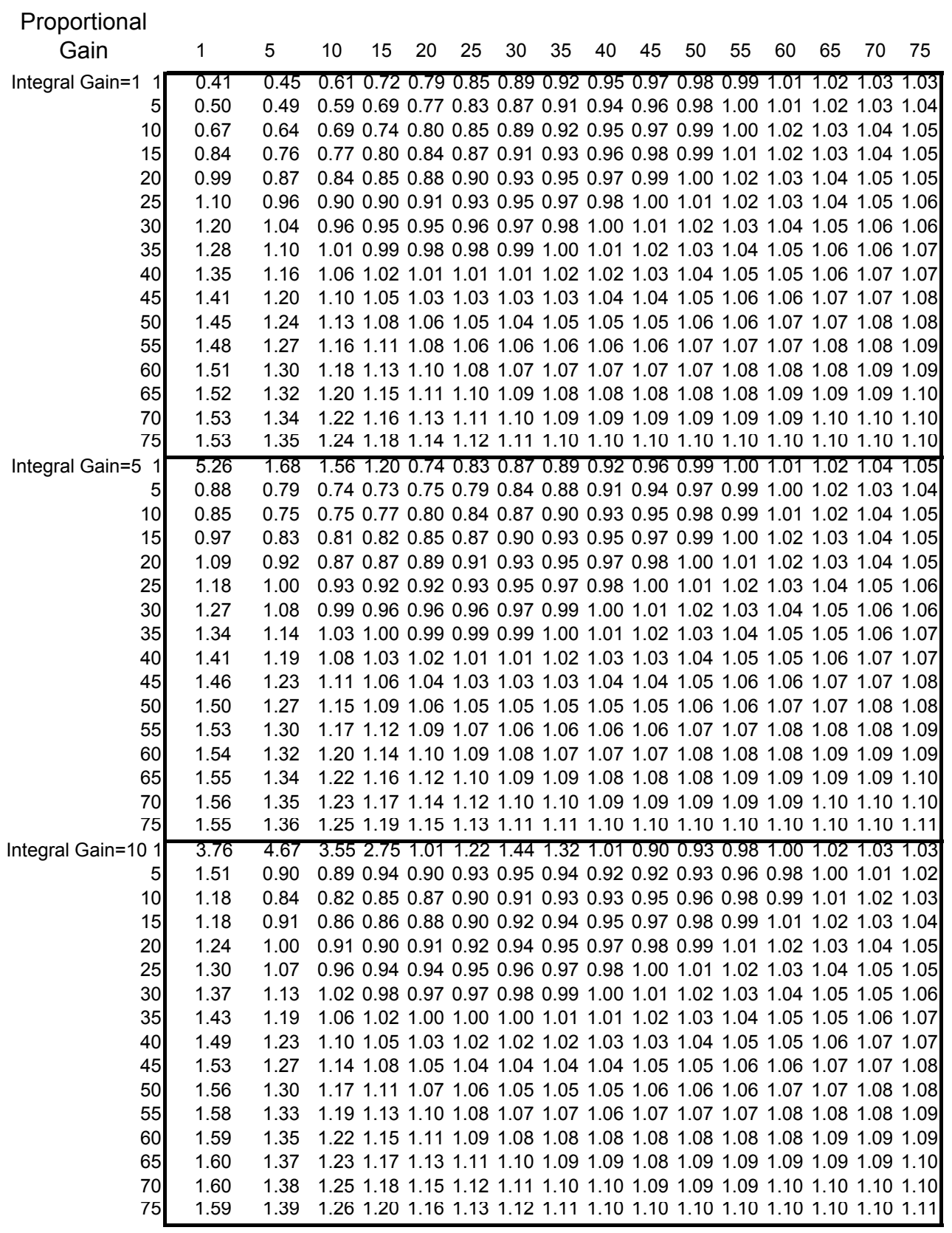


Table C-11: Actuator duty cycle obtained using the non-linear model and highwind4 as wind input file.

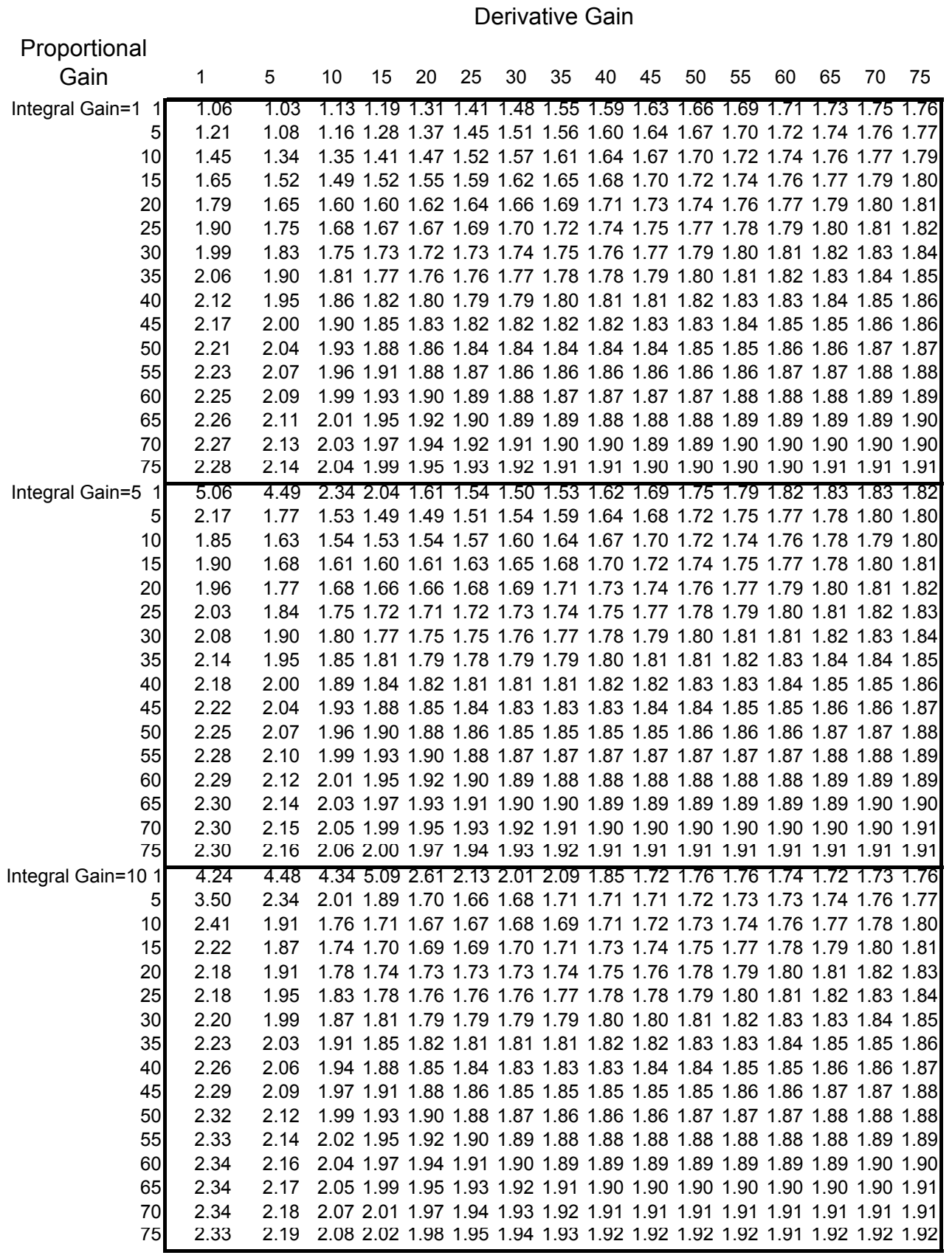


Table C-12: Actuator duty cycle obtained using the non-linear model averaged over five wind input cases.

Derivative Gain

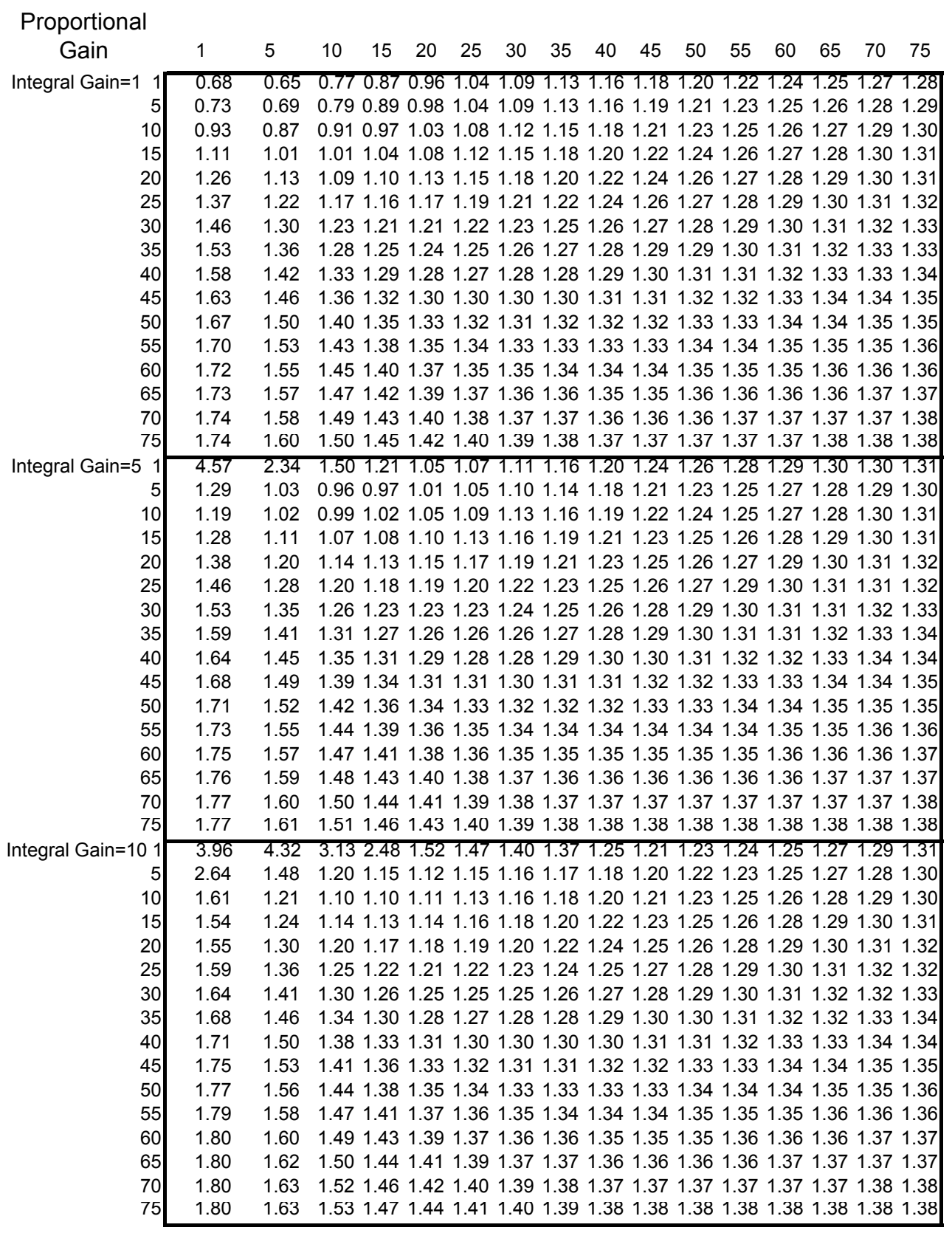


APPENDIX D

APPLICATION OF SYSTEMATIC METHODOLOGY

USING THE LINEAR MODEL II 
Table D-1: RMS speed error obtained using the non-linear model and medwind 2 as wind input file.

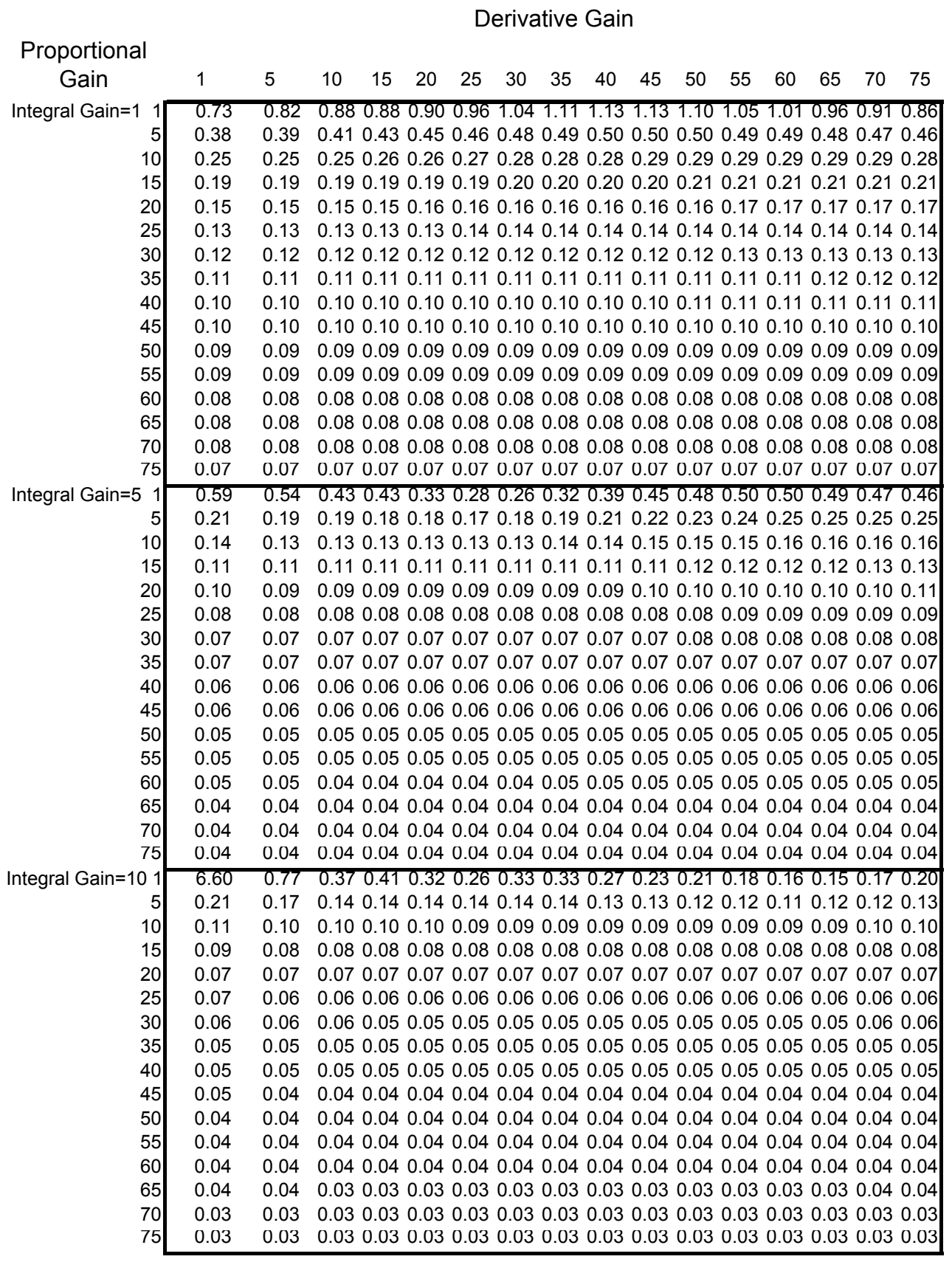


Table D-2: RMS speed error obtained using the non-linear model and wind 3 as wind input file.

Derivative Gain

\begin{tabular}{|c|c|c|c|c|c|c|c|c|c|c|c|c|c|c|c|c|}
\hline roportional & & & & & & & & & & & & & & & & \\
\hline Gain & 1 & 5 & 10 & 15 & 20 & 25 & 30 & 35 & 40 & 45 & 50 & 55 & 60 & 65 & 70 & 75 \\
\hline Integral Gain=1 & 0.39 & 0.32 & 0.33 & 0.36 & 0.40 & 0.45 & 0.49 & 0.52 & 0.54 & 0.54 & 0.54 & 0.54 & 0.53 & 0.52 & 0.52 & 0.51 \\
\hline & 0.24 & 0.22 & 0.22 & 0.23 & 0.24 & 0.25 & 0.26 & 0.27 & 0.28 & 0.28 & 0.29 & 0.29 & 0.29 & 0.29 & 0.30 & 0.30 \\
\hline 10 & 0.19 & 0.18 & 0.17 & 0.17 & 0.18 & 0.18 & 0.19 & 0.19 & 0.19 & 0.20 & 0.20 & 0.20 & 0.20 & 0.21 & 0 & 0.21 \\
\hline 15 & 0.16 & 0.15 & .15 & 0.15 & 0.15 & 0.15 & 0.15 & 0.15 & 0.16 & 0.16 & 0.16 & 0.1 & & 0.16 & & 0.17 \\
\hline 20 & 0.14 & .13 & .13 & 0.13 & 0.13 & 0.13 & 0.13 & 0.13 & 0.13 & 0.13 & 0.14 & 0.14 & 0.14 & 0.14 & 0.14 & 0.14 \\
\hline 25 & 0.12 & 0.12 & 0.12 & 0.12 & 0.12 & 0.12 & 0.12 & 0.12 & 0.12 & 0.12 & 0.12 & 0.12 & 0.12 & 0.12 & 0.12 & 0.12 \\
\hline 30 & 0.11 & 0.11 & 0.11 & 0.11 & 0.11 & 0.11 & 0.11 & 0.11 & 0.11 & 0.11 & 0.11 & 0.11 & 0.11 & 0.11 & 0.11 & 0.11 \\
\hline 35 & 0.10 & 0.10 & 0.10 & 0.10 & 0.10 & 0.10 & 0.10 & 0.10 & 0.10 & 0.10 & 0.10 & 0.10 & 0.10 & 0.10 & 0.10 & 0.10 \\
\hline 40 & 0.09 & 0.09 & 0.09 & 0.09 & 0.09 & 0.09 & 0.09 & 0.09 & 0.09 & 0.09 & 0.09 & 0.09 & 0.09 & 0.09 & $0.0 \mathrm{~s}$ & 0.09 \\
\hline 45 & 0.09 & 0.09 & 0.09 & 0.09 & 0.09 & 0.09 & 0.09 & 0.09 & 0.09 & 0.09 & 0.09 & 0.09 & 0.09 & 0.09 & $0.0 s$ & 0.09 \\
\hline 50 & 0.08 & 0.08 & 0.08 & 0.08 & 0.08 & 0.08 & 0.08 & 0.08 & 0.08 & 0.08 & 0.08 & 0.08 & 0.08 & 0.08 & 0.0 & $0 . c$ \\
\hline 55 & 0.08 & 0.08 & 0.08 & 0.08 & 0.08 & 0.08 & 0.08 & 0.08 & 0.08 & 0.08 & 0.08 & 0.08 & 0.08 & 0.08 & 0.0 & $0 . C$ \\
\hline 60 & 0.07 & 0.07 & 0.07 & 0.07 & 0.07 & & 0.07 & 0.07 & 0.07 & 0.07 & 0.07 & 0.07 & 0.07 & 0.0 & 0 & 0.07 \\
\hline 65 & 0. & 0.07 & 7 & 0.07 & 0.07 & 0.07 & 0.07 & 0.07 & 0.07 & 0.07 & 0.07 & 0.07 & 0 & 0.07 & 0 & 0.07 \\
\hline 70 & 0.07 & 0.07 & 0.07 & 0.07 & 0.07 & 0.07 & 0.07 & 0.07 & 0.07 & 0.07 & 0.07 & 0.07 & 0.07 & 0.07 & 0.07 & 0.07 \\
\hline 15 & 0.06 & 0.06 & $0.06^{\circ}$ & 0.06 & 0.06 & 0.06 & 0.06 & 0.06 & 0.06 & 0.06 & 0.06 & 0.06 & 0.06 & 0.06 & 0.06 & 0.06 \\
\hline tes & 0.86 & 0.44 & 0.36 & 0.26 & 0.20 & 0.19 & 0.17 & 0.13 & 0.11 & 0.13 & 0.15 & 0.16 & 0.17 & 0.1 & 0.16 & 0.16 \\
\hline & 0.22 & 0.18 & 0.15 & 0.13 & 0.11 & 0.10 & 0.09 & 0.08 & 0.08 & 0.08 & 0.08 & 0.08 & 0.08 & 0.0 & 0.0 & 0.09 \\
\hline 10 & 0.13 & 0.11 & 0.10 & 0.09 & 0.08 & 0.07 & 0.07 & 0.06 & 0.06 & 0.06 & 0.06 & 0.06 & 0.06 & 0.0 & 0.0 & 0.06 \\
\hline 15 & 0.10 & 0.09 & 0.08 & 0.07 & 0.06 & 0.06 & 0.06 & 0.05 & 0.05 & 0.05 & $0 . C$ & 0.05 & 0.05 & 0.0 & 0.0 & 0.05 \\
\hline 20 & 0.08 & 0.07 & 0.06 & $0 . C$ & 0.06 & 0.05 & 0.05 & 0.05 & 0.05 & 0.05 & & 0.05 & 0.05 & 0.0 & 0.0 & 0.05 \\
\hline 25 & 0.07 & 0.06 & 0.06 & 0.05 & 0.05 & 0.05 & 0.05 & 0.05 & 0.05 & 0.05 & 0. & 0.04 & 0.04 & 0.0 & 0. & 0.05 \\
\hline 30 & 0.06 & 0.05 & 0.05 & & 0.05 & & 0.04 & 0.04 & 0.04 & 0.04 & & 0. & 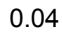 & 4 & 0 & 0.04 \\
\hline 35 & 0. & 0.05 & 0 & 0. & 0.04 & 0.04 & 0.04 & 0. & 0.04 & 0. & 0. & 0 & 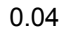 & 0 & 0 & 0. \\
\hline 40 & 0. & 0.05 & 0. & 0.04 & 0.04 & 0.04 & 0.04 & 0.04 & 0.04 & 0.04 & 0.04 & 0 & 0 & 0.04 & 0 & 0.04 \\
\hline 45 & 0.0 & 0.04 & 0.04 & 0.04 & 0.04 & 0.04 & 0.04 & 0.04 & 0.04 & 0.04 & 0.04 & 0.04 & 0.04 & 0.04 & 0. & 0.04 \\
\hline 50 & 0.0 & 0.04 & 0.04 & 0.04 & 0.04 & 0.04 & 0.04 & 0.04 & 0.04 & 0.04 & 0.04 & 0.04 & 0.04 & 0.04 & 0.04 & 0.0 \\
\hline 55 & 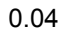 & 0.04 & 0. & 0.04 & 0.04 & 0.04 & 0.04 & 0.04 & 0.04 & 0.03 & 0.03 & 0.03 & 0.03 & 0.03 & 0. & 0.03 \\
\hline 60 & 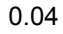 & 0.04 & 0. & 0.04 & 0.03 & 0.03 & 0.03 & 0.03 & 0.03 & 0.03 & 0.03 & 0. & 0.03 & 0.0 & 0. & 0.03 \\
\hline 65 & 0. & 0.04 & 0.03 & 0.03 & 0.03 & 0.03 & 0.03 & 0.03 & 0.03 & 0.03 & 0.03 & 0.03 & 0.03 & 0.0 & 0.03 & 0.03 \\
\hline 70 & 0.03 & 0.03 & 0.03 & 0.03 & 0.03 & 0.03 & 0.03 & 0.03 & 0.03 & 0.03 & 0.0 & 0.0 & 0.0 & 0.0 & 0.0 & 0.03 \\
\hline & 0.03 & 0.03 & 0.03 & 0 & 0.03 & U. & U. & 0.03 & 0 & 0.03 & 0 & 0. & 0 & 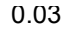 & 0 & \\
\hline 101 & 5. & 0.80 & 0.34 & 0 & 0.2 & 0.2 & 0.2 & 0.17 & 0. & 0.12 & 0. & 0. & 0. & 0. & 0. & \\
\hline & 0.2 & 0.19 & 0. & & 0. & 0. & 0. & 0. & 0. & 0. & 0. & & & 0 & & 0. \\
\hline 10 & 0.14 & 0.11 & 0.10 & 0.09 & 0.08 & 0.08 & 0.07 & 0.07 & 0.06 & 0.06 & 0.06 & 0. & 0.05 & 0.05 & 0. & 0.04 \\
\hline 15 & 0.10 & 0.08 & 0.07 & 0.07 & 0.06 & 0.06 & 0.06 & 0.05 & 0.05 & 0.05 & 0.05 & 0.04 & 0.04 & 0.04 & 0. & 0.04 \\
\hline 20 & $0 . C$ & 0.07 & 0.06 & 0.06 & 0.05 & 0.05 & 0.05 & 0.04 & 0.04 & 0.04 & 0.04 & 0.04 & 0.04 & 0.03 & 0. & \\
\hline 25 & $0 . C$ & 0.06 & 0.05 & $0 . C$ & 0.04 & 0.04 & 0.04 & 0.04 & 0.04 & 0.04 & 0.03 & 0.03 & 0.03 & 0.03 & 0.03 & \\
\hline 30 & 0. & 0.05 & 0.04 & 0.04 & 0.04 & 0.04 & 0.04 & 0.03 & 0.03 & 0.03 & 0.03 & 0.03 & 0.03 & 0.03 & 0.03 & 0 \\
\hline 35 & 0.05 & 0.04 & 0.04 & 0.04 & 0.04 & 0.03 & 0.03 & 0.03 & 0.03 & 0.03 & 0.03 & 0.03 & 0.03 & 0.03 & 0.03 & 0.03 \\
\hline 40 & 0.04 & 0.04 & 0.04 & 0.03 & 0.03 & 0.03 & 0.03 & 0.03 & 0.03 & 0.03 & 0.03 & 0.03 & 0.03 & 0.03 & 0.03 & 0.03 \\
\hline 45 & 0.04 & 0.04 & 0.03 & 0.03 & 0.03 & 0.03 & 0.03 & 0.03 & 0.03 & 0.03 & 0.03 & 0.03 & 0.03 & 0.02 & 0.02 & 0.02 \\
\hline 50 & 0.03 & 0.03 & 0.03 & 0.03 & 0.03 & 0.03 & 0.03 & 0.03 & 0.03 & 0.03 & 0.03 & 0.02 & 0.0 & 0.0 & 0.0 & 0.02 \\
\hline 55 & 0. & 0.03 & 0.03 & 0.03 & 0.03 & 0.03 & 0.03 & 0.03 & 0.02 & 0.02 & 0.02 & 0.0 & 0.02 & $0 . C$ & 0. & 0.02 \\
\hline 60 & $\Omega$ & 0.03 & 0.03 & 0.03 & 0.03 & 0.03 & 0.02 & 0.02 & 0.02 & 0.02 & 0.02 & 0.02 & 0.02 & 0.0 & 0.02 & 0.0 \\
\hline 65 & 0. & & 0.03 & 0.03 & 0.02 & 0.02 & 0.02 & 0.02 & 0.02 & 0.02 & 0.02 & 0.0 & 0.02 & 0.02 & 0.02 & ( \\
\hline 10 & 0. & & 0.02 & 0.02 & 0.02 & 0.02 & 0.02 & 0.02 & 0.02 & 0.02 & 0.02 & 0.02 & 0.02 & 0.02 & 0.02 & 0.0 \\
\hline 15 & 0.03 & 0.02 & 0.02 & 0.02 & 0.02 & 0.02 & 0.02 & 0.02 & 0.02 & 0.02 & 0.02 & 0.02 & 0.02 & 0.02 & 0.02 & \\
\hline
\end{tabular}


Table D-3: RMS speed error obtained using the non-linear model and wind4 as wind input file.

Derivative Gain

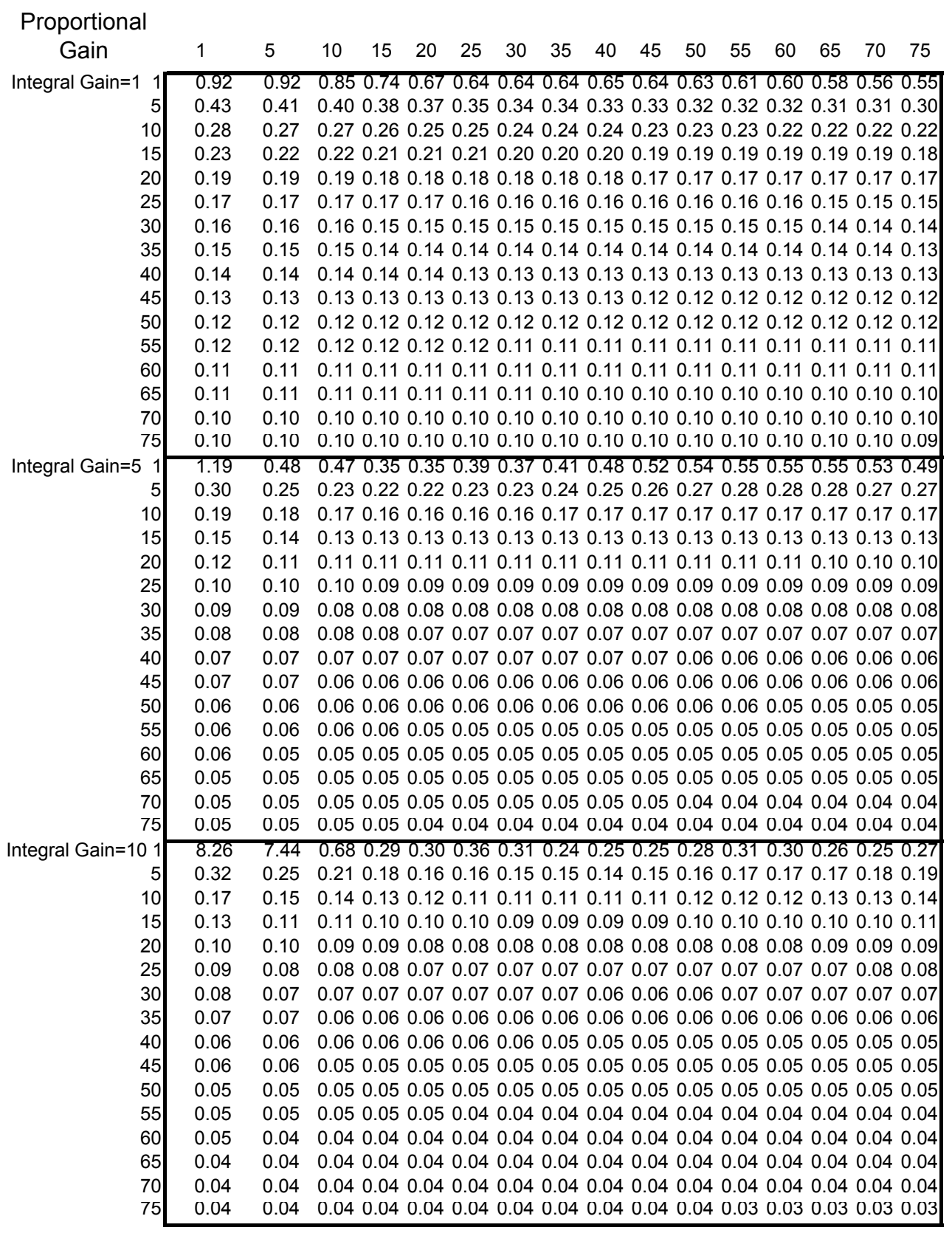


Table D-4: RMS speed error obtained using the non-linear model and wind5 as wind input file.

Derivative Gain

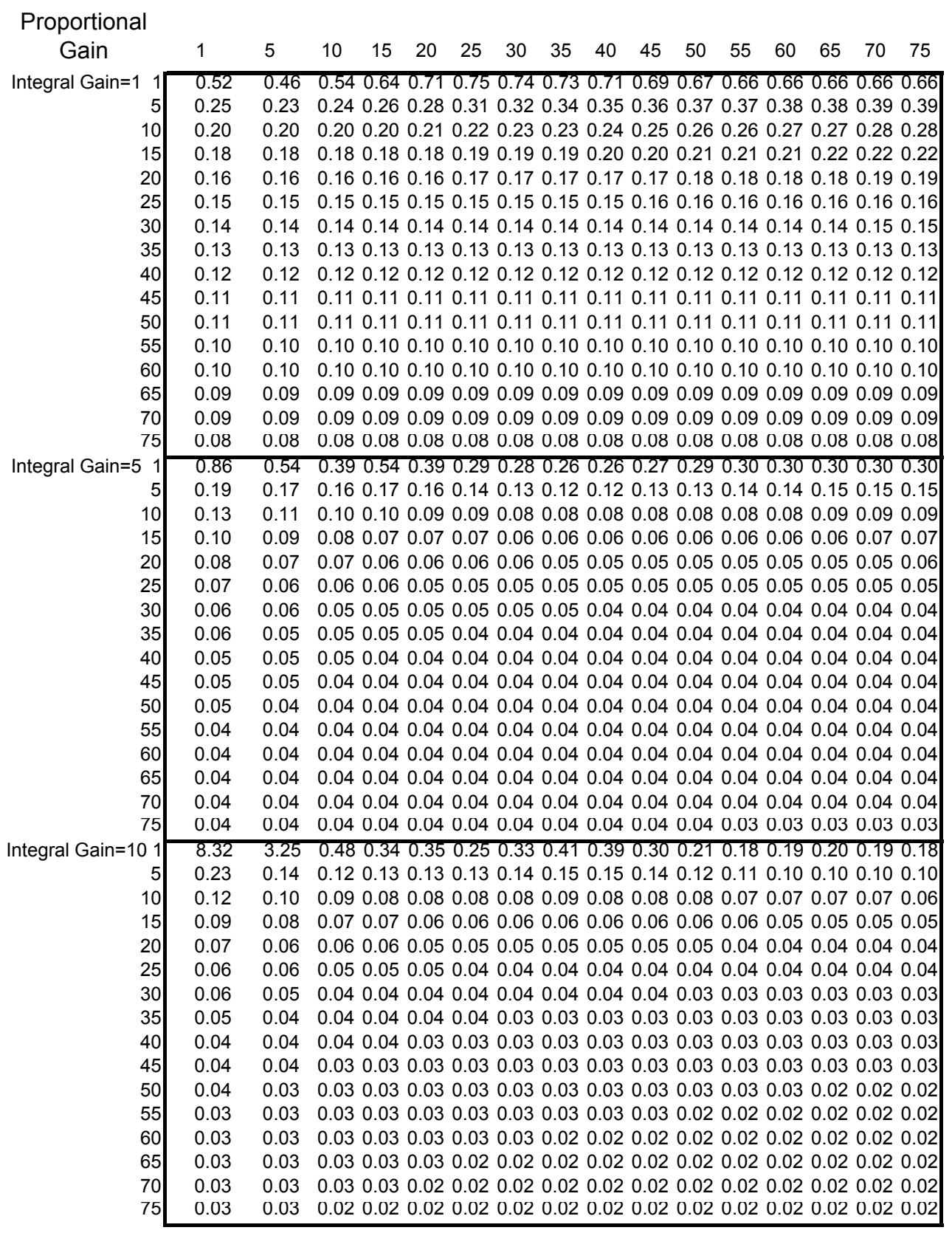


Table D-5: RMS speed error obtained using the non-linear model and highwind4 as wind input file.

Derivative Gain

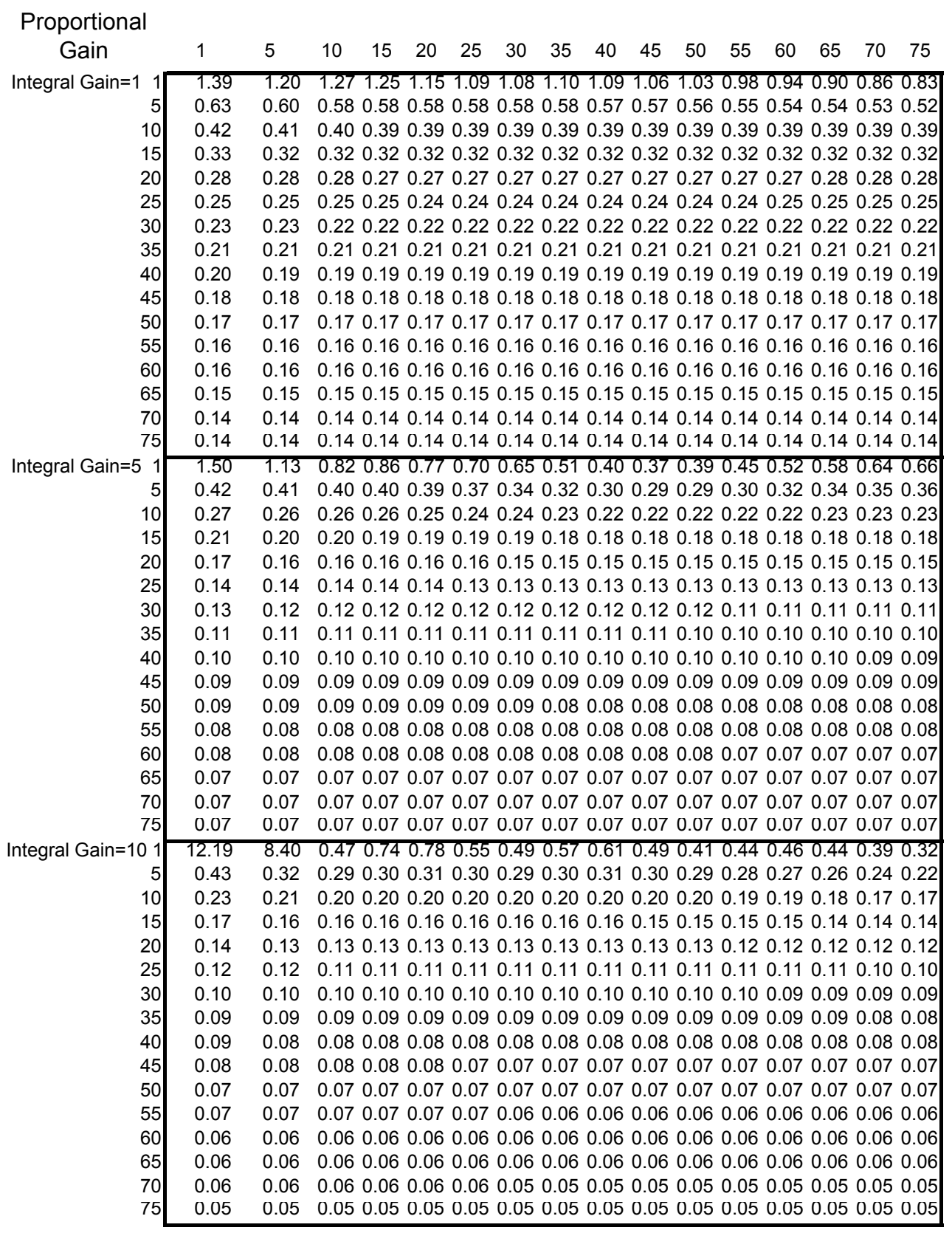


Table D-6: RMS speed error obtained using the non-linear model averaged with all five wind input cases.

Derivative Gain

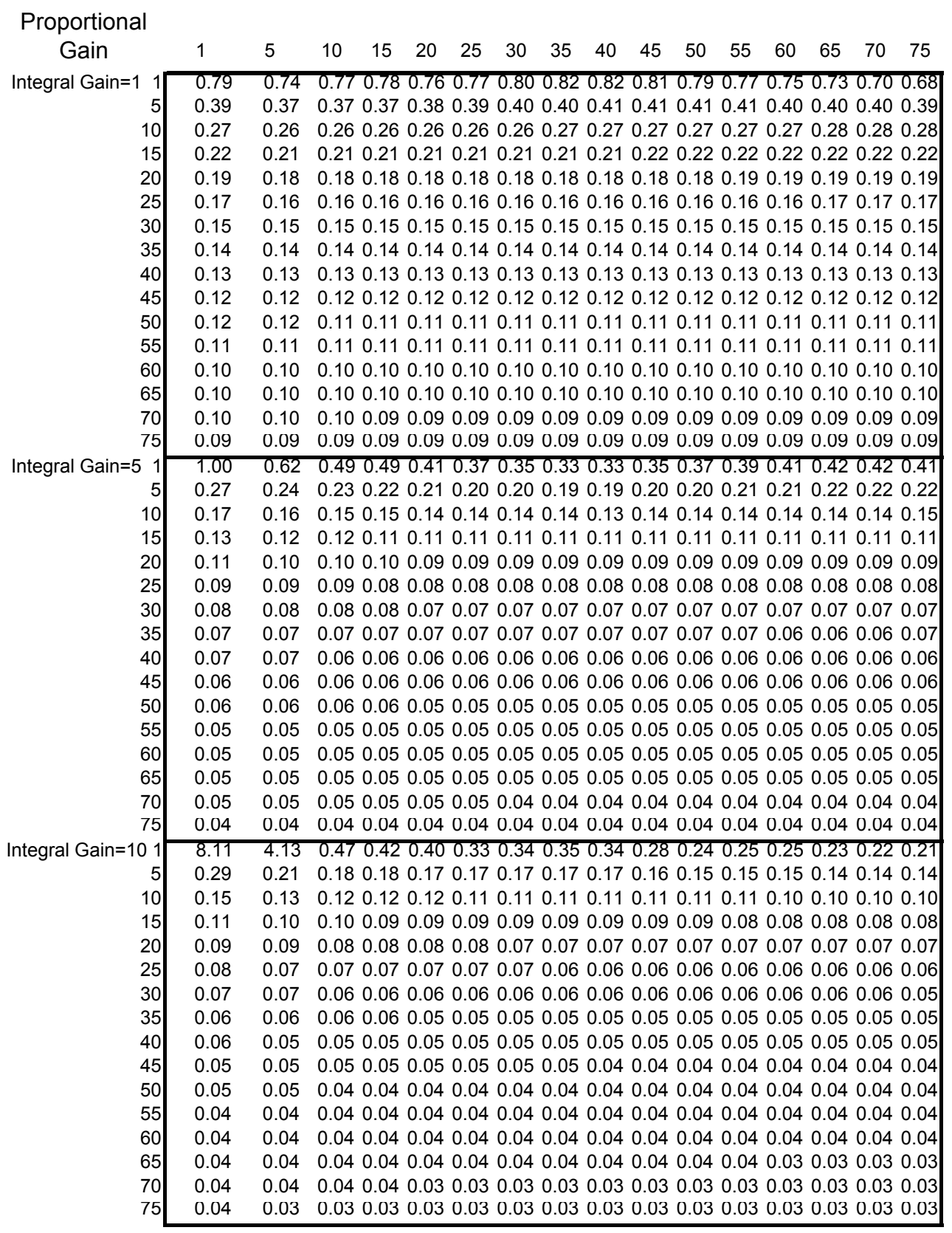


Table D-7: Actuator duty cycle obtained using the non-linear model and medwind 2 as wind input file.

Derivative Gain

\begin{tabular}{|c|c|c|c|c|c|c|c|c|c|c|c|c|c|c|c|c|}
\hline roportional & & & & & & & & & & & & & & & & \\
\hline Gain & 1 & 5 & 10 & 15 & 20 & 25 & 30 & 35 & 40 & 45 & 50 & 55 & 60 & 65 & 70 & 75 \\
\hline Integral Gain=1 & 0.57 & 0.57 & 0.64 & 0.71 & 0.77 & 0.80 & 0.83 & 0.85 & 0.86 & 0.87 & 0.88 & 0.89 & 0.90 & 0.91 & 0.92 & 0.92 \\
\hline & 0.61 & 0.60 & 0.66 & 0.72 & 0.77 & 0.80 & 0.83 & 0.85 & 0.87 & 0.88 & 0.89 & 0.90 & 0.91 & 0.92 & 0.93 & 0.93 \\
\hline 10 & 0.74 & 0.70 & 0.73 & 0.77 & 0.80 & & 0.85 & 0.87 & 0.88 & 0.89 & 0.91 & 0.92 & 0.92 & 0.93 & 0 & 0.94 \\
\hline 15 & 0.86 & 0.78 & 0.79 & 0.81 & 0.83 & 0.85 & 0.87 & 0.88 & 0.89 & 0.91 & 0.92 & 0.92 & & 0.94 & & 0.95 \\
\hline 20 & 0.96 & 0.85 & 0.83 & 0.84 & 0.86 & 0.87 & 0.88 & 0.90 & 0.91 & 0.92 & 0.92 & 0.93 & 0.94 & 0.94 & 0.95 & 0.95 \\
\hline 25 & 1.03 & 0.91 & 0.87 & 0.87 & 0.88 & 0.89 & 0.90 & 0.91 & 0.92 & 0.92 & 0.93 & 0.94 & 0.94 & 0.95 & 0.96 & 0.96 \\
\hline 30 & 1.08 & 0.96 & 0.91 & 0.90 & 0.90 & 0.90 & 0.91 & 0.92 & 0.93 & 0.93 & 0.94 & 0.94 & 0.95 & 0.95 & 0.9 & 0.96 \\
\hline 35 & 1.12 & 0.99 & 0.94 & 0.92 & 0.92 & 0.92 & 0.92 & 0.93 & 0.93 & 0.94 & 0.94 & 0.95 & 0.96 & 0.96 & 0.96 & $0 . s$ \\
\hline 40 & 1.14 & 1.02 & 0.96 & 0.94 & 0.93 & 0.93 & 0.93 & 0.94 & 0.94 & 0.95 & 0.95 & 0.96 & 0.96 & 0.96 & 0.5 & 0.97 \\
\hline 45 & 1.16 & 1.04 & 0.98 & 0.96 & 0.95 & 0.94 & 0.94 & 0.95 & 0.95 & 0.95 & 0.96 & 0.96 & 0.96 & 0.9 & 0. & 0.97 \\
\hline 50 & 1.16 & 1.06 & 1.00 & 0.97 & 0.96 & 0.95 & 0.95 & 0.95 & 0.96 & 0.96 & 0.96 & 0.97 & 0.97 & 0.9 & 0.9 & $0 . c$ \\
\hline 55 & 1.17 & 1.07 & 1.01 & 0.98 & 0.97 & 0.96 & 0.96 & 0.96 & 0.96 & 0.96 & 0.97 & 0.97 & 0.97 & 0.9 & 0. & 0.9 \\
\hline 60 & 1.16 & 1.08 & 1.02 & & 0. & & 0.97 & 0.97 & 0.97 & 0.97 & 0.97 & 0.97 & 0 & 0.98 & 0 & 0.98 \\
\hline 65 & 1 & 1.08 & 1.03 & 1.00 & 0.99 & 0.98 & 0.98 & 0.97 & 0.97 & 0.97 & 0.98 & 0.98 & 0 & 0.98 & 0 & 0.98 \\
\hline 70 & 5 & 1.08 & 1.04 & 1.01 & 1.00 & 0.99 & 0.98 & 0.98 & 0.98 & 0.98 & 0.98 & 0.98 & 0.98 & 0.98 & 0. & 0.98 \\
\hline 15 & 1.14 & 1.09 & 1.04 & 1.02 & 1.00 & $0.9 y$ & $0.9 y$ & 0.98 & 0.98 & 0.98 & 0.98 & 0.98 & 0.98 & 0.98 & 0.98 & 0.98 \\
\hline ntes & 1.93 & 1.27 & 0.92 & 0.82 & 0.76 & 0.79 & 0.86 & 0.91 & 0.95 & 0.95 & 0.95 & 0.95 & 0.94 & 0.9 & 0.9 & 0.94 \\
\hline & 0.88 & 0.75 & 0.74 & 0.76 & 0.78 & 0.81 & 0.85 & 0.88 & 0.90 & 0.91 & 0.9 & 0.93 & 0.93 & 0.9 & 0.9 & 0.95 \\
\hline 10 & 0.89 & 0.78 & 0.78 & 0.80 & 0.82 & 0.84 & 0.86 & 0.88 & 0.89 & 0.91 & 0.92 & 0.93 & 0.9 & 0.9 & 0.9 & 0.95 \\
\hline 15 & 0.96 & 0.84 & 0.82 & 0.83 & 0.85 & 0.86 & 0.88 & 0.89 & 0.90 & 0.91 & 0.5 & 0.9 & 0.9 & 0.9 & 0. & 0.96 \\
\hline 20 & 1.03 & 0.89 & 0.86 & & 0.87 & & 0.89 & 0.90 & 0.91 & 0.92 & & 0. & 0.94 & 0.9 & 0 & 0.96 \\
\hline 25 & 1.08 & 0.94 & 0.89 & 0.8 & 0.89 & 0.90 & 0.91 & 0.91 & 0.92 & 0.93 & 0. & 0.94 & 0.9 & 0.9 & 0 & 0.96 \\
\hline 30 & 1.13 & 0.98 & 0.93 & & 0. & 0. & 0.92 & 0.92 & 0.93 & 0.94 & & 0.95 & 0 & . & 0 & 0. \\
\hline 35 & 1.1 & 1.01 & 0. & 0. & 0. & 0. & 0.93 & 0. & 0.94 & 0. & 0. & 0 & & 0 & 0 & 0.97 \\
\hline 40 & 1.1 & 1.04 & 0.97 & 0.95 & 0.94 & 0.94 & 0.94 & 0.94 & 0.95 & 0.95 & 0.95 & 0 . & 0 & 0.96 & 0 & 0.97 \\
\hline 45 & 1.1 & 1.06 & 0.99 & 0.97 & 0.95 & 0.95 & 0.95 & 0.95 & 0.95 & 0.96 & 0.96 & 0.96 & 0.97 & 0.97 & 0.97 & 0.97 \\
\hline 50 & $1.1 \mathrm{~s}$ & 1.07 & 1.01 & 0.98 & 0.97 & 0.96 & 0.96 & 0.96 & 0.96 & 0.96 & 0.96 & 0.97 & 0.97 & 0.97 & 0.97 & 0.97 \\
\hline 55 & 1.1 & 1.08 & 1.02 & 0.99 & 0.98 & 0.97 & 0.97 & 0.96 & 0.96 & 0.97 & 0.97 & $0 . \varsigma$ & 0.97 & 0.9 & 0.9 & 0.98 \\
\hline 60 & 1.18 & 1.09 & 1.03 & 1.00 & 0.98 & 0.98 & 0.97 & 0.97 & 0.97 & 0.97 & 0.97 & 0.97 & 0.97 & 0.9 & 0.98 & 0.98 \\
\hline 65 & 1. & 1.09 & 1.04 & 1.01 & 0.99 & 0.98 & 0.98 & 0.98 & 0.98 & 0.98 & 0.98 & 0.98 & 0.98 & 0.9 & 0.9 & 0.98 \\
\hline 70 & 1.16 & 1.09 & 1.04 & 1.0 & 1.00 & 0.99 & 0.9 & 0.98 & 0.98 & 0.9 & 0.9 & 0.9 & 0.9 & 0.9 & 0. & 0.98 \\
\hline & 1.15 & 1.09 & 1.05 & 1. & 1.01 & 1. & U. & 0.99 & 0 & 0 & 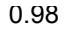 & 0 & 0 & 34 & 0 & 0.99 \\
\hline in $=101$ & 4.16 & 3.39 & 7.33 & 1.2 & 0.99 & 0.94 & 0.99 & 0.90 & 0.86 & 0.87 & 0.88 & 0. & 0.92 & 0.9 & 0. & \\
\hline & 1.45 & 0.92 & 0.83 & & 0.8 & & 0.87 & 0. & 0.87 & 0.88 & 0. & & & C & & 0.5 \\
\hline 10 & 1.09 & 0.86 & 0.83 & 0.83 & 0.85 & 0.86 & 0.87 & 0.88 & 0.89 & 0.90 & 0.91 & 0.92 & 0.5 & 0.94 & 0. & 0.9 \\
\hline 15 & 1.10 & 0.90 & 0.85 & 0.85 & 0.86 & 0.88 & 0.89 & 0.90 & 0.90 & 0.91 & 0.92 & 0.93 & 0.94 & 0.95 & 0. & 0.96 \\
\hline 20 & 1. & 0.94 & 0.89 & 0.88 & 0.88 & 0.89 & 0.90 & 0.91 & 0.92 & 0.92 & 0.93 & 0.94 & 0.94 & 0.95 & 0.96 & \\
\hline 25 & 1. & 0.98 & 0.92 & 0.90 & 0.90 & 0.91 & 0.91 & 0.92 & 0.93 & 0.93 & 0.94 & 0.94 & 0.9 & 0.9 & 0.96 & \\
\hline 30 & 1. & 1.01 & 0.95 & 0.92 & 0.92 & 0.92 & 0.92 & 0.93 & 0.93 & 0.94 & 0.94 & 0.95 & 0.95 & 0.96 & 0.96 & 0.96 \\
\hline 35 & 1.2 & 1.04 & 0.97 & 0.94 & 0.93 & 0.93 & 0.94 & 0.94 & 0.94 & 0.95 & 0.95 & 0.96 & 0.96 & 0.96 & 0.97 & 0.97 \\
\hline 40 & 1.21 & 1.06 & 0.99 & 0.96 & 0.95 & 0.94 & 0.95 & 0.95 & 0.95 & 0.95 & 0.96 & 0.96 & 0.96 & 0.97 & 0.97 & 0.97 \\
\hline 45 & 1.22 & 1.08 & 1.01 & 0.98 & 0.96 & 0.96 & 0.95 & 0.95 & 0.96 & 0.96 & 0.96 & 0.96 & 0.97 & 0.97 & 0.97 & 0.97 \\
\hline 50 & 1.21 & 1.09 & 1.02 & 0.99 & 0.97 & 0.97 & 0.96 & 0.96 & 0.96 & 0.96 & 0.97 & 0.97 & 0.9 & 0.97 & 0.97 & 0.98 \\
\hline 55 & 1.2 & 1.1 & 1.03 & 1.00 & 0.98 & 0.97 & 0.97 & 0.97 & 0.97 & 0.97 & 0.97 & 0.97 & 0.97 & 0.98 & 0.98 & 0. \\
\hline 60 & 1.2 & 1.1 & 1.04 & 1.01 & 0.99 & 0.98 & 0.98 & 0.97 & 0.97 & 0.97 & 0.98 & 0.98 & 0.98 & 0.98 & 0.98 & 0 \\
\hline 65 & 1. & 1.1 & 1.05 & 1.02 & 1.00 & 0.99 & 0.98 & 0.98 & 0.98 & 0.98 & 0.9 & 0.9 & 0.98 & 0.9 & 0. & ( \\
\hline 10 & 1. & 1.1 & 1.05 & 1.02 & 1.01 & 1.00 & 0.99 & 0.99 & 0.98 & 0.98 & 0.98 & 0.98 & 0.98 & 0.98 & 0.98 & \\
\hline 15 & 1.16 & 1.10 & 1.06 & 1.03 & 1.01 & 1.00 & $0.9 y$ & $0.9 y$ & $0.9 y$ & $0.9 y$ & $0.9 y$ & $0.9 y$ & $0.9 y$ & $0.9 y$ & $0.9 y$ & \\
\hline
\end{tabular}


Table D-8: Actuator duty cycle obtained using the non-linear model and wind 3 as wind input file.

Derivative Gain

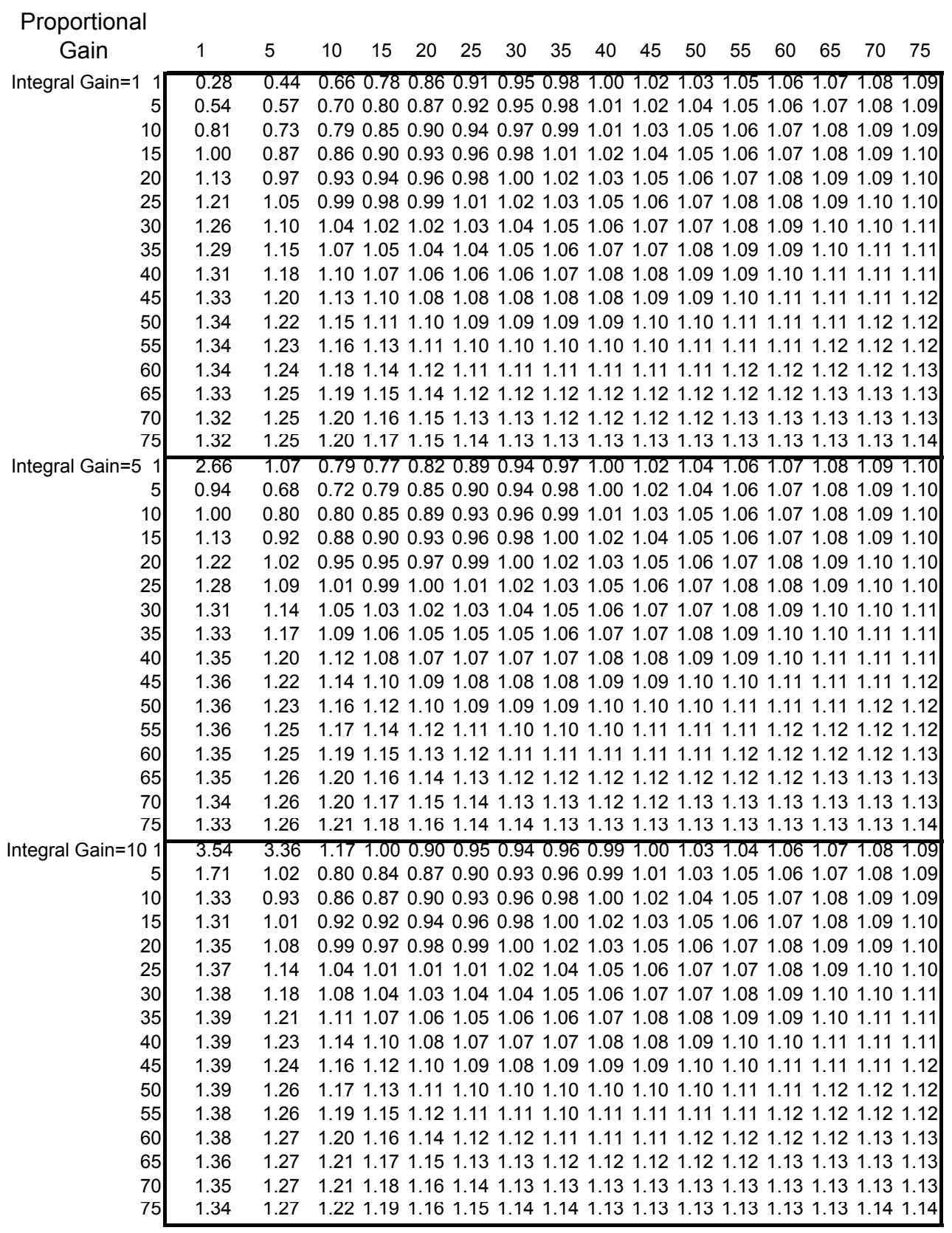


Table D-9: Actuator duty cycle obtained using the non-linear model and wind4 as wind input file.

Derivative Gain

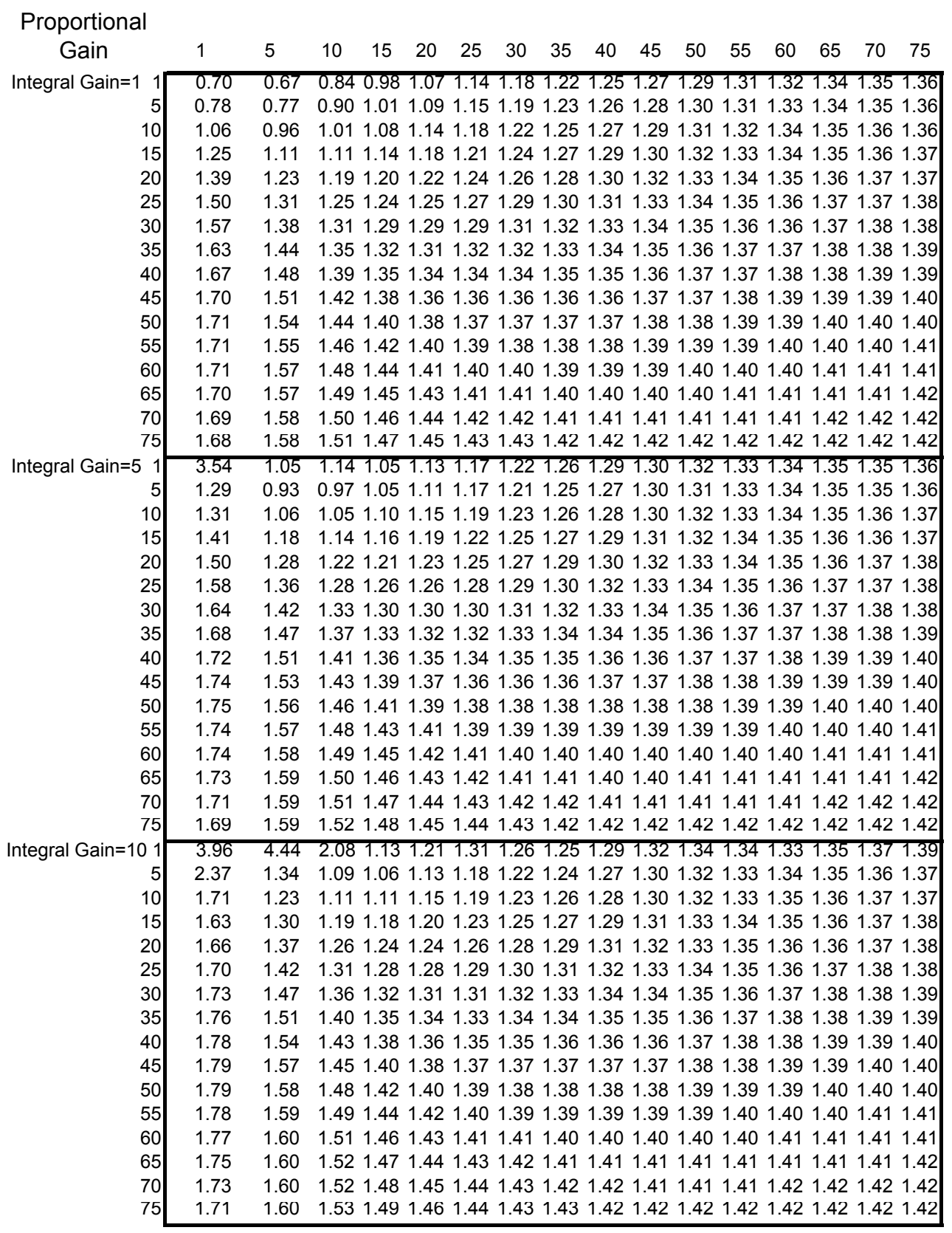


Table D-10: Actuator duty cycle obtained using the non-linear model and wind5 as wind input file.

Derivative Gain

\begin{tabular}{|c|c|c|c|c|c|c|c|c|c|c|c|c|c|c|c|c|}
\hline Proportional & \\
\hline Gaın & 1 & 5 & 10 & 15 & 20 & 25 & 30 & 35 & 40 & 45 & 50 & 55 & 60 & 65 & 70 & 75 \\
\hline Integral Gain=1 & 0.39 & 0.40 & 0.60 & 0.72 & 0.78 & 0.83 & 0.86 & 0.88 & 0.90 & 0.91 & 0.92 & 0.93 & 0.94 & 0.95 & 0.96 & 0.96 \\
\hline & 0.51 & 0.52 & 0.62 & 0.71 & 0.78 & 0.82 & 0.85 & 0.88 & 0.90 & 0.91 & 0.93 & 0.94 & 0.95 & 0.96 & 0.96 & 0.97 \\
\hline 10 & 0.71 & 0.66 & 0.70 & 0.75 & 0.80 & 0.83 & 0.86 & 0.89 & 0.90 & 0.92 & 0.93 & 0.94 & 0.95 & 0.96 & 0.97 & 0.97 \\
\hline 15 & 0.89 & 0.77 & 0.77 & 0.80 & 0.83 & 0.85 & 0.88 & 0.90 & 0.91 & 0.92 & 0.94 & 0.95 & 0.96 & 0.96 & 0.97 & 0.98 \\
\hline 20 & 1.02 & 0.86 & 0.83 & 0.84 & 0.86 & 0.87 & 0.89 & 0.91 & 0.92 & 0.93 & 0.94 & 0.95 & 0.96 & 0.97 & 0.97 & 0.98 \\
\hline 25 & 1.11 & 0.94 & 0.88 & 0.87 & 0.88 & 0.89 & 0.91 & 0.92 & 0.93 & 0.94 & 0.95 & 0.96 & 0.96 & 0.97 & 0.98 & 0.98 \\
\hline 30 & 1.19 & 1.00 & 0.92 & 0.91 & 0.91 & 0.91 & 0.92 & 0.93 & 0.94 & & 0.95 & 0.96 & & 0.97 & & \\
\hline 35 & 1.24 & 1.04 & 0.96 & 0.93 & 0.93 & 0.93 & 0.93 & 0.94 & 0.95 & & 0.96 & 0.97 & 0.97 & 0.98 & 0.9 & 0.99 \\
\hline 40 & 1.27 & 1.08 & 0.99 & 0.96 & 0.95 & 0.94 & 0.95 & 0.95 & 0.96 & & 0.97 & 0.97 & 0.98 & 0.98 & 0.9 & 0 \\
\hline 45 & 1.28 & 1.10 & 1.02 & 0.98 & 0.96 & 0.96 & 0.96 & 0.96 & 0.96 & 0.97 & 0.97 & 0.98 & 0.98 & 0.99 & 0.9 & 0.99 \\
\hline 50 & 1.29 & 1.12 & 1.04 & 1.00 & 0.98 & 0.97 & 0.97 & 0.97 & 0.97 & 0.98 & 0.98 & 0.98 & 0.99 & 0.99 & 0.99 & \\
\hline 55 & 1.28 & 1.13 & 1.05 & 1.01 & 0.99 & 0.98 & 0.98 & 0.98 & 0.98 & 0.98 & 0.98 & 0.99 & 0.99 & 0.99 & 1.00 & 1. \\
\hline 60 & 1.28 & 1.14 & 1.07 & 1.03 & 1.01 & 1.00 & 0.99 & 0.99 & 0.99 & 0.99 & 0.99 & 0.99 & 0.99 & 1.00 & 1.00 & 1.0 \\
\hline 65 & 1.27 & 1.14 & 1.08 & 1.04 & 1.02 & 1.00 & 1.00 & 0.99 & 0.99 & 0.99 & 0.99 & 1.00 & 1.00 & 1.00 & 1.00 & 1.0 \\
\hline 70 & 1.25 & 1.15 & 1.08 & 1.05 & 1.03 & 1.01 & 1.01 & 1. & 1.00 & 1.00 & 1.00 & 1.00 & 1. & 1.00 & 1.01 & 1.01 \\
\hline 15 & 1.24 & 1.14 & 1.09 & 1.06 & 1.04 & 1.02 & 1.01 & 1.01 & 1.01 & 1.00 & 1.00 & 1.00 & 1.01 & 1.01 & 1.01 & 1.0 \\
\hline & 3.00 & 1.36 & 0.86 & 0.95 & 0.72 & 0.77 & 0.83 & 0.85 & 0.88 & 0.90 & 0.93 & 0.94 & 0.95 & 0.96 & 0.97 & 0.98 \\
\hline 5 & 0.77 & 0.68 & 0.70 & 0.73 & 0.75 & 0.79 & 0.83 & 0.86 & 0.88 & 0 . & 0.92 & 0.94 & c & 96 & 0. & 0.97 \\
\hline 10 & 0.87 & 0.72 & 0.73 & 0.76 & 0.79 & 0.82 & 0.85 & 0.88 & 0.90 & 0. & 0.93 & 0.94 & 0 & 0.96 & 0.97 & 0.97 \\
\hline 15 & 1.00 & 0.82 & 0.79 & 0.80 & 0.83 & 0.85 & 0.87 & 0.89 & 0.91 & 0. & 0.93 & 0.94 & 0. & 0.9 & 0.97 & .98 \\
\hline 20 & 1.10 & 0.90 & 0.85 & 0.84 & 0.86 & 0.87 & 0.89 & 0.91 & 0.92 & 0.9 & 0.94 & 0.95 & 0.96 & 0.9 & 0.91 & 0.98 \\
\hline 25 & 1.18 & 0.97 & 0.90 & 0.88 & 0.88 & 0.90 & 0.91 & 0.92 & 0.93 & 0.94 & 0.95 & 0.96 & 0.96 & 0.9 & 0.9 & 0.98 \\
\hline 30 & 1.24 & 1.02 & 0.94 & 0.91 & 0.91 & 0.91 & 0.92 & 0.93 & 0.94 & 0.95 & 0.95 & 0.9 & 0.97 & 0.9 & 0.9 & 0.98 \\
\hline 35 & 1.29 & 1.07 & 0.97 & 0.94 & 0.93 & 0.93 & 0.94 & 0.94 & 0.95 & 0.95 & 0.96 & 0.97 & 0.97 & 0.98 & 0.9 & 0.99 \\
\hline 40 & 1.31 & 1.10 & 1.00 & 0.97 & 0.95 & 0.95 & 0.95 & 0.95 & 0.96 & 0. & 0.97 & 0.97 & 0.98 & 0.98 & 0.9 & 0.99 \\
\hline 45 & 1.32 & 1.12 & 1.03 & $0 . S$ & 0.97 & 0.96 & 0. & 0.96 & 0.97 & & 0.97 & 0.98 & & 0.99 & 0.99 & 0.99 \\
\hline 50 & 1.32 & 1.14 & 1 & 1.0 & 0.98 & 0.9 & 0. & 0.97 & 0.97 & 0. & 0.98 & 0.98 & 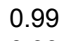 & 0.99 & 0 & 1.00 \\
\hline 55 & 1.31 & 1.15 & 1.06 & 1.02 & 1.00 & 0. & 0. & 0.98 & 0.98 & 0. & 0.98 & 0.99 & 0 & 0.99 & 1.00 & 1.0 \\
\hline 60 & 1.30 & 1.15 & 1.07 & 1.03 & 1.01 & 1.00 & 0. & 0.99 & 0.99 & 0. & 0.99 & 0.99 & 0 & 1.00 & 1.00 & 1.00 \\
\hline 65 & 1.28 & 1.16 & 8 & 1.04 & 1.02 & 1.01 & 1.00 & 1.00 & 1.00 & 0. & 1.00 & 1.00 & 1.00 & 1.00 & 1.00 & 1.01 \\
\hline 70 & 1.27 & 1.15 & 1.09 & 1.05 & 1.03 & 1.02 & 1.01 & 1.00 & 1.00 & 1.00 & 1.00 & 1.00 & 1.00 & 1.00 & 1.01 & 1.01 \\
\hline 15 & $1.2 b$ & 1.16 & 1.10 & 1.06 & 1.04 & 1.02 & 1.02 & 1.01 & 1.01 & 1.01 & 1.00 & 1.00 & 1.01 & 1.01 & 1.01 & 1.01 \\
\hline tegral Gain=101 & 4.02 & 4.65 & 1.56 & 1.15 & 1.00 & 0.92 & 0.99 & 1.04 & 0.92 & 0.86 & 0.88 & 0.91 & 0.93 & 0.94 & 0.95 & 0.96 \\
\hline & 1.58 & 0.76 & 0.74 & $0 . \varepsilon$ & 0.83 & 0.85 & 0.87 & 0.88 & 0.88 & 0. & $0.8 s$ & 0.9 & 0.5 & 0.9 & 0.95 & 0.96 \\
\hline 10 & 1.16 & 0.80 & 0.77 & $0 . \varepsilon$ & 0.83 & 0.85 & 0.8 & 0.88 & 0.89 & 0. & 0. & 0.9 & $0 . \varsigma$ & 0.9 & 0. & 0.96 \\
\hline 15 & 1.17 & 0.89 & 0.82 & 0. & 0.84 & 0.86 & 0.8 & & 0. & & 0 & $0 . \varsigma$ & & 0 & 0 & 0.97 \\
\hline 20 & 1.2 & 0.96 & 0.87 & $0 . \varepsilon$ & 0.87 & $0 . \varepsilon$ & $0 . \varepsilon$ & 0.91 & 0. & 0. & 0. & 0. & 0. & 0.96 & 0. & 0.97 \\
\hline 25 & 1.2 & 1.02 & 0.92 & 0.8 & 0.89 & 0.90 & 0.91 & 0.92 & 0.93 & 0. & 0.95 & 0.95 & 0.96 & 0.97 & 0.97 & 0.9 \\
\hline 30 & 1.3 & 1.06 & 0.96 & 0.93 & 0.92 & 0.92 & 0.92 & 0.93 & 0.94 & 0. & 0.95 & 0.96 & 0.97 & 0.97 & 0.98 & 0.98 \\
\hline 35 & 1.3 & 1.10 & 0.99 & 0.95 & 0.94 & 0.94 & 0.94 & 0.94 & 0.95 & 0. & 0.96 & 0.97 & 0.97 & 0.98 & 0.98 & 0.99 \\
\hline 40 & 1.3 & 1.13 & 1.02 & 0.9 & 0.96 & 0.95 & 0. & 0.95 & 0. & 0. & 0.97 & 0.97 & 0 & 0.98 & 0.99 & \\
\hline 45 & 1.3 & 1.15 & 1.04 & 1.00 & 0.98 & 0.97 & 0.96 & 0.96 & 0.97 & 0.97 & 0.97 & 0.98 & 0.98 & 0.99 & 0.99 & \\
\hline 50 & 1.36 & 1.16 & 1.06 & 1.01 & 0.99 & 0.98 & 0.98 & 0.97 & 0.98 & 0.98 & 0.98 & 0.98 & 0.99 & 0.99 & 0.99 & 1.00 \\
\hline 55 & 1.34 & 1.17 & 1.07 & 1.03 & 1.00 & 0.99 & 0.99 & 0.98 & 0.98 & 0.98 & 0.99 & 0.99 & 0.99 & 0.99 & 1.00 & 1.00 \\
\hline 60 & 1.33 & 1.17 & 1.09 & 1.04 & 1.02 & 1.00 & 0.99 & 0.99 & 0.99 & 0.99 & 0.99 & 0.99 & 0.99 & 1.00 & 1.00 & \\
\hline 65 & 1.31 & 1.17 & 1.09 & 1.05 & 1.03 & 1.01 & 1.00 & 1.00 & 1.00 & 1.00 & 1.00 & 1.00 & 1.00 & 1.00 & 1.00 & \\
\hline 70 & 1.29 & 1.17 & 1.10 & 1.06 & 1.04 & 1.02 & 1.01 & 1.01 & 1.00 & 1.00 & 1.00 & 1.00 & 1.00 & 1.00 & 1.01 & 1.01 \\
\hline 15 & 1.21 & 1.16 & 1.10 & $1.0 /$ & 1.04 & 1.03 & 1.02 & 1.01 & 1.01 & 1.01 & 1.01 & 1.01 & 1.01 & 1.01 & 1.01 & \\
\hline
\end{tabular}


Table D-11: Actuator duty cycle obtained using the non-linear model and highwind4 as wind input file.

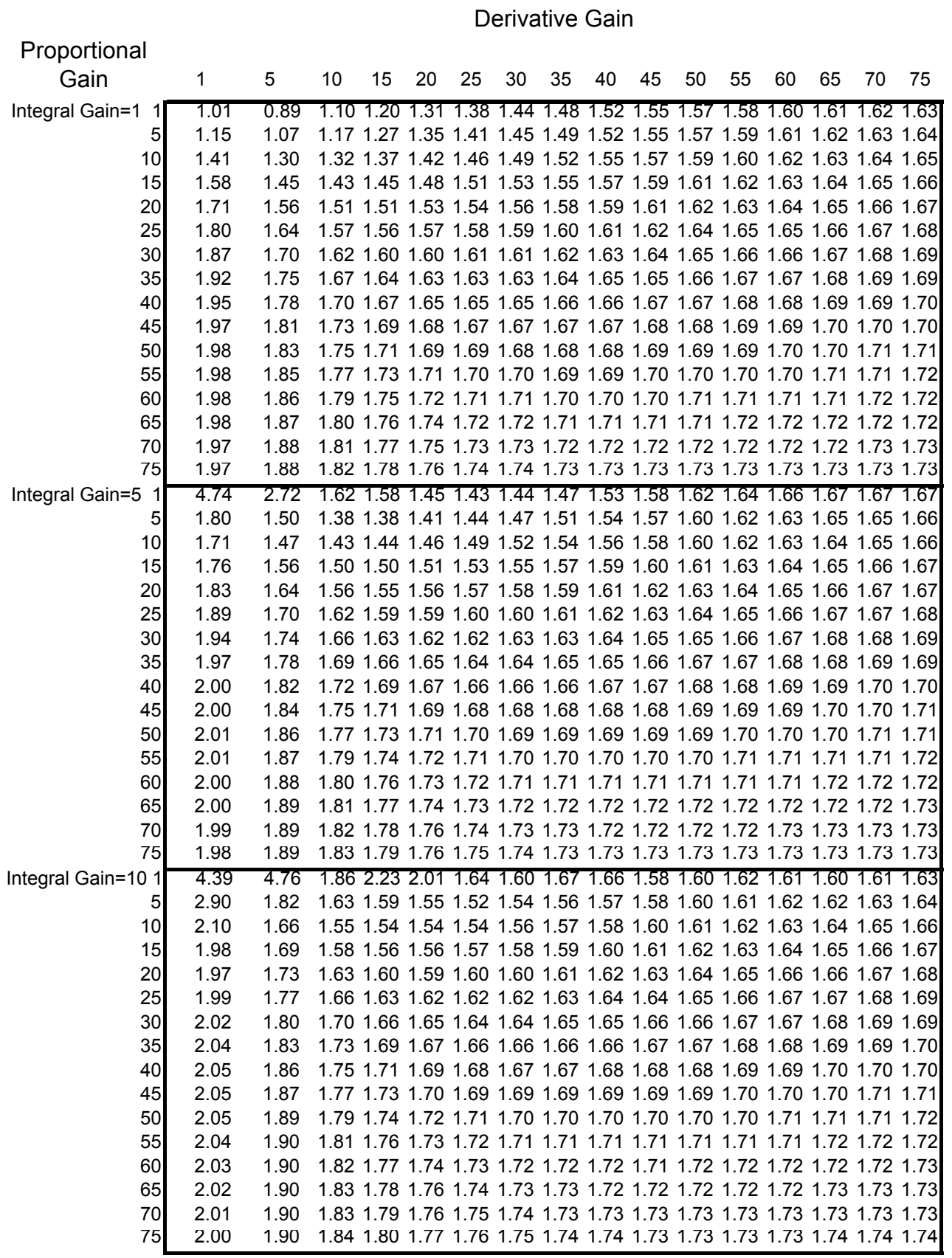


Table D-12: Actuator duty cycle obtained using the non-linear model averaged over five wind input cases.

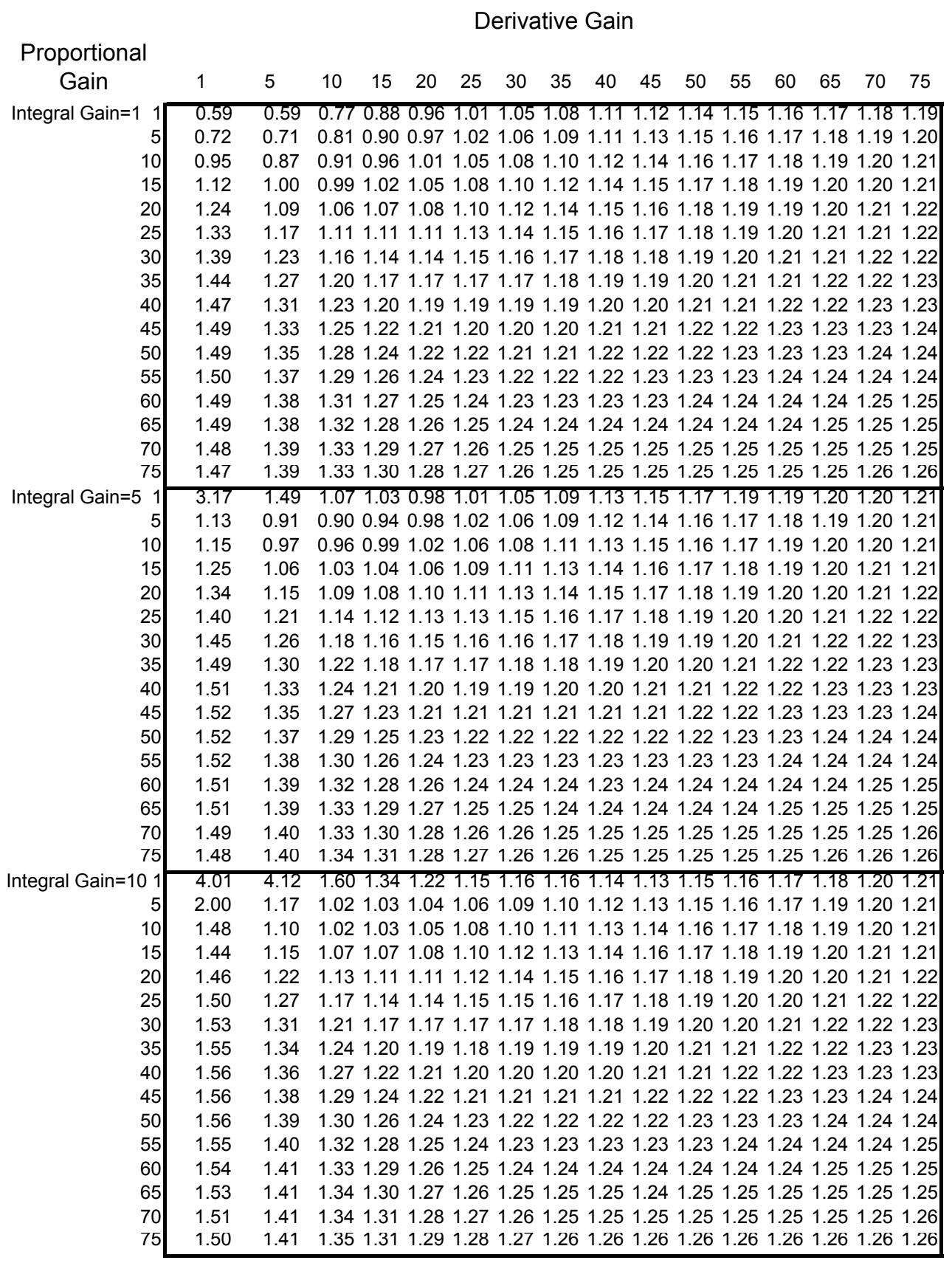




\section{REPORT DOCUMENTATION PAGE}

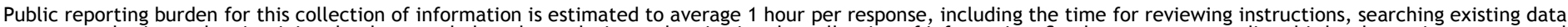

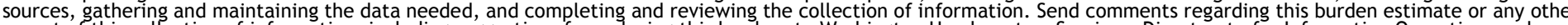

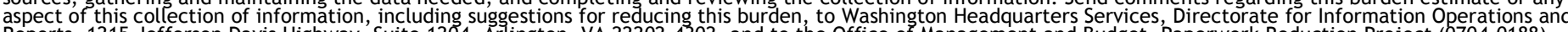
Davis Highway, Suite 1204, Arlington, VA 22202-4302, and to the Office of Management and Budget, Paperwork Reduction Project (0704-0188) Washington, DC 20503.

\begin{tabular}{|l|l|l}
\hline 1. AGENCY USE ONLY (Leave blank) & $\begin{array}{l}\text { 2. REPORT DATE } \\
\text { July 1999 }\end{array}$ & $\begin{array}{l}\text { 3. REPORT TYPE AND DATES COVERED } \\
\text { Technical Report }\end{array}$ \\
\hline 4. TITLE AND SUBTITLE
\end{tabular}

\section{TITLE AND SUBTITLE}

Variable-Speed Wind Turbine Controller Systematic Design Methodology: A Comparison of NonLinear and Linear Model-Based Designs

5. FUNDING NUMBERS

WE901110

\section{AUTHOR(S)}

M.M. Hand

7. PERFORMING ORGANIZATION NAME(S) AND ADDRESS(ES)

8. PERFORMING ORGANIZATION REPORT NUMBER

9. SPONSORING/MONITORING AGENCY NAME(S) AND ADDRESS(ES)

National Renewable Energy Laboratory

1617 Cole Blvd. AGENCY REPORT NUMBER

Golden, CO 80401-3393

11. SUPPLEMENTARY NOTES

12a. DISTRIBUTION/AVAILABILITY STATEMENT

12b. DISTRIBUTION CODE

National Technical Information Service

U.S. Department of Commerce

5285 Port Royal Road

Springfield, VA 22161

\section{ABSTRACT (Maximum 200 words)}

Variable-speed, horizontal axis wind turbines use blade-pitch control to meet specified objectives for three regions of operation. This paper focuses on controller design for the constant power production regime. A simple, rigid, non-linear turbine model was used to systematically perform trade-off studies between two performance metrics. Minimization of both the deviation of the rotor speed from the desired speed and the motion of the actuator is desired. The robust nature of the proportional-integral-derivative (PID) controller is illustrated, and optimal operating conditions are determined. Because numerous simulation runs may be completed in a short time, the relationship of the two opposing metrics is easily visualized.

Traditional controller design generally consists of linearizing a model about an operating point. This step was taken for two different operating points, and the systematic design approach was used. A comparison of the optimal regions selected using the non-linear model and the two linear models shows similarities. The linearization point selection does, however, affect the turbine performance slightly. Exploitation of the simplicity of the model allows surfaces consisting of operation under a wide range of gain values to be created. This methodology provides a means of visually observing turbine performance based upon the two metrics chosen for this study. Design of a PID controller is simplified, and it is possible to ascertain the best possible combination of controller parameters. The wide, flat surfaces indicate that a PID controller is very robust in this variable-speed wind turbine application.

\section{SUBJECT TERMS}

wind energy, wind turbines, wind turbine design

15. NUMBER OF PAGES

16. PRICE CODE

17. SECURITY CLASSIFICATION OF REPORT Unclassified
18. SECURITY CLASSIFICATION OF THIS PAGE Unclassified
19. SECURITY CLASSIFICATION OF ABSTRACT Unclassified
20. LIMITATION OF ABSTRACT

UL 